\title{
INTERNATIONAL
} JOURNAL

\section{OF SPELEOLOGY}

F. E. L. LBRARY

EDITORS:

G. CLAUS, R. HUSSON, G. Y ICHELA'S ${ }^{1970}$ DO NOT RLMONE

WHITE, W. B., G. L. JEFFERSON \& J. F. HAMAN, Quartzite Karst in Southeastern Venezuela . . 309 MAGNIEZ, G., Répartition géographique et validité de l'espèce troglobie Asellus lusitanicus Frade (Crustacé Asellote) . . . . . . . . . . . . . . . . . . . . . . . . . . . . 315 BURGHELE-BALACESCO, A., Les Mycetophilidae (Diptères) cavernicoles de la collection Biospeologica . . . . . . . . . . . . . . . . . . . . . . . . . . . . . 319 GRAF, F. \& C. MARVILLET, Sur la faculté d'absorption de substances colorées par la cuticule de Caecosphaeroma burgundum Dollfus, Crustacé Isopode des eaux souterraines . . . . . . . . . . . . 335 NEGREA, A., L. BOTOSANEANU \& S. NEGREA, Documents pour servir à la connaissance de la faune des Mammifères des grottes du Banat (Roumanie) . . . . . . . . . . . . . . . . . . . PETROVA, A., Deux nouveaux Halacariens d'Israel-Limnohalacarus capernaumi n. sp. et Lohmannella

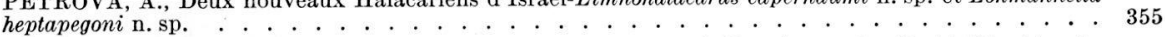
VACHON, M., Neobisium (Roncobisium) allodentatum n.sg., n. sp. de Pseudoscorpion Neobisiidae (Arachnides) habitant une caverne du département de Saône-et-Loire, France . . . . . . . . . . . . . . 363 WATSON, R. A., Underground Solution Canyons in the Central Kentucky Karst, USA . . . . . . . 369 BERNASCONI, R., Die Lampen-Moosflora der Beatushöhle und deren Vergleich mit anderen europäischen Höhlen . . . . . . . . . . . . . . . . . . . . . . . . . . . . . . . . . . . . . MASON-WILLIAMS, M. A., Further Investigations into Bacterial and Algal Populations of Caves in South Wales MASON-WILLIAMS, M. A., \& K. BENSON-EVANS, Summary of Results Obtained during a Preliminary Investigation into the Bacterial and Botanical Flora of Cave in South Wales . . . . . . . . Kentucky . . . . . . . . . . . . . . . . . . . . . . . . 403 VANLANDINGHAM, S. L., A New Species of Gomphonema Diatoms from Mammoth Cave, Kentucky 405 CLAUS, G., Bioluminescence in Melosira varians Ag. . . . . . . . . . . . . . . . . . . . . . . 407 HUSMANN, S., Die ökologische Stellung der Höhlen- und Spaltengewässer innerhalb der subterran-

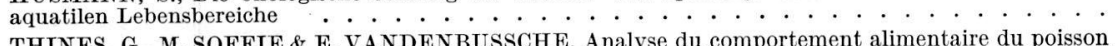
THINES, G., M. SOFFIE \& E. VANDENBUSSCHE, Analyse du comportement alimentaire du poisson cavernicole aveugle Anoptichthys Gen. et d'hybrides $\mathbf{F}_{1}$ (Astyanax $\times$ Anoptichthys) et $\mathbf{F}_{2} \quad . \quad . \cdot . \cdot \cdot$
DESCIMON, H., \& CL. MARVILLET, Mise en évidence de substances fluorescentes dans les organes jaunes de Caecosphaeroma burgundum Dollfus, Crustacé Isopode des eaux souterraines . . . . . . . 449 KOL, E., Algal Growth Experiments in the Baradla Cave at Aggtelek (Biospeleologica hungarica XXI) 457

\section{VERLAG VON J. CRAMER}




\section{Diatomeenschalen im elektronenmikroskopischen Bild}

von Prof. Dr. J. G. Helmcke (Forschungsgruppe für Mikromorphologie im Fritz-Haber-Institut, Berlin-Dahlem) u. Dr.W. Krieger ( $\dagger$ ). Unter Mitarbeit von Dr. U. Geissler (Berlin), Dr.J. GerLofr (Berlin) u. Dr. B. Reimann (La Jolla, Calif., USA).

Jeder Band mit etwa 100 Originalphotos und einem Textheft in dauerhafter Kassette. Groß-Oktav. Band I-V (wovon Band I+ II in zweiter Auflage) lieferbar. Preis je Band DM 75.- (\$18.75)

Das Werk wird fortgesetzt, in jedem Jahr soll ein Band erscheinen.

\section{Index Hepaticarum}

An Index to the Liverworts of the world by C. E. B. Bonner, Geneva, Switzerland.

Volume I (containing issues 2-4): Acbiton to Cystolejeunea. 1962/63. VIII, 926 pages. Wrappers.

Issue 1: Plagiocbila. 1962. VIII, 340 pages. Wrappers.

DM 150.- (\$37.50)

DM 55.- (\$13.75)

This Index including all species of Hepaticae described up to the end of 1960 will be published in issues at irregular intervals, it will be complete in 1965. The price per sheet of 16 pages is DM 2.50. Orders can only be accepted for the complete work. The first volume, consisting of issues $2-4$, is now ready and can be bound. The first issue (Plagiocbila) must remain unbound and will be inserted lateron in its alphabetical order.

\section{Fungi in Oceans and Estuaries}

by Prof. Dr. T. W. Johnson, jr. (Botany Department, Duke University, Durham, NC., USA) and Prof. Dr. F. K. Sparrow, jr. (Botany Department, University of Michigan, Ann Arbor, Mich., USA). 1961. XXIV \& 668 pages, 19 tables, 7 figures in the text and 312 figures on 17 plates.

Clothbound

DM 120.- (\$30.-)

With the comprehensive work the authors have solved the difficult problem of compiling all knowledge of marine mycology ... Even if the reader may have a different opinion in interpreting some of the problems, the book is a very valuable contribution to mycology and will be indispensable for the specialist in marine mycology. Also every other mycologist whether he is interested in taxonomy, physiology or ecology will profit by using it, and students of adjacent fields, like marine zoology or algology, will have to consult this book about many questions."

(J. Kohlmeyer in Nova Hedwigia IV, $3+4$ )

\section{Flora of Lowland Iraq}

By Prof. Dr. K. H. Rechinger (Director of the Natural History Museum, Vienna). 1964. VIII, 736 pages. Clothbound.

DM 150.- $(\$ 37.50)$

This is the first and only existing flora of the area concerned. It is intended for the student as well as for any person interested in the botany of Iraq and adjacent countries. It will be welcome to the specialist as a source of quick reference as well as to ecologists, agronomists, range-managers etc. Many well known specialists have contributed treatments of individual families or genera, including the well known Kew Agrostologist Dr. N. L. Bor.

\section{The Agaricales in Modern Taxonomy}

By Dr. Rolf Singer (Facultad de Ciencias Exactas y Naturales, Universidad de Buenos Aires). 2nd edition 1962 Royal-Octavo. VIII, 916 pages. 73 plates one of which is coloured. Clothbound. Coloured dust jackett.

DM 120.- (\$30.- £ $1015 \mathrm{~s})$

,... In a short notice one cannot indicate all the important or novel conclusions adopted in such a monumental work. This is not just another system of classification. It is a comprehensive manual of Agaric studies up to 1950 and as such is indispensable to all serious mycologist whether specially interested in Agarics or not. Certainly it should be in the library of every higher educational institution where botany is taught ..."

\section{Die Gattung Cosmarium}

(R.W.A.Dennis in Kew Bulletin 1952; 98-100)

von Dr. Willi Krieger ( $\dagger$ ) u. Dr. JohanNes Gerloff (Kustos am Bot. Museum, Berlin-Dahlem) Lieferung 1: 1962. Groß-Oktav. Seite III-XVIII, 1-112. Tafel 1-23. Eine Abbildung im Text.

Broschiert.

DM 35.- (\$8.75)

Dieses Werk war ursprünglich als Teil von KRIEGERs Desmidiaceenbearbeitung im Rabenhorst geplant. Die Grundkonzeption dieses Werkes wurde auch für die Bearbeitung der Gattung Cosmarium beibehalten. Aus diesem Grunde wurden auf den beigegebenen Tafeln auch alle infraspezifischen Taxa abgebildet. Der Beschreibung der Arten, die etwa 4-5 Lieferungen ausfüllen wird, folgt ein allgemeiner Teil mit ökologischen Angaben etc. Die Bestellung der ersten Lieferung verpflichtet zum Bezug des gesamten Werkes. 


\title{
Quartzite Karst in Southeastern Venezuela
}

\author{
By William B. White ${ }^{1}$ ), Gene L. Jefferson ${ }^{2}$ ), and Jon F. Haman ${ }^{3}$ )
}

With one figure in the text

\section{Introduction}

About $300 \mathrm{~km}$. south of Cuidad Bolivar and the Orinoco River lies Venezuela's Gran Sabana. It is a vast upland surrounded by the Precambrian rocks of the Guiana Shield. The bedrock is the Roraima Quartzite recently shown to be of lower Proterozoic Age (1.7 m.y.) by Snelling (1963). At the center of the upland is Mount Auyan-Tepui, a table mountain of quartzite rising to an elevation of 1,000 meters above the surrounding Sabana. The entire area has a mesa and butte topography with mesas ranging in size from a fraction of a square kilometer to perhaps $15 \mathrm{~km} .^{2}$. The annual rainfall on the Sabana is reported to be $1,000 \mathrm{~mm}$. but the tops of the high mesas may receive as much as $7,500 \mathrm{~mm}$. The climate is humid and hot with alternating wet and dry periods. The geology of the area has been described by Lopez et al. (1942).

In outcrop the Roraima Quartzito appears as a red, mediumgrained sandstone, often deeply weathered on the surface. Beneath the weathered zone, it is often nearly white and very well cemented. The petrographic microscope shows the rock to be an orthoquartzite becoming locally arkosic with about $5 \%$ feldspar. The grains are wellrounded, cemented with quartz, and often have quartz overgrowths. The rock breaks with a conchoidal fracture, apparently across the grain.

\footnotetext{
1) Department of Geochemistry and Mineralogy, Pennsylvania State University, University Park, Pennsylvania, U.S.A.

$\left.{ }^{2}\right)$ Stauffer Chemical Company, Green River, Wyoming, U.S.A.

3) Department of Geology, University of Utah, Salt Lake City, Utah, U.S.A.
} 
Field work for this paper was done in connection with general geological studies in the area in the summer of 1958. Observations reported here were made in that part of the Sabana immediately surrounding the village of Canaima on the Carrao River.

\section{Karst Features}

Weathering of the Roraima Quartzite has produced a number of small-scale surface features which superficially resemble karst features developed on a limestone topography. Recent discussions of karst development on granite (Klaer, 1957; Rasmusson, 1959; Wojcik, 1961) have focused attention on solutional weathering in less-soluble rocks. It is thus of interest to investigate a possible karst on quartzite. The nomenclature follows more or less the suggestions of Bögli (1960).

Karren: Tops of mesas and buttes are frequently surfaced with small pits (Trittkarren) and grooves and intermediate ridges (Rinnenkarren). The relief of groove to ridge is about 25 to $50 \mathrm{~cm}$. The pits are gently concave; the ridges are smoothly rounded, not jagged like tropical karren in limestone.

Kluftkarren: The top of a small butte near Canaima has a flattish top which slopes about $10^{\circ}$ following the dip of the east flank of the Carrao syncline. Cutting across this surface from one rim to the other are a number of crevices. They are skewed to both dip and strike and appear to be strongly joint controlled. An average crevice is 3 to 5 meters wide and perhaps 3 meters deep. The walls are very steep and in places are completely vertical. The bottom is usually swampy and may contain small puddles of water. The bottom has a divide in the middle from which water drains in both directions to the rim of the butte. After heavy rains the buttes of the Canaima region spurt numerous 500-meter high waterfalls which issue from the ends of these crevices. Tate (1938) presents a number of photographs of features on the summit of Auyan-Tepui showing deep canyons and crevices that appear to be of similar origin. Again joints seem to be the controlling factor.

Shafts and similar features: Walls of cliffs with active waterfalls sometimes show a vertical concave cylindrical depression with an outline remarkably similar to a vertical shaft in limestone. The most spectacular of these is that of Angel Falls. Behind the waterfall is a half-shaft nearly 1,000 meters high. It was seen from an airplane only and could not be examined in detail.

Possibility of caves: If the surface features are a genuine karst then the possibility should exist for solution caves in quartzite. None were 
observed in the lower buttes and valleys where weathering is not so intense, but the rim of Auyan-Tepui where weathering is at a maximum bears definate possibilities. Many of the waterfalls pour from crevices up to 30 meters below the rim but these are probably just deep narrow canyons. One small fall, however, was observed spurting from the quartzite cliff at the contact between the "A" and "B" members of the Roraima some 250 meters below the rim and 750 meters above the valley floor. No crevice was visible and it appears to be the terminus of a true subterranean drainage tube in the quartzite.

\section{Evidence for Solutional Origin}

The best evidence for a solutional origin for the land forms is derived from the petrography of the Roraima Quartzite. Thin sections of the weathered zone show that there has been a considerable amount of conversion of quartz to opal. In addition the wall of a small fissure cave discovered in the ridge above Canaima had a thin coating of opal flowstone providing further evidence for the solution and later redeposition of silica. Detailed descriptions of two representative specimens are given below:

\section{Specimen No. 1}

Location: Outcrop at lower end of Mayupa Rapids on the Carrao River. "D" member of the Roraima series.

Hand Specimen Description: Grey fine-grained very dense quartzite. Concoidal fracture. Prominent weathered border with thin hematite stained zone next to the fresh rock.

Microscopic Description: Texture: Particle size range 0.2 to $0.5 \mathrm{~mm}$. No visible bedding. Grain sphericity - fair. Grain roundness - excellent. Alteration: Intense weathering. Mineral composition: Primary-quartz; alteration products - chalcedony and opal; introduced minerals - hematite. Cementation: Authigenic overgrowths on quartz grains. Alteration processes: Alteration of both authigenic overgrowths and quartz grains to opal with some crystallization of the opal as chalcedony. Hematite occurs mostly as a coating around grain margins in areas already well altered. The inner zone (seemingly unaltered in hand specimen) shows some alteration to opal and chalcedony while in the weathered zone the individual grains are almost completely detached and altered to opal with very little chalcedony. 
Specimen No. 2

Location: Outcrop in a small fissure cave along a joint on the ridge just east of Canaima. "D" member of the Roraima series.

Hand Specimen Description: Brown, fine-grained, dense quartzite with a coating of white-grey flowstone which forms some rudimentary stalactites.

Microscopic Description: Texture: Particle size range 0.2 to $0.5 \mathrm{~mm}$. Some alignment of prismatic grains. Sphericity - fair. Grain roundness - fair. Flowstone very delicately banded. Alteration: Intense weathering. Mineral composition: Primary - quartz, 95\%; feldspar (microcline and andesine), 5\%. Secondary - opal and chalcedony. Flowstone is of opal. Introduced - hematite.

The basic mechanism of silica solution seems to be hydration of quartz to opal and leaching of the resulting gel. Several cases of boulders with indurated exteriors underlain by a mush of grains of quartz and chalcedony were noted. The hardened exterior is formed of grains of the same composition well-cemented by opal.

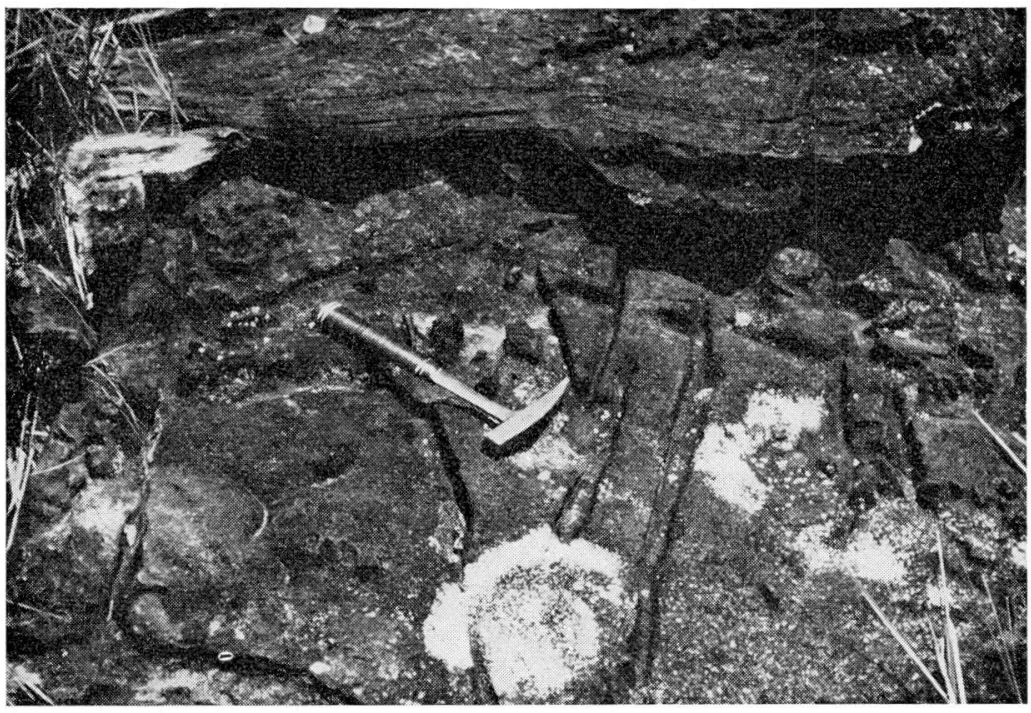

Fig. 1. Rinnenkarren in quartzite in the Carrao River Valley at about 1,000 meters elevation.

Evidence for the solutional origin of the karren is also provided by their distribution in elevation. In the valley floors karren are limited to small pits and grooves with a relief of only a few centimeters (fig. 1). 
On the tops of intermediate buttes 300 to 500 meters above the valley, the relief of the karren is of the order of a few meters. The uppermost "A" member of the Roraima Quartzite outcropping along the rim of Auyan-Tepui was observed from an airplane to be cut into jagged pinacles with a relief of tens of meters. The rainfall increases with elevation from about $1,000 \mathrm{~mm}$. at the 1,000-meter elevation of the valley floor to $7,500 \mathrm{~mm}$. at the 2,000 -meter elevation of the mountain summit. Thus solutional action apparently increases with increasing precipitation.

\section{Mechanism of Solution}

Perhaps the most important question concerns the solubility of silica under tropical weathering conditions. Krauskopf (1956) has studied the solubility of $\mathrm{SiO}_{2}$ under various conditions. The primary factor controlling $\mathrm{SiO}_{2}$ solubility is temperature, with $\mathrm{pH}$ playing a minor role up to $\mathrm{pH}$ 9. The solubility of amorphous silica is $100 \mathrm{ppm}$. at $25^{\circ} \mathrm{C}$. and reaches $400 \mathrm{ppm}$. at the boiling point of water - a value exceeding the solubility of calcite. However, these data are for amorphous silica; the solubility of crystalline quartz is about $14 \mathrm{ppm}$. Other authors such as Morey et al. (1962) place the equilibrium solubility of quartz at the much lower value of $6 \mathrm{ppm}$. However, Morey et al. note that it is possible to form supersaturated solutions of quartz with concentrations as high as $395 \mathrm{ppm}$. at $25^{\circ} \mathrm{C}$. by agitating quartz-water mixtures for 370 days.

It can be seen that the solution of quartz would be a slow process, but if the tropical climate can weather quartz to opal then solution of opal would take place nearly as quickly as limestone dissolves in temperate climates. The critical factor may be the nature of the weather in the Gran Sabana. The rock has a dark surface and early forenoon sunshine from a clear sky will raise the surface temperature of the rocks to perhaps $40^{\circ}$ to $50^{\circ} \mathrm{C}$. Around 2: 00 P.M. the sky clouds over very quickly and rain pours torrentially onto the hot surface. The amount of surface layer dissolved under these conditions may be quite high. Water soaking into the porous outer crust could activate the weathering process but subsequent evaporation of the water would leave the silica behind. Only the outer layers of the crust would be carried off in solution in each subsequent rainfall.

The necessity for extreme surface weathering offers an explanation for the lack of subsurface karst development. Only on exposure to tropical weathering conditions would rapid conversion of quartz to 
opal take place. Inside the quartzite mass the solubility remains low and cavern development would not usually take place.

However, the petrographic and chemical evidence is such that a solutional origin of the observed landforms seems feasible. Thus the term "quartzite karst" is correctly applied.

\section{ACKNOWLEDGEMENT}

We are grateful to Dr. Eugenio DeBellard Pietri for his many assistances during our stay in Venezuela and to Rudy J. F. Truffino for his services as a guide.

\section{ABSTRACT}

Minor weathering forms on the Roraima Quartzite in the Carrao River Basin of Southeastern Venezuela have the appearance of the karren that form on limestone surfaces in karst terrains. Climatological and chemical evidence indicates that these forms were generated by a solutional mechanism and that this area thus exhibits a minor karst topography on quartzite.

\section{RÉSUMÉ}

De petites formes d'érosion sur les Quartzites de Roraima dans le Bassin du Carrao, au Sud-Ouest du Vénézuela, ont l'apparence des lapiaz qui naissent sur le calcaire des régions karstiques. Des observations climatiques et chimiques indiquent que ces formes sont dues à des mécanismes de mise en solution, et que cette région nous montre une microtopographie karstique sur quartzite.

\section{REFERENCES}

BöGLI, A. (1960) - Kalklösung und Karrenbildung. Zeitschr. Geomorph., Supp. 2, Karstmorphologie: 4-21.

Klaer, W. (1957) - Verwitterungsformen im Granit auf Korsika. Erdkunde 11: $1-156$.

Krauskopf, K. B. (1956) - Dissolution and Precipitation of Silica at Low Temperatures. Geochim. Cosmochim. Acta 10: 1-26.

Lopez, V. M., Mencher, R., and Brineman, J. H. (1942) - Geology of Southeastern Venezuela. Geol. Soc. Am. Bull. 53: 849-872.

Morey, G. W., Fournier, R. O., and Rowe, J. J. (1962) - The Solubility of Quartz in Water in the Temperature Interval from $25^{\circ} \mathrm{C}$. to $300^{\circ} \mathrm{C}$. Geochim. Cosmochim. Acta 26: 1029-1043.

Rasmusson, G. (1959) - Karstformen im Granit des Fichtelgebirges. Die Höhle 10:1-4.

Snelling, N. J. (1963) - Age of the Roraima Formation, British Guiana. Nature 198: 1079.

Tate, G. H. H. (1938) - Auyantepui. Geograph. Rev. 28: 452-474.

WoJcık, Z. (1961) - Karst Phenomena and Caves in the Karkonosze Granites. Die Höhle 12: 1-44. 
Répartition géographique et validité de l'espèce troglobie Asellus lusitanicus Frade (Crustacé Asellote).

\author{
Par Guy Magniez ${ }^{1}$ )
}

Avec planche 61 (1)

Asellus (Coxasellus) lusitanicus Frade (1938) a été découvert dans les eaux de l'aqueduc d'Alviela qui alimente Lisbonne en eau potable. Ces eaux proviennent des résurgences des calcaires jurassiques d'Estramadure, situées au N-NE de la ville: Alenquer à $35 \mathrm{~km}$, Ota à $40 \mathrm{~km}$ et les Olhọs d'Agua à $80 \mathrm{~km}$ environ. Cette espèce anophtalme appartient au "groupe coxalis», comme Asellus arthrodilus Braga (1945), autre forme hypogée de lá région de Coimbra et Asellus coxalis ibericus Braga (1946), espèce oculée et pigmentée découverte d'abord dans la région de Porto, mais dont l'aire de répartition s'étendrait jusqu'au Pays Basque. Cette dernière espèce constituerait peut-être la souche de plusieurs formes hypogées du Sud-Ouest européen.

En août 1957, une expédition de l'Union Spéléologique de l'Université de Londres explora les grottes du petit massif karstique de la Serra d'Aire, à $100 \mathrm{~km}$ au N-NE de Lisbonne, dans des calcaires jurassiques également. Dans trois de ces cavités, les spécialistes de l'expédition capturèrent des Aselles. Ce sont respectivement:

- Mindhinu Cave (Références MJ 6 P; MJ 7 P; MJ 8 P), d'où proviennent 3 individus, dont un grand mâle de $7,8 \mathrm{~mm}$ relativement bien conservé.

- Moinhos Velhos (Réf. MJ 9 P), avec un mâle de 7,5 mm.

- Contenda Cave (Réf. MJ 10 P), avec un mâle de 8,1 mm.

Dans les trois cas, les Aselles ont été trouvés à l'obscurité complète, dans de petites flaques et non en eaux courantes. Dans la première cavité existait aussi Niphargus sp. Dans la troisième qui se développe à $200 \mathrm{~m}$ d'altitude seulement au niveau du poljé de Minde, la température atteignait $16^{\circ} \mathrm{C}$.

Par l'intermédiaire de Mr. le Professeur Vandel, que je remercie de sa confiance, j'ai pu avoir communication de ces Asellides. Ils sont

1) Laboratoire de Biologie Animale et Générale, Faculté des Sciences, Dijon, France. 
identiques dans les trois stations. Il s'agit bien d'Asellus lusitanicus dans chaque cas et tous les individus présentent les divers caractères spécifiques décrits par Frade. Quelques schémas peuvent compléter la description de l'auteur. La marge médiale du sympodite du pléopode 2 du mâle porte une rangée de 4 longues tiges plumeuses (Fig. 1B), tandis que l'extrémité de son endopodite constitue un goulot bien marqué et fendu sternalement sur toute sa hauteur. L'angle entre goulot et apophyse est faible $\left(30^{\circ}\right.$ environ) (Fig. 1 C). Les pléopodes 4 et 5 (Fig. $1 \mathrm{D}$ et $\mathrm{E}$ ) sont caractéristiques du groupe "coxalis».

Il faut encore noter le grand nombre d'articles des antennes (65 pour le plus grand mâle), mais cette caractéristique est variable avec la taille de l'animal et ce nombre s'accroît normalement au cours des mues successives. Il en est de même pour le nombre d'épines sternales aux dactylopodites des péréiopodes 2 à 7 : ainsi, le mâle de $7,8 \mathrm{~mm}$ possède 2 épines seulement à tous les dactylopodites, sauf le deuxième, qui possède déjà 3 épines. Par contre, le mâle de $8,1 \mathrm{~mm}$ montre 3 épines à tous les dactylopodites, c'est donc un caractère morphologique qui ne doit donc être envisagé que pour les individus parvenus au maximum de leur taille.

Lorsque, en 1938, Frade décrivit Asellus lusitanicus, il le fit avec toutes les réserves d'usage, car pour lui la systématique des Asellides devrait être l'objet de travaux de révision périodique, compte tenu des incertitudes qui y régnaient. Il admettait aussi que la création d'une espèce nouvelle dans ce groupe pouvait fort bien n'être considérée que comme une commodité temporaire. Or, aujourd'hui, Asellus lusitanicus est connu de quatre stations distinctes. La station-type de l'aqueduc d'Alviela a dû être peuplée par les Aselles de la résurgence des Olhos d'Agua (Biospeologica, LIV, p. 390) captée pour les besoins de Lisbonne. Ces quatre localités se trouvent dans le même massif calcaire dont les eaux souterraines doivent servir de milieu de vie à ce Crustacé; de plus, A. lusitanicus est bien distinct des autres Aselles anophtalmes du Portugal, en particulier d'A. arthrodilus des environs de Coimbra, et parfaitement identifiable. Il est donc intéressant de pouvoir confirmer le bien-fondé de la création de cette espèce par Frade et de contribuer ainsi à la connaissance de l'histoire complexe du groupe dans les régions périméditerranéennes.

\section{RÉSUMÉ}

L'Asellide troglobie Asellus lusitanicus Frade (1938) est maintenant connu dans trois grottes des calcaires jurassiques de la Serra de Aire (Portugal central). Il semble être une bonne espèce anophtalme au sein du groupe "coxalis 》. 


\section{SUMMARY}

The troglobitic Asellid Asellus lusitanicus Frade (1938) is now known from three caves of the Serra de Aire (Central Portugal). It seems to be a good eyeless species of the "coxalis" group.

\section{BIBLIOGRAPHIE}

Braga, J. M. (1945) - Un nouvel Aselle cavernicole du Portugal; A. arthrodilus n. sp. Mem. Est. Mus. Univ. Coimbra 169:1-15.

- (1946) - Quelques Asellides nouveaux du Portugal. Mem. Est. Mus. Zool. Univ. Coimbra 173: 9-18.

Chappuis, P. A. (1953) - Sur la systématique du genre Asellus. Notes Biospéol. Paris $7: 67-79$.

Cons, D. (1959) - The Caves of the Serra de Aire Massif, Central Portugal. Trans. Cave Research Group G. B. 5, 2: 61-103.

Frade, F. (1938) - Un Asellus nouveau des eaux souterraines du Portugal. Bull. Soc. Port. Sc. Nat. Lisbonne 13, 5: 17-24.

- (1939) - Un Crustacea cavernicola de Portugal. Naturalia, Lisbonne $3,1 / 2: 72-77$.

- (1945) - Crustaceos dulciaquicolas de Portugal. Bol. no 26 Com. Fisc. Aguas de Lisboa.

Magniez, G. (1966) - Asellus coxalis ibericus en France. Actes VIIe Cong. Nat. Spéléol., Bordeaux (sous presse).

Margaleff, R. (1953) - Los crustaceos de las aguas continentales ibericas. Inst. Forest. Invest. exp., Minist. Agr., Madrid 10:1-243.

Racovitza, E. G. (1922) - Description de trois Asellus (Isopodes) cavernicoles nouveaux. Bull. Soc. Sc. Cluj 1: 401-410.

\section{EXPLIGATION DE LA PLANCHE 61 (1)}

Les schémas se rapportent à des appendices d'un mâle adulte de 7,8 mm de Mindhinu Cave (Référence du Cave Research Group of Great Britain : M.J.6.P.) : A - pléopode 1 gauche, face sternale; B - pléopode 2 gauche, face sternale; $\mathrm{C}$ - extrémité du précédent à très fort grossissement; D pléopode 4 droit, face sternale; $\mathrm{E}$ - pléopode 5 gauche, face sternale. - Les échelles sont graduées en microns. 

Les Mycetophilidae (Diptères) cavernicoles de la collection Biospeologica (IVe-VIIIe séries des «Grottes visitées»)

\author{
Par Anca Burghele-Balacesco ${ }^{1}$ )
}

Avec planches $62(1)-63(2)$

Récemment (1965), lors de la révision du matériel de la collection Biospeologica, les séries I indiqué la présence de six espèces de Mycetophilidae: Messala saundersi Curtis, Speolepta leptogaster Winn., Exechia exigua Lundst., E. jenkinsoni Winn., Rhymosia dziedzickii Edw. et Rhymosia sp. Ce matériel avait été antérieurement identifié par Bezzi (1911).

En poursuivant l'examen des Diptères de cette collection, nous avons choisi pour le moment uniquement les Mycetophilidae des séries IVe_VIIIe des «Grottes visitées». Leur étude fait l'objet du présent travail.

Nous avons pu constater à cette occasion la grande richesse de ce matériel, car trente espèces ont été capturées, parmi lesquelles quelques unes en très grand nombre d'exemplaires (Messala saundersi, Rhymosia dziedzickii, $R$. fenestralis, $R$. gracilipes).

En même temps, l'étude des insectes de cette famille, nous a mis en présence de deux espèces nouvelles - Exechia peyerimhoffi n. sp. et Rhymosia pseudocretensis n.sp. - et nous a permis de figurer pour la première fois les ovipositors des femelles de Exechia coremura Edw. et $E$. landrocki Lundst. Nous signalons aussi la présence parmi les représentants de la faune cavernicole de quelques espèces rares: Exechia pollicata Edw., E. unguiculata Lunst., Rhymosia cretensis Lundst.

Le matériel de la collection Biospeologica, les séries IVe_VIIIe des «Grottes visitées» provient de France, d'Espagne, d'Autriche, de Yougoslavie, de Roumanie, d'Algérie et du Kenya et fut recueilli par Argod-Vallon, Bolivar, Breuil, Chappuis, Fage, Fagniez, Jeannel, Magdelaine, Paris, Peyerimhoff, Puşcariu, Racovitza, Ribaut, Roth, Sollaud et Winkler.

\footnotetext{
1) Institutut de Speologie, Str. Dr. Capsa 8, Bucuresti 15, Roumanie.
} 


\section{Liste des espèces identifiées}

Fam. MYCETOPHILIDAE

\section{Subfam. BOLITOPHILINAE}

Bolitophila maculipennis Walk., Bolitophila coronata Mayer;

Messala saundersi Curt., Messala spinigera Edw., Messala speleicola Tollet, Messala cinerea (Meig.), Messala cooremani Tollet, Messala lengersdorfi Tollet.

\section{Subfam. SCIOPHILINAE}

Speolepta leptogaster (Winn.).

\section{Subfam. MYGETOPHILINAE}

Fungivora sp. 1, Fungivora sp. 2;

Phronia willistoni Dzied., Phronia sp.

Exechia coremura Edw., Exechia vizzavonensis Edw., Exechia indecisa Walk., Exechia jenkinsoni Edw., Exechia intersecta Meig., Exechia pollicata Edw., Exechia palettata Burgh., Exechia landrocki Lundst., Exechia unguiculata Lundst., Exechia pulchella Winn., Exechia peyerimhoffi n. sp.;

Rhymosia fenestralis Meig., Rhymosia gracilipes Dzied., Rhymosia dziedzickii Edw., Rhymosia fasciata Meig., Rhymosia tolleti Burgh., Rhymosia cretensis Lunds., Rhymosia pseudocretensis n. sp.

\section{Liste des grottes et des espèces recueillies}

$$
\text { IVe série }
$$

354 Grotte des Voleurs, Pyrén.-Orient., France. 5-VII-1910: Rhymosia gracilipes 1 ㅇ.

366 Grottes des Judeous, Htes-Pyrénées, France. 14-VII-1910: Rhymosia gracilipes 2 ㅇ.

377 Cova de Vinyoles, Prov. de Lerida, Espagne. 23-VIII-1910: Rhymosia gracilipes 1 ㅇ.

396 Cueva de la Castañeda, Prov. de Santander, Espagne. 9-VII-1910: Rhymosia dziedzickii 13.

423 Grotte de Gournier, Isère, France. 31-III-1911: Rhymosia dziedzickii 1 o.

428 Grotte des Rochers Martel, Drôme, France. 2-IV-1911: Messala spinigera 5 ㅇ.

429 Grotte de la Luire, Drôme, France. 2-IV-1911: Exechia indecisa 1 ㅇ, $1 \delta^{\star} ;$ E. vizzavonensis 1 우.

430 Grotte du Brudour, Drôme, France. 3-IV-1911: Messala saundersi 1 ㅇ.

433 Le Perthus del Drac, Alpes-Maritimes, France. 11-IV-1911: Rhymosia dziedzickii 1 +.

436 Ifri Maareb, Algérie. 10-VII-1911: Rhymosia gracilipes 1 +, 1 to.

444 Grotte d'en Brixot, Pyrén.-Orient., France. 1-VI-1911: Messala saundersi 2 o; Rhymosia dziedzickii 1 ㅇ; Exechia pulchella 1 ㅇ.

444A Grotte d'en Brixot (entrée de la grotte, principalement produits de tamisage). 1-VI-1911: Messala saundersi 1 ㅇ. 
445 Grotte Sainte Marie, Pyrén.-Orient., France. 1-VI-1911: Rhymosia gracilipes 2 ㅇ․

446 Forat la Bou, Prov. de Lerida, Espagne. 16-VI-1911: Rhymosia. dziedzickii 1 ㅇ.

447 Esplluga Llorna, Prov. de Lerida, Espagne. 16-VI-1911: Rhymosia gracilipes 4 우, 5 ot.

448 Lo Grallé, Prov. de Lerida, Espagne. 17-VI-1911: Rhymosia gracilipes 2 ㅇ, 2 s.

450 Cova del Sanat, Prov. de Lerida, Espagne. 18-VI-1911: Rhymosia

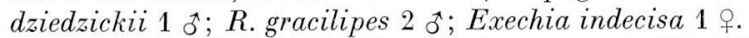

451 Minas de Canal, Prov. de Lerida, Espagne. 18-VI-1911: Exechia jenkinsoni 1 ㅇ.

457 Cuevas de Buerba, Prov. de Huesca, Espagne. 24-VI-1911: Bolitophila coronata 4 + ; Rhymosia dziedzickii 1 ㅇ, 2 ơ; R. gracilipes 1 ㅇ, 2 o.

458 Forau de la Drolica, Prov. de Huesca, Espagne. 26-VI-1911: Rhymosia fenestralis 1 ㅇ, 1 ơ ; Exechia vizzavonensis 1 ㅇ.

459 Cueva del paco de Naya, Prov. de Huesca. Espagne. 28-VI-1911: Rhymosia dziedzickii 3 o , 4 ơ ; Exechia jenkinsoni 2 ot.

483 Ifri Khaloua, Algérie. 10-VIII-1911: Exechia coremura 1 ㅇ, 2 ot.

$$
\text { Ve série }
$$

512 Cueva de San Garcia, Prov. de Burgos, Espagne. 13-VI-1912: Rhymosia dziedzickii 2 ot.

515 Cueva de la Fuente del Pato, Prov. de Burgos, Espagne. 12-VI-1912: Rhymosia dziedzickii 1 ㅇ.

521 Cueva del Berrueco, Prov. de Cadiz, Espagne. 15-IV-1912: Rhymosia dziedzickii 1 ot.

523 Grotte de Birbaret, Drôme, France. 2-V-1911: Messala speleicola 2 ‥

525 Grotte de Pialoux, Drôme, France. 19-III-1912: Rhymosia dziedzickii 2 t.

528 Grotte de Bec-pointu, Drôme, France. 9-IV-1912: Rhymosia dziedzickii 5 우, 2 ㅊ.

529 Grotte de Col des Taillières, Drôme, France. 9-IV-1912: Rhymosia dziedzickii 2 ot.

530 Grotte de Pélebit, Drôme, France. 9-IV-1912: Rhymosia fenestralis 1 ㅇ, 1 ot.

542 Grotte de Campbell, Prov. de Kénya, Afrique orient. Angl. 28-I-1912: Rhymosia cretensis Lundst. 2 万.

546 Grotte d'Artigues-vieilles, Aude, France. 9-IX-1912: Messala saundersi

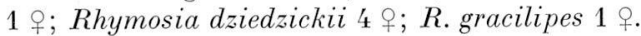

547 Grotte du Bac de la Caune, Aude, France. 10-IX-1912: Rhymosia fenestralis 3 ㅇ, 2 ơ $R$. dziedzickii 1 ô.

548 Grotte de Belvis, Aude, France. 10-IX-1912: Rhymosia gracilipes 1 ô.

549 Grotte d'Espezel, Aude, France. 11-IX-1912: Rhymosia dziedzickii 1 ㅇ.

552 Grotte de Peyrsunard, Ariège, France. 13-IX-1912: Rhymosia fene-

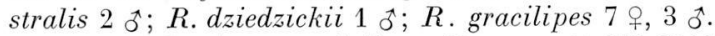

553 Grotte de l'Echarton, Ariège, France. 13-IX-1912: Rhymosia dziedzickii 2 ô.

554 Grotte de Lestelas, Ariège, France. 14-IX-1912: Rhymosia dziedzickii 4 ㅇ, 3 ô; R. gracilipes 1 i ; Exechia pulchella 1 ot. 
556 Grotte du Mont de Chac, Hte-Garonne, France. 15-IX-1912: Rhymosia fenestralis 2 +, 4 ô; R. dziedzickii 2 ot; Exechia pulchella 1 ot.

561 Grotte de Gouillou, Hte-Garonne, France. 17-IX-1912: Rhymosia fenestralis 1 ㅇ, 1 to.

567 Grotte du Brudour, Drôme, France. 13-V-1912: Messala saundersi 1 q ; M. spinigera 3 웅 Bolitophila maculipennis 3 ㅇ.

581 Caouno del Bac, Aude, France. 13-X-1912: Rhymosia dziedzickii 1 ㅇ, 3 s.

586 Grotte du Saut, Aude, France. 20-X-1912: Rhymosia dziedzickii 4 ô.

587 Grotte des Mythones, Aude France. 20-X-1912: Rhymosia fenestralis 2 ơ; $R$. dziedzickii 7 ㅇ, 1 tै; $R$ gracilipes 1 ot.

589 Grotte de Rochefort, Mayenne, France. 30-XI-1912: Messala saundersi 1 ㅇ.

597 Grotte de la Bertasse, Tarn-et-Garonne, France. 29-XII-1912: Rhymosia gracilipes 1 우.

602 Rivière souterraine de Cabéon. Tarn, France. 31-XII-1912: Messala saundersi 8 of; Rhymosia dziedzickii 1 ô; R. fasciata 1 ot.

603 Grotte de Cabéon, Tarn, France. 31-XII-1912: Messala saundersi 2 + ; Rhymosia fasciata 1 ot.

605 Trou du Capucin, Tarn-et-Garonne, France. 2-I-1913: Messala saundersi 1 오.

606 Rivière intermittente de Bonne, Tarn-et-Garonne, France. 2-I-1913: Rhymosia fasciata 1 ㅇ.

615 Grotte de Capelle, Lot, France. 7-I-1913: Rhymosia fasciata 1 + ; Exechia intersecta 1 o.

616 Grotte de Finou, Lot, France. 7-I-1913: Messala saundersi 1 ㅇ․

627 Grotte de Malarode, Basses-Pyrénées, France. 8-VIII-1913: Rhymosia dziedzickii 1 ㅇ, 1 ot.

638 Grotte de Rébénacq, Basses-Pyrénées, France. 8-VIII-1913: Messala saundersi 1 ㅇ.

643 Grotte d'Iribery, Basses-Pyrénées, France. 11-VIII-1913: Rhymosia dziedzeckii 1 ot.

685 Grotte de la Source de Béhérobie, Basses-Pyrénées, France. 4-IX-1913: Exechia pulchella 3 ô.

701 Khaloua, Algérie. 1-VII-1913: Rhymosia gracilipes 2 ㅇ, 1 ơ; Exechia sp. 2 ㅇ.

702 Ifri bou-Anou, Algérie. 28-VII-1913: Exechia peyerimhoffi 1 ㅇ, 1 ot.

705 Ifri Maareb, Algérie. 29-VII-1913: Rhymosia dziedzickii 2 \%; R. gracilipes 6 ㅇ, $4 \sigma^{*} ; R$. pseudocretensis 1 to .

707 Ifri bou-Amane, Algérie. 29-VII-1913: Rhymosia dziedzickii 2 ㅇ, 1 § .

711 Tifritz Si Aït M'hammed ou-Ali, Algérie. 30-VII-1913: Exechia peyerimhoffi 4 우, 3 오.

714 Tessereft Tabort Boufrîchen, Algérie. 1-VIII-1913: Exechia peyerimhoffi 2 ㅇ.

721 Tessereft Guiril, Algérie. 1-VIII-1913: Exechia peyerimhoffi 2 우 3 o*.

$$
\text { V Ie série }
$$

737 Grotte du Bois de Delon, Hérault, France. 28-XII-1913: Rhymosia gracilipes 1 ot.

738 Grotte des Rives, Hérault, France. 29-XII-1913: Messala saundersi 1 우 Rhymosia tolleti 2 ơ; R. gracilipes 2 ㅇ․ 
739 Grotte de la Salpêtrière, Gard, France. 29-XII-1913: Rhymosia gracilipes 2 ㅇ.

742 Grotte de Cesteragne, Hérault, France. 31-XII-1913: Rhymosia dziedzickii 1 ㅇ.

746 Grotte de Trabuc, Gard, France. 3-I-1914: Rhymosia gracilipes 1 +.

749 Baume des Italiens, Gard, France. 5-I-1914: Messala saundersi 5 ; Rhymosia dziedzickii 1 ô.

751 La Coquelière, Ardèche, France. 6-I-1914: Messala saundersi 4 ㅇ.

754 Grotte de l'Assiette, Ardèche, France. 7-I-1914: Rhymosia dziedzickii 10 .

755 Grotte du Cuivre, Ardèche, France. 7-I-1914: Messala saundersi 1 +.

757 Grotte nouvelle de Valon, Ardèche, France. 8-I-1914: Rhymosia gracilipes 1 ot.

758 Grotte du Soldat, Ardèche, France. 9-I-1914: Rhymosia gracilipes 1 of.

761 Grotte du Château d'Ebbou, Ardèche, France. 10-I-1914: Messala saundersi 1 ㅇ.

773 Grotte de Luegg, Krain, Autriche. 26-IV-1914: Messala saundersi 1 ㅇ.

781 Cueva de Bujaruelo, Prov. de Huesca, Espagne. 17-VII-1914: Bolitophila coronata 1 ㅇ.

782 La Dragonera de Santa Helena, Prov. de Huesca, Espagne. 19-VII-

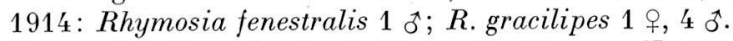

786 Cueva del Orso de Ansó, Prov. de Huesca, Espagne. 29-VII-1914: Phronia willistoni, centaines d'exemplaires; Rhymosia gracilipes 5 , 1 ơ $^{*}$ Exechia unguiculata 1 ㅇ.

792 Caverna de San Román de Candomó, Prov. de Oviedo, Espagne. 29-V-1915: Rhymosia dziedzickii 2 ㅇ, 1 o.

808 Grotte de l'Espugne, Hte-Garonne, France. 6-VII-1914: Rhymosia

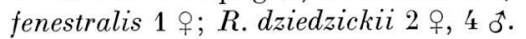

819 Grotte de la Baume-Archée, Doubs, France. 27-IV-1916: Rhymosia dziedzickii 1 ㅇ.

830 Cueva de Reguerillo, Prov. de Madrid, Espagne. 5-VIII-1916: Rhymosia dziedzickii 1 ㅇ, 3 o.

864 Cueva de Basondo, Prov. de Vizcaya, Espagne. 16-IX-1917: Messala saundersi 1 ㅇ.

873 Grotte de Cravanche, Terr. de Belfort, France. 10-VIII-1917: Messala saundersi 1 o ; Rhymosia dziedzickii 1 ơ.

876 Grotte des Faux-Monnayeurs, Doubs, France. 28-IX-1917: Messala saundersi 1 오.

879 Grotte de Mémont,Doubs, France.4-VIII-1916: Rhymosiadziedzickii 1 ơ $^{*}$.

893 Ifri Khaloua, Algérie. 29-VIII-1915: Exechia coremura 1 ô; E. pollicata 1 ot.

895 Ifri bou-Anou, Algérie. 30-V-1914: Rhymosia gracilipes 2 ơ; Fungivora sp. $1: 1$ ㅇ.

896 Ifri bou-Anou, Algérie. 23-V-1915: Rhymosia gracilipes 1 t.

898 Ifri bou-Amane, Algérie. 2-VII-1914: Messala saundersi 2 + ; Rhymosia dziedzickii 4 + 9,7 ๙.

901 Ifri n'Tazeront n'Ahmed ou-Amar, Algérie. 23-X-1915: Messala saundersi 1 ot.

907 Ifri n'Terga Roumi, Algérie. 9-VII-1914: Rhymosia gracilipes 1 o.

922 Tessereft Agouni Tamkijet, Algérie. 28-VIII-1915: Exechia coremura

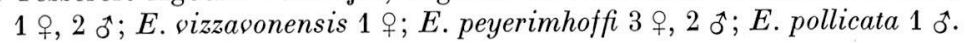




\section{VII e série}

941 Grotte de l'Haïouat de Pelou, Htes-Pyrénées, France. 6-VIII-1919: Messala saundersi 1 o ; Rhymosia dziedzickii 1 o; R. fasciata 1 ô.

943 Grotte de Gouillou, Hte-Garonne, France. 7-VIII-1919: Messala saundersi 1 \%; Rhymosia fenestralis 1 \%; R. dziedzickii 1 o.

946 Cueva de Arrobieta, Prov. de Giupúzcoa, Espagne. 19-VIII-1919: Rhymosia fenestralis 1 ; ; R. dziedzickii 6 +, 5 o .

950 Cueva de Hernialde, Prov. de Guipúzcoa, Espagne. 21-VIII-1919: Rhymosia fcnestralis 1 ․

954 Cueva de Malkoraundi, Prov. de Navarra, Espagne. 23-VIII-1919: Rhymosia fenestralis 1 đ.

955 Cueva de Legorras, Prov. de Alava, Espagne. 27-VIII-1919: Rhymosia dziedzickii 1 q.

958 Cueva de San Valerio, Prov. de Guipúzcoa, Espagne. 30-VIII-1919: Messala saundersi 1 \%.

959 Cueva de Aitzquirri, Prov. de Guipúzcoa, Espagne. 31-VIII-1919: Rhymosia dziedzickii 1 ot.

960 Cueva de Aitzeguia, Prov. de Guipúzcoa, Espagne. 31-VIII-1919: Rhymosia dziedzickii 1 ㅇ, 2 ô.

961 Azkonar sulueta, Prov. de Guipúzcoa, Espagne. 31-VIII-1919: Rhymosia gracilipes 3 ㅇ, 1 s.

965 Gueva de Atabo, Prov. de Navarra, Espagne. 3-XI-1919: Messala saundersi 1 \% ; Rhymosia dziedzickii 9 ㅇ, 4 ot.

967 Cueva de San Roque de Utzcorta, Prov. de Vizcaya, Espagne. 8-IX1919: Messala saundersi 3 ㅇ.

994 Cueva de Arrobieta, Prov. de Guipúzcoa, Espagne. 28-IV-1919: Rhymosia dziedzickii 1 ㅇ, 3 ô.

998 Coves de Carvathal, Prov. de Estramadura, Espagne. 16-VI-1918: Rhymosia gracilipes 1 to.

1006 Grotte de Balot, Côte-d'or, France. 12-IV-1918: Rhymosia fasciata 2 ㅇ, 2 ot.

1021 Forat de Quiteria, Prov. de Castellón de la Plana, Espagne. 12-IV1920: Rhymosia gracilipes 1 ㅇ.

1022 Cova del Puntal, Prov. de Castellón de la Plana, Espagne. 12-IV-1920: Rhymosia gracilipes $1 \hat{\delta}$.

1032 Cova gran de la Febró, Prov. de Tarragona, Espagne. 22-IV-1920: Rhymosia dziedzickii 1 q.

1035 Grotte de l'Homme-Mort, Aude, France. 23-V-1920: Rhymosia dziedzickii 20 .

1041 Grotte de Lherm, Ariège, France. 28-V-1920: Rhymosia dziedzickii 2 ㅇ, 3 ot.

1066 Peştera de la Alun, Bihor, Roumanie. 19-VIII-1921: Speolepta leptogaster 1 ; ; Messala lengersdorfi 6 ․

1073 Ghețarul de la Barsa, Bihor, Roumanie. 30-VIII-1921: Bolitophila maculipennis 1 ㅇ.

1081 Hoancele Caldarilor, Turda, Roumanie. 4-X-1921: Exechia landrocki 3 ㅇ, 6 o.

1093 Peştera Lucia Mare, Alba, Roumanie. 27-V-1922: Rhymosia dziedzickii 1 ‥

1098 Coiba Mare de la Casa de Piatra, Turda, Roumanie. 2-VI-1922: Messala lengersdorfi 23 ㅇ. 
1102 Peştera de la pareții Corlatului, Bihor, Roumanie. 8-VI-1922 : Messala lengersdorfi 1 ㅇ.

1110 Peştera de la Dîmbul Colibii, Bihor, Roumanie. 13-VI-1922: Rhymosia dziedzickii 1 ㅇ.

1112 Ghețarul de la Barsa, Bihor, Roumanie. 21-VI-1922: Messala lengersdorfi 1 \%; Speolepta leptogaster 1 +.

1151 Ledenica na maloj Brezovici, Oblast Morava, Yugoslavie. 5-VI-1923: Messala lengersdorfi 11 ․

1156 Prekonoska pester, Oblast Timok, Yugoslavie. 11-VI-1923: Rhymosia fenestralis 2 ㅇ, $2 \hat{0}$.

1160 Sveta voda, Oblast Cacak, Yugoslavie. 16-VI-1923: Messala sp.; Rhymosia fenestralis 1 ㅇ.

1162 Megara pecina, Oblast Uzice, Yugoslavie. 19-VI-1923: Rhymosia fenestralis 1 i ; R. dziedzickii 4 ㅇ.

1164 Velika pecina, Oblast Uzice, Yugoslavie. 23-VI-1923: Messala cooremani 1 i; Rhymosia fenestralis $1+2,2$; R. gracilipes 2 + ; Fungiøora sp. $2: 4$ 우 3 ot.

1197 Peștera Mica de pe Corlata, Alba, Roumanie. 27-VI-1924: Fungiøora sp. 2:1 우 Phronia sp. 1 ㅇ.

1210 Peştera de la Bisericuța, Alba, Roumanie. 30-VII-1924: Messala saundersi 1 ㅇ․

1258 Peştera de la perețiii Corlatului, Bihor, Roumanie. 21-V-1926: Rhymosia dziedzickii 1 ㅇ.

1273 Grotte de Moulis, Ariège, France. 4-VIII-1925: Exechia pulchella 4 우, 1 o

$$
V I I I^{\mathrm{e}} \text { série }
$$

1308 Peştera de la Izbundici, Bihor, Roumanie. 21-V-1928: Messala saundersi 1 \&; Rhymosia dziedzickii 1 ㅇ.

1311 Peştera Mare de la Balta, Mehedinți, Roumanie. 3-VI-1928: Rhymosia fenestralis 2 ot.

1312 Peştera de la Vîrful Inalt, Mehedinţi, Roumanie. 3-VI-1928: Rhymosia fenestralis 3 ot.

1317 Peştera de la Mînastirea Tismana, Gorj, Roumanie. 6-VI-1928: Rhymosia fenestralis 1 ․

1318 Peştera de la Fuşteica, Gorj, Roumanie. 8-VI-1928: Exechia palettata 2 ㅇ, $10^{*}$.

1320 Peştera de la Patrunsa, Gorj, Roumanie. 10-VI-1928: Rhymosia fenestralis 10 .

1344 Peştera de la Cornetul Vîrcanilor, Mehedinți, Roumanie. 16-VI-1929: Rhymosia fenestralis 1 ơ; Exechia jenkinsoni 1 우.

1347 Peştera de la Dîlma cu brazi I, Hunedoara, Roumanie. 21-VI-1929: Exechia vizzavonensis 1 ㅇ.

1350 Peştera de la Piatra Arsa din Cernişoara, Gorj, Roumanie. 22-VI-1929: Rhymosia fenestralis 1 ơ; Exechia palettata 1 o.

1360 Peşterile de la Sohodolul din Polovragi, Gorj, Roumanie. 14-V-1930: Rhymosia fenestralis 1 ㅇ.

1364 Peştera de la Rîpa Vînata, Gorj, Roumanie. 17-V-1930: Rhymosia fenestralis 8 o, 8 万.

1365 Peştera de la Cloşani, Mehedinți, Roumanie. 5-V-1928: Rhymosia fenestralis 1 o. 
1367 Peştera de la Piatra Micá, Mehedinţi, Roumanie. 18-V-1930: Messala cinerea 1 ㅇ.

1368 Peştera de la Cheia Comoriştii, Mehedinți, Roumanie. 19-V-1930: Rhymosia fenestralis 2 \&, 1 ot.

1378 Peştera Criva, Mehedinți, Roumanie. 23-V-1930: Rhymosia fenestralis 2 ㅇ, 3 ơ; Exechia pulchella 1 ㅇ.

1380 Peştera Muierilor I, Gorj, Roumanie. 25-V-1930: Rhymosia fenestralis 1 ô.

1383 Peştera Pîrlazului, Gorj, Roumanie. 26-V-1930: Rhymosia fenestralis 4 ơ

1396 Peştera din Valea Cutilor, Bihor, Roumanie. 30-VII-1930: Messala saundersi 1 + ; Rhymosia dziedzickii 4 +, 3 ô.

1408 Peştera de la Horn, Bihor, Roumanie. 4-VIII-1938: Bolitophila coronata 1 ㅇ.

1410 Peştera de la Alun, Bihor, Roumanie. 5-VIII-1938: Messala cooremani 1 ‥

1411 Peştera Zmeilor din Onceasa, Bihor, Roumanie. 7-VIII-1938: Messala cinerea 3 ; ; Bolitophila maculipennis 1 ㅇ.

1413 Baia de aur de la Someşul rece, Cluj, Roumanie. 21-VII-1929: Messala saundersi 1 o ; Rhymosia dziedzickii 1 ot.

\section{Quelques considérations sur les espèces mentionnées}

Bolitophila maculipennis Walk.

Matériel: France 567; Roumanie 1073, 1411.

L'espèce est connue dans toute l'Europe mais n'avait pas été signalée du domaine souterrain jusqu'à présent. Les exemplaires recueillis par Leruth dans les grottes de Roumanie avait été nommés par Lengersdorf $B$. maculipennis, d'une manière erronée. Ils appartiennent à l'espèce $B$. coronata Mayer, comme l'a montré Tollet en 1955.

\section{Bolitophila coronata Mayer}

Matériel : Espagne 457, 781 ; Roumanie 1408.

Cette espèce était connue en Europe centrale et du domaine souterrain, seulement dans les grottes de Transylvanie (Roumanie), où elle fut mise en évidence par Tollet dans le matériel recueilli par Leruth. Récemment elle fut identifiée par Matile dans deux grottes de Suisse. Le fait d'avoir été trouvée en Espagne, étend considérablement son aire d'expansion vers l'Ouest.

\section{Messala saundersi Curt.}

Matériel : Espagne 864, 958, 965, 967 ; France 430, 444, 444A, 546, 567, 589, 602, 603, 605, 616, 627, 638, 639, 738, 749, 751, 755, 761, 773, 873, 876, 941, 943; Roumanie 1210, 1308, 1396, 1413; Algérie 898,901 . 
Parmi les Bolitophilinae c'est l'espèce dont le plus grand nombre d'exemplaires fut recueilli.

Messala spinigera Edw.

Matériel : France 428, 567.

Elle fut trouvée dans les grottes de la Suisse par Matile (1962), selon lequel elle serait une trogloxène accidentelle. En milieu épigé, elle est connue d'Angleterre. Nous l'avons retrouvée récemment dans les grottes en Roumanie et maintenant pour la première fois, dans les grottes de la France.

\section{Messala speleicola Tollet}

Matériel : France 523.

Elle fut décrite par Tollet d'après une seule femelle recueillie par Leruth en Roumanie; nous l'avons retrouvée ( 2 +) dans le matériel de la collection Biospeologica, dans une seule grotte, en France.

\section{Messala cinerea Meig.}

Matériel : Roumanie 1367, 1411.

Espèce répandue dans les grottes de toute l'Europe. Tollet a élucidé en 1955 l'écologie de cette espèce, qui fait partie des trogloxènes réguliers de l'association pariétale.

\section{Messala cooremani Tollet}

Matériel : Yougoslavie 1164; Roumanie 1410.

Cette espèce a été décrite par Tollet d'après le matériel recueilli par Leruth dans les grottes de Transylvanie. Le fait de l'avoir trouvée dans plusieurs grottes de Roumanie ainsi qu'en Yougoslavie, nous permet d'affirmer qu'elle fait partie des trogloxènes réguliers de l'association pariétale.

\section{Messala lengersdorfi Tollet}

Matériel : Roumanie 1066, 1098, 1102, 1112 ; Yougoslavie 1151.

De même que l'espèce précédente, $M$. lengersdorf fut décrite d'après quelques femelles recueillies par Leruth en Roumanie. Trogloxène régulier de l'association pariétale. 


\section{Speolepta leptogaster Winn.}

Matériel : Roumanie 1066, 1112.

Cette espèce, la seule troglophile de cette liste nous l'avons trouvée dans le matériel de la collection Biospeologica, dans une seule grotte de Roumanie. Un plus grand nombre d'exemplaires a été recueilli sous forme de larves, dont nous ne nous occuperons pas dans ce travail.

\section{Exechia coremura Edw.}

Matériel : Algérie 483, 893, 922.

L'espèce fut décrite par Edwards en 1928 d'après deux ô et une 우 recueillis au mois d'avril, à Vizzavona forest, en Corse. Nous l'avons identifiée dans le matériel de la collection Biospeologica en deux grottes d'Algérie au mois d'août. Nous ajoutons à la description d'Edwards un dessin de l'ovipositor (fig. 1).

\section{Exechia vizzavonensis Edw.}

Matériel : France 429; Espagne 458; Algérie 922 ; Roumanie 1347, 1410.

Nous avons décrit récemment (1966) la femelle de cette espèce de Bulgarie, où quatre exemplaires furent recueillis dans l'aven Reznjovete, près de Vratza. Elle fut décrite par Edwards de Corse et ces dernières années fut identifiée dans le domaine souterrain en plusieurs pays, ce qui nous permet de la placer parmi les trogloxènes réguliers.

\section{Exechia indecisa Walk.}

Matériel : France 429; Espagne 450.

Espèce recoltée dans les grottes de France, de Suisse, de Roumanie, de Tchécoslovaquie et d'Espagne. La plus grande partie des captures furent effectuées pendant les mois d'hiver (novembre-avril); e'est pourquoi nous considérons Exechia indecisa comme un élément trogloxène régulier hibernant. Nous avons dessiné l'ovipositor en reproduisant plus de détails que Landrock (fig. 2).

\section{Exechia jenkinsoni Edw.}

Matériel : Espagne 451, 459; Roumanie 1344.

Trogloxène régulier de l'association pariétale. Connue des grottes de France, de Roumanie et maintenant d'Espagne. Capturée notamment pendant les mois d'été. 


\section{Exechia intersecta Meig.}

Matériel : France 615.

Espèce recueillie habituellement rarement dans le domaine souterrain. Cependant, en Roumanie, un nombre considérable d'exemplaires furent trouvés dans les grottes pendant l'hiver. Nous avons dessiné l'ovipositor (fig. 3).

\section{Exechia pollicata Edw.}

Matériel : Algérie 893, 922.

L'espèce a été décrite d'Angleterre en 1924. Elle a été retrouvée depuis par Lackschewitz en Léttonie et maintenant par nous même dans le matériel de la collection Biospeologica, provenant de deux grottes d'Algérie. Il semble donc que l'espèce est rare, douée d'une large aire d'expansion. Au Nord de l'Europe elle a été recueillie dans le domaine épigé, en Algérie dans le milieu souterrain.

\section{Exechia palettata Burgh.}

Matériel : Roumanie 1318, 1350.

Ce matériel fut utilisé pour la description d'E. palettata que nous avons faite récemment (1965). Espèce très proche d'E. pollicata, de laquelle elle se distingue cependant nettement par la structure de l'hypopyge. Etant donné que cette espèce fut entre temps identifiée par nous en d'autres grottes de Roumanie, nous considérons qu'il s'agit d'un trogloxène régulier de l'association pariétale.

\section{Exechia landrocki Lundst.}

Matériel: Roumanie 1081.

L'espèce a été décrite d'après un seul mâle capturé par Fray en Laponie. Tollet l'a retrouvée - 3 mâles provenant de trois grottes dans le matériel recueilli par Leruth en Transylvanie. Nous l'avons identifiée maintenant toujours en Roumanie, d'après 9 exemplaires, parmi lesquelles des femelles. Nous complétons la description de Lundström par un dessin de l'ovipositor (fig. 4).

\section{Exechia unguiculata Lundst.}

Matériel: Espagne 786.

Espèce connue à ce jour dans les grottes de Roumanie et dans des galeries de mine en France. C'est selon nous, un trogloxène régulier de l'association pariétale, hibernante. 


\section{Exechia pulchella Winn.}

Matériel : France 444, 554, 556, 685, 1273, 1378.

Elle fut encore capturée dans les grottes de Suisse et de Roumanie. Trogloxène régulier de l'association pariétale.

\section{Exechia peyerimhoffi n. sp.}

Cette espèce fait partie du groupe d'espèces E. fusca Meig., E. confinis Winn., E. spinigera Winn., E. frigida Holm., E. spinuligera Lundst. Toutes ces espèces sont proches aussi bien par l'aspect général du corps que par la structure de l'hypopyge et de l'ovipositor. Les deux branches du forceps supérieur chez les deux premières espèces sont inégales, l'externe étant notablement plus courte que l'interne. Chez les trois dernières, les deux branches sont de longueur presque égale, très courtes chez E. frigida et un tiers environ de la longueur totale du forceps, chez E. spinigera et E. spinuligera.

E. spinuligera a été décrite par Lundström en 1912 d'après un matériel recueilli en Laponie. Celui-ci l'avait identifié initialement comme étant E. spinigera. A la suite d'une correspondance qu'il entretint avec Dziedzicki, ce dernier qui avait étudié les collections de Winnertz, attira son attention sur le fait que le matériel capturé en Laponie ne pouvait pas être atribué à l'espèce spinigera Winn. et qu'il s'agissait d'une espèce nouvelle, que Lundström décrivit ultérieurement sous le nom de E. spinuligera.

En 1924 Edwards met en synonymie les deux espèces, synonymie adoptée ultérieurement par Landrock (1927).

Barendrecht (1938) attira l'attention sur le fait que les deux espèces ne sauraient être identiques, vu que Dziedzicki avait étudié aussi bien l'E. spinigera de la collection de Winnertz que les spécimens d'E. spinuligera de Lundström et avait remarqué des différences nettes, ce qui ressort aussi des dessins des deux auteurs. D'accord avec Barendrecht, nous croyons aussi qu'il s'agit de deux espèces bien distinctes. Du reste, Barendrecht avait redessiné l'hypopyge de E. spinuligera, dessin qui est nettement différent de celui que Dziedzicki avait fait pour E. spinigera (1915).

L'espèce nouvelle que nous décrivons se rapproche le plus d'E.spinuligera, de laquelle cependant elle se différencie clairement par la structure de l'hypopyge qui peut être remarquée sur la figure 5.

ㅇ, §ิ. Face, front et occiput bruns. Palpes et antennes jaunes. Mésonotum entièrement brun, recouvert de deux rangées de longues soies discales ainsi que des soies semblables sur les côtés, spécialement sur les calus huméraux. Deux soies propleurales. Sc libre à l'apex. R-m 
deux fois et demie plus longue que la tige de la fourche médiane. Tibias antérieurs plus courts que l'article basal des tarses. Abdomen du mâle brun. Chez la femelle, abdomen brun avec des bandes jaunes basales s'élargissant latéralement sur les segments 2-5.

Hypopyge fig. 5. Les forceps supérieurs se terminent par deux branches, celle interne lancéolée, celle externe aciculaire. Ovipositor fig. 6.

Longueur du corps 3,5-4 mm.

Matériel : Tous les exemplaires proviennent d'Algérie. 1 ㅇ, 1 ๙ - 702, Ifri bou-Anou, 28-VII-1913; 2 - -711 , Tifritz Si Ait M'hammed ouAli, 30-VII-1913; 2 - 714, Tessereft Tabort Boufrichen, 1-VIII-1913 ; 2 ㅇ, 3 ô-721, Tessereft Guiril, 1-VIII-1913; 3 ㅇ, 2 ㅅ- 922, Tessereft Agouni Tamkijet, 28-VIII-1915. Le matériel a été recueilli par Peyerimhoff, à qui nous rendons hommage en lui dédiant cette nouvelle espèce.

\section{Rhymosia fenestralis Meig.}

Matériel : Espagne 458, 782, 946, 950, 954 ; France 530, 547, 552, 556, 561, 587, 808, 943 ; Yougoslavie 1156, 1160, 1162, 1164 ; Roumanie 1311, 1312, 1317, 1320, 1344, 1350, 1360, 1364, 1365, 1368, 1378, 1380, 1383.

Trogloxène régulier de l'association pariétale, estivant, répandu dans les grottes de toute l'Europe. En Roumanie, c'est le Mycétophilide le plus souvent rencontré dans les grottes.

\section{Rhymosia dziedzickii Edw.}

Matériel : Espagne 396, 446, 450, 457, 459, 512, 515, 521, 792, 830, 946, 955, 959, 960, 965, 994, 1032 ; France 423, 433, 444, 525, 528, 529, $546,547,549,552,553,554,556,581,586,587,602,627,643,742$, 749, 754, 808, 819, 873, 879, 941, 943, 1035, 1041 ; Algérie 705, 707, 898; Yougoslavie 1162 ; Roumanie 1093, 1110, 1258, 1308, 1396, 1413.

Dans le matériel de la collection Biospeologica, c'est l'espèce représentée par le plus grand nombre d'exemplaires. Elle semble avoir une répartition plus méridionale que l'espèce apparentée $R$. fenestralis. En Espagne et en France c'est l'espèce la plus commune des grottes, cependant qu'en Roumanie c'est Rhymosia fenestralis qui est la plus répandue.

\section{Rhymosia fasciata Meig.}

Matériel : France 602, 603, 606, 615, 941, 1006.

Trogloxène régulier de l'association pariétale, commun dans les grottes de toute l'Europe pendant l'hiver. Hibernante. 


\section{Rhymosia tolleti Burgh.}

Matériel : France 738.

Ce matériel ainsi que les nombreux exemplaires capturés dans les grottes de Roumanie, a été utilisé par nous pour la description de l'espèce. Trogloxène régulier de l'association pariétale.

\section{Rhymosia gracilipes Dzied.}

Matériel : Espagne 377, 447, 448, 450, 457, 782, 786, 961, 998, 1021, 1022 ; France 354, 366, 445, 546, 548, 552, 554, 587, 597, 737, 738, 739, 746, 757, 758; Yougoslavie 1164; Algérie 436, 701, 705, 895, 896, 907.

Trogloxène régulier de l'association pariétale, répandu dans les grottes de toute l'Europe.

\section{Rhymosia cretensis Lundst.}

Matériel : Kenya 542.

Cette espèce a été décrite par Lundström d'après un couple capturé par Biró en Crète. Selon nos connaissances l'espèce n'avait plus été trouvée que maintenant dans le matériel de la collection Biospeologica provenant d'une grotte de Kenya.

\section{Rhymosia pseudocretensis n. sp.}

§. Très voisin de $R$. cretensis. Face, front et occiput bruns. Palpes et antennes jaunes. Mésonotum entièrement brun, recouvert de deux rangées de longues soies noires discales; une seule soie propleurale. Sc libre à l'apex. R-m deux fois et demie plus longue que le pétiole de la fourche médiane. Tibias antérieurs plus courts que l'article basal des tarses. Abdomen brun ; 2-5 segments avec une tache jaune latérobasale.

La forme générale de l'hypopyge semble indiquer que $R$. cretensis et $R$. pseudocretensis sont très proches l'une de l'autre. Elles se distinguent par la conformation de l'appendice ventral et par la forme et la pubescence des forceps (fig. 7, A et 8, B).

Longueur du corps : $4 \mathrm{~mm}$.

Matériel : 1 ô - 705 Algérie, Ifri Maareb, 29-VII-1913. Leg. Peyerimhoff. 


\section{RÉSUMÉ}

L'étude des Mycetophilidae de la collection Biospeologica, les séries IVe à VIIIe des «Grottes visitées» fait l'objet du présent travail. Trente espèces ont été identifiées parmi lesquelles deux espèces nouvelles d'Algérie: Exechia peyerimhoffi n. sp. et Rhymosia pseudocretensis $\mathrm{n}$. sp. Nous signalons aussi la présence parmi les représentants de la faune cavernicole de quelques espèces rares - Exechia pollicata Edw., E. unguiculata Lundst. et Rhymosia cretensis Lundst. - et nous figurons pour la première fois les ovipositors de Exechia coremura Edw. et $E$. landroki Lundst.

\section{SUMMARY}

Study of the Mecetophilidae of the Biospeologica collection (Series IV to VIII of "Grottes visitées" was the objective of the present study. Thirty species have been identified, including Exechia peyerimhoffi n. sp. and Rhymosia pseudocretensis $\mathrm{n}$. sp. The cave fauna contains several rare species Exechia pollicata Edw., E. unguiculata Lundst., and Rhymosia cretensis Lundst. The ovipositors of Exechia coremura Edw. and E. landrocki Lundst. are figured for the first time.

\section{BIBLIOGRAPHIE}

Barendrecht, G. (1938) - The Dutch Fungivoridae in the collection of the Zoological Museum at Amsterdam. Tijdd. v. Ent. 81 : 35-54.

Burghele, A. (1965) - Specii noi de Mycetophilidae cavernicole din Romania. Lucr. Inst. Speol. "E. Racovița” IV: 171-179.

- (1966) - Diptères cavernicoles recueillis en Bulgarie. Inter. Journ. of Speleol. II, part. 3: 303-308.

Chappuis, P. A., et Jeannel, R. (1951) - Enumération des grottes visitées 1927-1949 (8e série). Biospeologica LXXII, Arch. zool. exp. gén. LXXXVIII, $2: 81-216$.

Degu Burghele, A. (1962-63) - Contribuții la studiul dipterelor cavernicole din peşterile R. P. Romane. Lucr. Inst. Speol. "E. Racovița" I-II : 475-494.

Dziedzicki, H. (1915) - Atlas des organes génitaux des types de Winnertz et des genres de sa collection de Mycétophiles. Publ. soc. sci. Varsov. : 1-16.

Edwards, F. W. (1924) - British Fungus-Gnats (Dipters, Mycetophilidae). With a revised Generic Classification of the Family. Trans. Ent. Soc. London 57: 505-690.

- (1928) - The Nematocerous Diptera of Corsica. Encycl. ent. Diptera IV : 157-189.

Husson, R. (1947) - Diptères des galeries de mines de France. Notes biospéol. Publ. Mus. nat. Hist. Nat. Paris I, 8: 37-52.

Jeannel, R., et Racovitza, E. G. (1912) - Enumération des grottes visitées 1909-1911 (4e série). Biospeologica XXIV. Arch. zool. exp. gén. IX: 501-667.

- - (1914) - Enumération des grottes visitées 1911-1913 (5e série). Biospeologica XXXIII. Arch. zool. exp. gén. 53: 325-558. 
Jeannel, R., et Racovit $z A$, E. G. (1918) - Enumération des grottes visitées 1913-1917 (6e série). Biospeologica XXXIX. Arch. zool. exp. gén. 57: $203-470$.

- - (1929) - Enumération des grottes visitées 1918-1927 (7e série). Biospeologica LIV. Arch. zool. exp. gén. 68, 2: 293-608.

LANDrock, K. (1927) - Fungivoridae in E. Lindner, Die Fliegen der palaearktischen Region, 8. Stuttgart: 1-195.

Lundströм, K. .(1909) - Beitrag zur Kenntnis der Dipteren Finnlands. Supplement. Acta soc. faun. flor. fenn. 32:1-67.

- (1911) - Neue oder wenig bekannte europäische Mycetophiliden I. Annal. mus. nat. Hung. IX: 390-419.

- (1912) - Beiträge zur Kenntnis der Dipteren Finnlands. Supplement II. Acta soc. faun. flor. fenn. 36: 1-70.

Matile, L. (1959) - Contribution à l'inventaire faunistique des cavités souterraines de l'ouest de la France. Diptères. Bull. soc. sci. nat. Ouest France IV : 15-26.

- (1962) - Contribution à l'étude de la faune cavernicole de la Suisse. Diptères. Bull. soc. ent. Suisse XXXV, 1-2: 121-130.

SEguY, E. (1963) - Diptères hypogés recueillis par M. Paul A. Remy en Yougoslavie. Mém. muz. nat. d'Hist. Nat. nouv. sér., A, Zool. XVIII, 3: 187-299.

Tollet, R. (1955) - Révision des Mycetophilidae cavernicoles de Transylvanie (Diptera, Nematocera) recueillis par R. Leruth. Mém. soc. Roy. Ent. Belg. XXVII : 443-465.

- (1959) - Contribution à l'étude des Diptères cavernicoles des grottes d'Italie et de Suisse et description de deux Mycétophilides nouveaux. Bull. et Ann. soc. Roy. Ent. Belg. XCV : 205-231.

\section{EXPLICATION DES PLANCHES $62(1)-63(2)$}

Fig. 1 : Exechia coremura Edw., ovipositor. Fig. 2 : Exechia indecisa Walk., ovipositor. Fig. 3: Exechia intersecta Meig., ovipositor. Fig. 4: Exechia landrocki Lunstr., ovipositor. Fig. 5 : Exechia peyerimhoffin. sp., hypopyge. Fig. 6: Exechia peyerimhoffi n. sp., ovipositor. Fig. 7: Rhymosia cretensis Lundst., hypopyge. A forceps. Fig. 8: Rhymosia pseudocretensis n. sp., hypopyge. B forceps. 


\title{
Sur la faculté d'absorption de substances colorées
} par la cuticule de Caecosphaeroma burgundum Dollfus, Crustacé Isopode des eaux souterraines.

\author{
Par François Graf et Glaude Marvillet ${ }^{1}$ )
}

Avec planche 64(1)

Chez les Caecosphaeroma burgundum récoltés en eaux souterraines propres, la cuticule n'est pas pigmentée et le corps tout entier est transparent. Les seules régions apparaissant colorées sont le tractus intestinal, l'hépatopancréas aux cellules riches en pigments noirs, et surtout les organes jaunes. Ces derniers, décrits par J. Daum (1954), ont été par la suite assimilés aux organes de Zenker présents chez les diverses espèces du genre Asellus, en raison de leurs concrétions riches en acide urique (R. Husson et H. Schorr, 1957 ; H. Schorr, 1957).

Cependant, quelques individus colorés en brun-noir ont été récoltés au Puits Groseille, en Côte d'Or, et à Gorze, en Moselle. Une observation plus précise de ces animaux permet de voir que leur coloration n'est pas uniforme, mais que la teinte d'ensemble résulte de la présence d'une multitude de petites taches sur la carapace.

Les recherches effectuées par R. Husson (1965) permettent de préciser qu'il ne s'agit probablement pas de pigments mélaniques, que l'action de la lumière est à écarter et que l'interprétation par de multiples petites lésions tégumentaires n'est pas satisfaisante. L'auteur fait remarquer que ces individus colorés ont été trouvés dans des flaques calmes. Nous n'avons en effet jamais observé, malgré de fréquentes et abondantes récoltes dans les eaux souterraines à cours rapide de l'Abîme de Bévy (Côte d'Or), de tels spécimens «colorés".

Au cours d'élevages de Caecosphaeroma burgundum, il apparaît souvent, dans les bacs dont le fond se recouvre lentement d'une mince couche de débris de feuilles et de bois, des individus qui présentent des taches brunes et noires sur le bord postérieur des tergites, les pattes

1) Laboratoire de Biologie Animale et Générale, Faculté des Sciences, 21 Dijon. 
et les pointes tergales. Cette observation nous a conduits à étudier systématiquement l'action de diverses substances colorées sur la cuticule de ces Crustacés.

Nous avons soumis ces Isopodes troglobies à l'action de trois types de produits: extraits de végétaux (eau de macération de feuilles, tannins), substances colorantes (rouge congo, bleu de méthylène) et suspension de particules charbonneuses (encre de Chine).

$1^{\circ}$ - Eau de macération de feuilles : Les Caecosphaeroma sont placés dans une eau rendue brune par macération de feuilles mortes d'orme. Après 48 heures les individus sont de teinte brune et deviennent presque noirs dans les jours suivants. La coloration est intense sur toutes les parties du corps, elle n'est pas uniforme, mais apparaît sous forme de nombreuses petites taches (Fig. 1 et 2, planche 64).

Si l'on gratte doucement la cuticule de tels individus, on constate que les taches ne sont que superficielles, la cuticule elle-même ne conservant qu'une faible teinte.

Lors de la mue, ces animaux abandonnent leur carapace colorée et demeurent transparents s'ils sont replacés en eau propre. Il est à noter que cette coloration se manifeste plus rapidement et plus intensément chez les individus qui ont mué peu de temps avant d'être placés dans cette solution.

Cette première expérience nous a conduit à vérifier l'action des tannins.

$2^{\circ}$ - Tannins: On utilise du tannin du commerce, en solution à $2 \%$. Peu soluble dans l'eau, il forme un dépôt brun au fond du bac. Après 48 heures d'immersion dans cette solution, les Caecosphaeroma sont tachetés en face dorsale et les pattes présentent de larges aires brunes qui résistent au grattage. Des coupes effectuées au niveau des pattes (Fig. 3) et des tergites (Fig. 4) montrent qu'il y a eu absorption de tannin dans la cuticule. Il semble que dans un premier temps les tannins soient retenus par une pellicule mucoïde qui recouvre la cuticule, il y a ensuite diffusion par contact. Cette interprétation explique l'aspect moucheté des animaux ainsi traités.

$3^{\circ}$ - Rouge congo: Avec une solution à $0,05 \%$ de rouge Congo, on obtient, en 10 à 15 heures, de très beaux Caecosphaeroma de teinte rouge-vif, coloration particulièrement intense au niveau des pointes tergales, de la tête et du pléo-telson. Par grattage les amas de colorant retenus dans la pellicule superficielle disparaissent, mais la cuticule reste rose. Replacés en eau propre, ces animaux ont conservé la teinte rose pendant plus d'un mois, c'est à dire jusqu'à la nouvelle mue. Des coupes effectuées à congélation ont montré, comme dans le cas précédent, un phénomène d'absorption du colorant dans la cuticule. 
$4^{\circ}$ - Bleu de méthylène : Il est employé très dilué, à partir d'une solution à $1 \%$. Les animaux sont bleus en 8 heures, bleu-foncé en 12 heures et violets en 15 à 20 heures. Les régions les plus colorées sont les mêmes qui prennent particulièrement bien le rouge congo. Le grattage et l'étude de coupes à congélation donnent des résultats identiques au cas précédent.

$5^{\circ}-$ Encre de Chine: Placés dans une solution d'encre de Chine très diluée, mais juste opaque, les Caecosphaeroma noircissent après 8 à 10 jours. Cette coloration, plus spécialement intense sur la face ventrale et les pattes, est due à la présence d'amas de particules charbonneuses. Ces amas sont superficiels et facilement éliminés par grattage. L'observation de coupes, après inclusion à la paraffine, ne révèle aucune trace d'encre de Chine dans la cuticule.

\section{Discussion des résultats}

De ces différents tests, il ressort que les substances solubles (bleu de méthylène, rouge congo, eau de macération de feuilles) aussi bien que les suspensions (tannin, encre de Chine), «colorent» intégralement les Caecosphaeroma burgundum, avec cependant une intensité plus forte au niveau des pattes, des pointes tergales, des bords inférieurs de la tête et du pléo-telson. On peut expliquer l'action préférentielle $\mathrm{du}$ «colorant» sur ces zones par le fait que la substance employée finit toujours par former un dépôt sur le fond du récipient. Les antennes, qui jamais ne sont au contact du fond, restent toujours dépourvues de coloration.

Les résultats de grattage et l'observation de coupes indiquent que la teinture de ces Crustacés s'effectue en deux temps. Dans un premier temps les substances sont agglutinées par le film mucoïde qui recouvre la carapace. Ces amas sont épars et apparaissent progressivement autour d'un germe agglutinant. Dans un second temps les substances sont ou non absorbées dans la cuticule. Cette absorption est particulièrement nette dans le cas des tannins, elle est impossible pour les particules charbonneuses de l'encre de Chine.

Les Caecosphaeroma brun-foncé, récoltés à Gorze par l'un de nous, présentaient des amas épars de particules agglutinées; des coupes effectuées à divers niveaux du corps ont révélé qu'il n'y avait aucune teinture de la cuticule.

Le cas de trois individus noirs, récoltés au Puits Groseille par notre collègue J.-P. Henry, est particulièrement probant. Ces animaux 
étaient cantonnés dans une petite flaque dont le fond était recouvert de cendres; ce cas est à rapprocher du traitement à l'encre de Chine. Ainsi nous pouvons conclure que les Caecosphaeroma burgundum naturellement colorés sont des individus qui ont séjourné dans des flaques stagnantes renfermant des particules susceptibles d'être agglutinées à la surface de leur cuticule ${ }^{2}$ ).

\section{RÉSUMÉ}

La découverte, dans certaines eaux souterraines, de Caecosphaeroma burgundum "pigmentés», en brun ou noir, a conduit à l'étude systématique de l'action de substances colorées sur ces Crustacés. Les résultats de ces expériences permettent d'affirmer que les colorations ainsi obtenues, ou observées dans les cas naturels, sont dues à l'agglutination de substances colorées en surface de la carapace et, dans certains cas, à une imprégnation de la cuticule elle-même.

\section{SUMMARY}

The discovery, in certain subterranean waters, of "pigmented," brown or black Caecosphaeroma burgundum, led to the systematic study of the action of pigmented substances on these crustaceans. The results of these experiments demonstrate that the colorations thus obtained or observed in nature are due to the agglutination of colored substances on the surface of the carapace and, in certain cases, to an impregnation of the cuticle itself.

\section{BIBLIOGRAPHIE}

DAum, J. (1954) - Zur Biologie einer Isopodenart unterirdischer Gewässer: Caecosphaeroma (Vireia) burgundum Dollfus. Ann. Univ. Sarav., Naturwiss. 3: 104-160.

Husson, R. (1965) - Existence d'individus pigmentés dans l'espèce troglobie Caecosphaeroma burgundum Dollfus (Crustacea-Isopoda). IVo Congr. Internat. Spéléol., Yougoslavie (sous presse).

Husson, R., et Schorr, H. (1957) - Mise en évidence d'acide urique dans les organes jaunes du Crustacé troglobie Caecosphaeroma burgundum Dollfus. C. R. Ac. Sc. 244: 513-515.

Schorr, H. (1957) - Untersuchungen über Purine und Pigmente in den ,,gelben Organen“ des Höhlenisopoden Caecosphaeroma burgundum Dollfus. Ann. Univ. Sarav., Naturwiss. 5: 311-328, 1956.

$\left.{ }^{2}\right)$ Suivant une communication épistolaire de Th. C. Barr, celui-ci est arrivé aux mêmes conclusions pour les Orconectes pellucidus noirs de Mammoth Cave. 


\section{EXPLICATION DE LA PLANCHE 64 (1)}

Fig. 1: Face ventrale d'un Caecosphaeroma burgundum coloré par eau de macération de feuilles. Longueur $9 \mathrm{~mm}$. On remarque la coloration plus accentuée des pointes tergales, du bord du pléo-telson, des soies des pléopodes. Les traînées noires antérieures et médianes correspondent à l'hépatopancréas. Les organes jaunes sont bien visibles.

Fig. 2: Le même individu, en vue latérale. Les multiples petites taches, montrant que la coloration n'est pas uniforme, ressortent déjà à ce grossissement.

Fig. 3: Coupe au niveau d'un péréiopode, chez un Caecosphaeroma burgundum plongé 48 heures dans une solution de tannin à $2 \%$. En $a$, la zone colorée correspond à l'une des aires brunes observées à faible grossissement. En $b$, une zone qui n'a pas pris la coloration. On distingue la couche mucoïde superficielle qui agglutine les particules en suspension.

Fig. 4: Coupe au niveau d'un tergite, chez le même animal. A partir d'une particule de tannin accolée en surface, la coloration diffuse dans la cuticule. 



\title{
Documents pour servir à la connaissance de la faune de Mammifères des grottes du Banat (Roumanie)
}

\author{
Par Alexandrina Negrea, Lazare Botoşăneanu, Ştefan Negrea ${ }^{1}$ )
}

Au cours des années 1960-1965 les auteurs ont effectué des recherches de caractère complexe dans les grottes du Banat. Ils ont rassemblé à cette occasion de riches matériaux de Mammifères actuels et fossiles dans plus de 70 grottes. Dans les pages qui suivront nous allons faire mention exclusivement des matériaux recueillis par nous mêmes, ainsi que de nos propres observations; tout ceci pourra profitablement compléter ce que d'autres auteurs avaient antérieurement réalisé dans cette région karstique.

Nous pensons, en disant ceci, à: Balogh, Bokor, Calinescu, Dumitrescu-Tanasachi et Orghidan, Halaváts, Hamar, Hoernes, Kadič, Maxim, Méhely, Nicolaescu-Plopşor et Mateescu, Orthmayr, Petényi, Paszlawski, Primics, Sencu, Teglas, Terzea (voir la bibliographie) ainsi qu'à d'autres auteurs.

Mentionnons que les pièces ostéologiques ont été recueillies soit en surface des dépôts de remplissage, soit en pratiquant des fouilles très superficielles, en remuant le matériel d'anciennes fouilles ou bien en examinant les restes de repas de carnassiers ou les ingluvies des Oiseaux. Une véritable fouille n'a jamais été pratiquée. De plus, on a toujours fait des captures de Chiroptères (les ectoparasites trouvés sur ceux-ci seront mentionnés) et on a pris note de toutes les observations possibles sur les autres Vertébrés rencontrés.

Toutes les grottes figurant dans la «Liste des grottes dans lesquelles des Mammifères ont été collectés ou observés», portent un numéro d'ordre qui sera utilisé dans la «Liste des espèces identifiées». D'autre part, presque toutes les grottes de notre liste portent, entre parenthèses, un numéro correspondant à celui du Répertoire des grottes de Roumanie figurant sur la carte des régions carpatiques de Roumanie (Orghidan et collab., 1965). Les grottes, peu nombreuses, ne figurant

1) Institutul de Speologie «Emil Rakovitza»», Str. Dr. Capşa nr. 8, Bucuresti 35 (Roumanie). 
pas dans ce Répertoire, pourront facilement être mises en place sur la carte, grâce à leur position dans notre Liste; on pourra trouver une présentation détaillée de presque toutes les grottes dans Botoşaneanu, Negrea et Negrea (1966) et dans Negrea, Negrea, Sencu et Botoşaneanu (1965).

Le matériel est gardé dans les collections de l'Institut de Spéologie «Emile Racovitza» de Bucarest.

Il nous est fort agréable d'adresser nos remerciements pour des déterminations et pour de précieux renseignements, aux personnes suivantes: Prof. Dr. Margareta Dumitrescu (Rodentia p.p., Insectivora, Chiroptera), Dr. Elena Terzea (Carnivora p.p., Lagomorpha, Rodentia p.p.), Dr. C. Radulescu et P. Samson (Carnivora p.p., Artiodactyla), Anca Burghele (Nycteribiidae) et Maria Georgescu (Ixodidae).

\section{Liste des grottes dans lesquelles des Mammifères ont été collectés ou observés}

Grottes situées dans le bassin supérieur de la Bega

1. P. $\left.{ }^{2}\right)$ de la Româneşti (590).Vulpes oulpes; Ursus arctos; Ursus spelaeus; Capra? Ovis ?; Apodemus sylsaticus; Myotis myotis; Miniopterus schreibersi.

2. P. Gaura din Cioaca Birtului (598). Glis glis; Myotis mystacinus.

3. Galeria de explorare din Valea cu Baia. Rhinolophus ferrum-equinum; Miniopterus schreibersi. Autres Vertébrés: larves de Salamandra maculosa.

\section{Grottes situées dans le bassin du Pogăniş}

4. P. Casa Lotrilor (506). Rhinolophus hipposideros.

Grottes situées dans le bassin de la Bîrzava au S et au SE de Reşița

5. P. Stîrnic (508). Ursus spelaeus; Cerous elaphus; Rupicapra rupicapra; Glig glis; Clethrionomys glareolus; Aroicola terrestris; Sorex minutus ?; Talpa europaea; Rhinolophus blasii; Rhinolophus ferrum-equinum; Rhinolophus hipposideros.

6. P. cu oase de la Stîrnic (509). Vulpes vulpes; Ursus spelaeus; Muscardinus avellanarius.

7. P. Gaura de la Capu Baciului (510). Vulpes sulpes; Martes foina; Sus scrofa (domesticus?); Rupicapra rupicapra; Microtus arealis; Apodemus sylsaticus; Crocidura leucodon; Rhinolophus hipposideros.

8. P. Gaura Pîrşului de la Capu Baciului (511). Canis familiaris; Ursus spelaeus; Sus scrofa (domesticus ?); Glis glis; Rhinolophus ferrum-equinum; Rhinolophus hipposideros.

9. P. Gaura Turcului (512). Rhinolophus ferrum-equinum; Miniopterus schreibersi.

10. P. Gaura Pîrşului (513). Sus scrofa (domesticus?); Rhinolophus mehelyi.

2) P. = abbréviation de »Peştera» (Grotte). 
Grottes situées dans le bassin supérieur du Caraş

11. P. Cîrnealǎ (535). Vulpes sulpes; Capreolus capreolus; Apodemus sylsaticus; Chiroptera (obs., indet.).

12. P. Buhui (536). Ursus spelaeus; Rhinolophus ferrum-equinum; Myotis myotis; Myotis oxygnathus.

13. P. Cuptoare (537). Glis glis; Myotis oxygnathus; Rhinolophus ferrumequinum; Rhinolophus hipposideros; Myotis myotis.

14. P. Salamandrelor. Aucun Mammifère. Autres Vertébrés: Salamandra maculosa.

15. P. nr. 2 de la Haldinǎ (540). Rhinolophus hipposideros.

16. P. Cerbului (516). Ursus spelaeus; Clethrionomys glareolus; Microtus aroalis; Apodemus sylvaticus; Myotis myotis; Myotis mystacinus. Tous les restes squelettiques de Rongeurs ont été trouvés dans l'ingluvie d'un Oiseau.

17. P. Popovăț (517). Ursus spelaeus; Felis sylvestris; Capreolus capreolus; Glis glis; Cricetulus migratorius; Apodemus sylvaticus; Clethrionomys glareolus; Rhinolophus ferrum-equinum; Rhinolophus hipposideros; Myotis myotis; Myotis becksteini; Myotis emarginatus; Myotis mystacinus; Barbastella barbastellus; Eptesicus nilssoni. Fort nombreux restes squelettiques de Chiroptères et de Rongeurs, surtout dans les zones stalagmitées et sèches. De nombreuses pièces sont même recouvertes d'une croûte ou inclues dans la croûte de calcite.

18. P. Comarnic (520). Rhinolophus ferrum-equinum; Rhinolophus hipposideros; Myotis myotis; Myotis oxygnathus.

19. P. din Valea Topliței. Lepus europaeus.

20. P. Racoviță. Vormela peregusna; Martes foina; Felis syloystris; Rupicapra rupicapra; Capra? Ovis ?; Glis glis; Muscardinus avellanarius; Clethrionomys glareolus; Microtus arealis; Microtus sp.; Apodemus sylsaticus; Myotis capaccini; Rhinolophus ferrum-equinum. Dans les niches latérales sèches et même dans la galerie principale, plusieurs "cimetières", agglomérations de restes squelettiques de Chiroptères et de Rongeurs.

21. P. de la Socolovǎț (518). Des os longs d'Artiodactyles (indet.) et des restes squelettiques de Rana sp. et d'Oiseaux ont été observés.

22. P. nr. 1 de sub Crno Pole. Capra? Ovis ? Chiroptera (obs., indet.).

23. P. nr. 2 de sub Crno Pole. Ursus arctos; Myotis capaccinii; Rhinolophus hipposideros.

24. P. Tolosu (522). Rhinolophus ferrum-equinum; Myotis myotis; Myotis oxygnathus; Myotis capaccinii; Myotis emarginatus; Pipistrellus pipistrellus.

25. P. din Drumul Prolazului (523). Rhinolophus hipposideros.

26. P. cu Fereastră (524). Glis glis; Chiroptera (obs., indet.).

27. P. de sub Cetate I (525). Cricetulus migratorius; Microtus?

28. P. de sub Cetate II (526). Aucun Mammifère. Autres Vertébrés: Cinclus cinclus (nidifiant dans la grotte).

29. P. Liliecilor (527). Felis cf. catus; Glis glis; Myotis myotis; Myotis capaccinii; Miniopterus schreibersi; Plecotus austriacus?

30. P. de după Cîrşa (530). Vulpes vulpes; Sus scrofa (domesticus ?); Glis glis; Myotis myotis; Pipistrellus pipistrellus; Rhinolophus ferrum-equinum.

31. P. Spinului (531). Rhinolophus ferrum-equinum.

32. P. Lizlonea. Aucun Mammifère. Autres Vertébrés: Salamandra maculosa.

33. P. de sub peştera Vraşka. Vulpes oulpes; Crocuta spelaea. 
34. P. nr. 2 din Cureacița. Crocuta spelaea; Felis catus; Apodemus sylvaticus.

35. P. nr. 3 din Cureacița. Sciurus vulgaris.

36. P. nr. 5 din Cureacița. Rhinolophus ferrum-equinum.

37. P. nr. 6 din Cureacița. Aucun Mammifère. Autres Vertébrés: Vipera berus berus (vivante).

38. P. Gaura lui Schimpfin (541). Ursus spelaeus; Clethrionomys glareolus; Sorex araneus; Rhinolophus blasii; Rhinolophus mehelyi. Autres Vertébrés: Natrix sp.

39. P. Galațiului (533). Meles meles.

40. P. cu apă din Cheile Gîrliştei (534). Microtus arvalis; Apodemus sylvaticus; Rhinolophus ferrum-equinum; Rhinolophus euryale; Rhinolophus blasii; Myotis myotis; Miniopterus schreibersi.

\section{Grottes creusées dans la montagne Rolul Nou (Giclova Montană)}

41. P. de sub Padina Popii (542). Capra? Ovis ?; Apodemus sylsaticus; Glis glis; Microtus?; Talpa europaea.

42. Avenul de la Fîntîna lui Ilie. Meles meles.

\section{Grottes situées dans le bassin du Miniş entre ses sources et Poneasca}

43. P. Ponor-Plopa (543). Rhinolophus ferrum-equinum. Autres Vertébrés: Salmo trutta $m$. fario, dans le ruisseau souterrain.

44. P. Ponor-Uscatǎ (544). Myotis oxygnathus.

45. P. Găurile lui Miloi II (550). Miniopterus schreibersi.

\section{Grottes situées dans le bassin du Lăpuşnic}

46. P. de la Vălee (553). Ursus spelaeus; Glis glis; Clethrionomys glareolus; Apodemus syloaticus; Spallax microphthalmus; Myotis myotis; Myotis oxygnathus; Rhinolophus ferrum-equinum; Rhinolophus hipposideros; Rhinolophus mehelyi. De nombreux restes squelettiques sont inclus dans le plancher stalagmitique ou bien recouverts d'une croûte de calcite.

\section{Grottes situées dans les gorges de la Nera}

47. P. Voinii (559). Rhinolophus ferrum-equinum.

48. P. lui Vît (560). Vulpes vulpes; Felis (Lynx) lynx; Ursus spelaeus; Capra ibex; Apodemus sylvaticus ?; Rhinolophus ferrum-equinum; Rhinolophus hipposideros.

49. P. Boilor (562). Rhinolophus ferrum-equinum; Rhinolophus hipposideros.

50. P. Mare de la Găuri (564). Ursus spelaeus; Sus scrofa (probablement sauvage); Sciurus vulgaris; Glis glis; Rhinolophus hipposideros.

51. P. Gaura Porcariului (565). Ursus spelaeus; Capreolus capreolus; Capra hircus; Glis glis; Rhinolophus ferrum-equinum; Myotis oxygnathus.

52. P. Dubova (566). Ursus spelaeus; Canis familiaris; Meles meles; Capreolus capreolus; Apodemus sylvaticus; Glis glis; Muscardinus avellanarius; Clethrionomys glareolus; Microtus arvalis; Pithymys subterraneus; Sciurus 
oulgaris; Crocidura leucodon; Talpa europaea; Myotis oxygnathus; Myotis myotis; Rhinolophus hipposideros; Rhinolophus ferrum-equinum; Rhinolophus blasii; Plecotus auritus.

53. P. Rolului (567). Rhinolophus blasii.

Grottes situées dans le bassin du Danube, à l'E. et au SE de Moldova Nouă

54. P. Ieskinia (568). Rhinolophus hipposideros.

55. P. Filipovo Dira (569). Vulpes vulpes; Chiroptera (obs., indet.)

56. P. de la Padina Matei (570). Mustela putorius; Felis sylvestris; Glis glis; Rhinolophus ferrum-equinum; Rhinolophus blasii; Miniopterus schreibersi.

57. P. Gaura Haiduceascǎ (571). Glis glis; Muscardinus avellanarius; Clethrionomys glareolus; Microtus arvalis; Apodemus sylsaticus; Sorex? Crocidura leucodon ?; Talpa europaea; Rhinolophus ferrum-equinum; Rhinolophus hipposideros. Sur la "terrasse» supérieure de la grande salle, importante agglomération de restes squelettiques de Chiroptères, Rongeurs et Insectivores, œuvre probablement d'un Mammifère de proie.

58. P. din Valea Čeuca (573). Felis sylvestris; Microtus arvalis; Rhinolophus ferrum-equinum; Rhinolophus blasii.

59. P. de la Izvoru Mînzului (576). Rhinolophus hipposideros.

60. P. U Lomu (578). Microtus arsalis; Apodemus sylvaticus.

61. P. Potoc (579). Vulpes oulpes.

62. P. Gaura cu Muscă (580). Myotis myotis; Myotis emarginatus; Miniopterus schreibersi; Rhinolophus ferrum-equinum; Rhinolophus blasii.

\section{Grottes creusées dans la Vallée de Berzasca}

63. P. de la Voinicovăț (496). Ovis ? Capra ?; Myotis emarginatus; Miniopterus schreibersi; Eptesicus serotinus.

64. P. din Cleanțu Pînzei (498). Rhinolophus ferrum-equinum.

65. P. din Cleanțu Zbegului (499). Vulpes oulpes; Glis glis; Cricetulus migratorius; Microtus arvalis.

66. P. Zamonița (500). Lutra lutra; Crocidura leucodon.

\section{Grottes creusées dans le massif Sucaru Mare}

(Défilé du Danube de Cazane)

67. P. nr. 2 de la Gura Ponicovei (493). Capra? Ovis ?; Rhinolophus hipposideros.

68. P. Gura Ponicovei (494). Vulpes oulpes; Crocuta spelaea; Mustela putorius; Martes martes; Martes foina; Ursus spelaeus; Capreolus capreolus; Ovis ? Capra ?; Glis glis; Clethrionomys glareolus; Apodemus sylvaticus; Myotis myotis; Nyctalus noctula; Plecotus auritus; Barbastella barbastellus; Pipistrellus pipistrellus; Eptesicus serotinus; Rhinolophus blasii. Autres Vertébrés: Tichodroma muraria, dans l'intérieur de la grotte, à quelques dizaines de mètres de l'entrée débouchant sur le Danube.

69. P. din Pînza Curii (Veterani) (495). Pipistrellus pipistrellus. Nous avons noté aussi des restes squelettiques de: Ursus sp., Mustellidae, Ovis, mais nous n'avons pas la certitude de ces déterminations. 
Grottes situées dans le bassin inférieur de la Cerna

70. P. Hoților (485). Rhinolophus blasii; Myotis myotis.

71. P. Mare de la Soronişte (488). Ursus spelaeus; Myotis oxygnathus.

72. P. Gaura Ungurului (491). Ursus spelaeus; Clethrionomys glareolus; Apodemus sylvaticus; Rhinolophus ferrum-equinum; Rhinolophus blasii; Myotis myotis.

\title{
Liste des espèces déterminées, avec observations $\left.{ }^{3}\right)$
}

\author{
Supraord. CARNIVORA (ord. FISSIPEDES)
}

\section{Fam. CANIDAE}

Canis familiaris L. 8 (max. sin. fragm.) 52 ( $\mathrm{M}^{2} \sin ., \mathrm{D}^{2-4} \sin$. , Cd $\sup$. $\sin$.).

Vulpes sulpes (L.). $\mathbf{1}$ (mdb.). 6 (crâne, cubitus, tibia). $\mathbf{7}$ (crâne juvénile). 11 (I, arc mdb.). 30 (max. sup. dextr. fragm.). 33 (fragm. mdb. sin.). 48 ( $\mathrm{P}^{2-}$ $\mathrm{M}^{2}$ dextr., $\mathrm{M}^{2}$ sin.). 55 ( $\mathrm{C}$ inf. dextr., $\mathrm{C}$ sup. sin.). 61 (obs. nombreux terriers de renard). 65 ( $\mathrm{M}_{1}$ dextr.). 68 ( $\mathrm{P}^{3}$ sin., crânes).

\section{Fam. URSIDAE}

Ursus arctos L. 1 (fragm. crâne). $\mathbf{2 3}$ (mdb., crâne, cent. pelv. : juv.).

$(\dagger)$ Ursus spelaeus Rosenm. 1 (C). 6 (C). 8 ( $\mathrm{P}_{4}$ sin., $\mathrm{I}_{3}$ dextr., $\left.\mathrm{I}^{2} \sin .\right)$. 16 ( $\mathrm{C}$ et nombreux autres fragments). 17 ( $\mathrm{I}^{3}$ sin. et nombreux os longs dans la croûte stalagmitique). $\mathbf{3 8}$ (fragm. crâne). $\mathbf{4 6}$ (C, nombreux os longs, Vertébres). 48 (metatarsien V dextr., os long). 50 (Canins, os longs). 51 ( $\mathrm{M}^{\mathbf{1}}$ sin., $\mathrm{M}_{1}$ dextr., $\mathrm{C}$ sup. sin.). $\mathbf{5 2}$ (os longs, leg. Tr. Novac). $\mathbf{6 8}$ (divers, mal conservés). $\mathbf{7 1}$ (depôt d'os longs). 72 ( $\mathbf{M}^{1}$ sin. fragm., etc.) Nous avons vu des pièces de Ursus spelaeus, encore inédites, de grottes du Banat, dans le Musée Régional du Banat (5; 18: provenance douteuse), dans le Musée minier d'Anina (12; V. Sencu a aussi trouvé Ursus spelaeus dans cette grotte) et, suivant des renseignements verbaux, on aurait trouvé cette espèce aussi dans 44 et $\mathbf{7 0}$.

Note: dans 69: canin de Ursus sp.

\section{Fam. MUSTELIDAE}

Mustela putorius L. 56. 68.

Vormela peregusna (Guldenstädt). 20 (crâne).

Martes foina (Erxleben). 7 (restes mal conservés). $\mathbf{2 0}$ (mdb. dextr.). 68 (crânes, arc mdb., 2 mdb. dextr.).

3) La date de la récolte n'est pas mentionnée quand il s'agit uniquement de pièces squelettiques; elle est indiquée, par contre, quand il est question d'animaux capturés vivants ou bien d'observations portant sur de tels animaux. Malheureusement, dans quelques cas nous n'avons plus pu indiquer exactement de quelles pièces il s'agissait pour telle ou telle espèce dans telle ou telle station. 
Martes martes L. 68 (mdb. sin. fragm.).

Meles meles (L.). 39 (arc. mdb.). 42 (crâne entier, crâne fragm.). 52 (arc mdb.).

Lutra lutra (L.). 66 (C inf. dextr., C sup. sin.). La grotte est parcourue par un ruisseau qui en sort par une assez grande ouverture.

Note: dans 69 : fragm. mdb. de Mustellidae (indet.).

\section{Fam. HYAENIDAE}

(†) Crocuta spelaea (Goldf.). 33 (max. inf. Au fond d'un petit aven). 34 (fragm. crâne, à même la surface du dépôt de remplissage massif). 68 (fragm. crâne).

\section{Fam. FELIDAE}

Felis catus L. 29 (fragm. carnassier, 2 fragm. canins:, ,cf. catus" ${ }^{\prime)} .34$ (crâne neural).

Felis sylvestris Schreber. 17 (cubitus et radius dextr., fragm. calcaneum sin., tibia sin. et dextr. fragm., bassin fragm.). $\mathbf{2 0}$ (arc mdb.). 56. $\mathbf{5 8}$.

$(\dagger)$ Felis (Lynx) lynx L. 48 (le matériel, recueilli dans l'argile d'un brunroux en surface de dépôts pléistocènes, a été publié par Terzea 1963).

\section{Ord. ARTIODACT YLA}

\section{Fam. SUIDAE}

Sus scrofa L. 7 ( $\mathrm{P}^{4--} \mathrm{M}^{2}$ dextr.). 8 (D $\mathrm{D}^{3-4} \sin ., \mathrm{D}_{2-4} \sin ., \mathrm{M}_{1} \sin$.). 10 (mdb. dextr. fragm.). 30 (I sup.). $\mathbf{5 0}$ ( $\mathrm{M}^{1} \sin$.). Dans les trois premières grottes il s'agit, probablement, du porc domestique; dans la 4-e il s'agit, probablement, du porc sauvage, mais le matériel insuffisant ne permet pas d'affirmer si c'est $S$. scrofa attila ou bien une forme fossile.

\section{Fam. CERVIDAE}

Cerous elaphus L. 5 ( $\mathrm{I}_{1-2}$ sin., $\mathrm{I}_{1-3}$ dextr.).

Capreolus capreolus (L.). 11 (palais avec les séries dentaires). 17 (mdb. sin. fragm., humer. + radius + metacarp dextr.). 51 (humer. dextr. fragm. dist., radius dextr. juv., metatars juv. fragm.). $\mathbf{5 2}$ (M. dextr. fragm.). 68.

\section{Fam. BOVIDAE}

Capra hircus L. $\mathbf{5 1}$ (mdb. sin. fragm., metacarp. sin., falanges).

Capra ibex L. 48 (fragm. coxal).

Rupicapra rupicapra (L.) 5 ( $\left.\mathrm{D}^{2-4} \sin .\right) .7$ ( $\left.\mathrm{D}^{2-4}, \mathrm{M}^{1-2}\right) .20$ ( $\mathrm{M}^{1}$ dextr., $\mathrm{M}^{2-3}$ sin., $\mathrm{M}_{2}$ dextr.).

Note: des pièces squelettiques indéterminables, soit de Ovis soit de Capra, ont été recueillies dans : 1, 20, 21, 22, 41, 63, 67, 68, 69.

Ord. LAGOMORPHA (DUPLICIDENTATA)

\section{Fam. LEPORIDAE}

Lepus europaea Pallas. 19 (max. sup. fragm.). 
Ord. RODENTIA (SIMPLICIDENTATA)

\author{
Fam. SGIURIDAE
}

Sciurus vulgaris L. $\mathbf{3 5}$ (un écureuil avec sa progéniture observé dans la grotte). 50 (mdb. dextr. fragm.). $\mathbf{5 2}$ (fragm. mdb.).

\title{
Fam. MUSCARDINIDAE
}

Glis glis L. 2 (mdb. sin. fragm.). 5. 8.13 (2 mdb., 2 cent. pelv., humerus, femur). 17 (2 fragm. crâne, 7 fragm. mdb.). $\mathbf{2 0}$ (mdb. sin.). 26 (mdb. dextr. sans dentition). 29 (fragm. mdb. dextr.). 30. 41 (fragm. crâne). 46 (4 mdb., 6 I sup., 4 I inf.). 50 (9 mdb., fragm. crâne). $\mathbf{5 1}$ (4 fragm. mdb.). $\mathbf{5 2}$ (6 mdb. sin., 5 mdb. dextr., fragm. crâne). 56 (mdb., crâne). 57. 65 (mdb. sin.). 68 (2 mdb. sin.).

Muscardinus avellanarius L. 6 (fragm. crâne, 3 fragm. max. sup., 2 mdb. sin., mdb. dextr.). 20 (crâne, mandibules). 52 (2 mdb. sin., mdb. dextr.). 57. Dans 20, observé des terriers.

\section{Fam. CRICETIDAE}

(†) Cricetulus migratorius Pallas. 17 (mandibules, dents). $\mathbf{2 7}$ (fragm. mdb.). 65 (mdb. dextr.). On sait que C. migratorius disparut d'Europe Centrale dès la fin du Pleistocène. Hamar (1963b) en a récemment mentionné des pièces trouvées dans des ingluvies d'Oiseaux dans deux stations de Moldavie septentrionale ce qui prouverait la réapparition de cette espèce sur le territoire de Roumanie.

\section{Fam. MICROTIDAE}

Clethrionomys glareolus (Schreber). 5. 16 (mdb. dextr. fragm.). 17 (mdb. sin. fragm.). 20 (2 mdb. sin., mdb. dextr., le tout fragm.). 38. 46 (2 mdb.). 52 (3 mdb. sin., 1 mdb. dextr.). 57. 68 (mdb. dextr.). 72 (mdb. dextr.).

Arvicola terrestris L. 5.

Microtus aroalis (Pallas). 7. 16 (mdb. dextr. fragm.) 20 (2 mdb. sin. fragm.). 40 (mdb. dextr., mdb. sin., les deux fragm.). 52 (3 mdb. dextr., 3 mdb. sin., mdb. sin. fragm.). 57. 58 (fragm. crâne, 2 mdb.). 60 (mdb. dextr.). 65 (fragm. crâne).

Note: des fragments de Microtus (ou d'un autre Microtide), dont l'identification n'a pas été possible, ont été recueillis dans : 20, 27, $4 \mathbf{1}$.

Pithymys subterraneus De Sélys Longchamp. 52 (mdb. sin., fragm. crâne).

\section{Fam. MURIDAE}

Apodemus sylvaticus (L.). 1 (2 fragm. max. sup.). 7. 11 (mdb.). $16\left(\mathrm{M}_{1}\right)$. 17. 20 (6 mdb. sin., 4 mdb. dextr., 11 mdb. fragm.). $\mathbf{3 4}$ (mdb. sin. fragm.). 40 (mdb. sin. fragm.). 41 (mandibules). 46 (2 mdb.). 48 (3 fragm., mdb. sans dentition). 52 (fragm. crâne, 28 mdb. sin., 25 mdb. dextr.). 57. 60 (fragm. crâne). 68 (fragm. reg. maxillaire, crâne, mdb. dextr., mdb. sin.). 72 (4 mdb. sin., 2 mdb. dextr.).

\section{Fam. SPALACIDAE}

Spalax microphtalmus Güld. 46 (mdb. sin.). 
Ord. INSECTIVORA

Fam. SORICIDAE

Sorex araneus L. 38.

Sorex minutus L. ?. 5. Seules des recherches stratigraphiques dans cette grotte pourraient permettre d'affirmer s'il s'agit de matériel fossile ou actuel.

Note: des pièces appartenant probablement à Sorex proviennent aussi de $\mathbf{5 7}$.

Crocidura leucodon Herman. 7. 52 (crâne, 2 mdb.). 66 (dent). Du matériel peu concludent a été recueilli aussi dans $\mathbf{5 7}$.

\section{Fam. TALPIDAE}

Talpa europaea L. 5. 41 (mdb.). 52 (6 mdb. dextr. + sin.). 57.

\section{Ord. CHIROPTERA}

\section{Fam. RHINOLOPHIDAE}

Rhinolophus ferrum-equinum Schreber. 3 (2 crânes, mdb.). 5 (12. XI. 61, coll. expl. vivants, obs. expl. isolés). 8 (pièces ostéologiques; 13. XI. 61, coll. expl. vivants, obs. expl. isolés dans la galerie principale, parasités par Nycteribia biarticulata Herman). 9 (30. IX. 61, coll. expl. vivants, obs. expl. isolés, non parasités). 12 (fragm. crâne; 28. IX. 61, coll. expl. vivants, obs. expl. isolé, inactifs, non parasités, dans la galerie principale et dans les salles et galeries latérales). 13 (5. X. 61, coll. expl. vivants, obs. expl. isolés, inactifs, non parasités). 17 (2 fragm. crâne, nombreux cadavres; 3. X. 61, coll. expl. vivants, obs. expl. isolés, jamais des colonies). 18 (crâne; 1.VII.61, obs. expl. isolés, actifs; 2. X. 61, coll. expl. vivants, obs. partout des expl. isolés, inactifs, non parasités, ainsi qu'une colonie de 500 expl. environ au point de station $48 ; 24$. X. 65 , obs. colonie de 20 expl. au point de station 52 et expl. isolés dans la galerie subfossile). $\mathbf{2 0}$ (26. IX. 65, obs. dans les deux galeries expl. isolés, inactifs ou peu actifs, non parasités). 24 (crâne, 2 mdb.). 30 (19. XI. 61, obs. expl. isolés, non parasités; 6. X. 63, obs. expl. isolés, actifs). $\mathbf{3 1}$ (30. VII. 64, obs. expl. actifs). 36 (6. X. 65, obs. expl. non parasité). 40 (fragm. crâne; 21. X. 55, obs. colonie d'individus actifs à $200 \mathrm{~m}$ depuis l'entrée; 1. VIII. 63, obs. colonie d'individus très actifs, au point de station $40 ; 9$. X. 63, obs. colonie de plusieurs centaines d'expl. moins actifs, parasités par Nycteribia biarticulata Hermann et des Ixodidae (Ixodides vespertilionarum?) au point de Station 36$) .43$ (2 crânes, mdb.; 25 . IX. 61 , coll. expl. vivants, obs. individus isolés et colonie formée de plusieurs groupes de 10-20 expl.). 46 (crâne). 47 (fragm. crâne, fragm. mdb.). 48 (2 mdb.). 49 (crâne, 4 mdb.; 10. X. 61., 1. X. 63, oks. expl. isolés, non parasités). 51 (fragm. crâne, 9 mdb.; 9. X. 61, obs. expl. actifs). 52 (2 fragm. crânes, 4 mdb.; dans la "Salle des Chauves-souris», grande colonie de plusieurs centaines d'exemplaires actifs, obs. le 12. X. 61 ; à 22. IX. 62, la grande colonie n'existait plus, il y avait seulement de petits groupes; à 5. X. 63, colonie de nouveau présente, composée d'expl. actifs). 56 (matériel ostéologique). $\mathbf{5 7}$ (riche matériel ostéologique). 58 (3 fragm. crânes; 9 . VI. 62, coll. expl. vivants, obs. petites colonies et expl. isolés). 62 (crâne, mdb. dextr.; 10. VI. 62, coll. expl. vivants, obs. expl. isoles, parasités par Penicil- 
lidia dufouri Westw., Nycteribia schmidli Schiner, N. biarticulata Herm., Acariens parmi lesquels l'Ixodide Ixodes chiropterorum Bab. \& Jan.; mais les Nycteribiides ont été pris aussi sur Miniopterus schreibersi et sur Myotis myotis). 64 (20. VI. 62, obs. expl. isolés, actifs). 72 (mdb. sin.).

Rhinolophus hipposideros Bechstein. 4 (25. VI. 63. coll. expl. vivants, obs. expl. isolés, actifs, non parasités). 5 (12. XI. 61, coll. expl. vivants, isolés). 7 (15. XI. 61, obs. quelques expl.). 8 (13. XI. 61, coll. expl. vivants, isolés, dans la galerie principale; 20. V. 65, obs. expl. isolé, actif). 13 (5. X. 61, coll. expl. vivants, isolés, inactifs). 15 (6. X. 61, obs. un exemplaire). 17 (crâne, etc.). 18 (2. X. 61, coll. expl. vivants, obs. expl. isolés, non parasités). 23 (4. X. 65, obs. un expl. non parasité). 25 (17. V. 65, obs. un exemplaire actif). 46 (crâne). 48 (11. X. 61, observation). 49 (10. X. 61, obs. expl. isolés). 50 (11. X. 61, observation). 52 (12. X. 61, obs. expl. isolés). 54 (7. VI. 62, obs. expl. parasité par Nycteribia biarticulata Herm.). 57 (riche matériel ostéologique). 59 (9. VI. 62, obs. expl. non parasité). 67 (crâne, 2 mdb.).

Rhinolophus mehelyi Matschie. 10 (mat. ostéol.). 38 (mat. ostéol.). 46 (mdb. sin, mdb. dextr.).

Rhinolophus euryale Blasius. 40 (crâne, max. inf.).

Rhinolophus blasii Peters. 5 (mat. ostéol.). 38 (17. XI. 61, coll. expl.vivants, obs. expl. isolés, non parasités). 40 (mdb.). 52 (crâne, 3 mdb.). 53 (crâne). 56 (mat. ostéol.). 58 (9. VI. 62, coll. expl. vivants, obs. petites colonies et expl. isolés, parasités: Nycteribia biarticulata Herm., Ixodes vespertilionis Koch, Aphaniptera indet.). 62 (3 crânes, 6 mdb.; 10. VI. 62, coll. expl. vivants, obs. expl. isolés). 68 (mat. ostéol.). 70 (crâne). 72 (6 crânes, 4 mdb. dextr.).

\section{Fam. VESPERTILIONIDAE}

Myotis myotis Borkhausen. 1 (11 crânes, 16 mdb., 2 mdb. juv.). 12 (2 crânes, 6 mdb.). 13 (5. X. 61, coll. expl. vivant, parasité par des Acariens). 16 (29. IX. 65, coll. expl. vivant, obs. expl. isolés assez alertes; parasites: Spinturnicidae indet.). 17 (5 crânes, etc.). 18 (fragm. mdb., etc.; 24. VII. 63, coll. expl. vivant, parasité par Nycteribia latreillii Leach, Penicillidia dufouri Westw.). 24 (4 crânes, 7 mdb.). 29 (mdb. et dents ; 25. VII. 63, coll. expl. vivants dans des colonies mixtes; obs. nombreuses colonies, soit formées seulement de M. myotis (juv., point de Station 21), soit mixtes; des centaines d'expl. dans chaque colonie; les Chauves-souris sont fort parasitées: Nycteribia latreillii Leach, N. schmidli Schiner, Penicillidia dufouri Westw., obs. aussi Acariens et Aphaniptères). 30 (mat. ostéol.). 40 (mdb.) 46 (humerus). 52 (7 mdb.). 62 (2 crânes avec dentition lactéale, 1 fragm. crâne, 6 mdb.; 10. VI. 62, coll. expl. vivant; obs. deux colonies de quelques centaines d'expl. chacune, dans la galerie à eau; pour les parasites, voir la mention faite pour cette grotte sous Rhinolophus ferrum-equinum; à 23. VI. 65, la colonie formée de quelques centaines d'expl. actifs, était présente au mème endroit). 68 (crâne, mdb.). 70 (crâne, mdb. sin.). 72 (fragm. mdb. sin.).

Myotis oxygnathus Monticelli. 12 (28. IX. 61, coll. expl. vivants, obs. expl. isolés, inactifs, partout dans la galerie principale et dans les latérales; parasites : Nycteribia latreillii Leach, Penicillidia dufouri Westw., Acariens indet.). 13 (crâne, 2 mdb.). 18 (2. X. 61, coll. expl. vivants, obs. expl. isolés, parasités par des Acariens indet.). 24 (2 crânes). 44 (crâne). 46 (19. VIII. 62, 
coll. expl. vivant, obs. peu nombreux expl. isolés, fort actifs). 51 (3 mdb.). 52 (crâne, 2 mdb.). 71 (fragm. mdb. sin.).

Myotis bechsteinii Kühl. $\mathbf{1 7}$ (crâne; peut-être d'autres pièces squelettiques aussi).

Myotis capaccinii Bonaparte. $\mathbf{2 0}$ (3 mdb.). 23 (mdb.). $\mathbf{2 4}$ (1 mdb., crâne). 29 (25. VII. 63, coll. expl. vivants, obs. dans des colonies mixtes avec M. myotis et Miniopt. schreibersi; parasités par Nycteribia pedicularia Latr. et Penicillidia dufouri West.

Myotis emarginatus Geoffroy. 17 (5 crânes, etc.). 24 (crâne). 62 (crâne). 63 (mdb. sin.).

Myotis mystacinus Kühl. 2 (mdb.). 16 (29. IX. 65, coll. expl. vivant, obs. expl. isolés, vivants, parasités par des Spinturnicidae). 17 (crâne, etc.).

Nyctalus noctula Schreber. 68 (2 crânes, 1 fragm. crâne, 7 mdb.).

Miniopterus schreibersi Kühl. 1 (crâne; 22. V. 63, coll. expl. vivants, obs. expl. isolés, inactifs, parasités par Nycteribia schmidli Schiner, Penicillidia dufouri Westw. et Acariens). 3 (23. V. 63, coll. expl. vivant, obs. seulement expl. isolés, parasités par des Acariens indet.). 9 (crâne). 29 (4 crânes, mdb.; 25. VII. 63, coll. expl. vivant dans une colonie mixte avec $M$. myotis et Miniopt. capaccinii; obs. d'autres grandes colonies mixtes; aux points de Station 34 et 36 à 25. VII. 63 et 31. VIII. 64, obs. colonies de jeunes de Miniopt. schreibersi; parasites: Nycteribia schmidli Schiner, Penicillidia conspicua Speiser, P. dufouri Westw.). 40 (mdb.; une colonie de Minioptères (?) actifs a été observée le 9 . X. 63 près de celle de Rhinolophes). 45 (2 mdb., 2 crânes, 1 crâne juv.). 56 (mat. ostéol.). 62 (3 crânes, 2 mdb. dextr.; 10. VI. 62 , coll. expl. vivant, obs. groupes de plusieurs expl.; pour les parasites, voir la mention de cette grotte sous Rhinolophus ferrum-equinum). 63 (2 crânes, mdb. dextr.).

Plecotus auritus L. 52 (5 mdb.). 68 (mdb.).

Plecotus austriacus Fischer ?. 29 (mdb.).

Barbastella barbastellus Schreber. 17 (2 crânes, etc.). 68 (crâne, mdb.).

Eptesicus serotinus Schreber. 63 (mdb. sin.). 68 (mdb. sin., mdb. dextr.). Eptesicus nilssoni Keyserl. et Blasius. 17 (crâne).

Pipistrellus pipistrellus Schreber. 24 (2 crânes). 30 (mat. ostéol.). 68 (20 crânes). 69 (crâne).

Note: dans plusieurs grottes, des colonies plus ou moins importantes de Chauves-souris ont pu être observées sans que des exemplaires puissent en être récoltés (ou bien le matériel collecté avait été perdu avant d'être identifié).1: colonie de quelques centaines d'expl. probablement Rhinolophes, dans la salle finale, obs. 12. V.63. 12: colonie obs. le 15. VII. 61, dans «l'avencheminée" près l'entrée par la doline. 20: colonie de quelques dizaines d'expl. actifs d'un Myotis, obs. le 26. IX. 65. 45: à 20. VI. 60, obs. colonie de 60 expl. sur la voûte à $3 \mathrm{~m}$ de hauteur; et le 17. VIII., obs. nombreux expl., mais isolés. 57: colonie de 400-500 expl. dans la coupole de la grande salle, à $25 \mathrm{~m}$ de hauteur ; formée de rhinolophes, la colonie est pratiquement inaccessible; obs. aussi, à $10 \mathrm{~m}$ depuis l'extrée, une colonie de quelques dizaines d'expl. 68: obs. plusieurs colonies, formées de dizaines ou de centaines d'expl., en juin, juillet, août, en divers endroits de la grande salle du système III.

Le matériel ostéologique et les animaux vivants que nous avons pu recueillir dans 70 grottes environ, a permis la détermination, avec une précision absolue, de 53 espèces de Mammifères fossiles et actuels. Il 
s'agit de 14 Carnivores, 6 Artiodactyles, 1 Lagomorphe, 10 Rongeurs, 3 Insectivores et 19 Chiroptères. Mentionnons, à titre d'éléments présentant un intérêt particulier d'un point de vue ou d'un autre: $\dagger$ Crocuta spelaea, $\dagger$ Felis lynx, Capra ibex, $\dagger$ Cricetulus migratorius, Rhinolophus mehelyi, Myotis bechsteini, Eptesicus nilssoni.

\section{RÉSUMÉ}

Dans 70 grottes environ du Banat, les auteurs ont rassemblé une collection de documents (matériel ostéologique et animaux vivants) se rapportant aux Mammifères, fossiles et actuels. Une liste des grottes est présentée et on donne pour chaque grotte l'énumération des formes signalées. Dans la seconde partie, on donne pour chaque espèce: les grottes ayant fourni le matériel, l'inventaire du matériel ostéologique, les observations faites sur les animaux vivants (et surtout sur les Chiroptères). 53 espèces de Mammifères fossiles et actuels ont pu être déterminées avec une précision absolue (dont 14 Carnivores, 6 Artiodactyles, 1 Lagomorphe, 10 Rongeurs, 3 Insectivores, 19 Chiroptères).

\section{SUMMARY}

The authors assembled from about 70 caves a rich collection of osteological material and specimens of living or fossil mammals. A list of the caves is given with an enumeration of the identified species for each cave. Under each species the caves which supplied the material are listed. This is followed by an inventory of the osteological material and by observations on the living animals (especially bats). Fifty-three mammal species (fossil and living) were accurately determined (14 carnivores, 6 artiodactyls, 1 lagomorph, 10 rodents, 3 insectivores, and 19 bats).

\section{BIBLIOGRAPHIE}

Balogh, E. (1937) - A Cuptorul Porcului barlang. MS.

- (1938a) - Fiutal barlangi medve (Ursus spelaeus Ros.) maradvániok a Popováci barlangból. Erdélyi Muzeum, t. XLIII.

- (1938b) - A nyest (Mustela foina) mint barlangi ragadozó. Erdélyi Muzeum, t. XLIII.

- (1940) - Rendellenességek barlangi medve (Ursus spelaeus Ros.) fogakon és csontokon. Erdélyi Muzeum, t. XLV, nr. 2.

- (1942a) - Ujadat a nyest élatmódjának ismeretéhez. Allatani Közlemények, t. XXXIX.

- (1942 b) - Osemberi maradvániok a Bánságihegyvidék két barlangjából. Közlemények az Erdélyi Nemzeti Muzeum Ėrem - és Régiségtárából, t. II.

- (1956) - A Popováci barlang. MS.

- (1957) - A Comárniki barlang teljes bépe. MS.

BокоR, E. (1921) - A magyarhoni barlangok izettlábui (Arthropoden der ungarischen Grotten). Barlangkutatás, t. IX, nr. 1-4.

Botoşaneanu, L., Negrea, A., et Negrea, St. (1966) - Grottes du Banat explorées de 1960 à 1962. Paris, C.N.R.S.

Galinescu, R. (1931) - Verzeichnis und Bibliographie der Säugetiere Rumäniens. Ztschr. für Säugetierkunde, t. 6, nr. 2. 
Dumitrescu, M., Tanasachi, J., et Orghidan, T. (1962-63) - Rǎspîndirea Chiropterelor în R. P. Română. Lucr. Inst. de speol. ,,Emil Racoviță“, t. I-II.

Halaváts, J., (1888) - Sztirnik barlang (Resica vidékén) emlös maradnányai. Természettudományi Köslöny, t. XX.

Hamar, M., (1963a) - Contributions to the study of the upper pleistoceneholocene fauna of small mammals (Chiroptera, Insectivora, Glires). Revue de Biologie, Académie de la R.P.R., t. VIII, nr. 2.

- (1963b) - Die Anwesenheit von Cricetulus migratorius (Pall. 1773) in Gewöllen von Asio otus (L.) und Athene noctua (Scop.) in Rumänien. Acta Theriol., t. VI, nr. 11.

Hoernes, R. (1875) - Vorlage von Wirbeltierresten (Ursus spelaeus und Capra ibex) aus der Bohuj-Höhle bei Anina. Verh. der k. k. Geol. Reichsanstalt.

KADIč, O. (1917) - Barlangi Közlemények, t.V.

Maxim, I. (1943) - La Chèvre des rochers "Ibex" dans le pléistocène de Roumanie. C. R. des Sèances de l'Acad. Sci. Roumanie, t. VII.

Méhely, L. (1900) - Monographia Chiropterorum Hungariae. Budapest.

Negrea, St., Negrea, A., Sencu, V., et Botoşaneanu, L. (1965) - Grottes du Banat (Roumanie) explorées en 1963. Int. Journ. Speleology, t. I, part. 4 .

Nicolaescu-Plopşor, C.S., et Mateescu, C. N. (1955) - Santierul arheologic Cerna-Olt. Stud. Cerc. Istorie Veche, t. VI, nr. 3-4.

Orghidan, T., Puşcariu, Val., Bleahu, M., Degu, V., Rusu, T., et Bunescu, A. (1965) - Harta regiunilor carstice din România. Lucr. Inst. de Speol. ,,Emil Racovițǎcc, t. IV.

Orтhмаул, T. (1872) - A barlangok paläontologiai és történeti jelentösége, tekintettel Magyarország, de különösen Délmagyarország barlangjaiva. A magyar orvosok és termeszetvizsgálok 1872 ben Herkules fürdön tartott vándorgyülésének munkálatai.

Paszlawski, J. (1918) - Mammalia. In: Fauna Regni Hungariae I. Budapest Petényi, S. J. (1880) - Carnivora, Chiroptera. Termés. Füsetek, t. 4.

Primics, G. (1890) - Spuren des Höhlenbären (U. spelaeus Blumenb.) in Ungarn. Földtani Köslony, t. XX, nr. 5-7.

Sencu, V. (1963) - Cercetări asupra carstului din jurul localitătii Anina (Banat); peşterile din bazinele pîraielor Anina şi Bohui. Probleme de Geografie, t. X.

Teglas, G. (1883) - A Buhuj (Bagolyvár) nevii scontbarlangvól. Természettudományi Közlöny, t. XV.

- (1884) - A Buhuj (Bagolyvár) nevii csontbarlang Stajerlak-Anina hatávában. A Magyar Tudományos Akadémia Math. es Term. Közleményi, t. XIX.

Terzea, El. (1963) - Observații asupra morfologici lui Felis (Lynx) lynx L. foss. şi cîteva considerații asupra răspîndirii speciei pe teritoriul R. P. R. Stud. Cerc. biol. Acad. R. P. R., ser. biol. anim., t. XV, nr. 3. 



\title{
Deux nouveaux Halacariens d'Israël - Limnohalacarus
} capernaumi n. sp. et Lohmannella heptapegoni n. sp.

\author{
Par Anelya Petrova ${ }^{1}$ )
}

Avec planches $65(1)-67(3)$

Le présent travail a pour objet du matériel récolté lors d'une excursion au lieu historique Capernaum (Capharnaüm) en Israël dans une source thermale, près du lac de Tibériade. Les indigènes nous ont expliqué que dans cette région il y a plusieurs sources analogues dites «salées», à cause de leurs eaux quelque peu saumâtres. On estime que dans l'Antiquité ces sources étaient au nombre de sept d'où le nom «Heptapegon» de cette localité près de Capernaum²). A l'heure actuelle on ne connaît que 5 de ces sources, qui jaillissent de la colline située à 50 mètres du lac de Tibériade dans lequel leurs eaux se jettent; leur température varie entre 29 et $32^{\circ} \mathrm{C}$ (Press, 1948).

La source, où le matériel a été récolté, se présente comme un pétit bassin plat d'environ 3-4 mètres de long et de même largeur, recouvert de gravier et de sable. L'eau jaillit presque de tous les côtés, à jets variables. L'échantillon a été pris après tamisage du gravier et du sable du fond de la source. La faune comporte des Ostracodes et Asellides souterraines, des Limaces Teodoxus, etc., ainsi que deux Halacariens appartenant aux genres Limnohalacarus et Lohmannella. Tous les deux se distinguent essentiellement des espèces déjà connues de leurs genres respectifs et nous les décrivons comme nouvelles.

\section{Limnohalacarus capernaumi $\mathbf{n}$. sp.}

oth olot yp e,S.T., tube No5(Plate1). Le corps sans l'organe maxillaire a une longueur dorsale de $360 \mu$, largeur $-216 \mu$. La plaque prédorsale est longue de $78 \mu$ et large de $90 \mu$. Sa partie postérieure est largement

\footnotetext{
1) Institut Zoologique et Musée, Boulv. Rouski, Sofia (Bulgarie).

2) Je tiens à exprimer ma gratitude à M. Ben-Shaked de la Légation d'Israël à Sofia pour son aimable aide lors des renseignements géographiques et historiques.
} 
arrondie, alors que le bord antérieur est plutôt découpé. Dans la partie proximale manque parmi les deux poils le petit sommet chitineux, propre à Limnohalacarus wackeri (Walter 1914) et à L. fontinalis Walter et Bader 1952.

Les plaques oculaires ont une forme pentagonale arrondie. Leur longueur est de $42 \mu$ et leur largeur - $48 \mu$. Elles portent sur leurs bords latéraux un pore glandulaire. Entre la plaque dorsale et les plaques oculaires, dans l'espace libre, il y a de chaque côté une soie fine.

Les plaques postoculaires, de forme triangulaire, sont longues de $42 \mu$ et larges de $30 \mu$. Elles portent dans leur coin latéral un organe d'aspect poreux.

La plaque dorsale est de forme elliptique, régulière - allongée, longue de $237 \mu$ et large de $138 \mu$. Au bout de la partie du premier tiers de la plaque il y a deux soies. Chez des exemplaires non traités au $\mathrm{KOH}$, on observe une plaquette cornée de couleur blanc-de-lait, analogue à celle du L. wackeri de Bulgarie (Plate 1: 1).

Sur la peau lignée, libre de plaques, il y a deux paires de pores glandulaires. Toutes les plaques sur la face dorsale du corps ont une structure réticulaire.

L'organe maxillaire (Plate 1:3) a une longueur de $84 \mu$ et sa largeur est de $54 \mu$ à la base et $72 \mu$ à la section la plus large. De toutes les espèces du genre, L. capernaumi n. sp. et $L$. fontinalis possèdent le plus court organe maxillaire. La mandibule de la nouvelle espèce représente par sa structure une position intermédiaire entre celle de L. cultellatus et $L$. wackeri. Alors que chez L. cultellatus l'onglet mandibulaire est uni à l'article basal et forme un stylet élancé (L. africanus semble avoir une structure identique), chez L. wackeri l'onglet est séparé et on voit bien l'endroit où il est fixé (Plate 1: 4). La longueur totale de la mandibule est de $81 \mu$ (plus courte en comparaison avec celle des 3 espèces susmentionnées).

Sur la partie dorsale de $\mathrm{P}_{2}$, les palpes (Plate 1:5) rappellent davantage ceux de $L$. wackeri et $L$. fontinalis que ceux de $L$. africanus et L. cultellatus. La longueur dorsale des articles est I $-6 \mu$, II $-48 \mu$, III $-18 \mu$, IV $-27 \mu$.

La plaque épimérale antérieure est longue de $108 \mu$ et large de $186 \mu$ au niveau de l'insertion de la III e paire de pattes. Comme chez $L$. wackeri il manque une encolure formée par l'allongement du camérostome, propre aux L. africanus et L. cultellatus. Sur la plaque se trouvent 3 paires de soies longues et fines et une paire de pores, situés à proximité du lieu de l'insertion de la III B.

La plaque épimérale postérieure porte également 2 soies longues et fines. 
La plaque génitale est longue de $186 \mu$ et large de $156 \mu$. Elle porte de nombreux poils courts, surtout à la partie postérieure autour de l'orifice génital. Les cupules génitales au nombre de 5 de chaque côté, sont situées aux bords latéraux du corps. L'organe génital est piriforme, long de $39 \mu$ et large de $24 \mu$. De chaque côté de l'ouverture sont situés 3 poils fins (Plate 1:2).

Entre les plaques, à la face ventrale, la peau est finement lignée. Entre la plaque épimérale et la plaque génitale il y a deux formations qui ressemble à de très petites plaquettes.

La longueur des articles des pattes sans les onglets est:

\begin{tabular}{ccccccc} 
Patte & 1 & 2 & 3 & 4 & 5 & 6 \\
\hline I & $24 \mu$ & $36 \mu$ & $54 \mu$ & $36 \mu$ & $42 \mu$ & $48 \mu$ \\
II & $24 \mu$ & $36 \mu$ & $48 \mu$ & $36 \mu$ & $48 \mu$ & $48 \mu$ \\
III & $48 \mu$ & $24 \mu$ & $45 \mu$ & $42 \mu$ & $78 \mu$ & $72 \mu$ \\
IV & $42 \mu$ & $24 \mu$ & $48 \mu$ & $48 \mu$ & $75 \mu$ & $48 \mu$
\end{tabular}

Les caractères plus spéciaux, propres aux pattes, sont les structures sous forme de crochet sur les articles 6 e. Elles sont plus accentuées aux paires de pattes I et II. Des 4 espèces connues jusqu'ici il n'y a que L. cultellatus qui ait une structure pareille et non seulement sur les articles 6e, mais aussi sur les articles 5 e des pattes (Plate 1: 6-9). Les deux soies peignées caractéristiques sont présentes sur III $B_{5}$. IV $B_{5}$ possède aussi une soie peignée sur son bout distal. La structure des onglets est analogue à celle de L. wackeri. Les denticules sont au nombre de 11-12 et sont mieux développées aux paires de pattes I et II (Plate 1: 10).

q paratype,S.T., tube No6(Plate 2). Sauf l'organe génital, la structure $\mathrm{du}$ corps est identique à celle du mâle. La longueur du corps est $360 \mu$, la largeur $237 \mu$. La plaque prédorsale est longue de $72 \mu$ et large de $88 \mu$, la plaque oculaire - $42 \mu$ de longueur et $57 \mu$ de largeur, la plaque postoculaire est longue $\mathrm{d} \epsilon 30 \mu$ et large de $18 \mu$ et la plaque dorsale est longue de $222 \mu$ et large de $108 \mu$.

L'organe maxillaire a les mèmes longueur et largeur que chez le mâle.

La longueur dorsale des articles du palpe est: I $-6 \mu$, II $-48 \mu$, III $-20 \mu$ et IV $-33 \mu$.

La plaque épimérale antérieure est longue de $108 \mu$ et large de $180 \mu$, la plaque génitale est longue de $174 \mu$ et large de $126 \mu$. Celle-ci porte aussi 5 paires de cupules génitales et 5 paires de poils fins, courts. L'ouverture génitale est large, située sur la partie distale de la plaque génitale. Sa longueur est de $62 \mu$ et sa largeur de $84 \mu$. De chaque côté il y a 4 poils fins courts (Plate 2: 2). 
Les pattes ont la même structure que chez le mâle.

La longueur des articles est:

\begin{tabular}{ccccccc} 
Patte & 1 & 2 & 3 & 4 & 5 & 6 \\
\hline I & $24 \mu$ & $36 \mu$ & $54 \mu$ & $36 \mu$ & $45 \mu$ & $57 \mu$ \\
II & $24 \mu$ & $36 \mu$ & $54 \mu$ & $36 \mu$ & $48 \mu$ & $54 \mu$ \\
III & $51 \mu$ & $24 \mu$ & $45 \mu$ & $42 \mu$ & $72 \mu$ & $72 \mu$ \\
IV & $51 \mu$ & $24 \mu$ & $48 \mu$ & $42 \mu$ & $72 \mu$ & $66 \mu$
\end{tabular}

$L$. capernaumi n. sp. - femelle, tout comme l'espèce américaine $L$. cultellatus et l'africaine L. africanus, porte ses œufs sur le cinquième article des pattes postérieures. Nous avons constaté 5-6 œufs par femelle dont quelques-uns déjà abandonnés par la larve qui s'y était développée. Comme dans la description faite par Viets (1940), ici aussi les œufs étaient dans des stades différents de développement: dans certains cas, pleins d'une matière de jaune d'œuf non différenciée, dans d'autres cas, une articulation bien visible des pattes est observée (Plate 2:3), une larve sortant de l'œuf (Plate 2: 4), ou bien des œufs abandonnés (Plate 2: 3).

Nymphe II a une longueur dorsale de $309 \mu$ et largeur de $174 \mu$. La plaque génitale porte 3 paires de cupules et 6 paires de poils courts. On y observe un organe génital provisoire (Plate $2: 5$ ).

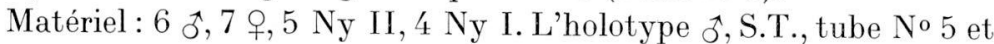
les paratypes sont conservés â l'Institut Zoologique et Musée à Sofia.

Avec la découverte du Limnohalacarus capernaumi n. sp. les espèces appartenant au genre Limnohalacarus atteignent le nombre de 5 soit :

1. Limnohalacarus wackeri (Walter 1914) - Europe.

2. Limnohalacarus africanus Walter 1935 - Afrique.

3. Limnohalacarus cultellatus Viets 1940 - Amérique du Sud.

4. Limnohalacarus fontinalis Walter et Bader 1952 - Afrique.

5. Limnohalacarus capernaumi n. sp. - Asie.

Tous les représentants du genre Limnohalacarus vivent en général dans les eaux souterraines; une exception cependant pour L. wackeri qui n'était connu, il y a peu de temps encore, que des eaux superficielles (lacs, marais, marécages de l'Europe du Nord) mais qui récemment a été trouvée aussi dans les eaux souterraines de puits en Bulgarie (Petrova, 1966).

L'espèce américaine L. cultellatus se trouve elle aussi dans des puits, dans des fossés et fentes remplis d'eau et dans des marécages qui, selon toute probabilité, sont alimentés par les eaux souterraines.

Les trois autres espèces n'ont été trouvées que dans des eaux souterraines - les deux espèces africaines $L$. africanus et $L$. fontinalis dans des puits et la nouvelle espèce $L$. capernaumi dans une source. 
Lohmannella heptapegoni n. sp. (Plate 3)

ô holotype, S.T., tube No7. La longueur dorsale du corps sans l'orgaen maxillaire est de $318 \mu$ et la largeur $204 \mu$ au niveau de l'insertion de la III e paire de pattes.

La plaque prédorsale a une longueur de $126 \mu$ et une largeur de $138 \mu$. Les bords antérieur et postérieur sont rectilignes. Les bords latéraux sont légèrement arrondis; il manque l'élargissement dans cette partie typique pour Lohmannella stammeri Viets 1939. Les coins distaux de la plaque sont bien arrondis. Dans la partie proximale sont disposées les deux longues soies typiques pour le genre et latéralement, près du bord de la plaque de chaque côté il y a un pore (Plate $3: 1$ ).

La plaque dorsale est longue de $150 \mu$ et large de $120 \mu$; elle est largement arrondie sur le bord frontal et légèrement rétrécie en arrière, ce qui la rend différente de celle de L. stammeri; dans sa partie antérieure elle porte 4 pores poilus.

Les plaques oculaires sont élancées, de forme analogue à celles du L. stammeri, mais il y manque l'allongement typique sous forme de goutte. Elles sont longues de $70 \mu$ et larges de $36 \mu$.

Sur les plaques dorsales on n'observe pas de structure réticulaire; l'espace qui les sépare est finement ligné.

L'organe maxillaire est long de $144 \mu$ et large de $84 \mu$; l'hypostome est muni de 2 paires de soies. L'onglet mandibulaire a la forme d'un ciseau (Plate 3:3) et moins bien tourné que chez L. stammeri, Porolohmannella violacea Kramer et $P$. cuetkovi Petrova. Les palpes sont accolés par leur face ventrale et forment avec l'hypostome une sorte de pince. La longueur dorsale des articles est: $\mathrm{P}_{1}-25 \mu, \mathrm{P}_{2}-97 \mu$, $\mathrm{P}_{3}-8 \mu, \mathrm{P}_{4}-23 \mu$. A la partie médiane $\mathrm{du}$ deuxième article manque l'enflure spécifique à L. stammeri.

La plaque épimérale antérieure est longue de $132 \mu$ et large de $180 \mu$; elle porte 3 paires de poils et la partie postérieure est arrondie.

Les plaques épimérales postérieures ont la forme triangulaire commune et sont également munis de 3 poils.

La plaque génitale (Plate $3: 2$ ) est oviforme à bord antérieur arrondi et à bords latéraux en saillie. Sa longueur est de $132 \mu$, sa largeur de $114 \mu$. Dans sa partie proximale elle porte 3 paires de soies. A la partie supérieure, près de l'organe génital, il y a 2 paires de soies plus longues et en dessous, tout autour, un nombre considérable de poils plus courts.

L'organe génital est elliptique, ayant le bord proximal légèrement pointu ; comparé à celui de L. stammeri, il est plus large (long de $49 \mu$ et large de $36 \mu$ ). De chaque côté il y a 3 cupules génitales internes et l'on peut voir à travers la peau le squelette chitineux du pénis. 
Les pattes sont munies de fortes soies. Les griffes sont reliées au dernier article par une pièce intermédiaire. Elles ne portent pas de peignes. La longueur dorsale des articles des pattes est:

\begin{tabular}{ccccccc} 
Patte & $\mathbf{1}$ & 2 & 3 & $\mathbf{4}$ & 5 & 6 \\
\hline I & $42 \mu$ & $42 \mu$ & $30 \mu$ & $48 \mu$ & $33 \mu$ & $24 \mu$ \\
II & $48 \mu$ & $42 \mu$ & $30 \mu$ & $60 \mu$ & $36 \mu$ & $24 \mu$ \\
III & $54 \mu$ & $42 \mu$ & $30 \mu$ & $42 \mu$ & $24 \mu$ & $27 \mu$ \\
IV & $54 \mu$ & $42 \mu$ & $31 \mu$ & $42 \mu$ & $30 \mu$ & $30 \mu$
\end{tabular}

L'holotype ô, S.T., tube $\mathrm{N}_{7}$ est conservé à l'Institut Zoologique et Musée à Sofia.

Lohmannella heptapegoni n. sp. est très proche de L. stammeri. Les deux espèces, bien qu'habitant des eaux peu saumâtres sont pour vues de cupules génitales internes, caractère que l'on considérait comme typique des seules formes marines. Pour L. stammeri, Viets (1939a) indique : «Die neue Lohmannella-Art ist morphologisch wegen Vorhandenseins innerer und Fehlens äußerer „Genitalnäpfe“ zu den echten „Meeresmilben“, den Halacaridae s. str. zu stellen. Wir wissen zunächst nicht, ob nicht diese Lohmannella in der gleichen Gegend auch marin vorkommt. Zumindest darf angenommen werden, daß sie einen starken Vorstoß ins Süßwasser getan hat, denn das Auftreten der Art in beiden Geschlechtern und beiden Nymphenstadien, dazu $2+1+5$ Tiere (an den Fundstellen der Höhle bei f, $t$ und hh) deuten nicht auf Zufallsfunde hin, sondern darauf, daß die betreffenden Höhlengewässer tatsächlich von dem Tiere bewohnt werden.»

La récolte d'un seul exemplaire de Lohmannella heptapegoni n. sp. alors que l'autre espèce fut recueillie en plusieurs exemplaires dans des stades différents, n'est pas de nature à nous persuader qu'il s'agit en l'occurrence de son habitat normal. Il y a lieu de supposer qu'elle vit aussi dans le lac de Tibériade, à 50 mètres de la source. Une communication souterraine probable entre le lac et la source permettrait la pénétration de L. heptapegoni $\mathrm{n}$. sp. du lac vers la source par cette voie. Des recherches supplémentaires à la fois aux sources et au lac seraient nécessaires pour trancher la question.

Viets nous indique quelques cas de récoltes d'espèces typiquement marines dans des eaux douces de lacs et de sources, telles que Copidognathus tectiporus Viets et $C$. tectiporus profundus Viets dans le lac d'Ohrid en Yougoslavie, ainsi que Rombognathus uniscutatus Viets de l'Adriatique dans des eaux douces de sources près de Rogivno (Viets, 1939 a, c). Indiquant la proximité entre les Porolohmannella andrei Angelier et Lohmannella falcata (Hodge), Angelier (1951) attire l'attention sur le caractère psammophile des $L$. falcata du littoral méditer- 
ranéen. Il emet la supposition de la possibilité d'un passage de cette espèce par voie interstitielle du littoral vers les eaux souterraines continentales.

La question relative aux espèces continentales de Lohmannella et aux relations entre Lohmannella et Porolohmannella est encore peu élucidée. Ce problème pour la solution duquel il y a déjà certaines données, sera examiné dans un travail ultérieur.

\section{RÉSUMÉ}

On communique deux nouvelles espèces d'Halacariens provenant d'une source thermale à eau peu saumâtre, près du lac de Tibériade, à Capernaum, Israël.

Limnohalacarus capernaumi $n$. sp. possède certains traits qui sont typiques aux espèces déjà connues de ce genre, mais se distingue par d'autres, qui lui sont propres.

Lohmannella heptapegoni $\mathrm{n}$. sp. est proche de Lohmannella stammeri Viets, dont il se distingue par la structure des plaques dorsales, le palpe et la forme de l'organe génital.

\section{ZUSAMMENFASSUNG}

Es werden zwei neue Arten Halacariden aus der Thermalquelle mit schwach brackischem Wasser beim See Tiberias in Capernaum, Israel, beschrieben.

Limnohalacarus capernaumi $n$. sp. besitzt einige Merkmale, die auch für die anderen schon bekannten Arten von der gleichen Gattung typisch sind, unterscheidet sich aber durch andere Merkmale, die nur für diese Art charakteristisch sind.

Lohmannella heptapegoni $\mathrm{n}$. sp. steht Lohmannella stammeri Viets nahe, von der sie sich durch die Struktur der Dorsalplatten, der Palpen und der Form des Genitalorgans unterscheidet.

\section{BIBLIOGRAPHIE}

André, M. (1946) - Halacariens marins. Faune de France. 46: 125-129, Paris (P. Lechevalier).

Angelier, E. (1951) - Porolohmannella andrei n. sp., un nouvel Halacarien recueilli dans le psammon d'eau douce. Bull. Mus. Paris, (s. 2), 24, 2: 195-199.

Pertova, A. (1965) - Hydracariens phréaticoles de la Thrace. In: Die Fauna Thrakiens II, Sofia. Bulg. Acad. Wissensch., Zool. Inst. u. Mus., p. 337 (en bulgare).

- (1966) - Hydrachnelles et Limnohalacarides d'un puis de la Bulgarie du Nord-Ouest (village Gorni-Ciflik, district de Belogradcik). Acta Mus. Maced. Sci. Nat. (sous cachet).

Press, I. (1948) - A topographical-historical Encyclopaedia of Palestine, p. 368-369. II, Rubin Mass Publisher, Jerusalem (en hébreu).

Romisn, G., et Viets, K. (1924) - Neue Milben. Arch. Naturg. 90. Jg., A, 4: $215-217$. 
Viets, K. (1927) - Mitteilung über das Vorkommen von Halacariden in der Kiemenhöhle des Flußkrebses. Verh. Intern. Ver. Limnol. Moskau 1925, 3, 2: 460-473.

- (1936) - Wassermilben oder Hydracarina (Halacaridae). In: Dahl, Tierwelt Deutschland, S. 526-528, 554-555. G. Fischer, Jena.

- (1939a) - Halacariden (Ascari) aus süditalienischen Höhlengewässern. (12. Mitteilung über Wassermilben aus unterirdischen Gewässern.) Arch. Hydrobiol. 35, 4: 625-630.

- $(1939 \mathrm{~b})$ - Meeresmilben aus der Adria (Halacaridae und Hydrachnellae). Arch. Naturg., N. F. 8-9: 91-94.

- (1939c) - Über die Milbengruppe der Porohalacaridae (Acari). Zugleich ein Beitrag zur Kenntnis der Milbenfauna der Bremer Umgegend und des Plöner Sees. Abh. naturw. Ver. Bremen. 31, 3: 502-514.

- (1940) - Zwei neue Porohalacaridae (Acari) aus Südamerika. Zool. Anz. 130, 7-8: 194-201.

Walte R, C. (1914) - Notizen über die Süßwasserformen nebst Beschreibung einer neuen Art. Arch. Hydrobiol. 9, 2: 277-285.

- (1917) - Schweizerische Süßwasserformen der Halacariden. Rev. Suisse Zool., Genève 25, 13: 411-414.

- (1935) - Hydracarina. In: Voyage de Ch. Alluaud et P. A. Chappuis en Afrique Occidentale française (Déc. 1930-Mars 1931). Arch. Hydrobiol. 28,1 : 73-75.

Walter, C., et Bader, C. (1952) - Hydracarina. In: Mission scientifique de l'Omo 7, 62 : 227-234.

\section{EXPLICATIONS DES PLANCHES 65 (1) - 67 (3) PLANCHE (65) 1}

I Limnohalacarus capernaumi n. sp.

ot holotype tube No 5

1 face dorsale

2 face ventrale

3 capitulum

4 mandibule

5 palpe

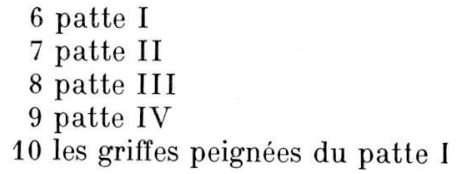

10 les griffes peignées du patte I

\section{PLANCHE 66 (2)}

II Limnohalacarus capernaumi $\mathrm{n}$. sp.

o paratype tube No 6

1 face dorsale

2 face ventrale

3 les œufs fixés au IV B 5

4 la larve quittant l'œuf

5 nymphe II

\section{PLANCHE $67(3)$}

III Lohmannella heptapegoni n. sp.

o holotype tube No 7

1 face dorsale

2 face ventrale

3 mandibule

4 palpe

5 patte I

6 patte II 
Neobisium (Roncobisium) allodentatum n. sg., n. sp. de Pseudoscorpion Neobisiidae (Arachnides) habitant une caverne du département de Saône-et-Loire, France.

\author{
Par Max Vachon ${ }^{1}$ )
}

Avec planches 68 (1) - 72 (5)

Messieurs Jean-Paul Henry, Guy Magniez et Claude Palévody, Assistants au laboratoire de Biologie générale de la Faculté des Sciences de Dijon, dirigé par Monsieur le Professeur Roger Husson, ont eu l'amabilité de me confier les Pseudoscorpions qu'ils ont capturés, en 1965, dans une grotte à Blanot, département de Saône-et-Loire. Les quatre individus récoltés ont des caractères très particuliers; nous proposons de créer pour cette nouvelle espèce un sous-genre nouveau : Roncobisium, ce nom précisant que l'espèce possède à la fois des caractères appartenant aux genres Roncus C. L. Koch et Neobisium J. C. Chamberlin.

\title{
Neobisium (Roncobisium) allodentatum n. sp.
}

Collections du Muséum national d'Histoire Naturelle, Paris. Grotte de Blanot (Saône-et-Loire), 1 đo type, 1 ô paratype, capturés dans la partie profonde de la grotte le 25-III-1964 par J. P. Henry; G. Magniez et C. Palévody ; 1 §ै, même station, 28-II-1965 par J. Magniez, dans un petit amas de bois pourri, couvert de moisissures, reposant sur un talus d'argile très fine ; 1 t type, 14-XII-1965 - J. P. Henry, même station. Les Pseudoscorpions s'y trouvaient en compagnie d'Acariens, de Collemboles (g. Onychiurus), de Diplopodes, de Campodés et d'Isopodes (Androniscus dentiger Verh.).

$$
\text { Description du ô type }
$$

Céphalothorax (fig. 1) plus long que large, avec un épistome am atténué ; 4 yeux nettement distincts, les antérieurs éloignés du front de plus de leur diamètre; 23 soies réparties en séries longitudinales

1) Muséum d'Histoire Naturelle, 61 Rue de Buffon, Paris $5^{\circ}$. 
différenciées : 4 antérieures, 6 oculaires, 6 médianes et 7 postérieures ; pas de petites soies latérales en avant des yeux.

Soies tergales (fig. 1) : 6-7-9-9-9-9-9-11-9-9 soies simples dont certaines plus longues sur les derniers tergites; tubercule anal orné de 4 soies ; région génitale (fig. 3) : 16 soies sur l'opercule génital, 27 soies groupées sur la plaque génitale postérieure et 3 soies le long de chaque stigmate antérieur; 8 soies sur le sternite suivant (sternite 4) en une seule rangée, 2 soies latérales le long des stigmates postérieurs; 6 soies à l'intérieur de la chambre génitale (fig. 4); 3 de chaque côté dans la région postérieure; sacs génitaux latéraux bien développés et amincis à leur extrémité distale; sac génital médian très long et pelotonné.

Chélicères très semblables à celles de la o (fig. 7) : tubercule fileur peu développé; doigt mobile sans dent médiane spécialement développée; une dizaine de dents au doigt fixe de formes variées; 1 soie au doigt mobile; 6 soies sur la main : 2 ventrales, 3 intermédiaires et 1 dorsale.

Flagelle (fig. 6) composé de 8 soies rigides dont les 2 antérieures, seules, sont dentelées d'un seul côté; la soie antérieure est renflée à sa base; les autres soies, simples, vont en diminuant de taille, les petites soies postérieures n'étant pas isolées des autres. Le flagelle a tous les caractères propres au genre Neobisium.

Hanches des pattes (fig. 2) : 5 soies distales à chaque lobe maxillaire, 6 soies sur les hanches des pattes-mâchoires ; 5 à 6 soies sur les hanches des pattes 1 à IV; angle interne des pattes 1 (fig. 2) avec un petit processus denticulé, angle externe avec un processus long et triangulaire.

Pattes-mâchoires (fig. 7 et 8 ) : trochanter allongé, sans tubercules distincts; fémur lisse, sans pédicule appréciable, 4,3 fois aussi long que large; tibia non renflé du côté interne, 3 fois aussi long que large, articulation s'étendant au 1/3 de la longueur entière de l'article; pince (sans pédicule) 4,1 fois aussi longue que large; doigts égaux, légèrement courbés, 1,5 fois aussi longs que la main avec pédicule et nettement plus longs que le fémur; main globuleuse à contours réguliers, 1,7 fois aussi longue que large, pédicule compris ; dents contiguës tout au long des doigts mais aplaties et non triangulaires, même disposition que chez la q (fig. 14); dents régulières, environ 90 au doigt fixe et 80 au doigt mobile; dents ne revenant pas à l'extrémité du doigt mobile (fig. 14) mais terminées par une dent élargie et bifide (dat); une dent accessoire du côté externe, au doigt mobile (fig. 14: dam) entre les trichobothries $t$ et $s t$.

Trichobothries (fig. 8) : et, it, est formant un groupe dont seules $e t$, it sont distales par rapport à $t$ (disposition rappelant celle existant 
chez Neobisium simile); it à la hauteur de $e t$; ist basal par rapport à st et situé environ au milieu du doigt fixe; $i b$ à la hauteur de $e b$; $e s b$ très nettement distale de $e b$ (caractère du genre Roncus) et éloignées de la largeur de plusieurs aréoles; $i b$ très nettement basale de $e s b$; $s t$ plus près de $t$ que de $s b$.

Pattes ambulatoires IV (fig. 9) : fémur allongé, 3,9 fois aussi long que large, articulation entre fémur et préfémur située au milieu de l'article; tibia allongé, 6 fois aussi long que large; tarse 1,6 fois aussi long que le basitarse; poil subterminal (fig. 9) avec 2 petites dents terminales et non en forme d'Y.

Dimensions en $\mathrm{mm}=$ corps : 2,02 ; c. th. : 0,65 ; pattes-mâchoires, fémur: 0,81-0,18; tibia: 0,62-0,21; main: 0,62-0,33; pince : 1,42-0,33 (sans pédicule); doigts : 0,95.

\section{Description du type 우}

La $o$ diffère très peu du $\hat{\sigma}$ comme le montrent les figures 10 à 13 . L'opercule génital ne porte que 6 soies en ligne et la plaque génitale postérieure qu'une série transverse de 14 soies. La figure 11 précise la disposition des plaques criblées médiane et latérales.

Les chélicères, les hanches des pattes-mâchoires sont identiques chez la $q$ et le $\hat{o}$; les articles des pattes-mâchoires possèdent des rapports morphométriques très voisins, fémur: 4,1, tibia: 3 , pince 4,1, main 1,9 fois aussi longs que larges. Les doigts, chez la $q$ sont un peu plus courts que chez le $\hat{\sigma}$ mais restent très nettement plus longs que le fémur. La disposition des trichobothries est identique chez le ô et la + (comparer fig. 8 et 13); esb est nettement éloignée et distale de $e b$; par contre, $i b$ est presque au niveau de $e s b$ (fig. 13); chez la + il existe, comme chez le $\sigma^{\star}$ (fig. 14) une grosse dent terminale, $d d$ et une dent accessoire, da. Le poil subterminal des pattes IV (fig. 9) possède 3 branches distales au lieu de $2 \mathrm{chez}$ le $\widehat{o}$ et n'est pas en forme d'Y.

Dimensions en $\mathrm{mm}=$ corps: 2,02 ; c. th. : 0,65 ; pattes-mâchoires, fémur : 0,80-0,18; tibia : 0,60-0,21; mains (avec pédicule) : 0,620,35 ; pince (sans pédicule) : 1,40-0,35; doigts : 0,92.

\section{Remarques}

Dans un travail précédent (Bull. Mus. Hist. nat., 36, 1, 1964) à propos de la description d'une nouvelle espèce : Roncus barbei, nous avons insisté sur les caractères permettant de différencier les deux genres Neobisium J. C. Chamberlin et Roncus C. L. Koch, ces deux genres étant très proches et, le plus souvent, distingués l'un de l'autre par le 
nombre des yeux : deux chez Roncus quatre chez Neobisium. Les variations que subit le nombre des yeux, surtout chez les formes cavernicoles dont la plupart sont aveugles, ne permettent pas de considérer le nombre des yeux comme un caractère générique valable. Nous avons alors envisagé de retenir deux autres caractères distinctifs, l'un tiré de la forme des soies flagellaires, l'autre de la position relative des trichobothries $e b$ et $e s b$.

Chez Roncus, les soies flagellaires sont toutes dentelées et la soie antérieure n'est pas dilatée à sa base; les trichobothries $e s b$ et $e b$ sont distantes de plusieurs aréoles et $e s b$ est nettement distale de $e b$ (fig. 8); le nombre des yeux est au maximum de deux (2 ou 0).

Chez Neobisium, les deux soies flagellaires distales sont, seules, dentelées et la soie antérieure est à sa base, dilatée (fig. 6); les deux trichobothries $e b$ et $e s b$ sont très voisines et au même niveau; le nombre des yeux est au maximum de quatre (4,2 ou 0$)$.

Les individus de la grotte de Blanot se classent facilement dans le genre Neobisium si l'on tient compte du nombre des yeux (quatre) et de la forme des soies flagellaires (fig. 6). Mais la position relative des trichobothries $e b$ et $e s b$ situerait cette espèce dans le genre Roncus.

L'existence de grosses dents accompagnant la série normale au doigt mobile des pinces : une dent accessoire distale bifide dat et une autre dans la moitié distale du doigt, dam (fig. 14) donne à cette espèce une position très particulière dans le genre Neobisium. C'est la raison pour laquelle nous proposons pour elle la création d'un nouveau sousgenre : Roncobisium dont les caractères particuliers et différentiels sont portés dans la clé de détermination suivante:

\section{Clé de détermination des sous-genres de Neobisium}

1. Pas d'yeux; téguments toujours décolorés, formes troglobies ..... 2

- des yeux, très rarement réduits; formes ou non troglobies ....... 3

2. Fémur des pattes-mâchoires nettement granulé ; cavernes de Bulgarie ............................. Heoblothrus Beier 1963

- fémur des pattes-mâchoires lisse ; cavernes européennes.

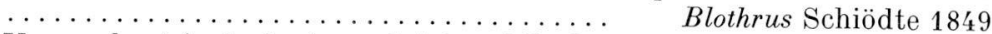

3. Une seule série de dents au doigt mobile des pattes-mâchoires .... 4

- dents accessoires accompagnant la série normale de dents; cavernes de France $\ldots \ldots \ldots \ldots \ldots \ldots \ldots \ldots \ldots \ldots \ldots \ldots \ldots \ldots \ldots \ldots$ Roncobisium n.sg.

4. Formes troglobies; appendices allongés, téguments peu colorés; doigt mobile des chélicères muni d'une lamelle et d'une série de dents très peu développées; Sardaigne, Italie, Dalmatie... Ommatoblothrus Beier 1956

- formes non troglobies mais pouvant vivre dans les cavernes; appendices non allongés; téguments colorés; doigt mobile des chélicères avec une série de dents distinctes dont l'une est souvent plus développée que les autres..................... Neobisium J. C. Chamberlin 1930 


\section{RÉSUMÉ}

Neobisium (Roncobisium) allodentatum, espèce vivant en France dans une caverne de Saône-et-Loire, appartient à un nouveau sous-genre de Neobisium dont les caractères essentiels sont la possession de dents accessoires aux pinces (fig. 14) et une position relative des trichobothries eb et esb (fig. 8) rappelant celle que l'on trouve chez les espèces du genre Roncus. Une clé de détermination précise la situation de ce nouveau sous-genre par rapport aux quatre autres sous-genres connus de Neobisium.

\section{SUMMARY}

Neobisium (Roncobisium) allodentatum, a species inhabiting a cave in Saône-et-Loire, France, belongs to a new subgenus of Neobisium of which the essential characters are the possession of accessory teeth on the chelae (fig. 14) and a relative position of trichobothria $e b$ and $e s b$ (fig. 8) recalling that of the species of Roncus. A determination key fixes the position of this new subgenus with respect to the four other known subgenera of Neobisium.

\section{EXPLICATION DES PLANCHES 68 (1) - 72 (5) \\ Neobisium (Roncobisium) allodentatum n. sp. type ơ}

Fig. 1: Céphalothorax et tergites 1,2 et 3. - Fig. 2: hanches des pattesmâchoires et des pattes ambulatoires.

\section{Neobisium (Roncobisium) allodentatum n. sp. type $\sigma^{*}$}

Fig. 3: région génitale et sternite IV. - Fig. 4: chambre génitale; atr. atrium; sgl: sac génital latéral, pair; sgm: sac génital médian, impair.

\section{Neobisium (Roncobisium) allodentatum n. sp.}

Fig. 5: chélicère gauche de la o type. - Fig. 6: flagelle de la chélicère du type ô. - Fig. 7: trochanter, fémur et tibia de la patte-mâchoire de gauche du type $\delta^{*}$ - Fig. 8 : pince de la patte-mâchoire gauche du type ô et, à côté, base de la pince droite. - Fig. 9: patte IV de gauche du type ô avec détail du poil subterminal: $\delta$ et $q$ types.

\section{Neobisium (Roncobisium) allodentatum n. sp. o type}

Fig. 10: Céphalothorax et tergite 1. - Fig. 11: région génitale et sternite IV, pcl, pcm: plaques criblées latérales et médiane.

\section{Neobisium (Roncobisium) allodentatum n. sp. \\ o type}

Fig. 12: trochanter, fémur et tibia de la patte-mâchoire de gauche. Fig. 13: pince de cette mème patte. - Fig. 14: extrémité du doigt mobile de la pince gauche; dat et dam: dents accessoires. 



\title{
Underground Solution Canyons in the Central Kentucky Karst, U.S.A.
}

\author{
By Righard A. Watson ${ }^{1}$ )
}

With 4 figures in the text

\section{Introduction}

Solution canyons are underground voids 1 to $15+$ meters wide, 3 to $45+$ meters high, and 30 to $300+$ meters long. Their floors are usually stepped, with the ceiling remaining at approximately one level while the overall size and height generally increases downstream (figure 1). Their courses are slightly sinuous, with some angular turns at joint intersections. They occur directly below or slightly offset from and

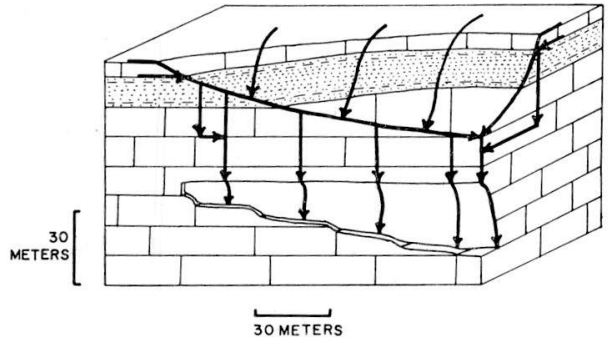

Fig. 1

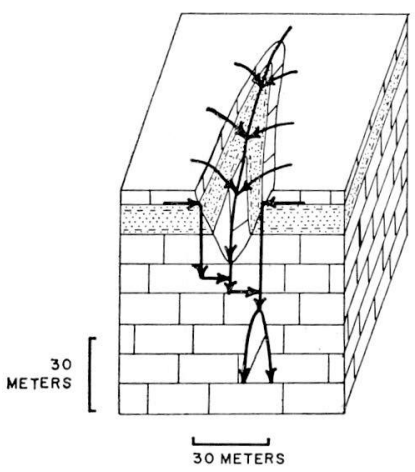

Fig. 2

Fig. 1. Idealized Block Diagram of Re-Entrant Valley and Underlying Solution Canyon: Longitudinal-Section. Arrows indicate concentration of surface and underground water flow.

Fig. 2. Idealized Block Diagram of Re-Entrant Valley and Underlying Solution Canyon: Cross-Section. Arrows indicate concentration of surface and underground water flow.

1) Cave Research Foundation: Department of Philosophy, Washington University, St. Louis, Missouri 63130, U.S.A. 
roughly parallel to the thalwegs of overlying re-entrant valleys which intersect the sandstone caprock of the ridges and are tributary to the major karst valleys. A section across a re-entrant valley and an underlying solution canyon would show a rough hour-glass shape (figure 2). The walls of solution canyons are generally vertically fluted.

\section{Habitat of the Solution Canyons}

The Central Kentucky Karst is an area of about 600 square kilometers lying on Mississippian rocks in south-central Kentucky along the edge of the Cincinnati Arch in the Interior Lowland Province, its center 160 kilometers south of Louisville. It is an integral part of a karsted limestone belt which extends from southern Indiana south through Kentucky into Tennessee along the entire west flank of the Cincinnati Arch. The Central Kentucky Karst hosts a through-flowing master karst stream, the Green River, and is composed of three major physiographic units separated by two major escarpments. In the southeast portion is the low-lying Sinkhole Plain at an average elevation of 195 meters. It is separated from the central Mammoth Cave Plateau at an average elevation of 255 meters by the northeast trending Dripping Springs Escarpment. North of the Green River which flows along the north edge of the Plateau at an elevation of 127.5 meters, the Pottsville Escarpment also trends northeast and separates the Plateau from the Hilly Country which has a maximum elevation of nearly 270 meters. Mammoth Cave National Park encloses portions of the Plateau and the Hilly Country, but unfortunately not of the Sinkhole Plain which lies in close physiographic relation.

Field investigations over the past 10 years have been made in the central part of the Mammoth Cave Plateau (figure 3). Here are found three major northwest-trending ridges - Joppa Ridge, Mammoth Cave Ridge, and Flint Ridge - with ridge-top elevations of approximately 255 meters. The ridges are over 8 kilometers long and vary in width from 0.9 to 1.4 kilometers. The surface of these mesa-like ridges dips gradually to the west. They are separated by two major karst valleys, also varying in width from 0.9 to 1.4 kilometers, with valley floor elevations from 165 to 210 meters. Eaton-Houchins Valley separates Flint Ridge from Mammoth Cave Ridge; Doyle Valley separates Mammoth Cave Ridge from Joppa Ridge. Beneath Flint Ridge is the Flint Ridge Cave System of which more than 88.5 continuous kilometers of pssages have so far been mapped (Smith, 1964). Beneath Mammoth Cave Ridge lies the famous Mammoth Cave System of 

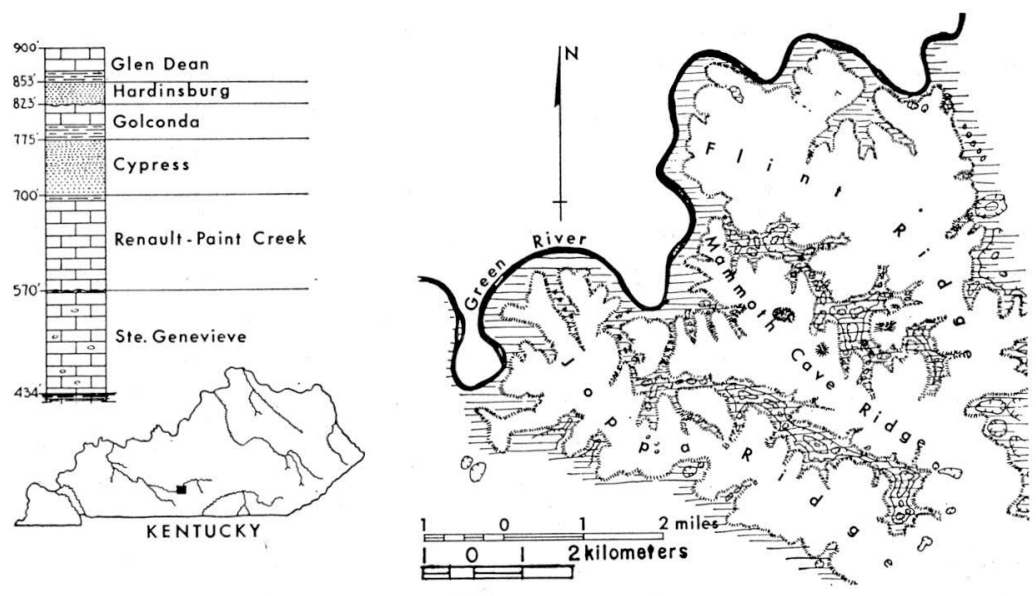

Fig. 3. The Mammoth Cave Plateau on Mississippian Rocks.

which some 72.5 continuous kilometers have been mapped. These are the two longest cave systems known on the North American continent. Recent exploration in the Flint Ridge System under Houchins Valley has penetrated to within 100 meters of passages in the Mammoth Cave System, and it is without question that the two systems will one day be joined. No extensive cave system is known to exist beneath Joppa Ridge, though geologic and physiographic relations indicate that there must be one there.

The ridges are held up by the capping Cypress Sandstone with enclosed layers of impermeable shale. This sandstone is up to 22.5 meters thick and overlies about 90 meters of cavernous Renault-Paint Creek and Ste. Genevieve Limestone (figure 3). The most recent stratigraphic study is found in Pohl and Cushman (1964). The formations dip gently to the northwest. The base of the Cypress Sandstone approximately follows the 210 meter contour, which thus is an important guideline in the interpretation of underground features. The average annual rainfall for the region is 115 to 130 centimeters, mean annual temperature is 12.2 to $13.3^{\circ} \mathrm{C}$., and the Plateau is covered with a temperate deciduous forest of oak-hickory and southern hardwoods, typical of the Interior Low Plateaus.

Throughout the cave systems, horizontal passages are intersected by solutional vertical shafts that are genetically unrelated to the passages. Vertical shafts are roofed, cylindrical voids of nearly uniform dimensions from top to bottom. They range in width from 0.9 to over 15 meters, and in height from 3 to over 45 meters. Ceilings are usually 
flat, and often contain floorless ceiling channels 10 to 30 centimeters deep. The walls of vertical shafts are usually vertically fluted. Their floors are often saucer-shaped, and all have small elliptical or canyonshaped drains which are seldom of dimensions large enough for a man to enter. Shafts sometimes form in coalescing groups, forming a void with a serrate plan. Since vertical shafts occur apart from, or indiscriminately intersecting one or more levels of horizontal cave passages, Pohl (1935, 1955; see also Merrill, 1960) has inferred that presently existing vertical shafts are younger than, and genetically unrelated to the major horizontal passages. Vertical shafts are found to occur only beneath the immediate vicinity where the impermeable sandstone caprock has been breached on the surface. Nearly 100 have been mapped, all appearing on the map near the base of the Cypress sandstone approximately along the 210 meter contour. Pohl reasoned that as subsurface water flows over the edge of the breached caprock, it finds its most immediate course to the base level down intersecting joints in the limestone. Down the line of intersection the solutional activity of vertically seeping water forms a vertical shaft.

It is certain that in some parts of the world vertical shafts are formed by waterfalls, as a cave stream finds or makes a breach so that it can move vertically from one level to another. It is probable that a few of the vertical shafts beneath the Mammoth Cave Plateau have been enlarged, if not formed, by waterfall action. As a waterfall retreats, it leaves a recessional gorge, and such canyon-like features have been identified underground in Iowa and Missouri. Features similar to recessional gorges are found beneath the Mammoth Cave Plateau. These gorge-like features seldom extend more than 30 meters horizontally. Except for one or two doubtful cases, they are seen to be the result of the intersection of several vertical shafts along a horizontal line, and not the result of the retreat of a waterfall. Much larger gorge-like solution canyons, morphologically and genetically similar to solutional vertical shafts, are the subject of the present investigation.

\section{Genesis of Solution Canyons}

It is evident that solution canyons are related genetically to solutional vertical shafts, forming where the intersection of the impermeable sandstone caprock permits the vertical descent of water through the jointed limestone. This breach in the caprock providing a vertical course for groundwater which had been flowing horizontally on top of the caprock is the first of three conditions necessary to the formation 
of solution canyons, and is one it shares with vertical shafts. Shafts form at the intersection of vertical joints, but the second condition necessary to the formation of solution canyons is not the intersection of joints, but the presence of one or more major vertical joints of relatively great length and depth. The third necessary condition is the presence of some means by which to concentrate a large quantity of water fairly uniformly along the joint. This condition is satisfied beneath the re-entrant valleys (figures 1 and 2). Surface runoff is conducted to the valley thalweg where a large quantity of water is lost underground. Ground water running off the impermeable top of the caprock is also concentrated for vertical descent along the valleywall intersections of the caprock. If a major joint is oriented near to, beneath, and roughly parallel to the thalweg of the valley (and thus also to the lines of intersection of the caprock by the two valley walls), then in seeking a vertical course to base level, water lost along the thalweg and along the lines of caprock intersection will descend fairly uniformly along the horizontal line of the vertical joint. Both surface and underground runoff is thus concentrated along a horizontal line. When an underlying major vertical joint is present to conduct this water to base level, the solutional activity of the vertically seeping water forms a solution canyon. At least 10 solution canyons are known in the Central Kentucky Karst, three of which will be described.

Penck Trail in the Flint Ridge Cave System is a series of solutional vertical shafts and solution canyons which extend for more than 300 meters under and parallel to, but offset from the thalweg of an overlying re-entrant valley (figure $4 \mathrm{a}$ ). Some of the shafts are coalesced along the horizontal line; other sections of Penck Trail have the features of solution canyons. Penck Trail, then, shows a form intermediate between a series of vertical shafts and a long solution canyon.

Black Canyon is a typical solution canyon in the Flint Ridge Cave System (figure 4b). Nearly 300 meters long and over 25 meters high with widths up to 12 meters, Black Canyon extends parallel to and directly below the thalweg of the overlying re-entrant valley. Along the same line downstream, and integrally connected to the solution canyon, is found the Overlook solutional vertical shaft complex. Thus, beneath the same re-entrant thalweg overlying slightly different joint conditions, a major solution canyon coalesces with a series of vertical shafts.

One of the longest solution canyons yet discovered in the Flint Ridge Cave System, Wow Canyon, is also intimately related to solutional vertical shafts (figure $4 \mathrm{c}$ ). Shaft complexes occur near both of its ends. This solution canyon runs for nearly 300 meters beneath the 


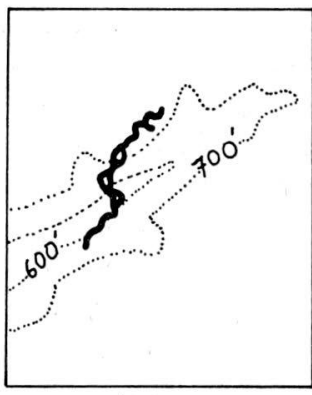

a.

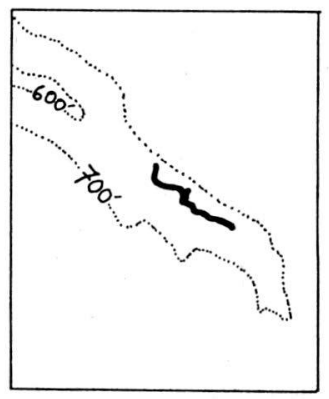

b.

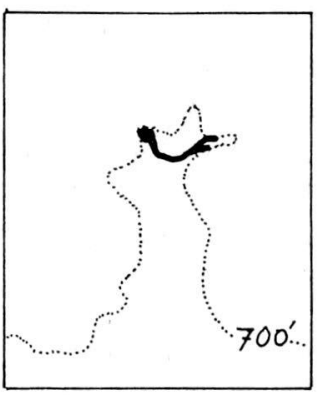

c.

\section{METERS}

Fig. 4. Maps of Solution Canyons and Solutional Vertical Shaft Series. (Traced from the map of the Flint Ridge Cave System, Smith, 1964.) a. Penck Trail. b. Black Canyon. c. Wow Canyon.

thalweg of the overlying re-entrant valley. At the upper end, the canyon averages 1.5 to 2 meters in width and 3 to 4.5 meters in height. The ceiling stays at the same level as the floor drops down a number of steps downstream, until at the lower end the canyon is 4.5 meters wide and over 25 meters high. An idealized longitudinal section illustrative of these relations is given in figure 1 . It should be noted that the diagram is somewhat deceptive, since neither the thalweg nor the joint plane is straight. The sinuous course of solution canyons is a result of the sinuosity of major joint planes, both along their horizontal and their vertical extents. Wow Canyon makes several angular turns, suggesting that in such long solution canyons, not one, but several similarly oriented major joints provide vertical water courses leading to the formation of the solution canyon.

Solution canyons, like solutional vertical shafts, can form only where there is a major vertical descent of water. Thus, both of these vertical features are concentrated beneath the edges of the ridges where the impermeable caprock is breached. Beneath the ridges under the caprock, vertical features are rare because there is no great concentration of water at high levels there seeking descent to base level. Beneath the major karst valleys there are also few major vertical features, since besides lacking means for concentration, the water is already near base level.

Like solutional vertical shafts, which enlarge vertically as well as horizontally as they evolve, solution canyons form by solution down their complete vertical extent contemporaneously. From the initiation 
of the solutional activity, water descends down the complete depth of the joint, and also along its entire horizontal extent. Enlargement of a solution canyon, then, is primarily through vertical solution down the walls, widening the solution canyon. The widening occurs first in the higher and perhaps less tight part of the joint. The increasing downstream width and height of a solution canyon is further related in general to the increasing downstream width and depth of the overlying re-entrant valley. Along any segment of the valley, more water is concentrated downstream on the thalweg than upstream. As the valley erodes headward, the upstream segments have been water courses for progressively shorter periods of time. Thus, underneath the downstream segments progressively more water over longer periods of time has been concentrated to seep down the major vertical joint, dissolving a deeper canyon there than beneath the upstream segments. This results in a solution canyon which is stepped downstream, and larger in width and height downstream, such as Wow Canyon. Thus, though a stepped solution canyon may appear to have been the result of ordinary canyon cutting by the small stream which may flow along its floor, the major depth and width of the solution canyon is due to the solutional activity of water seeping down its walls. In Wow Canyon there has undoubtedly been some lowering of the floor due to water flowing along it. The increased downstream width and height, however, is primarily related to the overlying valley which concentrates the water. It also may be that the original depth of the major Wow Canyon joint is shallower upstream, contributing to the lesser height of the canyon there. Black Canyon, for example, though slightly stepped upstream, is nearly uniform in height along its horizontal extent.

\section{Conclusion}

Solution canyons are major underground features formed by the solution of vertically seeping water down major joint planes. Their formation beneath the Mammoth Cave Plateau depends upon three necessary conditions: (1) A breached impermeable caprock which permits the vertical descent of water through the jointed limestone. (2) One or more major vertical joints of relatively great length and depth. (3) The presence of re-entrant valleys which concentrate surface and subsurface runoff along the thalweg parallel to the underlying major joint. Water concentrated along this line will seek the quickest course to base level, which will be the major joint. The solutional activity of water seeping relatively uniformly down such a joint results in the formation of a solution canyon. 


\section{SUMMARY}

Solution canyons are underground voids 1 to $15+$ meters wide, 3 to $45+$ meters high, and 30 to $300+$ meters long. Floors are stepped, ceilings level. Size increases downstream. Their course is sinuous, with some angularity. They occur parallel to and directly under or slightly offset from the thalwegs of re-entrant valleys tributary to major karst valleys. A section across a re-entrant and underlying solution canyon shows a rough hour-glass shape. Solution canyons are related genetically to solutional vertical shafts, forming where removal of the impermeable sandstone caprock permits the vertical descent of water through jointed limestone. Surface runoff concentrates along re-entrant thalwègs where a large quantity of water goes underground. This water, plus subsurface water flowing over the caprock breached by the valleys, follows the easiest route to baselevel down major vertical joints oriented parallel to the thalwegs. Solution by water seeping down these joint planes forms solution canyons.

\section{ZUSAMMENFASSUNG}

Lösungskanyons sind unterirdische Höhlen, 1-15 oder mehr Meter weit, 3-45 oder mehr Meter hoch und 30-300 oder mehr Meter lang. Der Boden ist gestuft, und die Decke ist eben. Die Größe erhöht sich in der Flußrichtung. Sie sind in der Längsrichtung gewunden mit einiger Scharfeckigkeit. Sie kommen vor parallel zu und direkt unter oder etwas zur Seite von Talwegen zurückführender Seitentäler, die in größere Karsttäler münden. Im Schnitt durch ein zurückführendes Tal und einen darunterliegenden Lösungskanyon führend, weisen sie die Form etwa eines Sanduhrglases auf. In ihrer Herkunft zeigen Lösungskanyons zu senkrechten Lösungsschichten Beziehungen, die geformt werden, wenn Entfernung des darüberliegenden undurchdringlichen Sandsteines den vertikalen Ablauf von Wasser durch den verbundenen Kalkstein möglich macht. Oberflächenwasser sammelt sich längs rückführender Talsohlen, wo große Mengen von Wasser in den Untergrund gehen. Dieses Wasser und auch das, das unterhalb der Oberfläche über den von Tälern durchbrochenen undurchdringlichen Sandstein fließt, folgt dem leichtesten Weg zum niedrigsten Niveau abwärts durch größere senkrechte Fugen, die parallel zu den Talsohlen verlaufen. Auflösung durch Wasser, welches durch diese Fugenebenen sickert, formt die Lösungskanyons.

\section{REFERENGES}

Merrill, G. K. (1960) - Additional notes on vertical shafts in limestone caves. Natl. Speleol. Soc. Bull. 22: 101-108.

Pонц, E. R. (1935) - Development of vertical shafts in limestone caves. Geol. Soc. America Proc. 1935: 96. (Abstract)

- (1955) - Vertical shafts in limestone caves. Natl. Speleol. Soc. Occasional Papers 2: 1-24.

Pонц, E. R., and Cushman, R. V. (1964) - Geologic features of the Mississippian plateaus in the Mammoth Cave area, Kentucky. Geol. Soc. Kentucky Guidebook 1964: 7-23.

Sмiтн, P. M. (1964) - The Flint Ridge Cave System: 1957-1962. Natl. Speleol. Soc. Bull. 26: 17-27, map. 


\title{
Underground Solution Canyons in the Central Kentucky Karst, U.S.A.
}

\author{
By Righard A. Watson ${ }^{1}$ ) \\ With 4 figures in the text
}

\section{Introduction}

Solution canyons are underground voids 1 to $15+$ meters wide, 3 to $45+$ meters high, and 30 to $300+$ meters long. Their floors are usually stepped, with the ceiling remaining at approximately one level while the overall size and height generally increases downstream (figure 1). Their courses are slightly sinuous, with some angular turns at joint intersections. They occur directly below or slightly offset from and

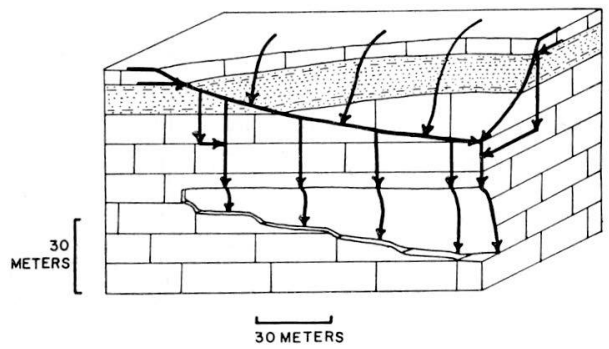

Fig. 1

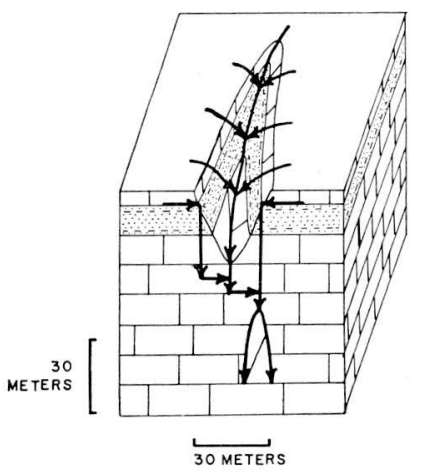

Fig. 2

Fig. 1. Idealized Block Diagram of Re-Entrant Valley and Underlying Solution Canyon: Longitudinal-Section. Arrows indicate concentration of surface and underground water flow.

Fig. 2. Idealized Block Diagram of Re-Entrant Valley and Underlying Solution Canyon: Cross-Section. Arrows indicate concentration of surface and underground water flow.

1) Cave Research Foundation: Department of Philosophy, Washington University, St. Louis, Missouri 63130, U.S.A. 
roughly parallel to the thalwegs of overlying re-entrant valleys which intersect the sandstone caprock of the ridges and are tributary to the major karst valleys. A section across a re-entrant valley and an underlying solution canyon would show a rough hour-glass shape (figure 2). The walls of solution canyons are generally vertically fluted.

\section{Habitat of the Solution Canyons}

The Central Kentucky Karst is an area of about 600 square kilometers lying on Mississippian rocks in south-central Kentucky along the edge of the Cincinnati Arch in the Interior Lowland Province, its center 160 kilometers south of Louisville. It is an integral part of a karsted limestone belt which extends from southern Indiana south through Kentucky into Tennessee along the entire west flank of the Cincinnati Arch. The Central Kentucky Karst hosts a through-flowing master karst stream, the Green River, and is composed of three major physiographic units separated by two major escarpments. In the southeast portion is the low-lying Sinkhole Plain at an average elevation of 195 meters. It is separated from the central Mammoth Cave Plateau at an average elevation of 255 meters by the northeast trending Dripping Springs Escarpment. North of the Green River which flows along the north edge of the Plateau at an elevation of 127.5 meters, the Pottsville Escarpment also trends northeast and separates the Plateau from the Hilly Country which has a maximum elevation of nearly 270 meters. Mammoth Cave National Park encloses portions of the Plateau and the Hilly Country, but unfortunately not of the Sinkhole Plain which lies in close physiographic relation.

Field investigations over the past 10 years have been made in the central part of the Mammoth Cave Plateau (figure 3). Here are found three major northwest-trending ridges - Joppa Ridge, Mammoth Cave Ridge, and Flint Ridge - with ridge-top elevations of approximately 255 meters. The ridges are over 8 kilometers long and vary in width from 0.9 to 1.4 kilometers. The surface of these mesa-like ridges dips gradually to the west. They are separated by two major karst valleys, also varying in width from 0.9 to 1.4 kilometers, with valley floor elevations from 165 to 210 meters. Eaton-Houchins Valley separates Flint Ridge from Mammoth Cave Ridge; Doyle Valley separates Mammoth Cave Ridge from Joppa Ridge. Beneath Flint Ridge is the Flint Ridge Cave System of which more than 88.5 continuous kilometers of pssages have so far been mapped (Smith, 1964). Beneath Mammoth Cave Ridge lies the famous Mammoth Cave System of 

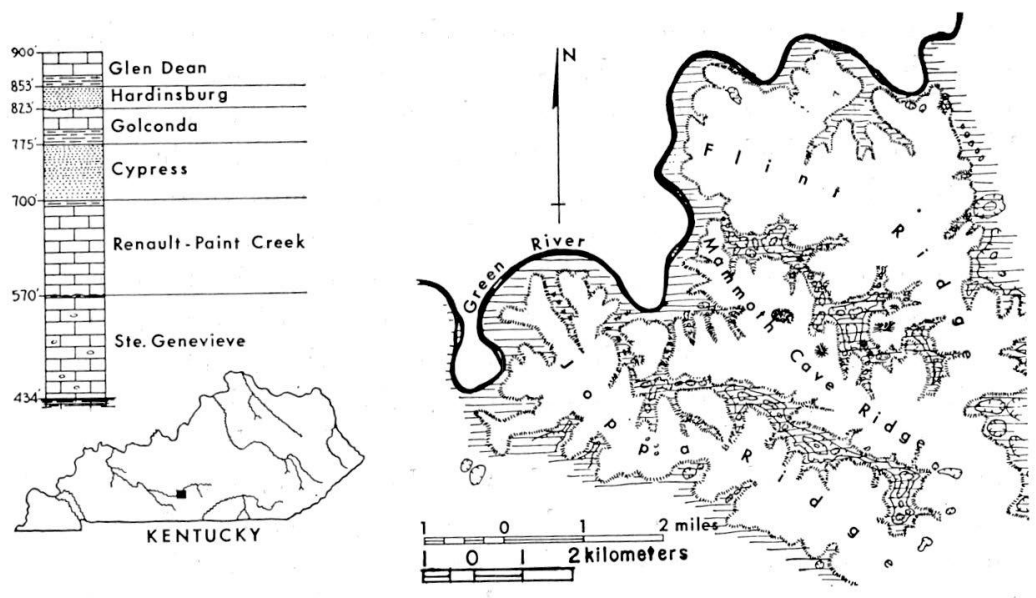

Fig. 3. The Mammoth Cave Plateau on Mississippian Rocks.

which some 72.5 continuous kilometers have been mapped. These are the two longest cave systems known on the North American continent. Recent exploration in the Flint Ridge System under Houchins Valley has penetrated to within 100 meters of passages in the Mammoth Cave System, and it is without question that the two systems will one day be joined. No extensive cave system is known to exist beneath Joppa Ridge, though geologic and physiographic relations indicate that there must be one there.

The ridges are held up by the capping Cypress Sandstone with enclosed layers of impermeable shale. This sandstone is up to 22.5 meters thick and overlies about 90 meters of cavernous Renault-Paint Creek and Ste. Genevieve Limestone (figure 3). The most recent stratigraphic study is found in Pohl and Cushman (1964). The formations dip gently to the northwest. The base of the Cypress Sandstone approximately follows the 210 meter contour, which thus is an important guideline in the interpretation of underground features. The average annual rainfall for the region is 115 to 130 centimeters, mean annual temperature is 12.2 to $13.3^{\circ} \mathrm{C}$., and the Plateau is covered with a temperate deciduous forest of oak-hickory and southern hardwoods, typical of the Interior Low Plateaus.

Throughout the cave systems, horizontal passages are intersected by solutional vertical shafts that are genetically unrelated to the passages. Vertical shafts are roofed, cylindrical voids of nearly uniform dimensions from top to bottom. They range in width from 0.9 to over 15 meters, and in height from 3 to over 45 meters. Ceilings are usually 
flat, and often contain floorless ceiling channels 10 to 30 centimeters deep. The walls of vertical shafts are usually vertically fluted. Their floors are often saucer-shaped, and all have small elliptical or canyonshaped drains which are seldom of dimensions large enough for a man to enter. Shafts sometimes form in coalescing groups, forming a void with a serrate plan. Since vertical shafts occur apart from, or indiscriminately intersecting one or more levels of horizontal cave passages, Pohl (1935, 1955; see also Merrill, 1960) has inferred that presently existing vertical shafts are younger than, and genetically unrelated to the major horizontal passages. Vertical shafts are found to occur only beneath the immediate vicinity where the impermeable sandstone caprock has been breached on the surface. Nearly 100 have been mapped, all appearing on the map near the base of the Cypress sandstone approximately along the 210 meter contour. Pohl reasoned that as subsurface water flows over the edge of the breached caprock, it finds its most immediate course to the base level down intersecting joints in the limestone. Down the line of intersection the solutional activity of vertically seeping water forms a vertical shaft.

It is certain that in some parts of the world vertical shafts are formed by waterfalls, as a cave stream finds or makes a breach so that it can move vertically from one level to another. It is probable that a few of the vertical shafts beneath the Mammoth Cave Plateau have been enlarged, if not formed, by waterfall action. As a waterfall retreats, it leaves a recessional gorge, and such canyon-like features have been identified underground in Iowa and Missouri. Features similar to recessional gorges are found beneath the Mammoth Cave Plateau. These gorge-like features seldom extend more than 30 meters horizontally. Except for one or two doubtful cases, they are seen to be the result of the intersection of several vertical shafts along a horizontal line, and not the result of the retreat of a waterfall. Much larger gorge-like solution canyons, morphologically and genetically similar to solutional vertical shafts, are the subject of the present investigation.

\section{Genesis of Solution Canyons}

It is evident that solution canyons are related genetically to solutional vertical shafts, forming where the intersection of the impermeable sandstone caprock permits the vertical descent of water through the jointed limestone. This breach in the caprock providing a vertical course for groundwater which had been flowing horizontally on top of the caprock is the first of three conditions necessary to the formation 
of solution canyons, and is one it shares with vertical shafts. Shafts form at the intersection of vertical joints, but the second condition necessary to the formation of solution canyons is not the intersection of joints, but the presence of one or more major vertical joints of relatively great length and depth. The third necessary condition is the presence of some means by which to concentrate a large quantity of water fairly uniformly along the joint. This condition is satisfied beneath the re-entrant valleys (figures 1 and 2). Surface runoff is conducted to the valley thalweg where a large quantity of water is lost underground. Ground water running off the impermeable top of the caprock is also concentrated for vertical descent along the valleywall intersections of the caprock. If a major joint is oriented near to, beneath, and roughly parallel to the thalweg of the valley (and thus also to the lines of intersection of the caprock by the two valley walls), then in seeking a vertical course to base level, water lost along the thalweg and along the lines of caprock intersection will descend fairly uniformly along the horizontal line of the vertical joint. Both surface and underground runoff is thus concentrated along a horizontal line. When an underlying major vertical joint is present to conduct this water to base level, the solutional activity of the vertically seeping water forms a solution canyon. At least 10 solution canyons are known in the Central Kentucky Karst, three of which will be described.

Penck Trail in the Flint Ridge Cave System is a series of solutional vertical shafts and solution canyons which extend for more than 300 meters under and parallel to, but offset from the thalweg of an overlying re-entrant valley (figure $4 \mathrm{a}$ ). Some of the shafts are coalesced along the horizontal line; other sections of Penck Trail have the features of solution canyons. Penck Trail, then, shows a form intermediate between a series of vertical shafts and a long solution canyon.

Black Canyon is a typical solution canyon in the Flint Ridge Cave System (figure 4b). Nearly 300 meters long and over 25 meters high with widths up to 12 meters, Black Canyon extends parallel to and directly below the thalweg of the overlying re-entrant valley. Along the same line downstream, and integrally connected to the solution canyon, is found the Overlook solutional vertical shaft complex. Thus, beneath the same re-entrant thalweg overlying slightly different joint conditions, a major solution canyon coalesces with a series of vertical shafts.

One of the longest solution canyons yet discovered in the Flint Ridge Cave System, Wow Canyon, is also intimately related to solutional vertical shafts (figure $4 \mathrm{c}$ ). Shaft complexes occur near both of its ends. This solution canyon runs for nearly 300 meters beneath the 


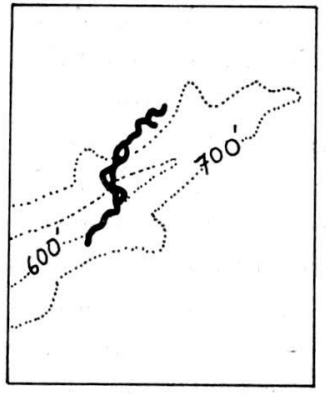

a.

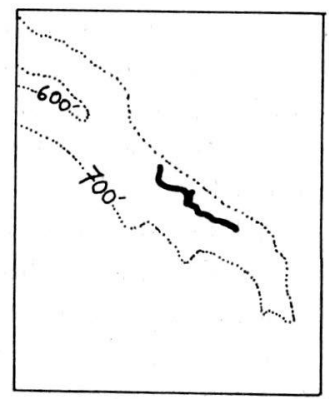

b.

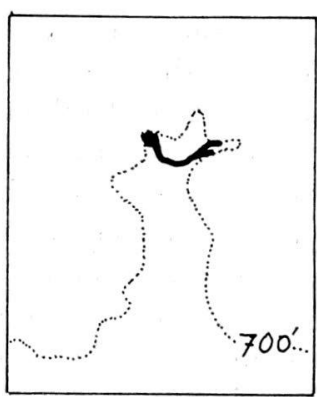

c.

\section{ME TERS}

Fig. 4. Maps of Solution Canyons and Solutional Vertical Shaft Series. (Traced from the map of the Flint Ridge Cave System, Smith, 1964.) a. Penck Trail. b. Black Canyon. c. Wow Canyon.

thalweg of the overlying re-entrant valley. At the upper end, the canyon averages 1.5 to 2 meters in width and 3 to 4.5 meters in height. The ceiling stays at the same level as the floor drops down a number of steps downstream, until at the lower end the canyon is 4.5 meters wide and over 25 meters high. An idealized longitudinal section illustrative of these relations is given in figure 1. It should be noted that the diagram is somewhat deceptive, since neither the thalweg nor the joint plane is straight. The sinuous course of solution canyons is a result of the sinuosity of major joint planes, both along their horizontal and their vertical extents. Wow Canyon makes several angular turns, suggesting that in such long solution canyons, not one, but several similarly oriented major joints provide vertical water courses leading to the formation of the solution canyon.

Solution canyons, like solutional vertical shafts, can form only where there is a major vertical descent of water. Thus, both of these vertical features are concentrated beneath the edges of the ridges where the impermeable caprock is breached. Beneath the ridges under the caprock, vertical features are rare because there is no great concentration of water at high levels there seeking descent to base level. Beneath the major karst valleys there are also few major vertical features, since besides lacking means for concentration, the water is already near base level.

Like solutional vertical shafts, which enlarge vertically as well as horizontally as they evolve, solution canyons form by solution down their complete vertical extent contemporaneously. From the initiation 
of the solutional activity, water descends down the complete depth of the joint, and also along its entire horizontal extent. Enlargement of a solution canyon, then, is primarily through vertical solution down the walls, widening the solution canyon. The widening occurs first in the higher and perhaps less tight part of the joint. The increasing downstream width and height of a solution canyon is further related in general to the increasing downstream width and depth of the overlying re-entrant valley. Along any segment of the valley, more water is concentrated downstream on the thalweg than upstream. As the valley erodes headward, the upstream segments have been water courses for progressively shorter periods of time. Thus, underneath the downstream segments progressively more water over longer periods of time has been concentrated to seep down the major vertical joint, dissolving a deeper canyon there than beneath the upstream segments. This results in a solution canyon which is stepped downstream, and larger in width and height downstream, such as Wow Canyon. Thus, though a stepped solution canyon may appear to have been the result of ordinary canyon cutting by the small stream which may flow along its floor, the major depth and width of the solution canyon is due to the solutional activity of water seeping down its walls. In Wow Canyon there has undoubtedly been some lowering of the floor due to water flowing along it. The increased downstream width and height, however, is primarily related to the overlying valley which concentrates the water. It also may be that the original depth of the major Wow Canyon joint is shallower upstream, contributing to the lesser height of the canyon there. Black Canyon, for example, though slightly stepped upstream, is nearly uniform in height along its horizontal extent.

\section{Conclusion}

Solution canyons are major underground features formed by the solution of vertically seeping water down major joint planes. Their formation beneath the Mammoth Cave Plateau depends upon three necessary conditions: (1) A breached impermeable caprock which permits the vertical descent of water through the jointed limestone. (2) One or more major vertical joints of relatively great length and depth. (3) The presence of re-entrant valleys which concentrate surface and subsurface runoff along the thalweg parallel to the underlying major joint. Water concentrated along this line will seek the quickest course to base level, which will be the major joint. The solutional activity of water seeping relatively uniformly down such a joint results in the formation of a solution canyon. 


\section{SUMMARY}

Solution canyons are underground voids 1 to $15+$ meters wide, 3 to $45+$ meters high, and 30 to $300+$ meters long. Floors are stepped, ceilings level. Size increases downstream. Their course is sinuous, with some angularity. They occur parallel to and directly under or slightly offset from the thalwegs of re-entrant valleys tributary to major karst valleys. A section across a re-entrant and underlying solution canyon shows a rough hour-glass shape. Solution canyons are related genetically to solutional vertical shafts, forming where removal of the impermeable sandstone caprock permits the vertical descent of water through jointed limestone. Surface runoff concentrates along re-entrant thalwegs where a large quantity of water goes underground. This water, plus subsurface water flowing over the caprock breached by the valleys, follows the easiest route to baselevel down major vertical joints oriented parallel to the thalwegs. Solution by water seeping down these joint planes forms solution canyons.

\section{ZUSAMMENFASSUNG}

Lösungskanyons sind unterirdische Höhlen, 1-15 oder mehr Meter weit, 3-45 oder mehr Meter hoch und 30-300 oder mehr Meter lang. Der Boden ist gestuft, und die Decke ist eben. Die Größe erhöht sich in der Flußrichtung. Sie sind in der Längsrichtung gewunden mit einiger Scharfeckigkeit. Sie kommen vor parallel zu und direkt unter oder etwas zur Seite von Talwegen zurückführender Seitentäler, die in größere Karsttäler münden. Im Schnitt durch ein zurückführendes Tal und einen darunterliegenden Lösungskanyon führend, weisen sie die Form etwa eines Sanduhrglases auf. In ihrer Herkunft zeigen Lösungskanyons zu senkrechten Lösungsschichten Beziehungen, die geformt werden, wenn Entfernung des darüberliegenden undurchdringlichen Sandsteines den vertikalen Ablauf von Wasser durch den verbundenen Kalkstein möglich macht. Oberflächenwasser sammelt sich längs rückführender Talsohlen, wo große Mengen von Wasser in den Untergrund gehen. Dieses Wasser und auch das, das unterhalb der Oberfläche über den von Tälern durchbrochenen undurchdringlichen Sandstein fließt, folgt dem leichtesten Weg zum niedrigsten Niveau abwärts durch größere senkrechte Fugen, die parallel zu den Talsohlen verlaufen. Auflösung durch Wasser, welches durch diese Fugenebenen sickert, formt die Lösungskanyons.

\section{REFERENCES}

Merrill, G. K. (1960) - Additional notes on vertical shafts in limestone caves. Natl. Speleol. Soc. Bull. 22: 101-108.

Pонц, E. R. (1935) - Development of vertical shafts in limestone caves. Geol. Soc. America Proc. 1935: 96. (Abstract)

- (1955) - Vertical shafts in limestone caves. Natl. Speleol. Soc. Occasional Papers 2: 1-24.

Pohl, E. R., and Cushman, R. V. (1964) - Geologic features of the Mississippian plateaus in the Mammoth Cave area, Kentucky. Geol. Soc. Kentucky Guidebook 1964: 7-23.

Sмгтн, P. M. (1964) - The Flint Ridge Cave System: 1957-1962. Natl. Speleol. Soc. Bull. 26: 17-27, map. 


\title{
Die Lampen-Moosflora der Beatushöhle und deren Vergleich mit anderen europäischen Höhlen
}

\author{
Von R. BERnASGONI ${ }^{1}$
}

\section{Frühere Arbeiten über die Lampen-Moosflora der Beatushöhle}

Der Raum um elektrische Glühbirnen in Schauhöhlen stellt einen besonderen Biotop für eine spezielle Florula dar (Vogellehner 1963b). Bereits 1904 wurde die Beatushöhle am Thunersee mit elektrischer Beleuchtung ausgerüstet (Stammler 1904), und 1924 berichtet Lüdy als erster über ihre Lampen-Florula, wobei er eine Farnart, eine Algenart sowie 8 Moosarten erwähnt. Es sind dies: Bryum sp.; Encalypta contorta Wulf.; Eurynchium schwartzi Turn. f. schistostegioides Gams; Fissidens decipiens DeNot; Hymenosytilium curvirostre Ehrb.; Isopterygium depressum Br. f. cavernarum Gams; Tortella tortuosa L. f. tenuis; Tortula muralis L. (Lüdy 1904; Morton, Gams 1925).

Die anatomischen Veränderungen dieser Höhlenmoose der Beatushöhle untersuchte Elise Hofmann (in: Morton 1927); sie fand dabei regelmäßige Reduktion der Beblätterung, der Blattzähnchen, des assimilierenden Gewebes, ferner eine Verlängerung des Stämmchens; dies alles wurde als Ökonomieprinzip gedeutet. Im folgenden sind diese Untersuchungen an 5 Beatushöhlenmoosen tabellarisch zusammengestellt und mit Normalformen verglichen.

Tabelle 1

Anatomische Veränderungen der Beatushöhlenmoose

\begin{tabular}{lcccc}
\hline Art & $\begin{array}{c}\text { Stämmchen- } \\
\text { querschnitt } \\
\mu\end{array}$ & $\begin{array}{c}\text { Länge } \times \text { Breite } \\
\text { der Epidermiszellen } \\
\mu\end{array}$ & Blattdicke & Rippendicke \\
\hline Tortula muralis & & & $\mu$ & $\mu$ \\
Höhlenform & 49 & $19 \times 9,8$ & 29 & 66 \\
Normalform & 52 & $33 \times 16,9$ & 32 & 70
\end{tabular}

1) Société Suisse de Spéléologie, Bern, Mergartenstr. 13, Suisse. 
Tabelle 1 (Fortsetzung)

\begin{tabular}{lcccc}
\hline Art & $\begin{array}{c}\text { Stämmchen- } \\
\text { querschnitt }\end{array}$ & $\begin{array}{c}\text { Länge } \times \text { Breite } \\
\text { der Epidermiszellen }\end{array}$ & Blattdicke & Rippendicke \\
\end{tabular}

\begin{tabular}{|c|c|c|c|c|}
\hline & $\mu$ & $\mu$ & $\mu$ & $\mu$ \\
\hline \multicolumn{5}{|c|}{ Tortella tortuosa } \\
\hline Höhlenform & 166 & $33 \times 9,8$ & 11 & 33 \\
\hline Normalform & 166 & $49 \times 8,6$ & 16 & 83 \\
\hline \multicolumn{5}{|c|}{ Encalypta contorta } \\
\hline Höhlenform & 247 & $33 \times 16,0$ & 23 & 71 \\
\hline Normalform & 249 & $33 \times 13,8$ & 24 & 61 \\
\hline \multicolumn{5}{|c|}{ Eurynchium schswartzi f. schistostegoides } \\
\hline Höhlenform & 132 & $74 \times 16,0$ & 16 & 43 \\
\hline Normalform & 265 & $91 \times 8,0$ & 9 & 41 \\
\hline \multicolumn{5}{|c|}{ Isopterygium depressum } \\
\hline Höhlenform & 182 & $66 \times 6,0$ & 13 & 13 \\
\hline Normalform & 265 & $96 \times 16,0$ & 16 & 16 \\
\hline
\end{tabular}

\section{Eigene Untersuchungen}

\subsection{Die untersuchten Fundorte}

Der touristisch ausgebaute Teil der Beatushöhle beträgt etwa $700 \mathrm{~m}$ und ist mit zahlreichen Lampen und Scheinwerfern ausgerüstet. Nicht jede Lampenumgebung besitzt eine gleichreiche Florula, einige weisen nur eine spärliche Algenflorula auf. Man beschränkte sich schließlich auf folgende 8 Fundorte, die besonders interessante oder reichhaltige Moosrasen aufwiesen. Von jedem Fundort bestimmte man die Temperatur, die relative Feuchtigkeit und die Beleuchtungsstärke. Zur Messung der Temperatur und der relativen Feuchtigkeit benützte man ein Psychrometer, zur Messung der Beleuchtungsstärke ein Luxmeter. Die Werte beziehen sich auf das Zentrum des Rasens.

Tabelle 2

Die untersuchten Fundorte

\begin{tabular}{|c|c|c|c|c|c|}
\hline & $\begin{array}{c}\text { Entfer- } \\
\text { nung vom } \\
\text { Eingang } \\
\text { m }\end{array}$ & $\begin{array}{l}\text { Lampe } \\
\text { W }\end{array}$ & $\begin{array}{c}\text { Tempe- } \\
\text { ratur } \\
\mathrm{G}^{\circ} \\
\end{array}$ & $\begin{array}{c}\text { Relative } \\
\text { Feuch- } \\
\text { tigkeit } \\
\% \\
\%\end{array}$ & $\begin{array}{c}\text { Beleuch- } \\
\text { tungs- } \\
\text { stärke } \\
\text { (Lux) }\end{array}$ \\
\hline Erste Quelle & 60 & 200 & 9,6 & 92 & 1100 \\
\hline Unterhalb steiler Treppe & 175 & 100 & 9,0 & 94 & 400 \\
\hline Beim alten Schalter & 195 & 60 & 10,2 & 95 & 360 \\
\hline Drei Schwestern (Gang) & 255 & 60 & 10,2 & 95 & $80-120$ \\
\hline Drei Schwestern (See) & 260 & 200 & 10,2 & 95 & 1100 \\
\hline Schlangengrotte & 675 & 150 & 11,8 & 87 & $<20-80$ \\
\hline Hexenkessel & 680 & 150 & 9,0 & 93 & 5000 \\
\hline Hades (Elephanten) & 685 & 60 & 9,0 & 93 & 7000 \\
\hline
\end{tabular}




\subsection{Die Moosflorula}

Die gesammelten Moose gelangten im frischen Zustand zur Bestimmung. Diese verdanke ich Herrn Dr. Ochsner, Muri AG.

Tabelle 3

Die gesammelten Moose

\begin{tabular}{ll}
\hline Fundort & Art \\
\hline Erste Quelle & Fissidens taxifolius f. cavernarum \\
Unterhalb steiler Treppe & Brachytecium salebrosum \\
& Eurynchium rusciforme \\
Beim alten Schalter & Eucladium verticillatum \\
Drei Schwestern (Gang) & Eucladium verticillatum f. cavernarum \\
Drei Schwestern (See) & Eucladium verticillatum f. tenuis \\
Schlangengrotte & Pohlia cruda \\
& Pellia epiphylla \\
Hexenkessel & Amblystegium juratzkanum \\
& Cratoneurum commutatum f. tenuis \\
& Eurynchium praelongum f. cavernarum \\
& Eurynchium praelongum typ. \\
& Bryum capillare \\
Hades (Elephanten) & Rhynchostegium murale \\
& Mniobrium albicans \\
& Fissidens taxifolius \\
& Eurynchium praelongum typ. \\
& Cratoneurum commutatum f. cavernarum
\end{tabular}

2.3. Einfluß des Höhlenklimas auf die Moosflorula

\subsubsection{Licht}

Das Lichtbedürfnis der Höhlenmoose ist meistens sehr gering (Morton, Gams 1925). Nach neueren Messungen (Vogellehner 1963a) dürfte eine Beleuchtungsstärke von 40 Lux die unterste Grenze für Moose sein; darunter wachsen nur noch Algen. Dieser Wert gilt z. B. für Fissidens taxifolius; bei anderen Arten (Eurynchium schwartzi, Cratoneurum commutatum) liegt sie bei 400 Lux. Vergleiche der Lichtmengen, welche den Moosen zur Verfügung stehen, zeigen zwischen einem extrem schattigen Außenstandort und einem optimalen Höhlenstandort praktisch keinen Unterschied: für Fissidens taxifolius wurden somit an diesen beiden Standorten rund 5 Kiloluxstunden gefunden. Die Beleuchtungsstärke um die Lampen nimmt mit zunehmender Entfernung von der Lampe nach folgendem Gesetz rasch $\mathrm{ab}$ :

$$
\text { Beleuchtungsstärke (Lux) }=\frac{\text { Lichtstärke (Lumen) }}{\text { Quadrat des Abstandes }\left(\mathrm{m}^{2}\right)}
$$


Die Lichtabnahme bewirkt entweder rhizoides Wachstum oder Umwandlung zu Höhlenformen und schließlich das totale Einstellen des Wachstums.

Der Bestand von Pohlia cruda weist z. B. nahe der Lampe einen grünen Gürtel, bei größerer Entfernung einen rhizoiden braunen Gürtel auf. Es wurden folgende Werte gemessen:

$$
\text { Tabelle } 4
$$

Der Moosbestand von Pohlia cruda

\begin{tabular}{lcc}
\hline Aussehen des Rasens & $\begin{array}{c}\text { Entfernung } \\
\text { von der Lampe } \\
\text { cm }\end{array}$ & $\begin{array}{c}\text { Beleuchtungs- } \\
\text { stärke } \\
\text { (Lux) }\end{array}$ \\
\hline Beginn des grünen Rasens & 20 & 3400 \\
Ende des grünen Rasens, & & \\
Beginn des rhizoiden Rasens & 50 & 1800 \\
Ende des rhizoiden Rasens & 150 & 140
\end{tabular}

Bei anderen Arten bilden sich bei abnehmender Beleuchtungsstärke Schatten- und schließlich Höhlenformen (Scialo- und Kryptomorphosen). So soll z. B. Isopterygium depressum bei $1 / 200$ bis ${ }^{1} / 300$ der Tageslichtintensität in seine f. cavernarum übergehen (Morton, Gams 1925).

Bei 3 Moosarten fanden wir folgende Reduzierungen:

Tabelle 5

Höhlenformen und Beleuchtungsstärken bei 3 Moosarten

\begin{tabular}{lrl}
\hline \multicolumn{1}{c}{ Moosart } & $\begin{array}{c}\text { Beleuch- } \\
\text { tungs- } \\
\text { stärke } \\
\text { (Lux) }\end{array}$ & \multicolumn{1}{c}{ Fundort } \\
\hline Eurynchium praelongum f. typ. & 7000 & Hades \\
& 5000 & Hexenkessel \\
Eurynchium praelongum f. cavernarum & 80 & Schlangengrotte \\
Cratoneurum commutatum f. cavernarum & 7000 & Hades \\
Cratoneurum commutatum f. tenuis & $<20$ & Schlangengrotte \\
Eucladium verticillatum f. typ. & 400 & unterhalb steiler Treppe \\
Eucladium verticillatum f. tenuis & 80 & Drei Schwestern \\
Eucladium verticillatum f. cavernarum & 120 & Drei Schwestern
\end{tabular}

Bei fast allen Moosarten, besonders aber bei Fissidens taxifolius, ist ein deutlicher Phototropismus festzustellen. Fissidens taxifolius (erste Quelle; Hexenkessel) richtet seine zweizeilig in einer Ebene liegenden Blättchen senkrecht gegen das Licht. Ein ebenfalls gegen das Licht 
gerichtetes Wachstum ist deutlich bei Eucladium verticillatum, Eurynchium schwartzi und Pohlia cruda zu beobachten. Das Wachstum von Amblystegium juratzkanum ist demgegenüber nicht phototropisch gerichtet.

\subsubsection{Temperatur}

Die Temperatur um die Lampen nimmt mit abnehmender Distanz zu. Bei Lampen mit 100-200 W ändert sich die Temperatur bei einer Entfernung von $20 \mathrm{~cm}$ kaum mehr; deshalb beginnt auch das Wachstum der Moosbestände in einer Entfernung von $20-30 \mathrm{~cm}$ von der Lampe. Beim Moosbestand von Pohlia cruda $(200 \mathrm{~W})$ wurden folgende Werte gemessen:

Tabelle 6

Der Moosbestand von Pohlia cruda

\begin{tabular}{ccc}
\hline Aussehen des Rasens & $\begin{array}{c}\text { Entfernung } \\
\text { von der Lampe } \\
\text { cm }\end{array}$ & $\begin{array}{c}\text { Temperatur } \\
\text { S })\end{array}$ \\
\hline Sterile Zone & 2,5 & 18,0 \\
& 5,0 & 15,2 \\
Beginn des grünen Rasens & 10,0 & 12,2 \\
& 15,0 & 10,1 \\
& 20,0 & 9,2 \\
& 30,0 & 9,0
\end{tabular}

\subsubsection{Feuchtigkeit}

Die relative Luftfeuchtigkeit beträgt bei den untersuchten Stellen 87-95\%. Änderungen durch das Heißwerden der Lampen konnten nicht festgestellt werden. Die hohe Luftfeuchtigkeit hat höchstens einen günstigen Einfluß auf das Mooswachstum.

\subsubsection{Substrat}

Sämtliche beobachteten Moosrasen wuchsen auf Höhlenlehm oder aus Felsspalten, die ebenfalls etwas Höhlenlehm enthielten.

\subsubsection{Fruchtkörperbildung}

Alle beobachteten Moose der Beatushöhle waren steril. Fruchtende Höhlenmoose sind übrigens nicht häufig beschrieben worden: so z. B. Amblystegium juratzkanum (Coûteau 1956; Koppe 1961); Seligeria doniana (Vogellehner 1963a); Cratoneurum commutatum (Vogellehner 1963a); Brachytecium velutinum (Koppe 1961); Leptobryum pyriforme (Boros 1964).

\footnotetext{
1) Gemessen $2 \mathrm{~cm}$ über dem Boden.
} 


\subsection{Charakterisierung der eingedrungenen Beatushöhlenmoose}

Unterteilt man die von Lüdy (1924) und von uns in der Beatushöhle gesammelten Moose in calcophile (kalkliebende), gesteinsindifferente, hygrophile (feuchtigkeitsliebende) und scialophile (schattenliebende), erhält man folgende prozentualen Zahlen (17 Arten):

\section{Tabelle 7}

Charakterisierung der Beatushöhlenmoose

\begin{tabular}{|c|c|c|}
\hline Substrat & calc & 6 Arten $=$ \\
\hline & gesteinsindifferente Moose & 11 Arten $=65 \%$ \\
\hline Klima: & $\begin{array}{l}\text { hygrophile Moose } \\
\text { scialophile Moose }\end{array}$ & $\begin{aligned} 10 \text { Arten } & =59 \% \\
4 \text { Arten } & =23 \%\end{aligned}$ \\
\hline
\end{tabular}

Es ist auffallend, daß sich die Höhlenmoosflorula aus Arten zusammensetzt, die zur Hauptsache gesteinsindifferent und hygrophil sind. Somit ist in erster Linie die hohe Luftfeuchtigkeit der Höhle der maßgebende Faktor, der die Zusammensetzung und Selektion der Höhlenmoosflorula bestimmt.

Sehr übereinstimmende Resultate haben wir beim Vergleich anderer bis heute bekannten europäischen Höhlenmoosfloren erhalten.

\section{Zusammenstellung der bis heute bekannten Lampen-Moosfloren europäischer Schauhöhlen}

3.1. Qualitative Zusammensetzung der Lampen-Moosflora aus 19 Schauhöhlen Europas

Es wurden folgende 19 Höhlen berücksichtigt:

1. Beatushöhle (Schweiz)

2. Grotte de Han (Belgien)

3. Charlottenhöhle (Schwäbische Alb)

\section{Alb (Deutschland)}

5. Recken- und Deckenhöhle (Westfalen)

6. Punkva- und Jaskine-Slobody-Höhlen (Tschechoslowakei)

7. Abaligeter-Höhle und weitere 3 Höhlen aus Ungarn
(Lüdy 1924;

eigene Resultate)

(Coûteaux 1956;

Duvigneaud 1939)

(Mahler 1960)

(Vogellehner

1963a)

(Koppe 1961)

(Boros 1964)

(Boros 1964) 
Tabelle 8

Die Lampen-Moosflorula von europäischen Höhlen

(Die Numerierung entspricht der obigen Höhlenliste)

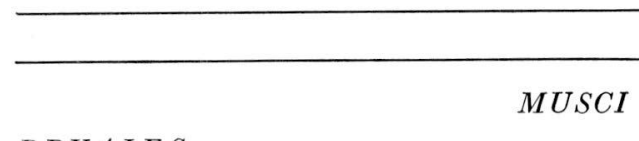

BRYALES

STEGOCARPI

\section{Weisiaceae}

Eucladium verticillatum Br. Eur.

Weisia (= Hymenostylium) microstomum Mül.

Weisia rutilans Lindb.

Hymenostylium curvirostre Lindb.

Gymnostomum rupestre Schleich.

Fissidentaceae

Fissidens taxifolius Hedw.

Fissidens cristatus Wils. ( $F$ F. decipiens DeNot)

Fissidens bryoides Hedw.

Fissidens pusillus Wils.

Fissidens exilis Hedw.

Seligeriaceae

Seligeria doniana G. Müll.

Pottiaceae

Tortella tortuosa Limpr.

Pottia truncatula Lindb.

Trichostomum mutabile Bruch.

Tortula muralis Hedw.

Barbula cylindrica (Tayl.) Schimp.

Barbula glauca (Ryan) Möll.

Barbula rigidula (Hedw.) Mitt.

\section{Encalyptaceae}

Encalypta contorta Lind. (= E. streptocarpa Hedw.)

\section{Bryaceae}

Bryum sp.

Bryum capillare L.

Bryoerythrophyllum recuroirostrum Chen.

Leptobryum pyriforme Schimp.

Mniobryum albicans Limpr.

Pohlia cruda Lindb. (=Webera cruda Bruch)

\section{Mniaceae}

Mnium punctatum Hedw.

Mnium affine Bland.

Mnium stellare Reich

Mnium subglobosum Br. Eur. (= M. pseudopunctatum Bruch. \& Schimp.)

\section{Thamniaceae}

Thamnium alopecurum Br. Eur.

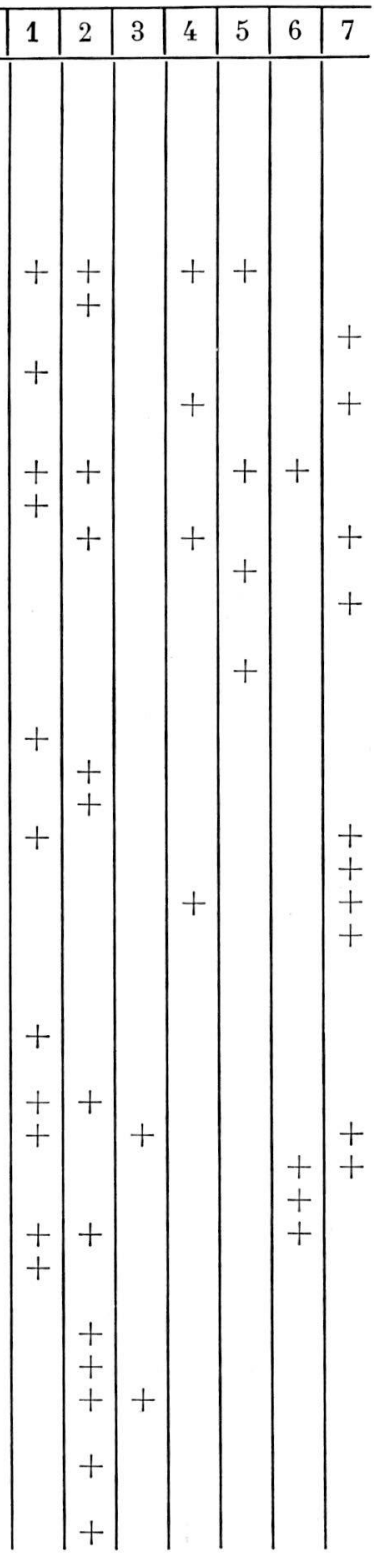


Tabelle 8 (Fortsetzung)

\begin{tabular}{|c|c|c|c|c|c|c|c|}
\hline & 1 & 2 & 3 & 4 & 5 & 6 & 7 \\
\hline CLE ISTOCAR P I & & & & & & & \\
\hline Phascaceae & & & & & & & \\
\hline Phascum acaulon L. (= Ph. cuspidatum Schreb.) & & & + & & & & \\
\hline PLE UROCARPI & & & & & & & \\
\hline Neckeraceae & & & & & & & \\
\hline Neckera complanata Hüben. & & & + & & & & \\
\hline Leskeaceae & & & & & & & \\
\hline Anomodon longifolius Bruch. & & & & + & & & \\
\hline Amblystegiaceae & & & & & & & \\
\hline Amblystegium juratzkanum Schimp. & + & + & & + & & & \\
\hline Amblystegium varium Lindb. & & + & & + & & + & \\
\hline Amblystegium serpens Br. Eur. & & & & + & & & + \\
\hline Amblystegium sprucei Br. Eur. & & & & + & & & \\
\hline $\begin{array}{l}\text { Chrysohypnum (= Campylium) sommerfeldti Roth } \\
\text { Brachyteciaceae }\end{array}$ & & + & & + & & & \\
\hline Brachytecium salebrosum Br.Eur. & + & & & & & & \\
\hline Brachytecium velutinum Br. Eur. & & & + & + & & & \\
\hline Brachytecium rivulare Br. Eur. & & & + & & & & \\
\hline Brachytecium rutabulum Br. Eur. & & & + & & & & \\
\hline Rhyncostegium murale Br. Eur. & + & + & & + & & & \\
\hline $\begin{array}{l}\text { Rhyncostegiella algiriana Broth. (= Rhynco- } \\
\text { stegium tenellum Br. Eur.) }\end{array}$ & & & & + & & & \\
\hline Eurynchium schwartzi Hobkirch (=E. prae- & & & & & & & \\
\hline $\begin{array}{l}\text { longum Auct.) } \\
\text { Eurunchium stockesi Br Eur }\end{array}$ & + & + & & & + & & \\
\hline Eurynchium rusciforme Milde (= Rhyncostegium & & + & & & & & \\
\hline rusciforme [Neck.] B. S.) & + & & & & & & \\
\hline Plagiotheciaceae & & & & & & & \\
\hline Plagiothecium (Taxiphyllum) depressum Dix. & + & + & & + & & & + \\
\hline Hypnaceae & & & & & & & \\
\hline Ctenidium molluscum Mitten. & & & + & & & & \\
\hline HEPATICAE & & & & & & & \\
\hline$J U N G E R M A N N A L E S$ & & & & & & & \\
\hline Haplolaeneae & & & & & & & \\
\hline Pellia fabbroniana Raddi ( = P. calycina N.v.E.) & & & & & & & + \\
\hline Pellia epiphylla Lindb. & + & & & & & & \\
\hline Pellia sp. & & + & & & & & \\
\hline Epigoniantheae & & & & & & & \\
\hline Lophozia sp. & & + & & & & & \\
\hline Metzgeriaceae & & & & & & & \\
\hline Metzgera sp. & & + & & & & & \\
\hline
\end{tabular}

\section{2. Ökologie der Höhlenmoose}

Folgende Tab. 9 beruht auf Angaben von Burck (1947) und von Lorch (1913). Man berücksichtigt Substrat und klimatologische Faktoren. 
Tabelle 9

Ökologie der Höhlenmoose

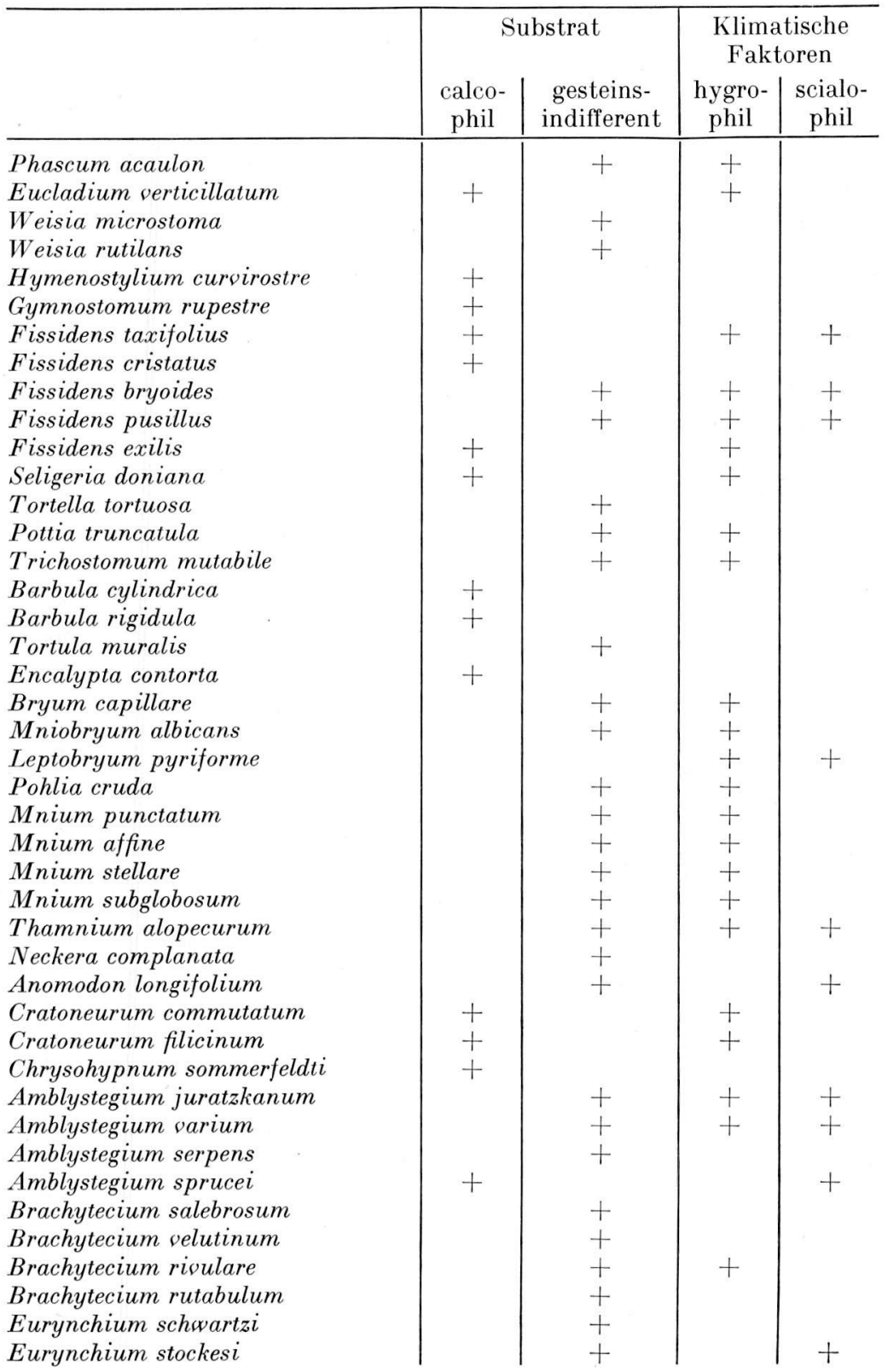


Tabelle 9 (Fortsetzung)

\begin{tabular}{|c|c|c|c|c|}
\hline & \multicolumn{2}{|c|}{ Substrat } & \multicolumn{2}{|c|}{$\begin{array}{c}\text { Klimatische } \\
\text { Faktoren }\end{array}$} \\
\hline & $\begin{array}{l}\text { calco- } \\
\text { phil }\end{array}$ & $\begin{array}{l}\text { gesteins- } \\
\text { indifferent }\end{array}$ & $\begin{array}{l}\text { hygro- } \\
\text { phil }\end{array}$ & $\begin{array}{l}\text { scialo- } \\
\text { phil }\end{array}$ \\
\hline $\begin{array}{l}\text { Eurynchium rusciforme } \\
\text { Rhyncostegium murale } \\
\text { Rhyncostegiella algiriana } \\
\text { Plagiothecium depressum } \\
\text { Ctenidium molluscum }\end{array}$ & + & $\begin{array}{l}+ \\
+ \\
+\end{array}$ & $\begin{array}{l}+ \\
+ \\
+ \\
+\end{array}$ & $\begin{array}{l}+ \\
+\end{array}$ \\
\hline
\end{tabular}

Der prozentuale Anteil der vier ökologischen Gruppen (48 Arten) ist:

\author{
Calcophile Arten \\ Gesteinsindifferente Arten \\ Hygrophile Arten \\ Scialophile Arten
}

$$
\begin{aligned}
& 16 \text { Arten }=33 \% \\
& 31 \text { Arten }=62 \% \\
& 27 \text { Arten }=56 \% \\
& 13 \text { Arten }=27 \%
\end{aligned}
$$

Wie dies für die Moosflorula der Beatushöhle festgestellt wurde, besteht der größte Anteil der Höhlen-Lampen-Moosflora aus gesteinsindifferenten und hygrophilen Arten; calcophile und scialophile Moose sind bedeutend schwächer vertreten.

\subsection{Die typischen Vertreter der Höhlen- Lampen-Moosflorula}

Neben vereinzelten Funden kommen gewisse Moosarten mit einer solchen Häufigkeit und Konstanz vor, daß man sie als typische Vertreter des Lampen-Biotops bezeichnen kann. Es handelt sich um folgende 10 Arten, die mindestens aus 3 der 7 Höhlen bzw. Höhlengruppen erwähnt wurden (vgl. Tab. 8).

Tabelle 10

Die typischen Höhlenmoose des Lampen-Biotops

Eucladium verticillatum

Fissidens taxifolius

Fissidens bryoides

Mniobryum albicans

Mnium capillare
Eurynchium schwartzi Rhyncostegium murale Plagiothecium depressum Amblystegium juratzkanum Amblystegium varium 
Die ökologische Verteilung dieser typischen Höhlenmoose ist folgende:

\section{Tabelle 11}

Ökologische Verteilung der typischen Höhlenmoose des Lampen-Biotops

Calcophile Arten
Gesteinsindifferente Arten
Hygrophile Arten
Scialophile Arten

Calcophile Arten

Hygrophile Arten
2 Arten $=20 \%$
8 Arten $=80 \%$
9 Arten $=90 \%$
6 Arten $=60 \%$

Somit lassen sich die typischen Höhlenmoose des Lampen-Biotops als hygrophile und gesteinsindifferente Arten charakterisieren.

\section{ZUSAMMENFASSUNG}

Es wird über die Lampen-Moosflora der Beatushöhle berichtet (Tab. 3). Ein statistischer Vergleich mit Lampen-Moosfloren aus 18 anderen europäischen Höhlen zeigt, daß die Zusammensetzung und die Selektion der Lampen-Moosflora überwiegend durch Hygrophilie und Gesteinsindifferenz bedingt sind (Tab. 9). 10 Arten können als typische Vertreter der LampenMoosflora bezeichnet werden.

\section{RÉSUMÉ}

On analyse la florule bryologique des lampes de la grotte St. Béat (Tab.3). Une comparaison statistique des florules des lampes d'autres 18 grottes européennes montre que la composition et la séléction de ces florules sont détérminées principalement par l'hygrophilie et l'indifférence au substrat (Tab. 9). 10 espèces peuvent être définies comme représentants typiques de la florule bryologique des lampes de grotte aménagées (Tab. 10).

\section{Nachtrag}

Weitere Angaben über die Lampen-Moosflora finden sich in: K. VERSeghy: Die Pflanzenwelt der Höhlen bei Lillafüred, Int. J. Spel. (1965) 1 (4), 553-560.

Es wurden aus den Forras- und Istvàn-Höhlen folgende Moosarten gesammelt:

Eucladium verticillatum Br. Eur. und seine var. angustifolia, Gymnostomum rupestre Schleich. und seine fa. ramosissima, Fissidens taxifolius Hedw. und minutulus Sull., Tortula muralis Hedw. und seine var. aestisa Brid., Barbula fallax Hedw. und unguiculata Hedw., Bryum caespiticium L., Bryoerythrophyllum recurvirostrum Chen., 
Pohlia sp.,

Funaria hygrometrica Sibth.,

Amblystegium riparium Br. Eur. und serpens Br. Eur.,

Brachytecium velutinum Br. Eur.,

Rhyncostegium murale Br. Eur.,

Eurynchium schwartzi Hobkirch,

Pellia fabbroniana Raddi.

\section{TERAT UR}

Boros, A. (1964) - Über die Moose, die unter dem Einfluß der elektrischen Beleuchtung in das Innere der Höhlen in Ungarn und in der Tschechoslowakei eindringen. Internat. J. Spel. $1(1-2)$ : 45-46.

Burck, O. (1947) - Die Laubmoose Mitteleuropas. Abhdlg. Senckenberg. Nat.forsch. Ges. (477): 5-198.

Coûteaux, M. (1956) - Le milieu de la flore et de la végétation des grottes de Han. Rass. spel. ital. 8 (3-4): 155-182.

Duvigneaud, P. - Les populations végétales des grottes de Han. Ass. franç. pour l'avancement des sciences, $63^{\mathrm{e}}$ session, 939-944. Liège.

Koppe, F. (1961) - Niedere Kryptogamen und Moose in sauerländischen Höhlen. Jhft. Karst- und Höhlenkunde (2) : 245-259.

Lorсн, W. (1913) - Die Laubmoose. In: G. Lindau: Kryptogamenflora für Anfänger, Bd. 5. Berlin.

- (1914) - Die Torf- und Lebermoose. In: G. Lindau: Kryptogamenflora für Anfänger, Bd. 6. Berlin.

LÜDy, W. (1924) - Pflanzenleben der Beatushöhlen am Thunersee. Mittlg. Naturforsch. Ges. Bern XLIII.

Mahler, K. (1960) - Über die Pflanzenwelt unserer Albhöhlen. Jhft. Karstund Höhlenkunde (1): 129-136.

Morton, F. (1927) - Ökologie der assimilierenden Höhlenpflanzen. Fortschritte der nat.-wiss. Forschung 12 (3) : 155-234.

Morton, F., und Gams, H. (1925) - Höhlenpflanzen, Bd. 5 der Speläologischen Monographien. Wien.

Stammler, M. (1904) - Der heilige Beatus, seine Höhle und sein Grab. Bern.

Vogellehner, D. (1963a) - Zur Pflanzenwelt um die Lampen in einigen Schauhöhlen der Schwäbischen Alb. Jhft. Karst- und Höhlenkunde (4) : 229-244.

- (1963b) - Elektrisch beleuchtete Schauhöhlen, ein neuer pflanzlicher Lebensraum. Mittlg. Vbd. dtsch. Höhlen- und Karstforscher 9 (2): $38-39$. 


\title{
Further Investigations into Bacterial and Algal Populations of Caves in South Wales
}

\author{
By M. Ann Mason Wildiams ${ }^{1}$ )
}

In 1958 a paper was published which outlined microbial populations found in air, soil and water of caves in South Wales, Great Britain (Mason-Williams and Benson-Evans, 1958). From those results it was obvious that the field covered in this initial paper was too wide for further and more detailed study. These subsequent investigations have been concerned only with aspects of the microbial floras of soils and waters of caves. The aerial floras form an absorbing study particularly with regard to the distribution of spores in relation to the draughts within the cave system, but this study is unfortunately very time-consuming and has had to be omitted from the work undertaken by the author.

The earlier work made it obvious that investigations into the physical and chemical features of the cave environment were necessary if a detailed and integrated picture of the microbial ecology of caves was to be obtained. Thus this report on the present state of knowledge of the microbial populations of caves in South Wales falls into two parts:

1. Environmental factors and methods used in measuring them.

2. Species of bacteria and algae found in soils and waters.

No attempt is made here to assess the roles of the various bacteria and algae as a paper considering their ecological importance has been published recently (Mason-Williams, 1965).

\section{Environmental Factors}

For measuring the various physical and chemical factors of the cave environment the following are the principal source references: Cullingford (1960), Geiger (1959), Iwatsuki and Ueno (1959), Mackereth (1963), Trombe (1952), Vandel (1964).

1) Department of Microbiology, University College, Cardiff, U. K. 
The majority of these references is concerned, however, either with the cave as a habitat for animals of macroscopic size, or with variations in physical conditions which could affect the precipitation or resolution of calcium carbonate. There is very little information available concerning minor variations in climate in different areas within a particular cave system. In many cases the reason for this has been the lack of portable instruments sufficiently accurate to make taking such measurements of any scientific value. Fortunately, instruments for physical measurements are becoming more readily available. It is now possible to obtain measurements of $\mathrm{pH}$, temperature and humidity within caves with a reasonable degree of accuracy under strictly reproducible conditions.

The instruments used for the measurements recorded here were:

$p H$. A battery operated portable $\mathrm{pH}$ meter (Analytical Instruments) which gives direct readings of $\mathrm{pH}$ to an accuracy of 0.01 units.

Humidity. A battery operated portable hygrometer (Shaws) which measures the percentage saturation of the air. This hygrometer can be fitted with probes of varying types for the measurement of the moisture content of air or soil. Once calibrated the accuracy of this instrument is high even when measuring humidities greater than $80 \%$.

Temperature. No portable instrument was available of any greater accuracy than a $-10^{\circ}$ to $50^{\circ} \mathrm{C}$. mercury thermometer. This could be read to an accuracy of $\pm 1 / 2{ }^{\circ} \mathrm{C}$.

\section{Table 1}

Some physical data from the cave system, Ogof Ffynnon Ddu.

\begin{tabular}{lccccc}
\hline \multicolumn{1}{c}{ Site } & $\begin{array}{c}\text { Distance from } \\
\text { nearest entrance } \\
\text { ft. }\end{array}$ & $\begin{array}{c}\text { Humidity } \\
\%\end{array}$ & $\begin{array}{c}\text { Temperature } \\
\text { air } \\
{ }^{\circ} \mathrm{C} \text { C. }\end{array}$ & $\begin{array}{c}\text { water } \\
{ }^{\circ} \mathrm{CH} \text {. }\end{array}$ & water \\
\hline 1. Entrance Passage & 130 & 85 & 10 & 7 & 7.8 \\
2. The Cathedral & 220 & 76 & 6.8 & 8.8 & 7.8 \\
3. The Junction & 800 & 83 & 8 & 9 & 7.8 \\
4. Lower Column Passage & 900 & 82 & 8.5 & 9.0 & 7.4 \\
5. Upper Column Passage & 1,000 & 81.5 & 9 & 9.2 & 7.8 \\
6. Candlestick pool & 1,000 & 81 & 9.8 & 8.7 & 8 \\
7. Loopways & 700 & 96 & 7.9 & 8.6 & 7.6
\end{tabular}

These readings illustrate well the range of variations in climates to be found in a particular cave system. For each site the value quoted is the average of a number of readings taken over a period of a few weeks. These readings are representative of those obtained in the 
spring months although apart from sites 1 and 2 , seasonal variations in this particular system are not well-marked.

In the cave environment various chemical factors can be measured and when considering the microbial populations one of the most important of these is the content of organic material to be found in water forming pools and streams. Table 2 gives some results of measurements of oxidisable organic matter as measured by the method given by Mackereth (1963) which is a comparative method measuring the amount of potassium permanganate consumed in oxidising organic matter under standard conditions.

\section{Table 2}

Organic oxygen demand as shown by the oxidation of acid permanganate (Mackereth, 1963). The results are expressed in milligrams of oxygen absorbed per litre of water

\begin{tabular}{lccc}
\hline \multicolumn{1}{c}{ Site } & Minimum & Maximum \\
\hline 1. Entrance Passage & 0.14 & 0.44 & (not subject to exterior \\
2. Cathedral & 0.35 & 0.35 & influences) \\
& & & " \\
3. Upper Column Passage & 0.17 & 0.23 & $"$, \\
4. Candlestick & 0.15 & 0.60 & $"$ \\
5. Loopways & 0.12 & 0.37 &
\end{tabular}

All the samples were taken from pools, none of which are fed from the main stream flowing through the cave.

It will be seen that appreciable quantities of organic matter are present in the waters of this cave, an important fact when populations of micro-organisms are being considered. It will also be seen that the variations in the readings obtained are relatively large. The variations are often greatest in regions of the cave system where outside influences are known to exist. For example, where the overburden of rock is thin and allows considerable surface drainage to percolate into the pools in caves or in regions of the system frequently visited by cavers.

In contrast the physical environment appears to be considerably more stable. Sufficient samples have been taken over a period of time to show that, away from the points at which the cave system is open to outside influences, the physical features of any particular point within the system remain stable for long periods of time and require major disturbances of the system for any significant variations to occur. 


\section{Microbial Populations}

It is convenient to present these under a number of different headings. The identifications of organisms have been made following the authority of Fritsch (1959), Pascher (1925), Breed et al. (1957) and Prévot (1961).

\section{Table 3}

Algal cultures from soil. The organisms listed here were isolated by the methods given in Mason-Williams and Benson-Evans (1958).

The frequency of isolations are shown as follows:

$$
\mathrm{f}=\text { frequent, } \mathrm{s}=\text { occasional, } \mathrm{r}=\text { rare }
$$

\begin{tabular}{|c|c|c|c|c|}
\hline Green algae & & Blue-green algae & & Diatoms \\
\hline Asterococcus superbus & $(\mathrm{r})$ & Anabaena inequalis & (f) & Fragilaria sp. (f) \\
\hline Chlorococcum humicolum & (f) & Aphanocapsa grevillei & (s) & Gomphonema \\
\hline Chlorochytrium viridis & $(\mathrm{r})$ & Chroococcus giganteus & $(\mathrm{r})$ & geminatum \\
\hline Chlorella oulgaris & $(\mathrm{s})$ & Chroococcus turgidus & (f) & Navicula spp. (f) \\
\hline Eremosphaera viridis & $(\mathrm{r})$ & Lyngbya martensiana & $(\mathbf{f})$ & Nitzschia spp. $(\mathrm{r})$ \\
\hline Gloeocystis gigas & (s) & Microcystis aeruginosa & $(\mathrm{r})$ & Synedra \\
\hline Gloeocapsa magma & $(\mathrm{r})$ & Nostoc muscorum & (f) & pulchella \\
\hline Gloeothece linearis & $(\mathrm{s})$ & Phormidium autumnale & (f) & \\
\hline Hormidium flaccidum & $(\mathbf{f})$ & Phormidium tenue & (s) & \\
\hline Oocystis solitaria & $(\mathrm{r})$ & Synechococcus & & \\
\hline Prasiola crispa & (f) & aeruginosa & (f) & \\
\hline Spirogyra sp. & $(\mathrm{r})$ & & & \\
\hline Stichococcus variabilis & $(\mathrm{s})$ & & & \\
\hline Tetraspora gelatinosa & (f) & & & \\
\hline Ulothrix tenuissima & $(\mathrm{r})$ & & & \\
\hline
\end{tabular}

Table 4

Algae associated with soft calcite deposits ${ }^{1}$ ) in caves

Green algae Blue-green algae

Binuclearia tectorum

Chlorococcum humicolum

Geminella mutabilis

Hormidium spp.

Scenedesmus acuminatus

Stichococcus bacillaris
Oscillatoria tenuis

Oscillatoria linaria

Synechococcus elongatus

1) These deposits are of the type known as Moonmilk in Great Britain. The term is not used here as it is ill-defined and has many different meanings. 
Table 5

Bacteria isolated from soils and calcarious deposits

\begin{tabular}{llll}
\hline Autotrophic forms & & Heterotrophic forms & \\
\hline Nitrosomonas europea & (s) & Azotobacter sp. & (s) \\
Nitrococcus europea & (s) & Bacillus cereus & (f) \\
Nitrobacter winogradski & (f) & Bac. cereus var. mycoides & (f) \\
Thiobacillus novellus & (r) & Bac. subtilis & (f) \\
& & Bac. sp. & (f) \\
& Bacterium sp. (Bergey, 1948) & \\
& Citrobacter sp. & (r) \\
& Clostridium pasteurianum & (f) \\
& Cl. tetani & (s) \\
& Cl. spp. & (s) \\
& Cytophaga sp. & (s) \\
& Flavobacterium spp. & (f) \\
& Macromonas bipunctata & (s) \\
& Micrococcus denitrificans & (f) \\
& M. luteus & (f) \\
& M. varians & (s) \\
& Nocardia spp. & (f) \\
& & Pseudomonas calcis & (s) \\
& & Ps. fluorescens & (r) \\
& & Shabdomonas linsbaueri & (f) \\
& & Streptomyces albus & (f)
\end{tabular}

The protozoan Cyrtolophosis mucicola was also found associated with bacteria and algae in soft deposits of calcite.

Table 6

Bacteria isolated in cultures from pools and films of water

\begin{tabular}{|c|c|c|c|}
\hline \multicolumn{2}{|l|}{ Autotrophic } & \multicolumn{2}{|l|}{ Heterotrophic } \\
\hline Nitrosococcus sp. & (s) & Aerobacter aerogenes & $(\mathrm{r})$ \\
\hline Nitrosomonas europaea & (s) & Azotobacter aquatilis & (f) \\
\hline Nitrobacter winogradski & (f) & Bacillus cereus & (f) \\
\hline Thiobacillus novellus & (r) & Bac cereus var. mycoides & (f) \\
\hline & & Bac. sp. & (f) \\
\hline & & Bacterium qualis (Bergey, 1948) & (s) \\
\hline & & Bact. sp. (Bergey, 1948) & (f) \\
\hline & & Caulobacteria $\left.{ }^{1}\right)$ & $(\mathrm{f})$ \\
\hline & & Chlamydobacteria ${ }^{2}$ ) & (f) \\
\hline & & Clostridium pasteurianum & (f) \\
\hline & & Cytophaga sp. & (s) \\
\hline
\end{tabular}

1) Probably members of genus Pasteuria.

2) Probably members of genera Sphaerotilus and Pelonema. 
Table 6 (Continnation)

\begin{tabular}{lll}
\hline Autotrophic & Heterotrophic & \\
\hline & Escherichia coli, irregular & $(\mathrm{r})$ \\
Micrococcus denitrificans & (f) \\
& Micrococcus spp. $\left.{ }^{1}\right)$ & (f) \\
Nocardia sp. & (s) \\
Streptomyces spp. & (s)
\end{tabular}

Table 7

Other micro-organisms from films of water

\begin{tabular}{ll}
\hline Diatoms & Zoo-plankton \\
\hline Navicula sp. & Ostracods \\
Pinnularia sp. & Several species of flagellated \\
& protozoa
\end{tabular}

\section{SUMMARY}

Some physical data collected over a period of a year in seven locations of the Ogof Ffynnon Ddu. cave system in South Wales are reported, including humidity, air and water temperature, $\mathrm{pH}$ of the water, as well as the organic oxygen demand of the water. It is shown that seasonal variations in the physical constant in this particular cave system are not well marked. Algae and bacteria were isolated from the soil samples and from calcareous deposits. A total of 30 algal species, of which 13 belong to the Cyanophyta, 22 to the Chlorophyta, and 7 to the Chrysophyta-Baccilariophyceae were found. Thirty-eight heterotrophic and 7 autotrophic bacteria were isolated. The thin films on water surfaces, besides diatoms, contained several flagellates and some ostracods, while some protozoa were found associated with the bacteria and algae in the soft calcite deposits.

\section{ZUSAMMENFASSUNG}

Einige physikalische Daten, die im Laufe eines Jahres von 7 Fundstellen des Ogof-Ffynnon-Ddu.- Höhlensystems in Süd-Wales gesammelt wurden, geben nicht nur die Feuchtigkeit, Luft- und Wassertemperatur, $\mathrm{pH}$-Gehalt, sondern auch den organischen Oxygenbedarf des Wassers an. Die Angaben zeigen, daß die jahreszeitlichen Abweichungen der materiellen Konstanten in diesem Höhlensystem nicht deutlich hervortreten. Algen und Bakterien wurden von Bodenproben und kalkigen Bodensätzen isoliert. Insgesamt wurden 39 Algenarten gefunden. Von diesen gehören 13 zu den Cyanophyten, 22 zu den Chlorophyten und 7 zur Klasse der Chrysophyta-Baccillariophyceae. 38 heterotrophe und 7 autotrophe Bakterien wurden isoliert. Der dünne Film der oberen Wasserflächen enthielt außer den Kieselalgen mehrere Flagellaten und einige Ostracoden, wobei einige mit den Bakterien und Algen assoziierende Protozoen in den weichen kalkigen Ablagerungen gefunden wurden.

1) Several different species showing differing pigmentation. 


\section{ACKNOWLEDGEMENTS}

The author wishes to thank Dr. Kathryn Benson-Evans and also members of the South Wales Caving Club for the assistance she has received in the course of this work.

\section{REFERENGES}

Breed, R. S., Murray, E. G. D., and Hitchens, P. A. (1948) - Bergey's Manual of Determinative Bacteriology, 6th ed. Williams and Wilkins Co., Baltimore.

Breed, R. S., Murray, E. G. D., and Smith, N. R. (1957) - Bergey's Manual of Determinative Bacteriology, 7th ed. Williams and Wilkins Co., Baltimore.

Culuingford, C. D. H. (1960) - British Caving, 2nd ed. Routledge and P. Kegan, London.

Fritsch, F. E. (1959) - The Structure and Reproduction of the Algae. Univ. Press, Cambridge.

Geiger, R. (1959) - The Climate Near the Ground.

Iwatsuki, O., and Ueno, K. (1959) - Mem. Coll. Sci. Univ. Kyoto Ser. B (Biol.) $26(3): 315$.

Mason-Williams, M. A. (1965) - Paper presented at IV. International Congr. Speleol. Belgrad.

Mason-Williams, M. A., and Benson-Evans, K. (1958) - Cave Res. Group, Great Britain. Pub. No. 8 .

Pascher, A. ed. (1925) - Die Süßwasserflora... G. Fischer, Jena.

Prevot, A. R. (1961) - Traité de systématique bactérienne. Duned, Paris.

Tromвe, F. (1952) - Traité de spéléologie. Payot, Paris.

VAndel, A. (1964) - Biospéléologie. Gauthiers-Villars, Paris. 



\title{
Summary of Results Obtained during a Preliminary Investigation into the Bacterial and Botanical Flora of Caves in South Wales
}

\author{
By M. Ann Mason Williams ${ }^{1}$ ) and Kathryn Benson-Evans ${ }^{2}$ )
}

In 1958 a paper, "A preliminary investigation into the bacterial and botanical flora of caves in South Wales" was published by the Cave Research Group of Great Britain. In it the authors, Ann Mason Williams and Kathryn Benson-Evans, gave details of an investigation into the populations of algae and bacteria found in caves in South Wales.

In view of the interest shown in the original paper, the editors kindly offered one of the authors the opportunity to re-publish the results. These are given in the form of tables with relevent comments appended.

The work reported in the original paper raised several important questions concerning the ecology of caves.

1. The effects of air-currents on the distribution of the microflora of caves.

2. The importance and significance to the cave environment of floods and visiting animals, including man.

3. The role of bacteria in the food chains of aquatic animals in caves.

4. The probable importance of the autotrophic micro-organisms in the economy of cave life.

Since the publication of the original paper, work has been carried out on these and other problems associated with the microbial populations of caves and the results are reported in papers in preparation.

\footnotetext{
1) Department of Microbiology, University College, Cardiff, U. K.

2) Department of Botany, University College, Cardiff U. K.
} 
Table 1

Average numbers of bacterial colonies developing on nutrient agar plates following exposure of the plates to the air for 30 minutes within various caves. The counts are those which had developed after 7 days incuation

\begin{tabular}{|c|c|c|c|c|}
\hline \multicolumn{2}{|c|}{ Incubation temperature } & \multirow{2}{*}{$\frac{37^{\circ} \mathrm{C} .}{30}$} & \multirow{2}{*}{$\frac{30^{\circ} \mathrm{C} .}{20}$} & \multirow{2}{*}{$\frac{18^{\circ} \mathrm{C} .}{70}$} \\
\hline Porth yr Ogof: & site 1. & & & \\
\hline & site 2. & 0 & 20 & 25 \\
\hline & site 3. & 2 & 0 & 18 \\
\hline \multirow[t]{3}{*}{ Little Garth: } & site 1. & 16 & 150 & 200 \\
\hline & site 2. & 0 & 70 & 25 \\
\hline & site 3. & 0 & uncountable ${ }^{2}$ ) & 3 \\
\hline Bridge Cave $^{1}$ ) & site 1. & 16 & 15 & 16 \\
\hline Ogof Ffynnon Ddu. & site 1. & 100 & 220 & 250 \\
\hline Cave $B$ & site 1. & 20 & 11 & 100 \\
\hline Cave $\mathrm{C}$ & site 1. & 20 & 50 & 25 \\
\hline
\end{tabular}

Table 2

Species of bacteria isolated from the air of various caves in South Wales (In the original paper, the species are given under the headings of the various caves from which they were isolated)

\begin{tabular}{ccc}
\hline & Incubation temperature \\
$37^{\circ} \mathrm{C}$. & $30^{\circ} \mathrm{C}$. & $18^{\circ} \mathrm{C}$. \\
\hline
\end{tabular}

\begin{tabular}{lll}
\hline Bacillus subtilis & Bac. cereus & Bac. cereus v. mycoides \\
Bac. megaterium & Bac. cereus v. mycoides & Bac. megaterium \\
Bac. pumilus & Bac. subtilis & Bac. spp. \\
Bac. spp. & Bac. megaterium & Bact. qualis \\
Bacterium qualis & Bac. spp. & Bact. mutabile \\
Bact. mutabile & Bact. qualis & Bact. spp. \\
Bact. spp. & M. luteus & Achromobacter sp. \\
Achromobacter $\mathrm{sp}$. & M. freudenreichii & M. freudenreichii \\
Flavobacterium $\mathrm{sp}$. & M. spp. (orange, buff & M. flasus \\
Micrococcus sp. & and white) & M. spp. (orange and \\
(orange pigmented) & Sarcina lutea & white pigmented) \\
M. luteus & Corynebacterium helvolum & Nocardia flasa \\
Micrococcus spp. & Nocardia sp. & Microbacterium sp. \\
(cream to white) & Streptococcus salivarius & \\
Sarcina sp. & & \\
Streptomyces albus & & \\
Nocardia rubra & & \\
Nocardia sp. & & \\
\end{tabular}

1) The plates from this site were all uncountable due to overgrowth of other species by a few rapidly growing species of Bacillus.

$\left.{ }^{2}\right)$ All the plates from this site showed numerous colonies of moulds many of which showed zones of inhibition around them. 
In the original paper it was remarked that the species and total numbers of bacteria found in the air of caves could be related to various known disturbances within and near the caves. For example, two sites gave noticeably high counts, site 1, the entrance passage in the Little Garth Cave, and site 1 in Ogof Ffynnon Ddu. These counts were attributable to frequent disturbance of the air and soil at these sites due to quarrying near the entrance to the Little Garth Cave, and to visiting cavers in Ogof Ffynnon Ddu. during the sampling times. Work done since the publication of the original paper has confirmed the view that the air flora of many of the smaller British caves is related directly to the frequency of disturbance of the cave air by outside influences. The air currents within the caves distribute the species brought in from outside the cave on clothing, by floods, or in animal droppings.

\section{Table 3}

Species of bacteria isolated from soil and water samples taken within the various caves

\begin{tabular}{ll}
\hline \multicolumn{1}{c}{ Soil } & \multicolumn{1}{c}{ Water } \\
\hline Bacillis subtilis & Bacillus cereus \\
Bac. cereus v. mycoides & Bac. cereus v. mycoides \\
Bac. cereus & Bac. sp. \\
Bac. sp. & "Clostridium pasteurianum \\
Bact. sp. & Bacterium sp. \\
Pseudomonas fluorescens & Escherichia coli (irregular) \\
Ps. pyocyanea & Aerobacter aerogenes \\
Achromobacter sp. & Micrococcus nitrificans \\
Citrobacter sp. & M. spp. \\
Micrococcus sp. & Leuconostoc sp. \\
Leuconostoc sp. & Streptomyces albus \\
" Clostridium pasteurianum ${ }^{1}$ ) & Nocardia sp. \\
Nocardia sp. & Microbacterium sp. \\
" Azotobacter sp. & "Azotobacter aquatile \\
"Nitrobacter winogradskyi & "Nitrobacter winogradskyi \\
"Nitrosococcus europaea & "Nitrosomonas europaea \\
& "Nitrosococcus sp. \\
& "Thiobacillus novellus
\end{tabular}

It will be noticed that the list given here includes a number of species capable of utilizing inorganic nitrogen for their nitrogen re-

\footnotetext{
1) Since the publication of the original paper, investigations into the species of anaerobic bacteria present in the muds of caves have shown that a wide variety of clostridial species are present in most caves. The commonest species are $C l$. tetani, Cl. butyricum and Cl. histolyticum.
} 
quirements, thus converting it to an organic form of use to other forms of life. These species are marked ".

In the original paper it was pointed out that the list gives only those species which could be identified to generic or specific level. The problem of the identification of the relatively large numbers of small gram indeterminate rods which have been found in the soil and water of caves is one which is also encountered by soil microbiologists and which still remains to be solved.

\section{Botanical Results}

It is not practical to give complete lists of the plants found, and only the more important features of them are given in this summary.

The botanical work was divided into two main parts, those plants associated with the threshold and those found within the cave.

Table 4

Macroscopic plants found in the threshold areas of caves

ANGIOSPERMS :

Chrysosplenium oppositifolium Outer regions with fairly high light intensity Oxalis acetosella PTERID OPHYTA:

Asplenium trichomanes

Asp. rutamuraria

Phyllitis scolopendrium

Athyrium filix-femina

Shady damp thresholds

Alka-tolerant forms growing on substrates of $\mathrm{pH} 6.0-7.0$

Only on more acid substrates, pH 5.5

BRYOPHYTES: 1. MUSCI :

Amblystegium serpens

Barbula recurvirostre

Mesophilous forms tolerating $\mathrm{pH}$ values

Thamnium alopecurum of $4.8-7.0$ found at most of the caves visited

Fissidens bryoides

F. taxifolius

Ctenidium molluscum

Mnium punctatum

Mnium undulatum

M. longirostrum

Mesophilous forms but found less frequently

Eurhynchium murale

Campylium sommerfeltii

Polytrichum juniperinum

Isopterygium elegans

Hypnum cupressiforme

Blindia acuta

Sphagnum plumulosum

Acid tolerant forms found at a few sites only 
Tabelle 4 (Fortsetzung)

Macroscopic plants found in the threshold areas of caves

BRYOPHYTES: 2. HEPATICAE:

Pellia epiphylla

Plagiochila asplenoides

Pellia fabbroniana

Mesophilous forms found at most of the sites visited

Conocephalum conicum

Mesophilous but found less frequently

In the threshold regions, the two important ecological factors were the substrate and the penetration of light. The light factor is of great importance, bringing about a distinct zonation of plants according to the light intensity they receive. A subsidiary effect of the light factor is that of its aspect. Marked differences in amounts of growth can be seen by comparing north-facing walls, which show abundant growth, with south-facing walls, which show scanty, and often atypical growth.

Amongst the bryophytes, the effect of the reduced light intensities was most noticeable in the changes which occurred in the growth habits of the various species found. At the higher light intensities, more or less normal growth forms were observed, but as the light intensity decreased, dendroid forms and smooth mats became less frequent, and growth occurred in rough or thalloid mats and wefts.

In the threshold areas, the species of algae found on the rocks and soil were limited, and the species found were mainly coccoid forms from the Myxophyta and the Chlorophyta, together with a few Diatoms, and one or two filamentous members of the Chlorophyta.

Within the Dark Zones of the caves, the only macroscopic green plants found growing were etiolated seedlings of oak, sycamore and the rush Juncus buffonius.

Cultural methods demonstrated that there are spores of many plants present in the soil of caves. Spores of bryophytes found around the threshold areas were very common, and seemed widespread through the caves from which soil samples were taken. The potential algal flora of caves is also very considerable, and cultural methods showed that light was the only limiting factor in preventing growth. The amount of growth obtained in experiments in which soil samples were illuminated for only 30 minutes, and then incubated in the dark, proved that algal spores are present in considerable quantities. It is postulated that the spores are present in sufficient quantities to provide sources of organic matter for saprophytic troglophiles. 


\section{SUMMARY}

The results of an investigation into the bacterial and botanical flora of South Welsh caves are presented in tabular form. Bacterial counts and species isolated from the caves both from soil and water samples as well as from the air, also the macroscopic plants found in the photic zone are enumerated.

\section{ZUSAMMENFASSUNG}

Die Ergebnisse der bakteriologischen und botanischen Untersuchung der Flora in den Süd-Wales-Höhlen sind tabellarisch dargestellt. Verzeichnet sind bakteriologische Zählungen, von Erd-, Wasser- sowie Luftproben isolierte Arten und auch die makroskopischen Pflanzen der belichteten Zone.

\section{REFERENGE}

Mason-Williams, M. A., and Benson-Evans, K. (1958) - A preliminary investigation into the bacterial and botanical flora of caves in South Wales. Cave Research Group of Great Britain. Pub. No. 8. 


\section{A Psychrophilic Yeast from Mammoth Cave, Kentucky}

By David Brashear, Ralph F. Wiseman and Thomas C. Barr, Jr. ${ }^{1}{ }^{2}$ )

In the course of our study of the indigenous microflora of Mammoth Cave, Mammoth Cave National Park, Kentucky, we have repeatedly encountered a yellowish, mold-like organism growing on dead crickets (Hadenoecus subterraneus Scudder), dead cave rats (Neotoma magister Baird), and on meat and fish baits placed in the cave to attract arthropods. The organism has been observed throughout the upper regions of the cave, especially in those areas which receive vadose waters percolating downward from the surface. The mean temperature of these areas is $13^{\circ} \mathrm{C}$. and the relative humidity is very near saturation at all times.

A sample of the organism was collected aseptically from a section of the cave (Radio Room, near Frozen Niagara) which is not open to the public and was subjected to microbiological examination. Pure cultures were obtained by plating on Difco Cornmeal agar and incubating at $20^{\circ}$ and $37^{\circ} \mathrm{C}$. The organism, which was not pigmented in the culture, proved to be diphasic, producing yeast-like colonies at $37^{\circ}$ and filamentous growth at $20^{\circ}$. Direct observation of microcultures incubated at $20^{\circ}$ revealed pseudohyphae with chlamydospores, while microcultures incubated at $37^{\circ}$ revealed budding, ovoidal cells. Good growth was obtained on Saboraud's agar and on sterilized chopped beef after 24 hours at $13^{\circ}$. These cultures contained ovoidal cells and pseudohyphae.

After three transfers on Cornmeal agar, the organism ceased growing at $37^{\circ}$, but growth was readily obtainable at $20^{\circ}$ and at $13^{\circ}$.

The organism fermented glucose, galactose, and maltose, but not sucrose or lactose, and produced a "feathery" mycelial growth on eosin-methylene blue agar.

\footnotetext{
1) Departments of Microbiology and Zoology, Institute of Speleology, University of Kentucky, Lexington, Kentucky, U.S.A. 40506.

2) This investigation was supported in part by a grant (G18765) from the National Science Foundation.
} 
Since the organism had many of the characteristics of Candida albicans (Lodder and Krieger-Van Rij, 1952), we attempted to determine its pathogenic potential in both warm- and cold-blooded animals. One ml. of a saline suspension of the cave yeast was injected intravenously into a rabbit and intraperitoneally into frogs. The known pathogen Candida albicans (Coyle strain) was injected into other animals and served as the control. The rabbits were held at room temperature for 12 days and the frogs at $13^{\circ}$ for one month. None of the animals died. After sacrifice, internal organs of the animals were examined; only the rabbit injected with the Coyle strain exhibited pathological conditions. The cave yeast, while not pathogenic and not recoverable from the rabbit, was cultured from the livers and peritoneal exudates of the frogs.

These results suggest that this yeast is a psychrophilic strain of C. albicans which - at least in rabbits - is non-pathogenic but shows a low grade parasitism in frogs.

\section{ACKNOWLEDGMENT}

We wish to express our appreciation to the Superintendent and staff of Mammoth Cave National Park for making this investigation possible.

\section{SUMMARY}

Samples collected in Mammoth Cave, Kentucky, revealed the presence of a psychrophilic yeast, tentatively identified as a strain of Candida albicans. The yeast is saprophytic on dead animal tissues and exhibits a pale yellow color when growing in the cave. In vitro, the yeast grows poorly at $37^{\circ} \mathrm{C}$. and well at $13^{\circ}$ and $20^{\circ}$, but loses its pigmentation. It is non-pathogenic in rabbits but appeares to show low-grade parasitism in frogs.

\section{ZUSAMMENFASSUNG}

Proben aus der Mammut-Höhle (Kentucky) zeigten, daß eine psychrophile Hefe, wahrscheinlich eine Candida-albicans-Rasse, in dieser Höhle vorkommt. Die höhlenbewohnende Hefe existiert als Saprophyt auf Geweben toter Tiere und zeigt eine überall bleichgelbe Farbe. In vitro wächst diese Hefe dürftig bei $37^{\circ} \mathrm{C}$, aber rüstig bei $13^{\circ}$ und $20^{\circ}$, unter Verlust des Pigments. Bei Kaninchen ist sie nicht pathogen, und bei Fröschen zeigt sie nur milden Parasitismus.

\section{REFERENCE}

Lodder, J., and Krieger-Van RiJ, N. J. W.(1952) - The Yeasts: A Taxonomic Study. Amsterdam: North-Holland Publ. Co. Pp. 471-474, $536-538$. 


\title{
A New Species of Gomphonema (Bacillariophyta) from Mammoth Cave, Kentucky
}

\author{
By Sam L. VanLandingham ${ }^{1}$ ) \\ With 1 figure in the text
}

In a previous paper appearing in this Journal (VanLandingham, 1965a), a series of diatoms was described from Mammoth Cave, Kentucky, from material collected in the cave by Dr. George Claus, Department of Marine Science, Long Island University, Greenvale, New York. Descriptions of three species of Cymbella from this material were not to be found in the literature and were described as new species in a paper in this Journal (1965b). In addition to the three species of Cymbella, a new species of Gomphonema is now proposed.

$$
\text { GOMPHONEMA HOTCHKISSII sp. nov. }
$$

Dimensions: Length $16 \mu$, width $5.5 \mu$, striae 9-10 in $10 \mu$.

Holotypus (nomenclatural type): VanLandingham Collection, slide 13 a.

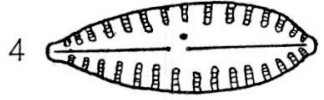

I c onotypus (nomenclatural type): Original camera lucida drawing by Dr. George Claus, Department of Marine Science, Long Island University, Greenvale, New York, Fig. 2; see also VanLandingham, 1965 a, Fig. 4.

Type locality: Mud from small ponds in Mammoth Cave (National Park), Kentucky.

Latin description: Valvae elongatae, lanceolatae; apicibus valvae rostratis distincte; area axiali gibbera valide; striis levite radiantibus; striae transapicales $\mathbf{9 - 1 0}$ in spatio 10 micronis. Longitudo cellularum, 16 micra, latitudo earum, 5.5 micra.

\section{Discussion}

This diatom is named in honor of Dr. A. T. Hotchkiss, Department of Biology, University of Louisville, Louisville, Kentucky.

1) Department of Biology, University of Louisville, Louisville, Kentucky. 
The most conspicuous features of this diatom are the subcapitate apices and the broad elliptical-shaped axial area. Apparently, it does not closely resemble any known diatom, but does show a superficial resemblance to Gomphonema parsulum Kützing which possesses a much less narrow axial area.

\section{SUMMARY}

In some materials collected from Mammoth Cave, Kentucky, a diatom was found which could not be identified with any known species. A taxonomic description of Gomphonema hotchkissii nov. spec. is given.

\section{ZUSAMMENFASSUNG}

In einigen in der Mammoth-Höhle, Kentucky, gesammelten Proben fand sich eine Kieselalge, die zu keiner bekannten Form gehört. Eine taxonomische Beschreibung der neuen Art Gomphonema hotchkissii nov. spec. ist angeführt.

\section{REFERENCES}

VanLandingham, S. L. (1965a) - Diatoms from Mammoth Cave, Kentucky. Internat. J. Speleol. 1 (4) : 517-539.

- $(1965 \mathrm{~b})$ - Three new species of Cymbella from Mammoth Cave, Kentucky. Internat. J. Speleol. 2 (1-2): 131-136. 


\section{Editor's Note}

\section{Bioluminescence in Melosira varians Ag.}

Mr. John R. Carter called our attention to a most interesting phenomenon, the bioluminescence in a diatom, which although already twice reported in the scientific literature, is not usually referred to. Therefore, it seemed to us to be of importance to call the attention of biospeleologists to this phenomenon and report again on the observations of Mr. Carter. The following note is composed from a letter received recently from this eminent diatomologist and we wish to express our gratitude to Mr. Carter for kindly supplying us with the data.

During the Second World War while on duty as a naval officer Mr. Carter examined an abandoned tin mine on the North Cornish Coast near Bedruthan on the north coast of Cornwall. In the exit tunnel from an old mine working which was driven straight back into the cliffs at about 150 feet above sea level a patch of blue-green luminescence could be seen on the wall. Though this tunnel was not examined to its full length the luminescence occurred in a place where day-light penetration was already minimal. It must have been approximately 70-80 yards away from the entrance. This is further substantiated by the fact that the entrance area could still be discerned if one turned towards it but facing the opposite direction already complete darkness prevailed there. A scraping was taken of this luminescent growth, wrapped in an envelope and the material was then kept for four hours in the collector's pocket. When microscopic examinations were conducted on this material it was found diatomaceous in origin. The identification resulted in Melosira varians Ag. During the four hours which elapsed from the taking of the material to its examination the luminescence of the filaments disappeared and could no longer be observed. The only interesting feature of the algae found was their very lightly pigmented chloroplast but no other cytological feature could be seen which could be correlated with the observed luminescence.

Mr. Carter mentions also that this case is not unique and has already been reported under similar circumstances by Schröder (1916). He himself, also, very briefly described his finding in The Microscope (1946). 


\section{SUMMARY}

Bluish green bioluminescence in a diatom, Melosira varians Ag. growing in an abandoned tin mine in Cornwall was observed. Upon microscopic examination the chloroplasts of the algae were found to be very pale but no other feature was seen which could be correlated with the luminescence.

\section{ZUSAMMENFASSUNG}

Blaugrünliche Lumineszenz wurde in einer Diatomee Melosira varians Ag. gefunden, welche in einer verlassenen Zinkmine in Schottland wuchs. Während mikroskopischer Untersuchung schienen die Chloroplasten der Algen fast farblos, doch keine andere Charakteristik, welche mit der Lumineszenz in Zusammenhang gebracht werden konnte, wurde festgestellt.

G. Claus

\section{REFERENCES}

Carter, J. R. (1946) - The Microscope 6 (3): 72.

Schröder, J. (1916) - Ver. Deutsch. Bot. Gaz. p. 796. 


\title{
Die ökologische Stellung der Höhlen- und Spaltengewässer innerhalb der subterranaquatilen Lebensbereiche
}

\author{
Von Siegfried Husmann ${ }^{1}$ ) \\ Mit fünf Abbildungen im Text $\left.{ }^{2}\right)$
}

Es sind jetzt nahezu 75 Jahre her, als H. Garman (1882, p. 240) versuchte, die Herkunft der Fauna weiträumiger Gebirgshöhlen zu deuten, indem er erklärte, daß die Vorfahren der Höhlentiere, insbesondere die der nichtaquatischen, wahrscheinlich bereits an ein Leben in der Erde ,angepaßt" waren, ehe die Höhlen entstanden; Spalten und Risse in felsigem Gestein könnten als primäre Lebensstätten der Höhlenfauna angesehen werden. $\mathrm{Zu}$ der gleichen Schlußfolgerung kam auch der Höhlenforscher C. H. Eigenmann (1909, p. 13), der dann sogar den Biotop „Höhle" als eine Sammelstätte (,collecting ground“) derartiger Spaltenbesiedler bezeichnete, nachdem H. Krause (1898, p. 652) in recht deutlicher Weise seiner im Gegensatz dazu stehenden Meinung Ausdruck verliehen hatte: „Nun, wer's glaubt, mag ja auch bei dem Glauben selig werden können, daß die Höhlen gleichsam zum Tummelplatz und Elysium der Blinden aller Thierklassen erschaffen seien..."

Dreiviertel Jahrhundert sind inzwischen vergangen; doch eine allseits anerkannte Antwort auf die Frage nach Herkunft, Wesen und ökologischer Stellung der „Höhlenfauna“" konnte bis heute noch nicht gefunden werden.

Die obenerwähnte, von Garman (1892) vertretene Auffassung, „Höhlentiere" seien in Wirklichkeit Immigranten aus endogäischen

\footnotetext{
1) Limnologische Flußstation des Max-Planck-Institutes für Limnologie, 6407 Schlitz/Hessen (Westdeutschland).

$\left.{ }^{2}\right)$ Anfertigung nach Entwürfen des Verfassers: Uta Schnell, Schlitz/ Hessen.
} 
Mikrokavernen, fand neuerdings wieder einen namhaften Höhlen- und Grundwasserforscher als entschiedenen Verfechter: St. Karaman (1954, p. 216) betont, es gäbe überhaupt keine „Höhlenfauna“. „Die in Höhlen vorgefundenen Landtiere sind eigentlich Bewohner der kleinen, engen Felsspalten, gleich unterhalb der Erdoberfläche." Mit gleichem Nachdruck wird von Karaman auch die Existenz einer äquatilen ,Höhlenfauna" in Abrede gestellt. Diese in Höhlentümpeln lebenden blinden und pigmentlosen Wassertiere werden ökologisch als Elemente der eigentlichen Grundwasserfauna eingeordnet, die nur durch Überschwemmungen oder mit Tropfwasser aus ihren mikrokavernalen Biotopen in Höhlengewässer geraten.

Im jugoslawisch geschriebenen Hauptteil seiner Abhandlung kommt Karaman (zit. n. Hadzi, 1958, p. 472) sogar zu der Feststellung, daß nur ein „Glauben an eine Höhlenfauna" bestehe.

Diese Formulierung Karamans klingt wie eine echohafte Antwort auf den oben zitierten Vorwurf ,Glaube macht selig", mit dem Krause (1892) die ersten Verfechter der heute von Karaman vertretenen Meinung abkanzelte.

Die von diesem erfolgreichsten jugoslawischen Grundwasserforscher als ,Glaube“ abgetane Auffassung über das Wesen der „Höhlentiere“ entstand - nach Karaman - historisch, weil man zuerst in befahrbaren Höhlen diese augenlosen, bleichen Wassertiere vorfand, die dann eben als ,Höhlentiere" bezeichnet wurden; doch durch die Entdeckung der „Grundwasserfauna" - so behauptet Karaman des weiteren - sei die ,"Theorie der Höhlenfauna" zu Fall gebracht worden.

Die Gegenseite wendete hierzu ein: ,Unserer Meinung nach ist eine solche Auffassung unhaltbar, weil sie zu einseitig ist, und was noch wichtiger ist, weil sie nicht den Tatsachen entspricht" (J. Hadzi, 1958, p. 472).

Die hier sich zeigende Aktualität des Problems der ökologischen Position der „Höhle“ und der „Höhlenfauna" gibt Anlaß, vom heutigen Stand der Grundwasser-Limnologie aus die ökologische Stellung der Höhlengewässer innerhalb der übrigen subterranaquatilen Lebensbereiche eingehend $\mathrm{zu}$ beurteilen.

\section{II}

Die im Untergrund der Landschaften in nahezu allen Regionen der Erde in Lücken und Spalten und weiträumigen Höhlungen sich sammelnden Gewässer unterliegen alle der Wirkung zweier Naturgegebenheiten, deren Gegebensein in die an sich so sehr eigenständigen ver- 
schiedenen subterranaquatilen Biozonen zu einem ökologischen Ganzen verbindet.

Der eine dieser beiden zwischen den unterirdischen Lebensstätten vermittelnd wirkenden Faktoren ist die in allen Subterrangewässern herrschende vollkommene Dunkelheit; der andere wird in Gestalt der totalen oder doch recht weitgehenden Isolation dieser endogäischen Gewässer gegenüber Temperaturschwankungen der Atmosphäre wirksam.

Dieses überall in unterirdischen Gewässern ökologisch so gravierend in Erscheinung tretende Extremfaktoren-Nebeneinander gibt dem Ökologen durchaus die Berechtigung, die Gesamtheit aller endogäischen Süßwasserlebensbereiche als „Großlebensraum“ (,Ökoregnum") anzusehen und folgerichtig auch allgemein von einer „,Grundwasserfauna" zu sprechen: von ,,stygobionten“, ,,stygophilen“" und ,,stygoxenen“ Grundwassertieren (A. Thienemann, 1925, p. 32); gleichgültig, ob diese Subterranorganismen in grundwasserführenden Lückensystemen von Sanden, Kiesen oder Grobgeröllen leben, in Spaltengewässern oder in Höhlentümpeln.

\section{III}

Der von den verschiedensten unterirdischen Gewässern erfüllte Großlebensraum ,Grundwasser" - das Ökoregnum, ,Stygon“ (S. Husmann, 1966) - erstreckt sich von grundwasserführenden weiträumigen Gebirgshöhlen über Spaltensysteme in anstehendem Gestein und weiter in die Zwischenräume von Gehängeschutt sowie in Mikrokavernenlabyrinthe kiesiger und sandiger Lockergesteinsablagerungen. Alles in allem erfüllen also die von Grundwassertieren besiedelten unterirdischen Gewässer ein weitverzweigtes Hohlraumsystem verschiedensten Volumens, das von Fels oder von Lockergesteinen aufgebaut sein kann.

Die kavernale Geräumigkeit der grundwasserführenden Lebensstätten bietet naturgemäß jeweils nur morphologisch geeigneten Gestaltstypen der unterirdischen Wassertierwelt Einlaß und Bewegungsfreiheit. Daher können grundwasserführende Kavernen mit einheitlich geräumigem Volumen für morphologisch ,,passende "Grundwassertiere den ,eigentlichen" Biotop darstellen, wie es ja besonders eindrucksvoll für die ,Lebensformtypen“ (Remane) der „Sand"- und Kieslückenfauna" der Fall ist, während diese intergranularen, extrem engen Lückensysteme andererseits für Grundwassertiere mit ,,zu großem" Körperumfang zwangsläufig zu einer ,ökologischen Schranke" werden. 

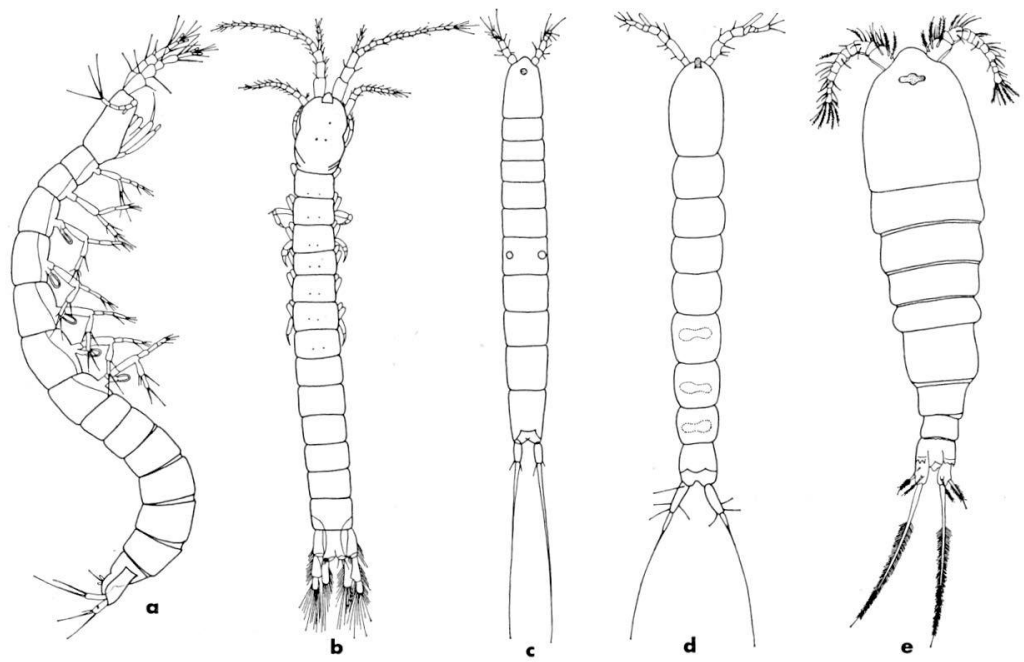

Abb. 1. Lebensformtypen des Mesopsammon; a: Leptobathynella amyxi (Siewing, 1956) (n. R. Siewing, 1956), b: Parastygocaris andina Noodt 1962 (n. W. Noodt, 1962), c: Horsiella brevicornis (Douve 1904) (n. W. Noodt, 1958), d: Parastenocaris entzi Török 1935 (n. P. Török 1935), e: Graeteriella unisetigera (Graeter 1908) (n. R. Gurney, 1932/1933).

So bietet sich der grundwassergefüllte Großlebensraum weitgehend als ein System ,ökologischer Nischen“ - in des Wortes treffendster Bedeutung - dar, die ihren typischen Besiedlern nur im ureigenen Bereich und zudem in geräumigere Hohlraumsysteme hinein Expansionsmöglichkeiten bieten.

Daher steht auch innerhalb der Fauna des grundwasserführenden Großlebensraumes ganz naturgemäß den Besiedlern von Sandlückensystemen das weiteste subterranökologische Feld zur Invasion offen; und tatsächlich gibt es einige Formen mesopsammaler Grundwassertiere, die offenbar in der ganzen Stufenfolge subterrankavernaler Grundwasserbiotope existenzfähig sind, wie beispielsweise Troglochaetus beranecki Delachaux sowie die Gattungen Parastenocaris Kessler (Abb. 1d), Graeteriella (Graeter) (Abb.1e) und Bathynella Vejdovsky, die eindeutig als typische Elemente des Mesopsammons gelten müssen, dabei aber die hier besonders hervorgehobene physiologische Bereitschaft ,,mitbringen“, auch in grundwasserführenden Bereichen von größerer Geräumigkeit gedeihen zu können.

Auch von einigen Elementen der ,Kieslückenfauna“ ist es bekannt, daß sie nicht allein in ihren „Hauptökotopen“ (Briegleb) vorkommen, 
sondern auch in Spaltengewässern und Höhlentümpeln; einige Beispiele: Asellus (Proasellus) casaticus Schiödte, Arten der Gattung Niphargus sowie Microniphargus leruthi Schellenberg.
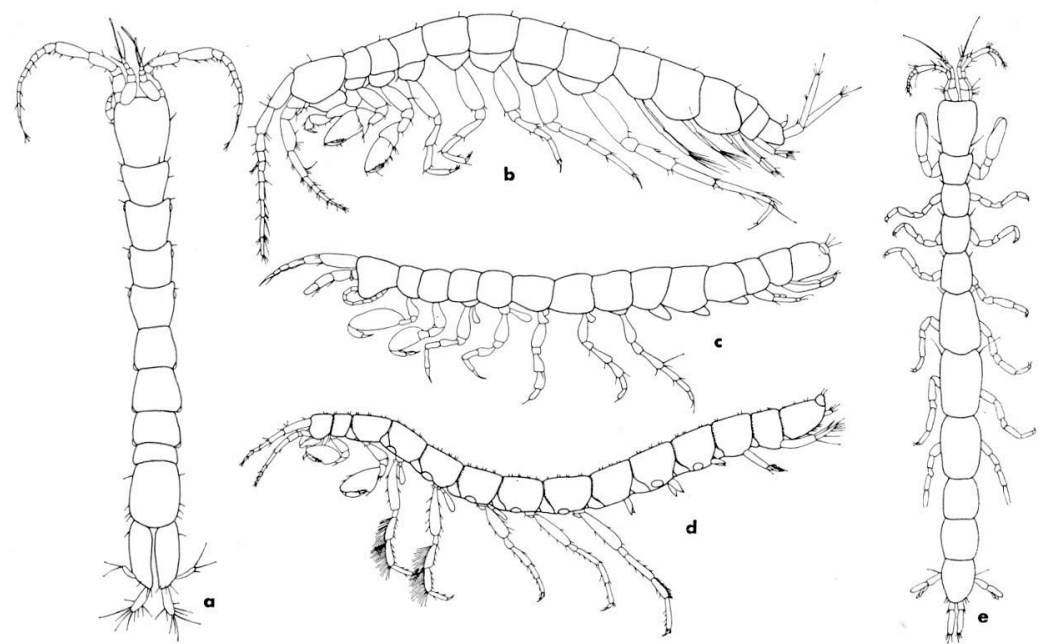

Abb. 2. Lebensformtypen des Mesopsephon; a: Microcharon stygius Karaman 1933 (n. St. Karaman, 1940), b: Bogidiella albertimagni Hertzog 1933 (n. St. Karaman, 1943), c: Ingolfiella acherontis (Karaman 1935) (n. St. Karaman, 1935), Ingolfiella leleupi Ruffo 1951 (n. S. Ruffo, 1951), e: Microcerberus stygius Karaman 1933 (n. St. Karaman, 1940).

Die durch ihre weite Geräumigkeit ausgezeichneten Felshöhlen mit den sich darin ansammelnden Wässern können bei einer dergestaltigen hohlraumabhängigen Besiedlungsstoßrichtung geradezu als ein besonders extremer Abschluß einer sich in allmählich größer werdender Raumausdehnung äußernden Stufenfolge von Subterranbiotopen angesehen werden.

Es liegt nahe, daß die weiträumigsten grundwasserführenden Hohlräume der Erdrinde wegen ihrer relativ leichten Zugänglichkeit den ersten Einblick in die unterirdische Wassertierwelt gestatteten (vgl. p. 410) und daß diese blinden, pigmentlosen, milchigweißen Besiedler der Höhlengewässer in ihrer Gesamtheit unvoreingenommen als Faunenelemente einer eigenständigen ,Höhlenfauna" betrachtet werden mußten, wie ja auch die zunächst als zönobiont anzusehen gewesenen ,Höhlen"tiere folgerichtig als ,troglobiont" (Racovitza, 1907) oder ,eucaval“" (Hesse, 1924) benannt wurden, wobei also eindeutig als Biotop zunächst nur die weiträumige Gebirgshöhle eine namensbestimmende Stellung einnahm, bis schließlich auch die weit- 
verzweigten Kleinsthöhlen - wie oben erwähnt - als Bioregionen in den Lebens,,raum" der ,,troglobionten“ - ,eucavalen“ - Tierwelt einbezogen werden mußten, und zwar sogar als ,eigentliche Biotope" einer ganzen Reihe dieser „Höhlentiere“ (vgl. p. 411).

\section{IV}

Es ist durchaus verständlich, daß nach der Entdeckung der artenund individuenreichen Interstitialfauna grundwasserführender Lockergesteine zunächst eine intensive Bestandsaufnahme der in diesen Lückenbiotopen lebenden Wassertiere einsetzte (vgl. Arbeiten von Angelier, Chappuis, Delamare-Deboutteville, Haine, Husmann, Jakobi, Karaman, Kiefer, Kulhavý, Meštrov, Motaş, Noodt, Orghidan, Pennak, Picard, Priesel-Dichtl, Ruffo, Schäfer, Schwoerbel, Viets, Wegelin u.a.); und immer noch ist diese zönologische Erschließung in vollem Gange, denn aus allen grundwasserführenden Klimazonen der Erde werden laufend neue Arten von in Sand- oder Kieslückensystemen lebenden Grundwassertieren gemeldet.

Das Wiederfinden von „Höhlentieren“ im Interstitialwasser von Lockergesteinen forderte schon gleich nach der Entdeckung dieser Mikrokavernenfauna dazu heraus, den offensichtlich ökologisch so ungeahnt vielgestaltigen Lebensraum dieser Elemente der „Höhlenfauna" in ökologische Bereiche eigener Prägung aufzugliedern.

Der Altmeister der biologischen Grundwasserforschung P. A. Chappuis war es, der den zunächst für das gesamte Grundwasser als Bezeichnung verwendeten Begriff ,nappe phréatique“ (vgl. Chappuis, 1950) schließlich zur speziellen Hervorhebung des in Lückensystemen von gerollten Lockergesteinen im Untergrund von Talauen und Terrassen ziehenden Interstitialwassers einführte (Chappuis, 1950), um diesen eigentlichen Lebensbereich der Sand- und Kieslückenfauna den grundwasserführenden Spalten und Höhlen gegenüberzustellen.

Die Begriffe ,nappe phréatique“ (Chappuis, 1950) oder ,phreatischer Biotop" (Motaş, 1958) betonen mit Recht die ökologische Einheit grundwasserführender Kavernensysteme in sandigen und kiesigen Aufschüttungen, ganz gleich, ob diese Lockergesteine den bodenbedeckten Untergrund von Talauen und Terrassen zusammensetzen oder aber Fließgewässerschotterbetten aufbauen.

Mit den Bezeichnungen ,ufernahes“" (S. Husmann, 1954, 1956) oder ,hyporheisches" (Orghidan, 1955) Grundwasser wurde der sandigkiesige Lückenbiotop in Gebirgsbachbetten als Lebensstätte eigener Prägung innerhalb des ,phreatischen Lebensraumes“ (Motaş) hervorgehoben und dem , interstitiellen Grundwasser in Talauen und Terrassen" (Husmann, 1954, 1956) gegenübergestellt. 
Bei der Abgrenzung dieser ökologischen Bereiche fanden jedoch die oben hervorgehobenen Befunde keine Berücksichtigung, daß nämlich „Sandlückensysteme“ und „,Kieslückensysteme“ als ,,Hauptökotope“ (Briegleb) ganz bestimmter, charakteristischer Lebensgemeinschaften anzusprechen sind. Um nun aber der ökologischen Bedeutsamkeit gerade der hohlraumformenden Substratkomponenten gerecht zu werden, war es notwendig, bei der Einteilung des interstitiellen Lockergesteinsgrundwassers in Lebensbereiche eigener Prägung neben der geomorphologischen Situation noch das Substratgefüge namensgebend heranzuziehen, mit anderen Worten: den "Sandlückenbiotop“" (,Psammal“", Sassuchin, Kabanov, Neizwestnova, 1927; „Mesopsammal“, Remane, 1940; „Limnopsammal“, Ruttner-Kollisko, 1957) und den Lebensraum der ,Kieslückenfauna“ (,Mesopsephal", Husmann, 1966) in entsprechender Weise zu kennzeichnen, das heißt: in Hinblick auf ihre Beziehungen zur Erdoberfläche oder aber hinsichtlich einer unter Umständen bestehenden totalen Isolation gegenüber Infiltrationen aus epigäischen Gewässern.

\section{V}

Die letztgenannten, endogäisch isolierten Biotope verdienen es auf Grund ihrer Abgeschlossenheit gegenüber biologischen Einflüssen aus oberirdischen Gewässern eigentlich einzig und allein mit Recht, daß man sie ohne jede Einschränkung nominell mit dem Strom der Unterwelt - „Styx“ - in Beziehung setzt (vgl. p. 411). Daher wurden wohlberechtigt derartige, gegenüber zönologischen Infiltrationen aus Oberflächengewässern abgeschirmte Bereiche des Großlebensraumes „Grundwasser" (,Stygon“) als „Eustygon“ (Husmann, 1966) besonders hervorgehoben und allen anderen Lebensbereichen des umfassenden ,Ökoregnums Stygon“ gegenübergestellt, die ihrerseits gerade dadurch zönologisch ausgezeichnet sind, daß ihre Lebensgemeinschaften sich aus Elementen teils echt subterraner, teils epigäischer Herkunft zusammensetzen, wie es beispielsweise für die in Lockerge steinsLückensystemen von Fließgewässerbetten lebenden Biozönosen innerhalb der Ökosysteme ,,Rhithron" und ,Potamon" (J. Illies, 1961) zutrifft. Die zönologisch vermittelnde Stellung dieser zwischen „Stygobios" einerseits und ,Rhithro"- beziehungsweise ,Potamobios" andererseits lebenden Biozönosen führte zu den Bezeichnungen „Stygorhithron" und „Stygopotamon" für die betreffenden grundwasserführenden Lückenbiotope in Fließgewässer-Schotterbetten (S. Husmann, 1966).

Die mesopsammale oder mesopsephale Beschaffenheit bestimmter Ökozonen dieser aquatilen Subterranbereiche wurde ebenfalls nomi- 
nell berücksichtigt, und zwar so, daß innerhalb des ,,phreatischen Biotops" (Motaş) folgende Lückenbiotope eigener Prägung gegenübergestellt wurden (S. Husmann, 1966):

$$
\begin{aligned}
& \text { „Eustygopsammal" - „Eustygopsephal" } \\
& \text { "Rhithrostygopsammal" - ,,Rhithrostygopsephal“" } \\
& \text { „Potamostygopsammal" - ,,Potamostygopsephal" }
\end{aligned}
$$

Über die ökologische Stellung dieser grundwasserführenden Interstitialbereiche der subterranen Biosphäre und hinsichtlich der zönologischen Eigenarten ihrer Lebensgemeinschaften wurde an anderer Stelle ausführlich berichtet (S. Husmann, 1966), so daß es hier genügen muß, im gesteckten Rahmen dieser Studie nur zusammenfassend das für unsere Erörterungen Wesentliche daraus zu skizzieren.
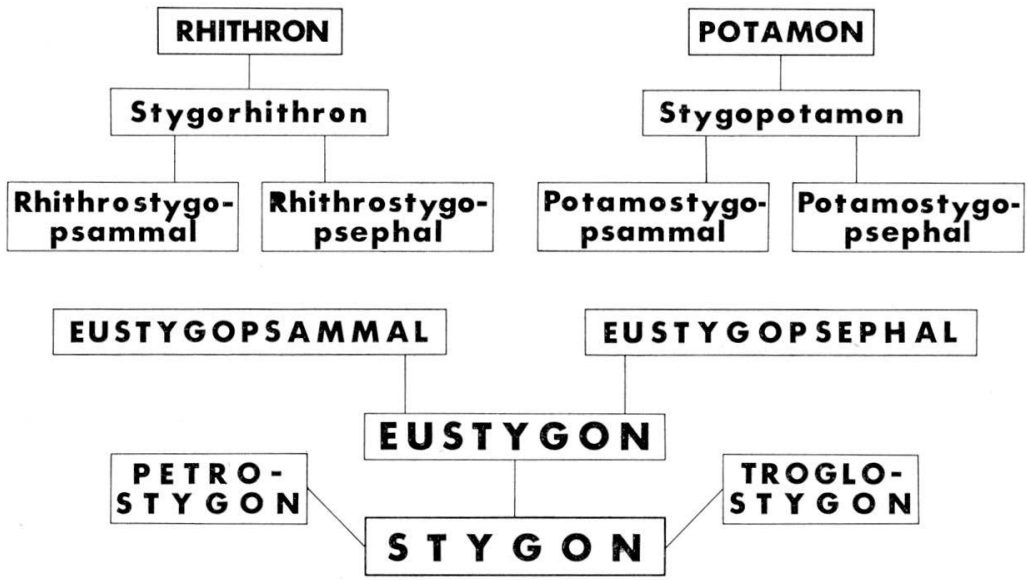

Abb. 3. Die Lebensbereiche des Ökoregnums ,,Stygon“.

(Aus: S. Husmann 1966)

Im Gegensatz zu den mesopsammalen und mesopsephalen Biotopen der Grundwasserfauna wurde für ,Spaltengewässer" im anstehenden Gestein sowie für aquatile Höhlenbiotope deren naturgegebene Zugehörigkeit zum ,Ökoregnum Stygon“ zunächst nur namensgebend hervorgehoben (Husmann, 1966, p. 244), indem für grundwasserführende Spalten in Felsgestein die Bezeichnung

$$
\text { ,.Petrostygon" }
$$

und für Grundwasseransammlungen in weiträumigen Gebirgshöhlen der Terminus

$$
\text { ,Troglostygon“" }
$$

vorgeschlagen wurde; und wenn nun die ökologische Stellung der Höhlen - und Spaltengewässer hier näher umrissen werden soll, so 
geschieht das also zugleich mit dem Ziel, die oben angedeutete Gliederung, die ja nur einen bestimmten Teil des Lebensraumes Grundwasser berücksichtigt, so zu erweitern, daß damit alle Lebensbereiche des Ökoregnums „,Stygon“ erfaßt werden.

\section{VI}

In der immer deutlicher hervortretenden ökologischen Erscheinung, daß die große Masse aquatiler , Höhlen“tiere als ,,eigentlichen Biotop" grundwasserführende Lückensysteme in Lockergesteinsaufschüttungen besiedelt (vgl. p. 411), sah St. Karaman (1954), wie schon berichtet wurde (vgl. p. 410), einen ausreichenden Anlaß, die, Theorie der Höhlenfauna" als ,zu Fall gebracht" anzusehen.

J. Hadzi (1958, p. 472) bezieht gegen die Auffassung, es gäbe in Wirklichkeit gar keine zönobionten Besiedler weiträumiger Gebirgshöhlen Stellung (vgl. p. 410) und betont, daß es eine Anzahl Tiere gibt, die ausschließlich in eigentlichen, begehbaren Höhlen gefunden wurden, und in Hinblick auf diese ökologische Gruppe könne man sich überhaupt nicht vorstellen, daß ihre Elemente als Glieder einer ,faune interstitielle" existieren könnten. Speziell an aquatilen Höhlentieren werden in diesem Zusammenhang allerdings nur die Garnelen (Decapoda/ Natantia) genannt, während A. Vandel (1964, p. 19) - mit gleicher ökologischer Wertung - die cavernicolen Crustaceen Caecosphaeroma, Monolistra, Sphaeromides, Troglocaris sowie die Vertebraten Amblyopsis, Caecobarbus, Anoptichthys und Proteus namhaft macht, ,,die gewiß niemals in ihrer Siedlungsgeschichte die interstitiellen Biotope besiedelt haben"; sie sind, so fährt Vandel fort, ,,direkt von den Gewässern der Erdoberfläche in die unterirdischen Flüsse und Seen eingewandert".

J. Hadzi (1958, p. 472) und A. Vandel (1964, p. 19) sprechen in ihren Erwiderungen gegen die von Karaman (1954, p. 216) geäußerte Ansicht, es existiere überhaupt keine eigentliche „Höhlen"fauna, lediglich von ,,interstitiellen Biotopen", die nicht als Lebensstätten für die obengenannten „Höhlentiere" denkbar seien. Ganz abgesehen davon, daß es meines Erachtens durchaus möglich erscheint, die Lückenbiotope in ausgesprochenen Grobgeröllen auch für einige dieser „,Höhlentiere“ als besiedelbar anzusehen, sei noch darauf hingewiesen, daß es neben weiträumigen Gebirgshöhlen und dem Interstitialbiotop der Geröll-Lückensysteme noch grundwasserführende Bereiche gibt, die durchaus als Lebensstätten eigener Prägung innerhalb des Ökoregnums ,,Stygon" angesehen werden müssen und als ,Hauptökotope" (Briegleb) bestimmter ,Höhlentiere“ gelten dürften: die grundwasser- 
führenden Felsspalten und ferner Zwischenraumsysteme in unterirdischen Ablagerungen zerfallener, ungerollter Felsgesteine. Dieser Lebensbereich wurde als ,Grundwasser in Spalten und Gehängeschutt" (S. Husmann, 1956, p. 152) erstmals besonders hervorgehoben und später als „Petrostygon" (S. Husmann, 1966) der aquatilen Bioregion weiträumiger Gebirgshöhlen an die Seite gestellt.

In der sich auf Grund einer verschiedenen Geräumigkeit ergebenden Stufenfolge von subterranaquatilen Lebensbereichen eigener Prägung (vgl. p. 412) kann die endopetrale wasserführende Dunkelregion ökologisch vermittelnd zwischen den Geröll-Lückenbiotop grober Lockergesteine - ,Mesopsephal" - und den subterranaquatilen Lebensbereich in befahrbaren weiträumigen Gebirgshöhlen gestellt werden.

\section{VII}

Die endopetrische Bioregion „Petrostyg on " ist wegen ihrer relativ geringen Geräumigkeit und der naturgegebenen massiven Isolation für limnologische Untersuchungen nicht ohne ungewöhnliche Schwierigkeiten direkt zugänglich; aber dennoch können die unterirdischen Gewässer von Felsspalten und endopetrischen Mikrokavernen auf indirekte Weise zönologisch erfaßt werden, und zwar dort, wo sie in weiträumige, befahrbare Höhlen beziehungsweise in die darin lokalisierten Höhlengewässer einmünden, oder auch an der Erdoberfläche, da, wo diese endopetralen Grundwässer quellenbildend zutage treten.

Es ist das Verdienst von W. Briegleb (1962), erkannt zu haben, daß sogar eines der Paradebeispiele (vgl. p. 417) zönobionter Faunenelemente der aquatilen Lebensgemeinschaften großräumiger Karsthöhlengewässer offensichtlich als typischer Besiedler der endopetrischen Ökoregion „Petrostygon“" angesehen werden muß: der Grottenolm (Proteus anguinus Laur.); denn nach den Befunden des obengenannten Verfassers stellte es sich eindeutig heraus, ,, daß der Schwerpunkt des Olm-Ökotops in derartigen unberührten Klüften liegt, in denen die Lebensbedingungen den Ansprüchen des Olms besser entsprechen als in den als Fundort bekannten Höhlen" (vgl. p. 425-427), was auch neuerdings von J. Hadzi (1965, p. 25) durch die Mitteilung der Beobachtung eingeräumt wird, daß nicht selten bei Sprengarbeiten, in deren Verlauf enge, mit Wasser gefüllte Spalten aufgeschlossen werden, Olme zutage gefördert werden, und zwar mit dem aus solchen freigelegten Klüften ausströmenden Wasser.

Planmäßige subterranlimnologische Untersuchungen in Zusammenhang mit Sprengarbeiten dürften überhaupt im Verbreitungsgebiet des Olmes zu noch tiefer greifenden Ergebnissen in dieser Hinsicht 
führen; denn zweifellos finden sich im Ausflußwasser von auf solche Weise aufgeschlossenen „Petrostygon“-Bereichen neben Proteus auch dessen ,Nährtiere " und sonstige Elemente der Spaltengewässerfauna, unter denen durchaus weitere Crustaceen-Arten aus der von Vandel (1964, p. 19) hervorgehobenen Gruppe (vgl. p. 417) ausschließlicher Bewohner von Höhlengewässern erwartet werden können.

Es erscheint nun ganz besonders aufschlußreich, auch andere „Höhlentiere" daraufhin zu untersuchen, inwieweit deren ökologische Verteilung dafür spricht, daß es sich bei diesen in weiträumigen, befahrbaren Höhlen gefundenen Arten in Wirklichkeit um Elemente der Mikrokavernenfauna des „Petrostygon“ handeln könnte.

Für eine solche ökologische Beurteilung nehmen aquatile Subterrantiere, die in Brunnen angetroffen wurden, eine sehr aussagekräftige Stellung ein, weil ja das in Trinkwasserbrunnen sich sammelnde Grundwasser durchweg den englumigen Zwischenraumsystemen in Lockergesteinen, Gehängeschutt und Felsspalten entstammt, weswegen schließlich die in Brunnen gefundenen Subterranorganismen sich im allgemeinen als Besiedler derartiger grundwasserführender Lückensysteme ausweisen oder doch zumindest bekunden, daß ,ihre " systematische Gruppe Mikrokavernensysteme zu besiedeln vermag.

\section{VIII}

Unter den von Hadzi und Vandel (vgl. p. 417) hervorgehobenen „Höhlentieren“, die von diesen Autoren als ausschließlich in Höhlen lebend bezeichnet werden, kommen „Höhlengarnelen" (Decapoda Natantia) und „Höhlenfische“ (Pisces) auch in Brunnen vor. Es soll nun im folgenden untersucht werden, inwieweit angenommen werden kann, daß ein Vorkommen derartiger blinder Tiere in Brunnen zu der Schlußfolgerung berechtigt, daß der „Hauptökotop“ dieser „Brunnenfische" und ,-garnelen" im petrostygonalen Grundwasser liegt und daß vom „Petrostygon" aus sowohl Brunnen als auch weiträumige Gebirgshöhlen von blinden Fischen und Garnelen besiedelt werden können. Hierzu soll von einer Aufstellung der bisher bekanntgewordenen Brunnenfundorte dieser Tiergruppen ausgegangen werden:

\section{A. Decapoda Natantia als Elemente der Brunnenfauna}

\section{ATYIDAE}

1. Troglocaris anophthalmus anophthalmus (Kollar 1848).

a) Brunnen nahe Monfalcone (Italien, Venezia Giulia); G. Müller, 1931, p. 207.

b) Brunnen nahe San Giovanni di Duino (Italien, Venezia Giulia); G. Müller, 1931, p. 206. 
c) Brunnen nahe Pulj (= Pola) (Jugoslawien, Istrien); G. Müller, 1931, p. 207.

2. Typhlatya monae Chace 1954.

Brunnen nahe El Molino, West-Indien, Mona Island;

F. A. Chace, 1954, p. 319.

3. Stygiocaris lancifera Holthuis 1960.

a) ,"Kudumurra-Brunnen".

b) ,Milyering-Brunnen“.

c) Mehrere Brunnen nahe Milyering.

a, b, c) West-Australien, Nordwestkap-Halbinsel, Yardie Creek Station.

L. B. Holthuis, 1960, p. 48; G. F. Mees, 1962, p. 30.

4. Stygiocaris stylifera Holthuis 1960.

a) ,,Kudumurra-Brunnen“.

b) Mehrere Brunnen nahe Milyering.

a, b) West-Australien, Nordwestkap-Halbinsel, Yardie Creek Station.

L. B. Holthuis, 1960, p. 54; G. F. Mees, 1962, p. 30.

\section{PALAEMONID A E}

5. Palaemonetes (Alaocaris) antrorum Benedict 1896. Artesischer Brunnen bei San Marcos, Texas;

J. E. Benedict, 1896, p. 615.

6. Troglocubanus gibarensis (Chace 1943).

Brunnen; Cuba.

F. A. Chace, 1943, p. 28.

7. Typhlocaris galilea Calman 1909.

Zisterne der Wassermühle nahe Tabghah am Nordende des Galiläa-Sees;

A. Craig-Bennett, 1938, p. 797.

8. Macrobrachium faustinum (De Saussure 1857).

Brunnen, Pos Caranja, W.-Lima, Bonaire;

F. A. Chace \& L. B. Holthuis, 1948, p. 23.

9. Macrobrachium aff. faustinum (De Saussure 1857).

Brunnen, Pos Caranja, W.-Lima, Bonaire;

W. L. Schmitt, 1936, p. 372; L. B. Holthuis, 1956, p. 67.

10. Euryrhynchus wrzesniowskii Miers 1877.

Brunnen in Cayenne, Französisch Guyana;

E. J. Miers, 1877, p. 663.

11. Euryrhynchus burchelli Calman 1907.

Brunnen in Para, Brasilien;

W. T. Calman, 1907, p. 297.

\section{B. Fische (Pisces Teleostei) als Elemente der Brunnenfauna}

\section{GYPRINIDAE}

1. Eilichthys microphthalmus Pellegrin 1929.

Mehrere Brunnen in Eil, Ital. Somaliland;

J. Pellegrin, 1929, p. 364 . 
II. BAGRIDAE

2. Trogloglanis pattersoni Eigenmann 1919. Brunnen in San Antonio, Texas;

C. H. Eigenmann, 1919, p. 397.

3. Satan eurystomus Hubbs \& Bailey 1947.

Artesischer Brunnen nahe San Antonio, Texas;

C. L. Hubbs \& M. Bailey 1947, p. 8.

4. Prietella phreatophila Caranza 1954.

Brunnen in El Potrero, Coahuila, Mexico;

J. Carranza, 1954, p. 129 u. 136.

III. CLARIIDAE

5. Uegitglanis zammaranoi Gianferrari 1923.

Mehrere Brunnen bei Uegit, Ital. Somaliland;

L. Gianferrari, 1923, p. 1-3.

6. Horaglanis krishnai Menon 1950.

Ein Brunnen bei Kottayan, Kerala, Süd-Indien;

A. G. Menon, 1950, p. 66.

IV. SYMBRANCHIDAE

7. Anommatophasma candidum Mees 1962.

a) ,"Tantabiddi-Brunnen“.

b) ,Milyering-Brunnen“.

c) ,Kudumurra-Brunnen“.

a, b, c) Yardie Creek Station, Nordwestkap-Halbinsel, Australien.

G. F. Mees, 1962, p. 28.

\section{PYGIDIIDAE}

8. Phreatobius cisternarum Goeldi 1904.

Zisterne auf der Insel Marajo, Amazonas-Mündung;

C. R. Goeldi, 1904, p. 549.

VI. AMBLYOPSID A E

9. Chologaster agassizi Putnam 1872

(= Chologaster papilliferus Forbes 1872).

Brunnen in USA;

A. Vandel, 1964, p. 267.

10. Typhlichthys subterraneus Girard 1859

(= Typhlichthys wyandotte Eigenmann 1905).

a) Brunnen nahe Bowling Green Ky, Californien;

Ch. Girard, 1859, p. 62.

b) Brunnen nahe Corydon, Indiana;

C. H. Eigenmann, 1905, p. 63.

11. Amblyopsis spelaea De Kay 1842.

Brunnen in Indiana;

L. P. Woods \& F. Inger, 1957, p. 245.

\section{ELEOTRIDAE}

12. Milyeringa veritas Whitley 1945.

a) ,Milyering-Brunnen".

b) ,Kudumurra-Brunnen“.

a, b) Yardie Creek-Station, Nordwestkap-Halbinsel, Australien; G. F. Mees, 1962, p. 29. 
VIII. GOBIIDAE

13. Luciogobius pallidus Regan 1940.

Brunnen in Japan;

T. Regan, 1940.

Bei der Untersuchung obiger Brunnenbiotope von ,Höhlentieren“ fanden die grundwasserführenden Schichten, in die die betreffenden Grundwassersammelbehälter eintauchen, nur in wenigen Fällen besondere Beachtung. Dennoch gibt es einige für unsere Fragestellung besonders aufschlußreiche Angaben, die durchaus dafür sprechen, daß wassererfüllte Spaltensysteme und Zwischenraumlabyrinthe eindeutig als ,Hauptökotope“ (Briegleb) der in den genannten Brunnen angetroffenen durchweg blinden und pigmentlosen Garnelen und Fische angesehen werden müssen.

Besonders eindrucksvoll sind in dieser Hinsicht die von G. F. Mees (1962) beschriebenen Biotopverhältnisse innerhalb des grundwasserführenden Gesteins im Einzugsmantel der ,Garnelen- und Fischbrunnen" Westaustraliens, in denen zwei blinde Decapoda Natantia (vgl. p. 420):

Stygiocaris lancifera Holthuis 1960,

Stygiocaris stylifera Holthuis 1960,

angetroffen werden konnten und in denen außerdem noch zwei Arten augenloser Fische (vgl. p. 421) leben:

Anommatophasma candidum Mees 1962,

Milyeringa veritas Whitley 1945.

Nach G. F. Mees (1962, p. 24, 26) stehen die von diesen Arten besiedelten Brunnen in einer Küstenterrasse von $1 \frac{1}{2}-3 \mathrm{~km}$ Breite, deren Untergrund aus Korallengestein, Schnecken- und Muschelschalen aufgebaut ist. Diese Ablagerungen sind von Rissen, engen Höhlungen und verbindenden Gängen (,,crevices, small holes and connecting corridors") durchzogen, so daß ein ausgedehntes subterranes Netzwerk von Wasseradern (,an extensive subterranean network of waterways") existiert, ,which forms the habitat of the fauna under discussion". Zu dieser Feststellung, daß die grundwasserführenden Risse, Spalten und sonstigen Lückensysteme den speziellen Biotop dieser blinden Besiedler unterirdischer Gewässer darstellen, führte auch die Beobachtung, daß Milyeringa veritas durch Spalten und Risse der Brunnenwandung hindurch in den jeweils als Sekundärbiotop angenommenen Brunnen einwandert und diese Öffnungen auch zur Rückkehr ins anstehende „Lückengestein“ benutzt (G. F. Mees, 1962, p. 26).

Ein ähnliches Verhalten beobachtete G. Thines (1958, p. 120) bei Uegitglanis zammaranoi Gianferrari in einem Brunnen bei Uegit in Italienisch-Somaliland (vgl. p. 421): Die Tiere verließen hastig einen 
kleinen Spalt (,,une petite crevasse ${ }^{6)}$ zwischen den Steinen der Seitenwand, was darauf schließen will, daß Uegitglanis zammaranoi in Wirklichkeit ein Besiedler des Grundwasserstromes ist, in dem der untersuchte Brunnen steht, welch letzterer somit als ein mehr oder weniger zufällig aufgesuchter Lebensbereich (,un habitat accidentel“) anzusehen ist.

Auch Anommatophasma candidum Mees 1962 ist ein Besiedler von Spalten- und Lückensystemen, die mit dem von G. F. Mees (1962) untersuchten westaustralischen Brunnen in Verbindung stehen. Doch diese Art erreicht ihre Brunnenbiotope nicht aus frei von Grundwasser durchströmten Mikrokavernen. Die aalartige Gestalt dieses zur Familie Synbranchidae zählenden Brunnenbesiedlers verleiht diesem auffallend weiß aussehenden „Blindfisch“ die Fähigkeit, normalerweise sogar Gesteinsspalten zu besiedeln, die nicht nur von Grundwasser durchflossen, sondern zudem noch von organischen und anorganischen Zerfallsteilen (,mud and debris“") ausgefüllt sind (vgl. G. F. Mees, 1962, p. 24). Diese Subterranfische bewegen sich schlängelnd und wühlend durch die labyrinthartigen grundwasserführenden Spaltensysteme hindurch und erreichen dabei unter Umständen Brunnen als zusätzliche Lebensstätten ${ }^{1}$ ).

Neben diesen ,Brunnenfischen“ sind noch einige blinde Fischarten bekanntgeworden, die innerhalb von Flußbetten in Gesteinszwischenräumen leben. Sie deuten ebenfalls darauf hin, daß naturgegebene Mikrokavernen als Hauptökotope blinder Wassertiere angesehen werden müssen.

\section{IX}

Aus der Familie Pygidiidae begegnete uns in der vorstehenden $\mathrm{Zu}$ sammenstellung von "Brunnenfischen" bereits eine blinde Art Phreatobius cisternarum Goeldi 1904 -, deren Vorkommen in einem Brunnen auf der Amazonasinsel Marajo (vgl. p. 421) darauf schließen ließ, daß diese Art die Lückensysteme des Brunneneinzugsgebietes besiedelt.

Aus dem Stromgebiet des Amazonas wurden noch zwei weitere Arten von ,Blindfischen“ bekannt, die ebenfalls den Pygidiidae angehören, und zwar einer neuen Unterfamilie: Glanapteryginae Myers

1) Mit der Erwähnung der Möglichkeit einer derartigen ,,Untergrundpassage" (,,underground passage“) versucht bereits C. L. Hubbs (1936, p. 166) das sympatrische Vorkommen zweier Formen des Höhlenfisches Rhamdia guatemalensis zu deuten: "These two forms probably migrated into this cave by different underground passages", wie ja auch schließlich das Vorkommen zweier Stygiocaris-Arten in einem Brunnen Australiens (vgl. p. 420) nur durch Untergrundpassage von zwei Entwicklungszentren her erklärbar ist. 
1944. Sie wurden im Gesteinsbett des Rio Negro unterhalb der Stromschnellen von Sao Gabriel entdeckt (G. S. Myers, 1944, p. 593). Die langgestreckte Gestalt dieser in wassererfüllten Lückensystemen zwischen Steinen oder in Spalten lebenden Fischarten

Pygidianops eigenmanni Myers 1944,

Typhlobelus ternetzi Myers 1944

darf ebenso berechtigt als ,lebensformtypisch" bezeichnet werden, wie die der in Sand- oder Kieslückensystemen vorkommenden wurmförmig gestreckten biotopeigenen Arten (vgl. p. 411 u. Abb. 1, 2).

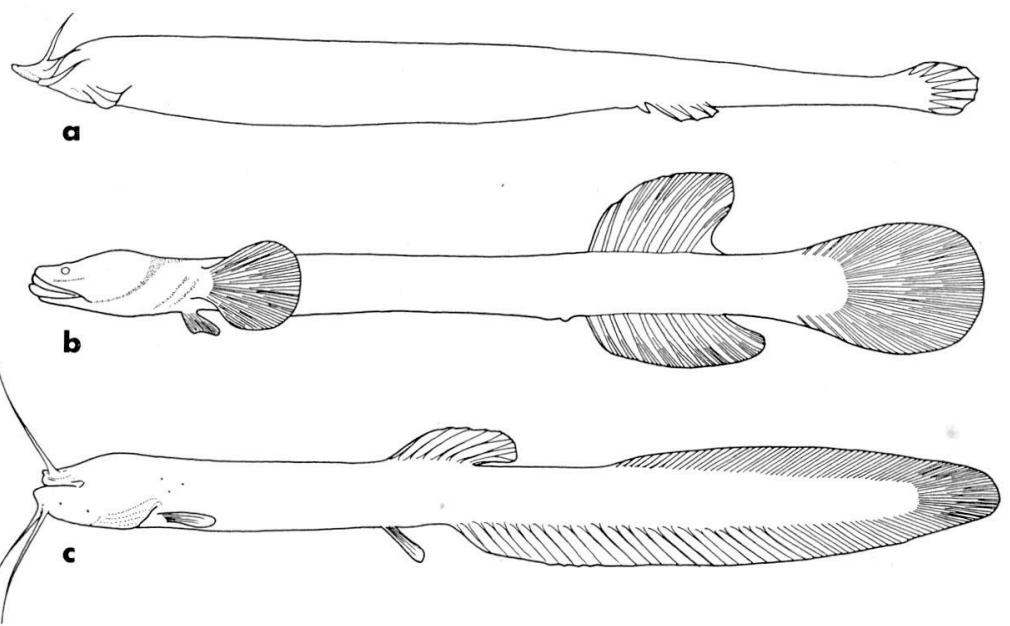

Abb. 4. Fische (Pisces) als Lebensformtypen der Lückensystemfauna; a: Typhlobelus ternetzi Myers 1944 (n. G. S. Myers, 1944), b: Luciogobius guttatus ama (Snyder 1909) (n. Snyder, 1909), c: Phreatobius cisternarum Goeldi 1904 (n.M.Reichel, 1927) (Längenmaße; a: 33,5 mm, b: 40,5 mm, c: 40,5 mm).

Aber auch die Blindheit und Pigmentlosigkeit der obengenannten „Rio-Negro-Fische“"1) stellt diese Arten - so wie die vorstehend erwähnten blinden, milchigweißen „Brunnenfische“ - ökologisch an die Seite von Subterranorganismen, deren Hauptökotop in wasserführenden Mikrokavernen zu suchen ist.

Blindheit und Pigmentlosigkeit - verbunden mit lebensformtypischer Gestalt oder relativ geringer Körpergröße - sind offenbar Eigenschaftskombinationen, die darauf schließen lassen dürfen, daß derartige Organismen als Hauptökotope Spaltengewässer oder sonstige wasserführende Lückenbiotope besiedeln.

1) Pygidianops eigenmanni ist vollkommen augenlos, Typhlobelus ternetzi weist Reste verkümmerter Augen auf; beide Formen sind vollkommen pigmentlos (G. S. Myers, 1944, p. 592, 593). 


\section{$\mathbf{X}$}

Die Annahme, daß wasserführende Zwischenraumsysteme im allgemeinen als ,eigentliche Biotope" blinder, pigmentloser Wassertiere anzusehen sind, da $\beta$ somit derartige in Brunnen, Höhlen oder Quellen angetroffene Faunenelemente zönologisch der Mikrokavernentierwelt zuzuordnen sind, diese ökologische Schlußfolgerung also ergibt sich auch aus einer naturgegebenen Regelmäßigkeit, nach der offensichtlich die Verteilung der Grundwassertiere innerhalb der subterranaquatilen Biotope eigener Prägung gesteuert wird. Für unser Vorhaben, die ökologische Position der Gewässer weiträumiger Gebirgshöhlen und ihrer Fauna festzulegen, ist es besonders aufschlußreich, den Lebens,,raum" „Höhle" in seiner Abhängigkeit von dieser subterranökologischen Gesetzmäßigkeit zu erfassen.

Das hier hervorgehobene allgemein in subterranlimnischen Biotopen wirkende ökologische Grundprinzip gibt sich vor allem in der Erscheinung zu erkennen, daß die Körpergestalt der Grundwassertiere - insbesondere der maximale Körperquerschnitt - insofern von entscheidender Bedeutung für die Hauptökotopwahl ist, als anscheinend grundsätzlich ein möglichst engräumiger grundwasserführender „Kleinsthöhlenbiotop" bevorzugt wird, dessen mikrokavernale Beengtheit allen ,zu großen" Feindarten zwangsläufig das Eindringen erwehrt. So leben ja auch bekanntlich die bei ihrem so überaus geringen Körperumfang extrem langgestreckten "Lebensformtypen“" (Remane) der "Sandlückenfauna“ (vgl. Abb.1) gemeinsam mit ihrer durch ,angemessene“ Körpergröße ausgezeichneten Begleitfauna in hochgradiger ,zönologischer Isolation“" gegenüber räuberischen Elementen der "Kieslückenfauna“. Diese Besiedler mesopsephaler Lückenbiotope finden in den Zwischenraumsystemen fein- bis grobkörniger Kiese ,ihren" optimalen Lebensbereich, und zwar ebenfalls auf Grund der auch darin gegebenen ökologischen Abgeschlossenheit gegenüber eigenen Feindarten von überlegener Körpergestalt. Auch die ,petrostygonalen“" Zwischenraumsysteme (vgl. p. 416) können ebenfalls entsprechende ökologische Schutzbereiche darstellen, was sich besonders deutlich bei den schon erwähnten (vgl. p. 418) speologischen Befunden von W. Briegleb (1962) zeigte. Diese allerdings in erster Linie die Ökologie des Olmes behandelnden Untersuchungsergebnisse enthalten Angaben, deren Auswertung im Rahmen unserer allgemein-subterranökologischen Fragestellung bedeutsame Aufschlüsse gibt; und daher soll noch einmal - entsprechend gezielt und schlußfolgernd - darauf eingegangen werden.

W. Briegleb (1962, p. 273, 274) stellt fest, daß die Olme mit ihrer stygobionten Begleitfauna innerhalb des untersuchten Höhlengewäs- 
sers nur in einem sogenannten „Randökotop“ leben, das heißt: in jener Höhlengewässerzone, in die das ,,petrostygonale" Grundwasser (vgl. p. 416) - aus dem eigentlichen ,Olm-Biotop" kommend - einmündet.

In diesem beengten „,Randökotop“ des Olmes fanden sich neben Proteus anguinus Laurenti noch andere, ,echte" Subterranorganismen: die Garnele Troglocaris spec. sowie Niphargus spec., die sich beide als wichtigste Beutetiere des Olmes erwiesen, ferner noch Asellus aquaticus (Linnaeus), mit Anpassungen an das Höhlenleben, sowie Trikladen.

Die außer Asellus aquaticus von der Erdoberfläche her in das von Briegleb untersuchte Höhlengewässer eindringenden ,zönophilen“ beziehungsweise ,zönoxenen“" „Höhlentiere“ - Forellen (Trutta), Flußkrebse (Astacus), Flohkrebse (Gammarus pulex), Trichopterenund Plecopterenlarven - überschreiten bezeichnenderweise eine bestimmte Grenze in der Tiefe des Höhlengewässers nicht; und diese „,vordere Linie" ihres sich durch den Höhleneingang in die Höhle einschiebenden Siedlungsgebietes ist zugleich die äußere Grenze des von Proteus, Troglocaris, Niphargus, Asellus und Trikladen besiedelten „Olm-Randökotops". Diese stygobionte Fauna findet im Bereich ihres Höhlengewässer-Refugiums eine offenbar sichere Zuflucht vor den gefräßigen Forellen (Trutta) und Flußkrebsen (Astacus), von denen diese Elemente der Spaltengewässerfauna buchstäblich ,,in die Enge getrieben" werden.

Die Tatsache, daß es den außerordentlich räuberischen Flußkrebsen und auch den sich ebenso verhaltenden Forellen ganz offensichtlich auf Grund ,innerer Faktoren" verwehrt ist, den Randökotop des Olmes (Proteus anguineus) und seiner stygobionten Begleitfauna über ein bestimmtes Maß einzuengen, zeigt, daß nicht immer nur allein der oben in den Vordergrund gestellte Grad der Geräumigkeit grundwasserführender Kavernen über das Eindringevermögen von außerhalb lebenden Tieren entscheidet, sondern daß die ,zönologische Isolation" kavernaler Biozönosen in bestimmten Fällen auch von Tieren nicht gestört werden kann, deren Körpergröße an sich ein Eindringen möglich machen würde, die aber innerhalb ihres ,Artbildes" nicht über die ,,physiologische Bereitschaft" verfügen, in unterirdischen Bereichen über eine bestimmte Grenze hinaus vorzudringen.

Diese Feststellung läßt erkennen, daß unser oben hervorgehobenes ökologisches Grundprinzip (vgl. p. 425) einer entsprechend umfassenderen Formulierung bedarf, zumal da sich im Wesen ähnliche zönologische Grenzbereiche auch in den Bioregionen der Mikrokavernenfauna nachweisen lassen, beispielsweise in den Übergangszonen vom „Stygorhithron“ zum „Eustygon“" (vgl. p. 415, 416), wo eine ganze 
Reihe von Arten der ,stygorhithrophilen“ Interstitialfauna nebst „,stygorhithrobionten“Wassermilben (Hydrachnellae und Halacaridae) es nicht vermag, über eine mehr oder weniger deutliche Grenze hinaus in die Randbereiche des Schotterbettes oder gar ins uferferne Talauengrundwasser (,Eustygon“) hinein vorzudringen (vgl.S. Husmann 1966).

Das für eine zönologische Beurteilung der ,Höhlenfauna "zweifellos sehr bedeutsame und auch innerhalb dieser Erörterungen daher verschiedentlich erwähnte ökologische Grundprinzip der Herausbildung von Hauptökotopen der Grundwasserfauna könnte bei Berücksichtigung der hier gekennzeichneten biotischen und abiotischen Faktoren in erster Fassung etwa so formuliert werden:

Der eigentliche Lebensbereich (Hauptökotop) von Grundwassertieren wird - neben sonstigen optimalen Lebensvoraussetzungen durch eine im Verhältnis zum Körperdurchmesser der einzelnen Arten extreme Engräumigkeit der besiedelten grundwasserführenden Kavernen gekennzeichnet, die deren Bewohnern eine hochgradige ,zönologische Isolation" und damit eine günstige ökologische Geborgenheit gewährt, indem allen ,,zu großen“ Feindarten und Nahrungskonkurrenten eine Immigration verwehrt wird. Diese ökologische Abschirmung gegenüber lästigen Mitbesiedlern kann zudem subterran stellenweise noch dadurch abgesichert werden, daß morphologisch an sich „,passende" Feindarten und Konkurrenten sich selber infolge einer ,physiologischen Ungeeignetheit" von der Immigration ausschließen.

\section{XI}

Wenn man nun also mit Recht für alle „Hauptökotope“ der Grundwasserfauna in bezug auf ihre charakteristischen Besiedler - neben allen sonstigen günstigen Lebensverhältnissen - eine auffallend extreme mikrokavernale Beengtheit als ganz besondere Voraussetzung der darin für diese Tiere herrschenden optimalen Lebensbedingungen ansehen kann, so müssen Gewässer in befahrbaren Höhlen als besonders ungünstige Lebens,,räume" stygobionter Grundwassertiere angesehen werden, weil darin der ökologisch so sehr bedeutsame Faktor ,Engräumigkeit" fortfällt. Das damit verbundene Fehlen einer existenzfördernden lebens,,raum"bedingten ,zönologischen Isolation“ (vgl. p. 425) kann sich in negativster Weise naturgemäß gegen typische Elemente der „Sand-“ und ,Kieslückenfauna“ auswirken, aber auch recht erheblich gegenüber Elementen der petrostygonalen (vgl. p. 416) Fauna, wie Briegleb (vgl. p. 426) herausfand.

Die Erfahrung, daß einzelne Arten der stygobionten Grundwassertierwelt unter Umständen Höhlengewässer recht individuenreich zu 
besiedeln vermögen, zeigt, wie sehr auch in Höhlen unter besonderen Voraussetzungen dennoch hin und wieder günstige Verhältnisse für Elemente der Lückenfauna herrschen können, beispielsweise dann, wenn sich diesen Tieren in Makrokavernen keine überlegenen räuberischen Wassertiere entgegenstellen, mit anderen Worten: wenn darin eine gleichwertig umfassende „ökologische Abgeschlossenheit“" herrscht, wie in den engräumigen Hauptökotopen der Interstitialfauna. Innerhalb von Höhlengewässern entscheidet also der Grad des zönologischen Einwirkens ,,lästiger" Faunenelemente über den Umfang einer biozönotischen Entfaltung dieser mikrokavernalen Grundwassertiere; und durch die hydrogeologische Verschiedenheit limnischer Höhlenbereiche wird es bedingt, daß es für die ökologischen Verhältnisse in „Wasserhöhlen“ ein ganzes Spektrum von Möglichkeiten gibt, von denen für Grundwassertiere jeweils eine zum Tragen kommen kann. Da diese Fülle ökologischer Möglichkeiten für in Höhlengewässer geratene Lückenbesiedler von einer günstigen ,zönologischen Isolation" bis zu einer totalen biozönotischen Unterlegenheit gegenüber Feindarten reichen kann, sind naturgemäß für Elemente der Interstitialfauna in Höhlengewässern alle möglichen Grade eines biozönotischen Sichbehauptens oder aber gar keine Existenzmöglichkeiten denkbar.

Die sich daraus ergebende Vielfalt biozönotischer Kombinationsmöglichkeiten spricht schon allein dafür, daß nicht nur die Berechtigung besteht, Höhlengewässer innerhalb des Ökoregnums „Stygon“ (vgl. p. 411) als Lebensbereiche besonderer Prägung anzuerkennen, sondern daß innerhalb dieser weiträumigen aquatilen Subterranregion sogar noch eine zönologische Zonierung vorgenommen werden kann, wie die von Briegleb (1962) erfaßten entsprechenden Verhältnisse in und an den Kontaktzonen stygobionter und rhithrobenthaler Biozönosen in Höhlen erkennen lassen (vgl. p. 426).

Ganz gleich, ob es überhaupt zönobionte Höhlentiere gibt oder nicht (vgl. p. 410), geschieht es also - so oder so - durchaus mit Recht, wenn von Grundwassertieren besiedelte Süßwasseransammlungen in Höhlen als aquatile Subterranbiotope eigener Prägung angesehen und als Bereiche eines besonderen Ökosystems - ,Troglostygon" - hervorgehoben werden.

\section{XII}

Der Lebensbereich der unterirdischen Gewässer in Höhlen, die Ökoregion ,Troglostygon “, umfaßt naturgemäß nur jene Höhlen, deren Gewässer eine rein limnische Natur aufweisen, ganz entsprechend der namensgebenden Beziehungsaufnahme zum kontinentalen 
Strom der Unterwelt „Styx“. Es gibt nun aber neben einem solchen „Limnotroglon" (=, Stygotroglon") noch einen weiteren makrokavernalen Lebensbereich eigener Prägung, dessen ökologische Eigenständigkeit durch einen über einer bestimmten Höhe liegenden Gehalt an im Wasser gelösten Salzen gekennzeichnet ist. Die ökologische Besonderheit dieser ,Meereshöhlen" betont bereits Th. Fuchs (1894, p. 54), und das insbesondere in Hinblick darauf, daß diese vom Licht abgeschlossenen Marinbiotope mit dem ebenfalls lichtlosen Lebensbereich ,Tiefsee“ ökologisch verwandt sind. Der genannte Autor weist auf den Blindfisch Stygicola dentata (Poey, 1856) hin, der auf Kuba in Höhlen vorkommt, ,, welche mit dem Meere kommuniciren", und dessen Nächstverwandte in der Tiefsee verbreitet sind, was sich insbesondere in der auffallenden Ähnlichkeit mit dem blinden Aphyonus gelatinosus zeigt, der bei Neu-Guinea in einer Tiefe von 1400 Faden erbeutet wurde.

Die gleichen ökologischen Beziehungen zwischen Marinhöhlen und Tiefsee belegt Th. Fuchs (1894, p. 55) mit dem Auffinden von Munidiopsis polymorpha Koelbel 1892 (Decapoda, Reptantia, Anomura), die in einer mit dem Meere in Verbindung stehenden Höhle im Untergrund der Insel Lanzarote lebt (vgl. K. Koelbel, 1892, p. 105) und die einer ,,ausgesprochenen Tiefseegattung" angehört, die ,,bisher nur in Tiefen von 100-2000 Faden gefunden" wurde.

Es ist bemerkenswert, daß Th. Fuchs (1894, p. 55) bereits den Hinweis gibt, daß es bekanntlich , auch im Gebiet des Mittelmeeres mit dem Meere kommunicirende und mit Meerwasser gefüllte Höhlen“" gibt und daß es ,, sicherlich von großem Interesse" sei, auch diese Höhlen zu untersuchen. Es mußte jedoch erst ein halbes Jahrhundert vergehen, bis es neuerdings den von beispielhaftem Unternehmungsgeist getragenen Forschungen der Arbeitsgruppe Riedl (R. Riedl, 1959, 1959 a, 1959 b, 1963, 1964, 1966 ; E. F. Abel, 1959, 1959 a; K. Banse, 1959; G. Czihak, 1954; K. Russ \& K. Rützler, 1959; F. Starmühlner, 1955, 1955 a; W. Wieser, 1954; sowie J. Laborel et J. Vacelet, 1958) zu verdanken ist, daß dieser Lebensraum der Meereshöhlen in seiner Vielfalt und ökologischen Sonderstellung intensiv erfaßt wurde.

Da es nun aber mit dem Meere in Verbindung stehende Höhlensysteme gibt, in denen landeinwärts der marine Einfluß nahezu abklingt, können limnische und marine Höhlenregionen mehr oder weniger kontinuierlich ineinander übergehen. Daher kann auch diese Studie über die ökologische Position der limnischen Höhlengewässer innerhalb des Ökoregnums „Stygon“ nicht abgeschlossen werden, ohne diesem ,,ökologischen Gefälle“ zwischen ,Limnotroglon“" (=, Troglostygon") und, Thalassotroglon" zu folgen. 
Der obenerwähnte, zugleich trennende und verbindende „Grenzunschärfebereich" (vgl. G. H. Schwabe u. H. Klinge, 1960) zwischen Limnotroglon und Thalassotroglon zeigt, wie eng die Berührungspunkte liegen, an denen ,Limnospeologie“ und ,Thalassospeologie“ zusammentreffen. Eine somit von beiden Forschungsrichtungen aus naheliegende Inbeziehungsetzung makrokavernaler limnischer und mariner Lebensbereiche würde jedoch nur ein unvollständiger Brükkenschlag zwischen mariner und limnischer Subterranökologie bleiben, wenn nicht die ebenfalls in ökologischen Grenzunschärfebereichen ineinander übergehenden mikrokavernalen limnischen und marinen Lebensstätten entsprechend in Beziehung gesetzt werden. Das soll hier nur andeutungsweise vorgenommen werden, indem unserem „Stygopsammal" das ,Thalassopsammal" und dem „Stygopsephal" ein ,Thalassopsephal" zur Seite gestellt wird (Abb. 5).

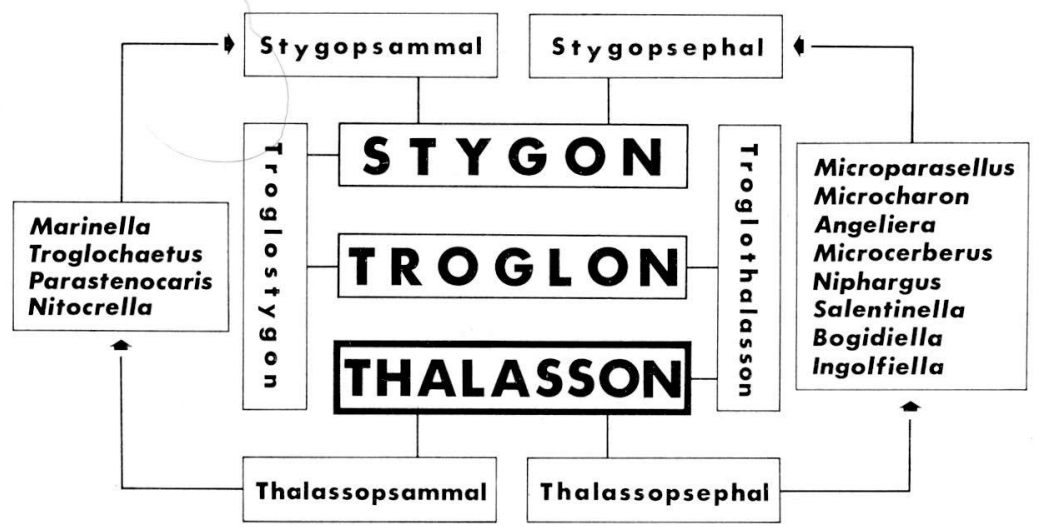

Abb. 5. Die ökologische und zönologische Verknüpfung mikro- und makrokavernaler Biotope und Biozönosen der Ökoregionen „Stygon“, ,,Thalasson" und , Troglon".

Wie eng gerade diese mikrokavernalen grundwasserführenden Biotope ökologisch verzahnt sind, geht daraus hervor, daß eine ganze Reihe limnischer Grundwassertiere im Mesopsammal beziehungsweise im Mesopsephal den ökologischen Übergang vom marinen zum limnischen Grundwasser vollziehen konnte (Abb. 5), und da einige dieser Immigranten sogar bis in limnische Höhlengewässer vorgedrungen sind (z. B.: Troglochaetus, Parastenocaris, Nitocrella, Microparasellus, Microcharon, Salentinella, Niphargus), wird ersichtlich, wie angebracht es ist, daß ,Limnospeologie“" und ,Thalassospeologie" sowie limnologische und marinökologische Grundwasserforschung ihr jeweiliges Arbeitsgebiet als Teil eines zusammengehörenden Ganzen sehen. 


\section{ZUSAMMENFASSUNG}

,,Höhlen-“ und „,Spaltengewässer" werden als subterranaquatile Ökosysteme (,,Troglostygon", ,,Petrostygon") den übrigen grundwasserführenden Lebensbereichen (z.B.,,Eustygon", ,,Stygorhithron“", ,Stygopotamon“) gegenübergestellt.

Die Besiedlung unterirdischer Biotope wird auf die Wirkung eines ,,Grundprinzips der Herausbildung von Hauptökotopen der Grundwasserfauna" zurückgeführt.

Nach dieser ökologischen Gesetzmäßigkeit, die im einzelnen erläutert und formuliert wird, sind grundwasserführende Lückenbiotope (z. B. ,,Eustygopsammal“", ,Rhithrostygopsephal“", ,Potamostygopsammal) als eigentliche Lebensbereiche der stygobionten Grundwasserfauna anzusehen, Höhlengewässer aber als Sekundärbiotope.

Die von Tieren besiedelten Meereshöhlen werden als Ökosystem ,,Thalassotroglon" in ihren Beziehungen zum ,Limnotroglon" (,,Troglostygon“) dargestellt.

Bei der damit vollzogenen Kontaktaufnahme zwischen „Limnospeologie" und ,Thalassospeologie" werden auch die limnischen und marinen mikrokavernalen Lebensbereiche mit berücksichtigt: ,"Thalassopsammal“ und ,,Thalassopsephal".

„Limnospeologie“ und „Thalassospeologie“ sowie limnologische und thalassologische Grundwasserforschung werden als biologische Arbeitsrichtungen charakterisiert, die der Erforschung eines ökologisch verknüpften Ganzen dienen.

\section{SUMMARY}

Bodies of waters in caves and in crevices of rocks are distinguished from the other subsoil water ecosystems ("eustygon", "stygorhithron", "stygopotamon") under the names "troglostygon" and "petrostygon".

The colonisation of subsoil water biotopes involves a fundamental principle which controls the development of the main biotopes for the stygobiont undergroundwater organisms.

According to this ecological rule, which is described in detail and formulated, the several interstitial biotopes (for example "eustygopsammal," "rhithrostygopsammal," "potamostygopsephal") are to be considered as the real biotopes of the stygobiont subsoil water organisms; waters in caves, on the contrary, are secondary biotopes of these animals.

Caves which contain marine water are described as ecostystem "Thalassotroglon" in their relation to "limnotroglon" (= "stygotroglon").

In this way the contact between "limnospeology" and "thalassospeology" is established, and the limnic and marine microcavernal biotopes - "thalassopsammal" and "thalassopsephal" - are also taken in consideration.

"Limnospeology" and "thalassospeology" as limnological and thalassological investigations of subsoil water are characterized as biological fields of work, which serve for the investigation of an ecological unit.

\section{LITERATUR}

Aвец, E. F. (1959) - Zur Kenntnis der marinen Höhlenfauna unter besonderer Berücksichtigung der Anthozoen. Ergebn. d. Österr. TyrrheniaExpedition 1952, Teil V. Pubbl. Staz. Zool. Napoli, Suppl. 30:1-94. 
AвeL, E.F. (1959 a) - Zur Kenntnis der Beziehungen der Fische zu Höhlen im Mittelmeer. Ergebn. d. Österr. Tyrrhenia-Expedition 1952, Teil XIV. Pubbl. Staz. Zool. Napoli, Suppl. 30: 519-527.

Angelier, E. (1953) - Recherches écologiques et biogéographiques sur la fauna des sables submergés. Arch. Zool. Expér. Gén. 90: 37-161.

BAnse, K. (1959) - Über die Polychaeten-Besiedlung einiger submariner Höhlen. Ergebn. d. Österr. Tyrrhenia-Expedition 1952, Teil XII. Pubbl. Staz. Zool. Napoli, Suppl. 30: 417-469.

Benedict, J. E. (1896) - Preliminary descriptions of a new genus and three new species of Crustaceans from an artesian well at San Marcos, Texas. Proc. U.S. Nat. Mus., vol. 18: 615-617.

Briegleb, W. (1962) - Zur Biologie und Ökologie des Grottenolms (Proteus anguinus Laur. 1768). Z. Morph. Ökol. Tiere 51: 271-334.

Calman, W. T. (1907) - On a Freshwater Decapod Crustacean collected by W. J. Burchell at Pará in 1829. Ann. Mag. nat. Hist. 19: 295-299.

Carranza, J. (1954) - Description del primer bagre anoftalmo y depigmentado en aguas Mexicanes. Ciencia XIV: 129-136.

Chace, F. A. (1943) - Two new blind Prawns from Cuba with a Synopsis of the subterranean Caridea of America. Proc. New Engl. zool. Cl. $22: 25-40$.

- (1954) - Two new subterranean shrimps (Decapoda: Caridea) from Florida and the West Indies, with a revised key to the American species. Journ. Wash. Acad. Sci. 44: 318-324.

Chace, F. A., und Holthuis, L. B. (1948) - Land and fresh water Decapod Crustacea from the Leerward Group and Northern South America. In: Hummelinck, Studies on the fauna of Curaçao, Aruba, Bonaire and the Venezuelan Islands 3: 21-28.

Chappurs, P. A. (1944) - Die Grundwasserfauna der Körös und des Szamos. A Magyar Tudományos Akadémia Kiadasa: 1-42.

- (1948) - Copépodes, Syncarides et Isopodes des eaux phréatiques de Suisse. Rev. Suisse Zool. 55 : 549-566.

- (1950) - La récolte de la faune souterraine. Notes biospéol. V: 7-35.

Craig-Bennett, A. (1938) - Record of Typhlocaris galilaea. Nature, 142 : 797.

Czıнак, G. (1954) - Die Schlangensterne einer submersen Höhle des Tyrrhenischen Meeres. Ergebn. d. Österr. Tyrrhenia-Expedition 1952, Teil III. Österr. Zool. Zeitschr. V: 15-29.

Defamare-Deboutteville, C. (1960) - Biologie des eaux souterraines littorales et continentales: 1-740. Herman, Paris.

Eigenmann, C. H. (1898) - The origin of cave faunas. Proceed. Ind. Acad. Sc. (1897): 229-230.

- (1905) - Divergence and Convergence in Fishes. Biol. Bull. VIII : 59-66.

- (1909) - Cave Vertebrates of America. A study of degenerative evolution. Carnegie Institut Washington Public. 104: 13.

- (1919) - Trogloglanis pattersoni, a new blind fish from San Antonio, Texas. Proceed. americ. philos. Soc. LVIII : 397-400.

Fuchs, Tн. (1894) - Über Tiefseetiere in Höhlen. Ann. K. K. Naturhist. Hofmuseum Wien IX: 54-55.

Garman, H. (1892) - The origin of the cave fauna of Kentucky, with a description of a new blind beetle. Science XX: 240-241. 
Gianferrari, L. (1923) - Uegitglanis zammaranoi, un nuevo siluride cieco africano. Atti. Soc. Ital. Sc. Nat. Milano LXII : 1-3.

Girard, M. D. (1859) - Ichthyological Notices. Proc. Acad. Nat. Sci. Phila.: 62-64.

Goeldi, E. (1904) - Nova zoologica aus der Amazonas-Region. Neue Wirbeltiere. Comptes-Rendus 6e Congrès internat. Zoologie, Berne: 542-549.

Hadzi, J. (1958) - Fortschritte in der Erforschung der Höhlenfauna des Dinarischen Karstes. Verh. Dtsch. Zool. Ges. (1957) 21:470-477.

- (1965) - Bemerkungen zu einigen biospeläologischen Problemen des Dinarischen Karstes. Nase Jame VII : 21-31.

Haine, E. (1946) - Die Fauna des Grundwassers von Bonn mit besonderer Berücksichtigung der Crustaceen.-Inaugural-Diss., Melle in Hannover.

Hertzog, L. (1936) - Crustaceen aus unterirdischen Biotopen des Rheintales bei Straßburg. I. Mitt. Zool. Anz. 114: 271-279.

Holthuis, L. B. (1956) - An enumeration of the Crustacea Decapoda Natantia inhabiting subterranean waters. Vie et Milieu VII : 43-76.

- (1960) - Two new species of atyid shrimps from subterranean waters of N.W. Australia (Decapoda Natantia). Crustaceana I : 47-57.

Huввs, C. L. (1936) - Fishes of the Yucatan Peninsula. Carnegie Institut Washington Public. 457: 157.

Huвbs, C. L., und Bailey, R. M. (1947) - Blind Catfishes from artersian waters of Texas. Occas. Papers Mus. Zool. Univ. Michigan 499.

Husman N, S. (1956) - Untersuchungen über die Grundwasserfauna zwischen Harz und Weser. Arch. Hydrobiol. 52: 1-184.

- (1957) - Die Besiedelung des Grundwassers im südlichen Niedersachsen. Beitr. Naturkde. Nieders. 10: 87-96.

- (1958) - Sand- und Schotterufer als Grenzbereiche limnologischer und bodenbiologischer Forschung. Gewässer und Abwässer 22: 66-69.

- (1966) - Versuch einer ökologischen Gliederung des interstitiellen Grundwassers in Lebensbereiche eigener Prägung. Arch. Hydrobiol. 62: 231-268.

ЈАковг, Н. (1954) - Biologie, Entwicklungsgeschichte und Systematik von Bathynella natans Vejd. Zool. Jb. Syst. 83:1-184.

Karaman, St. (1935) - Die Fauna der unterirdischen Gewässer Jugoslawiens. Verh. Int. Ver. Limnol. 7: 46-73.

- (1954) - Über unsere unterirdische Fauna. Acta. Mus. Maced. Sc. Nat. I: 195-216.

Kiefer, F. (1957) - Die Grundwasserfauna des Oberrheingebietes mit besonderer Berücksichtigung der Crustaceen. Beitr. nat. Forsch. Südwestdeutschland 16:65-91.

- (1960) - Psammobionte Ruderfußkrebse (Crust. Cop.) aus dem Gebiet der Unterweser und von der Insel Helgoland. Zool. Anz. 165: 30-37.

Koelbel, K. (1892) - Beiträge zur Kenntnis der Crustaceen der Canarischen Inseln. Ann. K. K. Naturhist. Hofmuseum Wien VII : 105-116.

Krause, E. (1898) - Die Augen der Blindfische. Promethius 457: 651-652.

KulHavý, V. (1961) - Über das Vorkommen der west- und osteuropäischen Elemente in der Crustaceenfauna der böhmischen unterirdischen Gewässer. Acta soc. zool. Bohemoslov. 25: 297-301.

Laborel, J. u. Vacelet, J. (1958) - Etude des peuplements d'une grotte sous-marine du golfe de Marseille. Bull. Inst. Océanogr. Monaco 55: $1-21$. 
Mees, G. F. (1962) - The Subterranean Freshwater Fauna of Yardie Creek Station, North West Cape, Western Australia. J. Roy. Soc. West. Austral. XLV: 24-32.

Menon, A. G. (1950) - On a remarkable blind Siluroid fish of the family Clariidae from Kerala (India). Rec. Indian Mus. XLVIII, I: 59-66.

MeEšrov, M. (1960) - Faunistisch-ökologische und biozönologische Untersuchungen unterirdischer Gewässer des Savetales. Bioloski Glasnik 13: 73-109.

Miers, E. J. (1877) - On a collection of Crustacea, Decapoda and Isopoda, chiefly from South America, with descriptions of new genera and species. Proc. zool. Soc. Lond. 1877: 653-679.

Мотаş, C. (1958) - Freatobiologia, o noua ramura a limnologiei : Natura 10 : 95-105.

- (1962) - Procédé des sondages phréatiques. - Division du domaine souterrain. - Classification écologique des animaux souterrains. - Le psammon. Acta. Mus. Mac. Sci. Nat. 8: 135-173.

Müller, G. (1931) - Sopra due Crostacei delle nostre acque carsiche. Atti. Mus. Stor. nat. Trieste 11: 206-216.

Myers, G. S. (1944) - Two extraordinary new blind Nematognath fishes from the Rio Negro representing a new subfamily, with a rearrangement of the genera of the family and illustrations of some previously described genera and species from Venezuela and Brazil. Proceed. California Acad. Sc. (4), XXIII, No. 40: 593-594.

NeEL, J. (1948) - A limnological investigation of the psammon in Douglas Lake. Trans. Amer. Microsc. Soc. 67: 1-53.

Noodt, W. (1952) - Subterrane Copepoden aus Norddeutschland. Zool. Anz. 148: 331-341.

Orghidan, T. (1955) - Un nou domeniu de viata acvatica subterana „,Biotopul Hiporeic". Bul. sti. sect. Biologie si sti. Agr. si sect. Geologie si Geografie 7: 657-676.

- (1959) - Ein neuer Lebensraum des unterirdischen Wassers: der hyporheische Biotop. Arch. Hydrobiol. 55: 392-414.

Pellegrin, J. (1929) - L'Eilichthys microphthalmus Pellegrin. Poisson cavernicole de la Somalie Italienne. Bull. Mus. Hist. Nat. Paris I: 363-364.

Pennak, R. W. (1940) - Ecology of the microscopic Metazoa inhabiting the sandy beaches of some Wisconsin lakes. Ecol. Monogr. 10: 537-615.

Pigard, J. Y. (1962) - Contribution a la connaissance de la faune psammique de Lorraine. Vie et Milieu 13: 471-505.

Priesel-Dichtr, G. (1959) - Die Grundwasserfauna im Salzburger Becken und im anschließenden Alpenvorland. Arch. Hydrobiol. 55: 281-370.

Regan, T. (1940) - The Fishes of the Gobiid genus Luciogobius Gill. Ann. Mag. nat. Hist. V: 462-465.

Remane, A. (1940) - Einführung in die zoologische Ökologie der Nord- und Ostsee. Tierw. Nord- u. Ostsee 1 a.

Riedi, R. (1959) - Die Hydroiden des Golfes von Neapel und ihr Anteil an der Fauna unterseeischer Höhlen. Ergebn. d. Österr. TyrrheniaExpedition 1952, Teil XVI. Pubbl. Staz. Zool. Napoli, Suppl. 30: $589-755$. 
RIE DEL, R. (1959 b) - Turbellarien aus submarinen Höhlen, 4. Faunistik und Ökologie. Ergebn. d. Österr. Tyrrhenia-Expedition 1952, Teil X. Pubbl. Staz. Zool. Napoli, Suppl. 30: 333-399.

- (1963) - Probleme und Methoden der Erforschung des litoralen Benthos. Verh. Dtsch. Zool. Ges. Wien 1963, Suppl. 26: 505-567.

- (1964) - Die Erscheinungen der Wasserbewegung und ihre Wirkung auf Sedentarier im mediterranen Felslitoral. Helgol. Wiss. Meeresunters. 10: $155-186$.

— (1966) - Biologie der Meereshöhlen. : 1 -636. P. Parey, Hamburg u. Berlin.

Russ, K., und Rützler, K. (1959) - Zur Kenntnis der Schwammfauna unterseeischer Höhlen. Ergebn. d. Österr. Tyrrhenia-Expedition 1952, Teil XVII. Pubbl. Staz. Zool. Napoli, Suppl. 30: 756-787.

Ruttaner-Kolisko (1957) - Der Lebensraum des Limnopsammals. Verh. Dtsch. Zool. Ges. Hamburg, Zool. Anz., Suppl. 20: 421-427.

Sassuchin, D. N., Kabanov, N. M., und Neizwestnova, K. S. (1927) - Über die mikroskopische Pflanzen- und Tierwelt der Sandfläche des Okaufers bei Murow. Russ. hydrobiol. Z. 6: 59-83.

Sch Ä fer, H. W. (1951) - Über die Besiedlung des Grundwassers. Verh. Internat. Verein. Limnol. 11: 324-330.

Sснмiтt, W. L. (1936) - Macruran and Anomuran Crustacea from Bonaire, Curaçao and Aruba. Zoologische Ergebnisse einer Reise nach Bonaire, Curaçao und Aruba im Jahre 1930. Zool. Jb. Syst. 67: 363-378.

Schwabe, G. H., und Klinge, H. (1960) - Gewässer und Boden als Forschungsgegenstand. Anales de Edafologia y Agrobiologia XIX: $519-568$.

Schwoerbel, J. (1961) - Über die Lebensbedingungen und die Besiedlung des hyporheischen Lebensraumes. Arch. Hydrobiol., Suppl. - FalkauSchriften - 25: 182-214.

- (1961 a) - Subterrane Wassermilben (Acari: Hydrachnellae, Porohalacaridae und Stygothrombiidae), ihre Ökologie und Bedeutung für die Abgrenzung eines aquatischen Lebensraumes zwischen Oberfläche und Grundwasser. Arch. Hydrobiol., Suppl. - Falkau-Schriften - 25: $242-306$.

- $(1964 b)$ - Die Bedeutung des Hyporheals für die benthische Lebensgemeinschaft der Fließgewässer. Verh. Internat. Verein. Limnol. 15: $215-226$.

Starmühlner, F. (1955) - Zur Molluskenfauna des Felslitorals und submariner Höhlen am Capo di Sorrento (Teil 1). Ergebn. d. Österr. Tyrrhenia-Expedition, Teil IV. Österr. Zool. Zeitschr. 6: 147-249.

- (1955a) - Zur Molluskenfauna des Felslitorals und submariner Höhlen am Capo di Sorrento (Teil 2). Ergebn. d. Österr. Tyrrhenia-Expedition, Teil IV. Österr. Zool. Zeitschr. 6: 631-713.

Teschner, D. (1963) - Die Biologie, Verbreitung und Ökologie der Grundwassermilbe Lobohalacarus weberi quadriporus (Walter 1947), Limnohalacaridae, Acari. Arch. Hydrobiol. 59: 71-102.

Thienemann, A. (1925) - Die Binnengewässer Mitteleuropas. Die Binnengewässer 1: 1-255. Schweizerbart, Stuttgart.

Thines, G. (1958) - Observations sur les habitats de l'Uegitglanis zammaranoi Gianferrari 1923, Clariidae aveugle de la Somalie italienne. Rev. Zool. Bot. Afric. LVII: 117-124. 
Uhlmann, D., und Schulze, E. (1961) - Zur Limnologie von Höhlengewässern. Verh. Int. Verein. Limnol. 14: 862-866.

VAndel, A. (1964) - Biospéologie. La Biologie des Animaux Cavernicoles: 1-619. Gauthier-Villars, Paris.

Wegelin, R. (1966) - Beitrag zur Kenntnis der Grundwasserfauna des Saale-Elbe-Einzugsgebietes. Zool. Jb. Syst. 93: 1-117.

Wieser, W. (1954) - Beiträge zur Kenntnis der Nematoden submariner Höhlen. Ergebn. d. Österr. Tyrrhenia-Expedition 1952, Teil II. Österr. Zool. Zeitschr. V: 172-230.

Woods, L. P., und Inger, R. F. (1957) - The Cave, Spring and Swamp Fishes of the Family Amblyopsidae of Central and Eastern United States. Amer. Midland Natural. LVIII : 231-256. 
Analyse du comportement alimentaire du poisson cavernicole aveugle Anoptichthys Gen. et d'hybrides $\mathrm{F}_{\mathbf{1}}$ (Astyanax $\times$ Anoptichthys) et $\mathrm{F}_{2}$

Par Georges Thines, Monique Soffie et Erik Vandenbussghe1)

\section{Introduction}

L'étude des comportements des poissons cavernicoles aveugles révèle, par comparaison avec les espèces oculées normales apparentées, un certain nombre de caractéristiques qui manifestent l'existence de régressions typiques, probablement liées aux régressions sensorielles et particulièrement à l'anophthalmie. Diverses observations que nous avons effectuées semblent toutefois suggérer que ces réductions comportementales doivent être interprétées autrement que comme de simples lacunes ou de simples vices d'exécution motrice consécutifs à la perte d'une sensibilité, comme, par exemple, l'absence pratiquement totale de réactions vibratoires que l'on observe chez le poisson aveugle Typhlogarra widdowsoni (Cyprinidae) en raison de la régression morphologique de la ligne latérale (Marshall et Thines, 1958), ou encore l'imprécision dans la localisation de la nourriture que l'on trouve chez la plupart des poissons anophthalmes, par suite de la disparition du contrôle visuel. Il faut admettre, semble-t-il, avec Kosswig (1965) que l'étude des comportements des animaux cavernicoles peutfournir des indices de l'évolution régressive de ces organismes, au même titre que l'étude anatomo-physiologique. Il n'est done pas illégitime de supposer, dans une semblable perspective, que les formes cavernicoles manifesteraient des régressions éthologiques typiques qui auraient atteint les comportements dans leurs capacités régulatrices mêmes.

Les observations que nous avons effectuées portent sur le comportement alimentaire d'alevins et d'adultes du genre Anoptichthys, poisson aveugle originaire d'une série de grottes situées dans le Mexique

1) Laboratoire de Psychologie Animale de l'Université de Louvain - Centre de Psychologie Expérimentale et Comparée - Pellenberg (Belgique). 
central $\left.^{1}\right)$. Elles nous ont permis, pensons-nous, de mettre en évidence des déficits caractéristiques susceptibles d'être interprétés comme des régressions fondamentales dans l'organisation des comportements.

\section{Analyse du comportement alimentaire}

Le comportement alimentaire des poissons cavernicoles aveugles du genre Anoptichthys que nous avons pu observer en aquarium, présente une stéréotypie marquée. L'introduction dans le milieu liquide, de petites particules de nourriture (Tubifex haché) détermine une accélération notable de la nage, suivie d'une plongée rapide vers le fond et d'une exploration active de celui-ci, jusqu'au moment où la nourriture est rencontrée et happée. Cette exploration est tellement caractéristique, que Thines et Kähling (1957) ont pu l'utiliser comme réaction conditionnée dans des expériences de dressage destinées à étudier les réactions chromatiques différentielles de la forme Anoptichthys jordani.

On peut également provoquer sans difficulté cette exploration du fond chez ces poissons aveugles, en introduisant simplement dans l'aquarium une baguette de verre trempée au préalable dans une population de Tubifex ou même dans de l'eau ayant contenu les vers pendant quelques minutes, en évitant toute perturbation mécanique. Il s'agit donc, primairement, d'une réaction de nature chémoréceptrice, indépendante de l'impact de la nourriture sur la surface de l'eau ou du faible courant local consécutif à sa descente. Le temps qui s'écoule entre l'introduction de la nourriture dans le milieu et les premiers signes d'exploration active est assez variable. Quant à l'exploration, hormis les cas assez exceptionnels où le poisson heurte par hasard la nourriture de la bouche au moment où celle-ci atteint le fond, elle est relativement longue comme on le verra plus loin. La

1) A la suite des recherches génétiques de Sadoglu (1956-1967) et de Kosswig (1960-1965), les trois formes Anoptichthys jordani Hubbs et Innes, Anoptichthys hubbsi Alvarez et Anoptichthys antrobius Alvarez doivent être considérées comme des sous-espèces plutôt que comme des espèces distinctes différentes de l'espèce ancestrale oculée Astyanax mexicanus Filippi. La question n'étant toutefois pas tranchée par les taxinomistes, nous utilisons exclusivement ici pour des raisons de commodité, la dénomination générique. Il y a lieu de signaler que le matériel adulte dont nous nous sommes servis appartient à des populations originaires de Cueva del Pachon, grotte du Mexique central abritant la forme décrite sous Anoptichthys antrobius. Ce matériel, de même que les hybrides, nous a été fourni gracieusement par le Professeur C. Kosswig, Directeur de l'Institut de Zoologie et du Musée Zoologique de la ville de Hambourg. Puisse-t-il trouver ici l'expression de notre gratitude pour l'aide ainsi apportée à nos recherches. Les alevins proviennent d'élevages génétiquement non contrôlés et ne permettent aucune détermination au-delà du genre tel qu'il est actuellement décrit. 
structure typique de la nage sur le fond qui suit la stimulation chimique initiale semble bien être une caractéristique générique de l'Anoptichthys. Nous ne l'avons jamais notée chez les Cyprinidae cavernicoles Caecobarbus geertsi et Typhlogarra widdowsoni que nous avons pu longuement observer en aquarium. Chez le Caecobarbus, la stimulation chimique détermine une accélération de la nage, laquelle devient saccadée. Après un certain temps de recherche active, le poisson conclut dans la plupart des cas par une plongée brusque à proximité de la nourriture. La durée totale d'exploration peut parfois atteindre plusieurs minutes. Il en va de même du Typhlogarra. De plus, ce poisson peut passer plusieurs fois au voisinage immédiat de la nourriture sans manifester aucun comportement de recherche, puis virevolter brusquement et saisir celle-ci lors d'un passage ultérieur. Il est à noter que chez l'Anoptichthys, la recherche de nourriture sur le fond s'observe déjà chez des alevins de $1 \mathrm{~cm}$ de long sous la même forme que chez les adultes.

Le tableau ci-dessous reproduit les temps observés, sous lumière naturelle, sur 5 alevins et sur 5 adultes du genre Anoptichthys. Dans toutes les observations, on introduisait au moyen d'une pipette une faible quantité de Tubifex toujours identique $(0,5 \mathrm{~cm}$ de la longueur de la pipette) dans l'aquarium (longueur : $35 \mathrm{~cm}$ - largeur : $20 \mathrm{~cm}$ profondeur de l'eau : $20 \mathrm{~cm}$ ), au moment où le poisson se trouvait le plus éloigné de l'observateur dans le sens de la longueur. Toutes les observations ont été effectuées sur des spécimens qui n'avaient reçu aucune nourriture depuis 2 jours. Le temps était noté au moyen d'un chronomètre de poche.

\section{Tableau 1}

Temps de réaction à la présence de Tubifex observés sur 5 alevins et sur 5 adultes du genre Anoptichthys. TR-1 : temps en secondes entre l'introduction de la nourriture dans l'aquarium et les premiers signes d'exploration active. TR-2: temps en secondes entre les premiers signes d'exploration active et la saisie de la nourriture. Temps total $=$ TR-1 + TR-2

\begin{tabular}{crrr|rrrr}
\hline & \multicolumn{4}{c}{ Alevins } & \multicolumn{4}{c}{ Adultes } \\
(longueur: $\pm 25 \mathrm{~mm}$ ) & \multicolumn{3}{c}{ (longueur: $\pm 55 \mathrm{~mm})$} \\
$\begin{array}{c}\text { Spécimen } \\
\text { No }\end{array}$ & TR-1 & TR-2 & $\begin{array}{c}\text { Temps } \\
\text { total }\end{array}$ & $\begin{array}{c}\text { Spécimen } \\
\text { No }\end{array}$ & TR-1 & TR-2 & $\begin{array}{c}\text { Temps } \\
\text { total }\end{array}$ \\
\hline 1 & 9 & 45 & 54 & 1 & 15 & 42 & 57 \\
2 & 10 & 30 & 40 & 2 & 10 & 22 & 32 \\
3 & 7 & 35 & 42 & 3 & 6 & 15 & 21 \\
4 & 15 & 35 & 50 & 4 & 5 & 17 & 22 \\
5 & 16 & 30 & 46 & 5 & 7 & 24 & 31 \\
Moyennes & 11 & 35 & 46 & & 9 & 24 & 33 \\
Variations & 3 & 4 & & & 3 & 7 & \\
moyennes & & & & & & &
\end{tabular}


Les moyennes de TR-1 sont très semblables chez les alevins et chez les adultes (11 et 9 secondes respectivement). Bien que ces données soient purement indicatives et ne se prêtent à aucune analyse statistique, on peut remarquer que dans l'ensemble le temps de réaction total tend à diminuer chez les adultes.

La saisie de la nourriture se produit donc, chez l'Anoptichthys, une demi-minute environ après que le poisson ait remarqué sa présence dans le milieu. Des observations semblables ont été effectuées sur 5 hybrides adultes $\mathrm{F}_{\mathbf{1}}$ (Astyanax $\times$ Anoptichthys) ainsi que sur 5 hybrides $\mathrm{F}_{2}$ (Tableau 2). Tous les individus utilisés présentaient de nettes déficiences de la morphologie oculaire. Celles-ci ont été décrites en détail par Kosswig (1965) sur des spécimens semblables. Parmi nos spécimens, l'individu le mieux équipé au point de vue oculaire $\left(\mathrm{F}_{2}\right.$ No 5) était microphthalme, son diamètre oculaire étant moitié moindre que celui d'un Astyanax normal. De plus, bien que l'organe visuel réduit fût visible de l'extérieur, aucune réaction à des objets en mouvement ne fut jamais observée, ce qui indique que la vision était très faible, voire absente.

\section{Tableau 2}

Temps de réaction à la présence de Tubifex observés sur 5 hybrides $\mathrm{F}_{1}$ (Astyanax $\times$ Anoptichthys) et sur 5 hybrides $\mathrm{F}_{2}$ (Spécimens adultes)

(Indications comme au tableau 1)

\begin{tabular}{|c|c|c|c|c|c|c|c|}
\hline \multicolumn{4}{|c|}{$\begin{array}{c}\mathrm{F}_{1} \\
\text { (longueur: } \pm 70 \mathrm{~mm} \text { ) }\end{array}$} & \multicolumn{4}{|c|}{$\begin{array}{c}\mathrm{F}_{2} \\
\text { (longueur : } \pm 70 \mathrm{~mm} \text { ) }\end{array}$} \\
\hline $\begin{array}{l}\text { Spécimen } \\
\quad \text { No } \\
\end{array}$ & TR-1 & TR-2 & $\begin{array}{l}\text { Temps } \\
\text { total }\end{array}$ & $\begin{array}{l}\text { Spécimen } \\
\text { No }\end{array}$ & TR-1 & TR-2 & $\begin{array}{l}\text { Temps } \\
\text { total }\end{array}$ \\
\hline 1 & 4 & 20 & 24 & 1 & 5 & 24 & 29 \\
\hline 2 & 4 & 12 & 16 & 2 & 7 & 16 & 23 \\
\hline 3 & 6 & 16 & 22 & 3 & 2 & 51 & 53 \\
\hline 4 & 6 & 7 & 13 & 4 & 2 & 11 & 13 \\
\hline 5 & 4 & 9 & 13 & 5 & 2 & 12 & 14 \\
\hline Moyennes & 5 & 13 & 18 & & 4 & 23 & 27 \\
\hline $\begin{array}{l}\text { Variations } \\
\text { moyennes }\end{array}$ & 1 & 4 & & & 2 & 12 & \\
\hline
\end{tabular}

Les valeurs de TR-2 sont très variables. La constatation la plus intéressante qui se dégage de l'examen du tableau 2 a trait à la durée du processus total. Celui-ci, on le voit, oscille chez tous les hybrides entre un quart de minute et une demi-minute environ, sauf dans un seul cas où il atteint l'ordre de la minute, l'allongement étant imputable, dans ce dernier cas, à la durée d'exploration. Chez la forme cavernicole aveugle, la durée du processus total, nous l'avons noté, est 
également de l'ordre de la demi-minute. Les hybrides observés se comportent donc, dans l'ensemble, comme des poissons aveugles, en ce qui concerne la recherche de la nourriture.

\section{Discussion}

Pour interpréter ces observations, il y a lieu de les rapprocher de quelques autres que nous avons effectuées sur le comportement alimentaire de l'espèce oculée ancestrale Astyanax mexicanus. Et ici, le tableau est tout différent. L'Astyanax est un poisson rapide équipé d'une vision excellente. Dès que la nourriture est introduite dans l'aquarium (l'observateur restant caché derrière un écran pour éviter toute réaction conditionnée anticipative), les animaux se précipitent sur celle-ci et la happent dans sa presque totalité avec une extrême précision avant qu'elle ait pu atteindre le fond. Dans un aquarium comportant une hauteur d'eau de $40 \mathrm{~cm}$, l'Astyanax peut happer successivement 4 à 5 particules différentes en l'espace de 3 à 4 secondes. La durée de la réaction chémoréceptrice initiale est tellement brève qu'il faut renoncer à l'estimer à l'ordre de la seconde par les moyens ordinaires. Quant à l'exploration ultérieure, elle fait totalement défaut en raison de la rapidité du repérage visuel. Une première conclusion que l'on peut tirer de ces données d'observation comparatives, est que les poissons cavernicoles et les hybrides étudiés, manifestent à l'égard de la présence de nourriture dans le milieu une réaction beaucoup plus lente que celle de la forme oculée ancestrale. Néanmoins, considérée isolément, la phase la plus courte du processus d'ensemble reste, tant chez l'A noptichthys que chez les hybrides, la réaction chémoréceptrice initiale, ce qu'il faut probablement attribuer au fait que ces formes dégénérées au point de vue visuel, possèdent encore de très bonnes capacités chémoréceptrices.

Dans des expériences utilisant la méthode du dressage, Humbach (1960) a en effet pu établir que l'A noptichthys est capable de distinguer de manière fort nette différentes qualités gustatives, de mème qu'une certaine diversité de stimuli olfactifs. Le poisson semble même posséder un sens olfactif supérieur à celui du Vairon (Phoxinus laevis). Le temps relativement long que met le poisson cavernicole à découvrir sa proie est donc principalement imputable à sa cécité, laquelle l'empêche de localiser la nourriture avec précision après l'intervention du message chimique, et l'oblige en conséquence à se livrer à une exploration laborieuse et prolongée. La régression comportementale résulte donc simplement dans ce cas, de l'efficacité moindre de la coordination chémoréceptomotrice par rapport à la coordination visuelle-motrice des poissons oculés normaux. 
Une seconde conclusion a trait aux conséquences biologiques de ce déplacement de la coordination sensori-motrice. Nos observations ont toutes été effectuées en utilisant des proies passives qui descendaient par gravité sur le fond de l'aquarium où, une fois arrivées, elles conservaient une localisation pratiquement invariable. Or, si dans ces conditions, les poissons aveugles éprouvent déjà pour les découvrir les difficultés signalées plus haut, il n'est pas étonnant que ces mèmes animaux éprouvent des difficultés plus grandes encore à établir le contact avec des proies mouvantes, même si celles-ci se déplacent lentement.

Lüling (1954) a observé que les jeunes larves et les alevins d'Anoptichthys jordani ne peuvent saisir des Cyclops vivants que dans les cas où ils les heurtent par hasard. Lorsque les petits Copépodes arrivent au cours de leurs déplacements à proximité immédiate des poissons (1 à $2 \mathrm{~mm}$ ), ceux-ci exécutent des mouvements buccaux de saisie dans la zone de turbulence locale, mais manquent néanmoins la proie dans la majorité des cas. C'est, à notre avis, la raison pour laquelle les Anoptichthys ont développé au cours de leur évolution régressive, pour rechercher leur nourriture, le comportement d'exploration $\mathrm{du}$ fond qui les caractérise, et qui s'observe du reste chez les Silures et chez d'autres Téléostéens à vision faible. Ce comportement, rappelons-le, n'existe pas chez la forme ancestrale oculée Astyanax mexicanus.

Il faut également remarquer que si les informations chémoréceptrices peuvent suffire au poisson pour détecter l'odeur d'un prédateur éventuel, la localisation de ce dernier doit en principe ètre aussi laborieuse que celle de la nourriture. Nous reviendrons sur ce point au paragraphe suivant, mais nous pouvons supposer dès maintenant qu'un poisson qui met au moins 30 secondes pour localiser une proie immobile, ne possèderait que des chances de survie très réduites s'il était mis en compétition dans le milieu épigé avec un prédateur mouvant armé contrôle visuel. Le milieu hypogé, dans lequel la vision n'est d'aucune utilité et où les prédateurs des vertébrés régressés sont exceptionnels ${ }^{1}$ ), apparaît donc bien, dans le cas qui nous occupe comme dans beaucoup d'autres, comme le seul capable de permettre la survie d'espèces aussi imparfaitement équipées au point de vue du contrôle sensori-moteur. Cette conclusion rejoint, du point de vue des struc-

1) La seule indication que nous possédions à ce sujet est celle fournie par Heuts et Leleup (1954) qui signalent la présence occasionnelle dans certaines grottes à Caecobarbus (Bas-Congo), de Silures prédateurs du poisson aveugle. Il est à noter toutefois que dans le milieu hypogé, le prédateur oculé ne peut utiliser, lui non plus, aucune information visuelle. 
tures du comportement des poissons aveugles, l'hypothèse de la troglobiose obligatoire émise par Fage (1931) à propos des déficits dans la régulations hygrométrique qui expliqueraient selon lui le peuplement des milieux hypogés par certaines espèces d'Araignées cavernicoles.

\section{Le rôle substitutif du comportement alimentaire chez Anoptichthys}

L'analyse du comportement alimentaire des poissons aveugles, et particulièrement de l'Anoptichthys, nous a révélé l'existence chez ces formes zoologiques dégénérées, d'imperfections notables dans la localisation spatiale, liées à la cécité et entrainant un délai considérable dans la saisie des proies par comparaison avec la forme ancestrale oculée. Cependant, les composantes mêmes du comportement alimentaire ne sauraient ètre considérées, en elles-mèmes, comme des régressions. Elles apparaissent au contraire comme des actions substitutives exigées par la disparition du contrôle visuel, et supposent un développement normal (même partiellement sus-normal d'après les travaux de Humbach, 1960) des sensibilités chimiques.

Tel que nous l'avons décrit, le comportement alimentaire du poisson aveugle met essentiellement en ouvre une coordination chémoréceptomotrice dont les effets adaptatifs sont, à égalité de conditions extérieures ${ }^{2}$ ), nettement inférieurs à ceux qu'assurent les mécanismes dont dispose la forme oculée.

Certaines observations semblent en outre indiquer que cette modification de la coordination sensori-motrice dominante a entraîné chez la forme cavernicole des altérations dans les montages comportementaux; ces altérations peuvent être interprétées, semble-t-il, comme des indices de régression éthologique. Et à ce propos, quelques observations intéressantes peuvent être signalées. Nous noterons en premier lieu que chez l'Anoptichthys, la plongée caractéristique vers le fond suivie de l'exploration active de celui-ci, peut être déclenchée par d'autres stimuli que les stimuli chimiques. Une perturbation

2) Cette égalité des conditions vise avant tout nos conditions expérimentales. Nous avons travaillé sous lumière naturelle et nous pensons qu'il était légitime de procéder de cette manière. La sensibilité photique diffuse établie chez plusieurs poissons aveugles (Thines, 1953-1954; Kuhn et Kähling, 1954 ; Thines et Kähling, 1957; Marshall et Thines, 1958) n’apporte aucun avantage à ceux-ci dans la localisation précise d'un objet sous lumière naturelle. Par contre, l'obscurité rend celle-ci impossible chez le poisson oculé, ainsi que nous le signalons à la note précédente. Les comportements respectifs des deux formes restent donc comparables dans la lumière. L'observation dans l'obscurité exige d'ailleurs des procédés spéciaux d'enregistrement. 
mécanique nette, tel qu'un choc appliqué aux parois de l'aquarium, ou un tourbillon local obtenu par la rotation d'une baguette de verre dans l'eau, détermine immédiatement la même réaction. Sans doute pourrait-on invoquer ici un processus de conditionnement, reposant sur l'association entre les bruits accompagnant la présentation régulière de nourriture et celle-ci même, supposition d'autant plus plausible à première vue que l'Anoptichthys peut être conditionné avec une relative facilité (Thines et Kähling, 1957). Il faut toutefois remarquer que des Anoptichthys vivant sans précautions particulières dans les conditions ordinaires du laboratoire, subissent de nombreuses stimulations mécaniques dont la grosse majorité ne sont pas associées à la nourriture. De plus, les formes jeunes de provenance lointaine réagissent immédiatement de la même manière. Sans exclure de façon absolue une acquisition réalisée à un moment particulier de l'ontogénèse, les observations très fréquentes que nous avons pu faire suggèrent que l'extériorisation du comportement alimentaire dans ces conditions survient comme substitut des réactions phobiques telles qu'elles se présentent chez l'Astyanax. Ces dernières se traduisent, comme chez la plupart des poissons oculés vivant en aquarium, par une nage rapide en zig-zag, au terme de laquelle l'animal va finalement se terrer dans un coin où il reste immobile.

Un autre fait, beaucoup plus probant et déjà interprété par Kosswig (1965) comme un indice de régression, semble plaider dans le même sens. Pfeiffer (1963) a en effet observé que la substance d'alarme spécifique, loin de déterminer la réaction phobique caractéristique connue chez les Ostariophysaires qu'il a recensés, induit les Anoptichthys à manifester une fois de plus leur comportement alimentaire typique. Ce dernier assume donc, dans ce cas encore, un rôle substitutif, mais cette fois à l'égard d'un comportement que les expériences étendues de l'auteur précité permettent de considérer comme un trait phylogénique essentiel des Cyprinoïdes. L'absence de cette réaction chez les Characidae dégénérés du genre Anoptichthys, doit être interprétée, à notre avis, comme une régression fondamentale des montages comportementaux typiques, surtout si l'on songe que la substance d'alarme agit de manière indiscutable chez 12 espèces de Characidae sud-américains, parmi lesquels figure l'Astyanax bimaculatus, proche parent de l'Astyanax mexicanus, ancêtre épigé de l'Anoptichthys. De plus, l'Astyanax bimaculatus réagit à la substance d'alarme secrétée par l'épiderme de l'Anoptichthys. Pfeiffer (1963) attribue la perte de cette réaction phobique chez la forme cavernicole à une régression d'ordre neurophysiologique. Celle-ci comporte, on le voit, de nettes conséquences sur le plan de l'éthologie de la forme que nous avons observée. 


\section{Discussion}

Du point de vue éthologique, le rôle substitutif assumé par le comportement alimentaire dans les deux situations que nous avons décrites, permet les commentaires suivants :

1. Le fait que l'exploration du fond en quête de nourriture puisse se manifester sans que la stimulation chimique normalement associée à la présence d'une proie soit au préalable intervenue, indique que le registre comportemental de la forme cavernicole s'est notablement rétréci. Etant donné que la réaction à la substance d'alarme est innée et apparaît à un certain stade du développement indépendamment de l'expérience antérieure (Pfeiffer, 1963), les manifestations substitutives du comportement alimentaire résultent probablement d'une déficience génétique dans la différenciation normale des conduites propres au genre Astyanax. Pour l'Anoptichthys, il ne survient plus, dès que la stimulation chimique est présente, de discrimination entre un signal de fuite et un signal de nourriture.

2. L'exploration du fond en quête de nourriture remplace des comportements de défense porteurs d'une signification biologique essentielle pour la survie de l'espèce. A supposer qu'une transformation de ce genre ait quelque chance de survenir dans le milieu épigé, elle n'y aurait évidemment aucune valeur de survie, en raison des conditions de compétition qui caractérisent celui-ci. Une fois de plus, elle est simplement tolérable dans le milieu hypogé, où la compétition est réduite au minimum.

3. Les fait que le comportement alimentaire vienne se substituer à des réactions phobiques qui se manifestent dans des situations urgentes (perturbation mécanique intense, présence de substance d'alarme), permet de mieux comprendre le rétrécissement du registre comportemental auquel nous avons fait allusion plus haut. On pourrait supposer, à la rigueur, que le déclenchement du comportement alimentaire par des stimuli mécaniques résulte évolutivement du fait que dans les milieux hypogés, les seules perturbations mécaniques nettes atteignant les poissons seraient liées à la présence de proies et non à la présence de prédateurs. Cette hypothèse serait d'ailleurs physiologiquement acceptable dans le cas de l'Anoptichthys, dont la ligne latérale, contrairement à celle du Typhlogarra, est fort bien développée (Grobbel et Hahn, 1958). Cependant, cette interprétation n'aurait de sens que si les poissons cavernicoles étaient capables, en se livrant à leur exploration alimentaire, de capturer des proies vivantes en mouvement, ces dernières étant les seules susceptibles de révéler leur présence par un signal mécanique local. Or, nous avons vu qu'une telle performance dépassait les capacité de localisation de l'Anoptichthys, 
et donc a fortiori de formes encore plus régressées comme Caecobarbus ou Typhlogarra.

L'obtention éventuelle d'une proie en mouvement ne constitue par conséquent pas, dans le cas qui nous occupe, le facteur positif hypothétique qui aurait pu orienter, d'une manière ou d'une autre, la substitution que nous observons actuellement. D'autre part, on laisse inexpliqué de cette manière le fait que l'exploration alimentaire puisse également être provoquée par la substance d'alarme.

L'absence de réaction typique à la substance d'alarme, considérée isolément, pourrait sans doute être rapprochée du fait que les poissons cavernicoles ne forment pas de bancs. Pfeiffer (1963) estime en effet que la réaction à la substance d'alarme protège essentiellement le banc et non l'individu isolé. La tendance à former des bancs existe chez la forme épigée ancestrale Astyanax; par ailleurs, la production par la forme régressée Anoptichthys, d'une substance d'alarme à laquelle elle ne réagit pas, mais à laquelle réagit l'Astyanax, semble indiquer l'existence chez la forme cavernicole d'un montage physiologique rémanent privé de la structure comportementale correspondante telle qu'elle existe chez l'ancêtre épigé. Dans cette perspective, la disparition de la réaction à la substance d'alarme, mécanisme essentiel de défense du groupe, pourrait ètre considérée comme concomitante à l'abolition de la tendance au groupement.

4. Une dernière question à laquelle il faudrait tenter de répondre est la suivante : comment se fait-il que ce soit le comportement alimentaire qui ait assumé le rôle substitutif que les observations relatées antérieurement permettent de lui attribuer? Il faut supposer que les réactions phobiques ancestrales typiques ont disparu chez la forme cavernicole régressée, en raison du fait que chaque fois que survenait une situation extérieure urgente, seule pouvait encore se manifester une forme de comportement qui, malgré les potentialités réduites du système nerveux, ne pouvait en aucune manière régresser et conservait nécessairement, dans le cadre écologique hypogé, la valeur de survie primordiale qu'elle possède dans n'importe quel habitat. Cette forme de comportement est la recherche active de la nourriture. Les réactions phobiques, présentant une valence de survie moindre dans le milieu hypogé, durent probablement ètre atteintes au premier chef au cours des processus de l'évolution régressive.

\section{RÉSUMÉ}

Le comportement alimentaire des poissons cavernicoles aveugles du genre Anoptichthys comprend deux phases, une phase chémoréceptrice initiale courte, et une phase d'exploration polarisée sur le fond relativement 
longue. La durée moyenne du processus total est d'un peu plus d'une demiminute, tant chez les alevins que chez les adultes. Les hybrides adultes Astyanax $\times$ Anoptichthys atteints de régressions oculaires marquées, se comportent comme la forme cavernicole aveugle. La recherche de la nourriture telle qu'elle s'effectue chez ces formes régressées, traduit les imperfections dans la localisation spatiale qui ont résulté de la disparition de la coordination visuelle-motrice par suite de la régression oculaire. Le comportement alimentaire se manifeste également à titre substitutif chez Anoptichthys lorsqu' interviennent des stimulations déterminant chez l'ancêtre épigé Astyanax des réactions phobiques caractérisées (stimulation mécanique intense, substance d'alarme - Pfeiffer, 1963). Cette substitution traduit un rétrécissement du registre comportemental chez la forme cavernicole, et est susceptible d'ètre interprété comme une régression dans la différenciation des comportements propres au genre ancestral. Les conséquences biologiques de cette situation font l'objet d'une discussion théorique.

\section{ZUSAMMENFASSUNG}

Bei blinden Höhlenfischen der Gattung Anoptichthys zeigt die Verhaltensweise während der Nahrungsaufnahme zwei Phasen: eine anfängliche, kurze chemorezeptorisch orientierte (phase chémoreceptrice), der eine relativ längere, auf den Boden gerichtete Absuchungsphase (phase d'exploration) folgt. Der gesamte Prozeß dauert bei juvenilen und auch bei adulten Fischen der genannten Gattung etwa 30 Sekunden oder ein wenig mehr.

Bei erwachsenen Hybriden von Astyanax $\times$ Anoptichthys, die eine erhebliche Rückbildung der Augen aufweisen, ist eine ebensolche Verhaltensweise festzustellen. Diese Art des Vorgehens bei der Futtersuche kann als Ausdruck dafür angesehen werden, daß die Blindheit, also der Fortfall einer visuell-motorischen Koordination, eine gewisse Unvollkommenheit der räumlichen Orientierung zur Folge hat.

Das Suchen nach Futter erfolgt bei Anoptichthys auch bei Reizen, die bei den sehenden Vorfahren - Astyanax - typische Schreckreaktionen hervorrufen. Das ist nach schweren mechanischen Reizen der Fall, wie auch bei Einwirkung eines Schreckstoffes (Pfeiffer, 1963). Eine solche Abänderung der Verhaltensweise ist unseres Erachtens ein Beweis dafür, daß das Verhaltensregister sich bei der Höhlenform verengert und dementsprechend eine Rückbildung erfahren hat.

Die biologischen Folgen dieser Erscheinung werden auf theoretischer Basis erörtert.

\section{B I B LIOGRAPH IE}

FAGE, L. (1931) - Biospeologica LV. Araneae, 5ème série, précédée d'un essai sur l'évolution souterraine et son déterminisme. Arch.Zool. Exp. Gén., 71: 99-291.

GroввеL, G., et Hанл, G. (1958) - Morphologie und Histologie der Seitenorgane des augenlosen Höhlenfisches Anoptichthys jordani im Vergleich zu anderen Teleostieren. Z. Morph. u. Oekol. Tiere, 47: 249-266.

Heuts, M. J., et Leleup, N. (1954) - La géographie et l'écologie des grottes du Bas-Congo. Les habitats de Caecobarbus geertsi Blgr. Ann. Mus. Royal du Congo Belge, Teroueren, 35, 71 pp., 39 fig. 
Huмвасн, I. (1960) - Geruch und Geschmack bei den augenlosen Höhlenfischen Anoptichthys jordani Hubbs und Innes und Anoptichthys hubbsi Alvarez. Thèse non publ. Uniø. Cologne. $88 \mathrm{pp}$.

Kosswig, C. (1960) - Zur Phylogenese sogenannter Anpassungsmerkmalen bei Höhlentieren. Int. Rev. Ges. Hydrobiol., 45: 439-512.

- (1965) - Génétique et évolution régressive. Res. Quest. Scient., 136, 2 : $227-257$

Kunn, O., et Käнlıng, J. (1954) - Augenrückbildung und Lichtsinn bei Anoptichthys jordani Hubbs und Innes. Experientia, X, 9: 385-388.

Luling, K. H. (1954) - Untersuchungen am Blindfisch Anoptichthys jordani Hubbs und Innes (Characidae). - II. Beobachtungen und Experimente an Anoptichthys jordani zur Prüfung der Einstellung zum Futter zum Licht und zur Wasserturbulenz. Zool. Jahrb. (Abt. Zool.), $65: 9-42$.

Marshall, N. B., et Thines, G. (1958) - Studies of the brain, sense organs and light sensitivity of a blind cave fish (Typhlogarra swiddowsoni) from Iraq. Proc. Zool. Soc. London, 131, 3: 441-456.

Pfeiffer, W. (1963) - Alarm substances. Experientia, XIX: 113.

SAD OGLU, P. (1956) - A preliminary report on the genetics of the Mexican cave Characins. Copeia, 1956: 113-114.

- (1957) - Mendelian inheritance in the hybrids between the Mexican blind cave fishes and their overground ancestor. Verh. Deut. Zool. Gesell. Graz, 432-439.

Thines, G. (1953) - Recherches expérimentales sur la photosensibilité du poisson aveugle Caecobarbus geertsi Blgr. Ann. Soc. Royale Zool. Belg. $84,2: 231-265$.

- (1954) - Etude comparative de la photosensibilité des poissons aveugles Caecobarbus geertsi Blgr. et Anoptichthys jordani Hubbs et Innes. Ann. Soc. Royale Zool. Belg., 85, 1: 35-58.

Thines, G., et Kähling, J. (1957) - Untersuchungen über die Farbempfindlichkeit des blinden Höhlenfisches Anoptichthys jordani Hubbs und Innes (Characidae). Z. Biol., 109: 150-160.

\section{EXPLIGATION DES PLANGHES 73 (1) - 76 (4)}

Pl. 73 (1) Répartition d'un groupe d'alevins d'Anoptichthys dans un aquarium avant l'introduction de la nourriture. - Pl. 74 (2) Répartition typique du même groupe sur le fond après introduction de la nourriture. - Pl. 75 (3) Anoptichthys adulte plongeant vers le fond - Pl. 76 et (4) explorant activement celui-ci en quête de nourriture. 


\title{
Mise en evidence de substances fluorescentes dans les organes jaunes de Caecosphaeroma burgundum Dollfus, Crustacé Isopode des eaux souterraines
}

\author{
Par H. Descimon ${ }^{1}$ ) et Cl. Marvillet ${ }^{2}$ )
}

Avec 2 figures dans le texte

Le Crustacé Caecosphaeroma burgundum, observé à l'état vivant, montre des taches jaunes réparties assez régulièrement sur tout le corps, mais particulièrement développées dans le prosoma et le pléotelson (Fig. 1). J. Daum, qui a étudié le premier la biologie de ce Sphéromien cavernicole dans le laboratoire du Professeur Husson, les a décrits sous le nom d'«organes jaunes» (R. Husson et J. Daum 1953; J. Daum 1954).
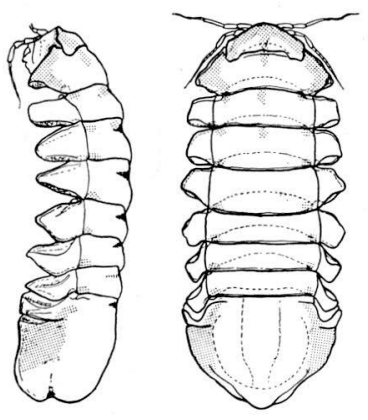

Fig. 1. Répartition des organes jaunes (en pointillé) chez Caecosphaeroma burgundum Dollfus examiné en position latérale (à gauche) et en face dorsale (à droite). On remarque la forte concentration de ces organes dans la partie antérieure du corps (tête et premier segment thoracique) et au niveau du pléotelson. Ces organes jaunes sont situés juste sous la carapace. (D'après J. Daum, 1954.)

Homologues des organes de Zenker, décrits dans la partie postérieure du corps d'Asellus aquaticus L., ils ont été retrouvés (R. Husson et J. Daum 1957) chez l'autre espèce du genre Caecosphaeroma (C. virei Dollfus des grottes du Jura) et dans deux autres Isopodes du genre Asellus, l'un épigé, A.meridianus Racovitza, l'autre hypogé, A.cavaticus Leydig (R. Husson et J. P. Henry 1963).

1) Laboratoire de Zoologie, Ecole Normale Supérieure - 24 rue Lhomond, Paris-Vo.

$\left.{ }^{2}\right)$ Laboratoire de Biologie Animale et Générale-Faculté des Sciences 21, Dijon. 
D'après J. Daum, il s'agit de conglomérats de cellules adipeuses de couleur jaune, contenant de nombreuses sphérules de diamètres variés, concrétions d'acide urique ou d'urates.

Les recherches entreprises par H. Schorr dans le même laboratoire, en utilisant les méthodes microchimiques mises au point par J. Schindler en 1950, ont mis en évidence la présence d'acide urique dans les concrétions des organes jaunes et l'absence d'urates et de guanine, sans pouvoir affirmer la présence éventuelle d'autres purines (R. Husson et H. Schorr 1957; H. Schorr 1957). La localisation de l'acide urique au sein même des cellules, attribuée aux sphérules, n'y était cependant pas déterminée de façon exacte.

Quant au pigment jaune responsable de la coloration, il entrelace tout l'organe d'un fin réseau irrégulier, indépendant des sphérules. La recherche des caroténoïdes par méthodes microchimiques, faite par Schorr, était demeurée négative.

Nous avons repris méthodiquement l'étude de ces pigments jaunes de façon à tenter la détermination de leur nature exacte.

\section{Vérifications préliminaires}

L'observation, au microscope polarisant, d'organes jaunes dilacérés, confirme la structure cristalline des abondantes sphérules qui représentent très probablement l'acide urique au sein des cellules.

Des chromatogrammes ont été effectués sur couche mince de silicagel à l'aide d'extraits d'organes jaunes et de spots témoins de carotènes. Leur révélation, par vaporisation de trichlorure d'antimoine en solution dans le chloroforme anhydre, reste négative et confirme l'absence de caroténoïdes dans les organes jaunes.

\section{Matériel et techniques}

Les animaux ont été récoltés dans le cours d'eau souterrain de l'abîme de Bévy (Côte-d'Or) et mis en élevage dans les chambres froides du laboratoire.

La technique analytique employée fait appel essentiellement à la chromatographie sur papier et couche mince de cellulose et à l'électrophorèse sur couche mince de cellulose.

Les animaux (110 individus, soit 3,5 g) sont broyés dans un petit broyeur de Potter, dans l'éthanol-chloroforme (1:1) (c.a. $5 \mathrm{ml} / \mathrm{g}$ ). Le broyat est centrifugé à $1000 \mathrm{~g}$, le surnageant est éliminé et l'opération est répétée dans les mêmes conditions. 
Le culot est repris dans $2,5 \mathrm{ml} / \mathrm{g}$ de méthanol-pyridine-eau (5:1:4), additionné de thiodiglycol $(0,5 \%)$, puis centrifugé; l'extraction est recommencée une seconde fois et les extraits sont fusionnés.

Pour les études individuelles, les animaux, ou les organes disséqués, sont simplement broyés une fois dans le méthanol-pyridine-eau et centrifugés.

Les chromatographies bidimensionnelles sont effectuées en série sur des feuilles $20 \times 20$ de papier Whatman no 1 . La combinaison de solvants utilisée est $n$-propanol-ammoniaque $1 \%(2: 1)$ puis $n$-butanolacide acétique-eau (20:3:7).

Quelques chromatographies unidimensionnelles ont été réalisées de la même manière dans le propanol-ammoniaque pour comparer divers organes dont les extraits ont été chromatographiés côte à côte.

L'extrait est évaporé à l'aide d'une microseringue à l'origine d'un chromatogramme (volume déposé : $50 \mu \mathrm{l}$ pour une chromatographie bidimensionnelle, $25 \mu \mathrm{l}$ pour une chromatographie unidimensionnelle).

D'autre part, des chromatographies semi-préparatives ont été effectuées sur papier Whatman 3 MM $20 \times 30 \mathrm{~cm}$ préalablement lavé; $1,5 \mathrm{ml}$ d'extrait est évaporé en ligne selon la petite dimension. Le solvant de chromatographie est le n-propanol-ammoniaque. Les bandes fluorescentes et absorbantes obtenues sont éluées dans l'eau (additionnée de $0,5 \%$ de thiodiglycol); l'éluat est ensuite lyophilisé et repris dans le méthanol-pyridine et utilisé pour la chromatographie unidimensionnelle en comparaison avec des substances témoins dans divers solvants.

L'électrophorèse est pratiquée sur couche mince de cellulose (tampon : acétate d'ammonium $\mathrm{pH} 6,3 ; 20 \mathrm{~V} / \mathrm{cm}$ ).

Les chromatogrammes et électrophorèse sont lus en lumière U.V. (365 et $254 \mathrm{~m} \mu$ ). Les substances puriques sont révélées par immersion dans l'éosine mercurique $\left(0,2 \%\right.$ d'éosine dans l'éthanol à $95^{\circ}$ saturé de chlorure mercurique), puis lavage dans l'alcool à $95^{\circ}$; les chromatogrammes sont observés en lumière U.V. Cette technique, très sensible, sera détaillée dans une publication ultérieure.

\section{Résultats}

\section{A. Etude des substances fluorescentes}

Six taches fluorescentes, dont certaines, bleues, apparaissent rapidement sous irradiation aux U.V., et deux taches absorbantes peuvent être observées sur les chromatogrammes bidimensionnels (Fig. 2). 
Parmi elles, les plus abondantes, 3 (violette), 6 (jaune) et 4 (absorbante) ont été plus particulièrement étudiées.

$1^{0}$ - Tache $n^{\circ} 3$. La bande correspondant à cette tache sur les chromatogrammes semi-préparatifs a été comparée avec l'isoxanthoptérine qui présente la même couleur de fluorescence et des valeurs de RF similaires. Une comparaison entre la substance 3 et l'isoxanthoptérine de synthèse a été effectuée dans 5 solvants choisis parmi ceux qui donnent la meilleure différenciation (Tabl. 1). Les RF coïncident dans tous les cas, une légère différence étant cependant

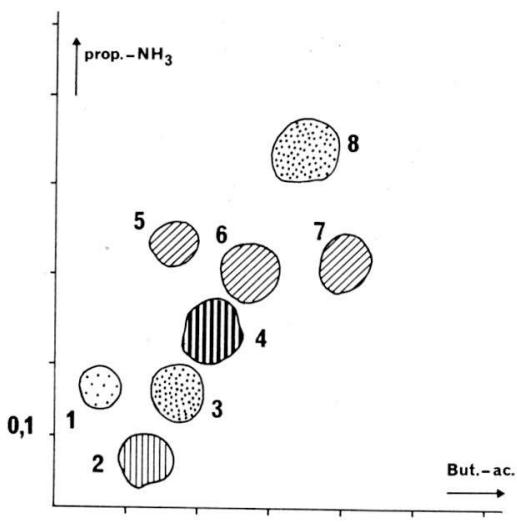
observée dans les chlorure d'ammonium. Les migrations électrophorétiques sont également identiques (déplacement de 0,45-0,60 cm en 2 heures vers la cathode).

Fig. 2. Chromatogramme bidimensionnel d'extrait de Caecosphaeroma burgundum : substances fluorescentes et absorbantes dans l'U.V.1: bleu. 2 : absorbant. 3 : violet. 4 : absorbant. $5,6,7$ : jaune ou jaune-vert. 8 : violet.

$2^{\circ}$ - Tache $n^{\circ} 6$. Cette substance a été comparée avec de la riboflavine et de la sépiaptérine témoin extraite du Papillon Colias croceus Fourcroy (H. Descimon 1965). Les valeurs de RF permettent d'exclure l'hypothèse que cette substance soit de la sépiaptérine; de même, alors que ce dernier composé s'altère rapidement sur les chromatogrammes en acide ptérine-6-carboxylique (la couleur de fluorescence passant progressivement du jaune au bleu), le pigment jaune de Caecosphaeroma reste stable dans les mêmes conditions. Ce fait permet d'écarter également la "xanthoptérine $\mathrm{B}_{2}$ " (M. Goto, M. Konishi, K. Sugiura, M. Tsusue 1966), elle aussi très labile. En revanche, cette stabilité relative rapproche la substance 6 de la riboflavine; les valeurs des RF ne présentent aussi que des différences légères, qui peuvent n'être dues qu'à l'impureté du produit chromatographié. Une étude sur de plus grandes quantités s'avère done nécessaire.

$3^{\circ}-$ Tache no 4. Celle-ci s'est révélée identique, par ses propriétés chromatographiques (Tabl. 1) et par sa révélation à l'éosine mercurique, à de l'acide urique synthétique. Ce résultat confirme les conclusions de H. Schorr. 


\section{Tableau 1}

Valeur des RF dans les différents solvants utilisés. PA: n-propanol-ammoniaque $1 \%(2: 1)$. BA: n-butanol-acide acétique-eau (20:3:7). IAA: isopropanol-acétate d'ammonium $2 \%(1: 1)$. $\mathrm{NH}_{4} \mathrm{Cl}: 3 \%$. PEE : pyridineéther-eau (4:3:3). FP : formiate de pyridine $\mathrm{pH} 6,5-0,1 \mathrm{~N}$. BPE : n-butanolpyridine-eau $(6: 4: 3)$

\begin{tabular}{lccccccc}
\hline & $\begin{array}{c}\text { Tache } 3 \\
\text { violet }\end{array}$ & $\begin{array}{c}\text { Isoxantho- Tache 6 } \\
\text { ptérine } \\
\text { témoin }\end{array}$ & $\begin{array}{c}\text { Sépia- } \\
\text { jaune } \\
\text { vert }\end{array}$ & $\begin{array}{c}\text { Ribo- } \\
\text { Colias }\end{array}$ & $\begin{array}{c}\text { Tache 4 } \\
\text { flavine } \\
\text { absor- } \\
\text { bante }\end{array}$ & $\begin{array}{c}\text { Acide } \\
\text { urique }\end{array}$ \\
\hline $\mathrm{PA}$ & 0,16 & 0,17 & 0,30 & 0,32 & 0,32 & 0,22 & 0,22 \\
$\mathrm{BA}$ & 0,19 & 0,20 & 0,27 & 0,34 & 0,29 & 0,19 & 0,19 \\
$\mathrm{IAA}$ & 0,39 & 0,38 & 0,40 & 0,49 & 0,42 & & \\
$\mathrm{NH}_{4} \mathrm{Cl}$ & 0,30 & 0,33 & 0,31 & 0,30 & 0,35 & & \\
$\mathrm{PEE}$ & 0,62 & 0,62 & 0,77 & 0,74 & 0,79 & & \\
$\mathrm{FP}$ & & & & & & 0,50 & 0,50 \\
$\mathrm{BPE}$ & & & & & & 0,13 & 0,13
\end{tabular}

La substance 2, absorbante, est probablement une purine, puisqu'elle réagit fortement à l'éosine mercurique. La comparaison avec des substances de synthèse (guanine, adénine, xanthine et hypoxanthine) n'a permis de l'identifier à aucun de ces composés.

La substance 8, présente en trop faible quantité, n'a pu être soumise à des essais systématiques, mais il est possible qu'il s'agisse de bioptérine.

L'appararition, sous irradiation U.V., de taches fluorescentes bleues, laisse à penser que des tétrahydroptérines sont présentes chez cet animal (I. Ziegler 1965; M. Goto, M. Konishi, K. Sugiura, M. Tsusue 1966).

\section{B. Répartition des substances fluorescentes selon les organes}

Des chromatogrammes unidimensionnels comparatifs d'extraits de différents organes (pléotelson, hépatopancréas, carapace et tête) montrent des différences notables dans les teneurs en substances fluorescentes ou absorbantes (Tabl. 2).

Tableau 2

Répartition des substances fluorescentes et absorbantes suivant les organes

\begin{tabular}{lccccc}
\hline & 2 & 3 & 4 & 6 & 8 \\
\hline $\begin{array}{l}\text { Pléotelson } \\
\text { Hépatopancréas }\end{array}$ & +++ & ++ & ++ & ++ & \\
$\begin{array}{l}\text { Carapace } \\
\text { Tête }\end{array}$ & & & + & & + \\
& & ++ & ++ & ++ &
\end{tabular}


L'examen de ce tableau montre que la substance 6 est particulièrement abondante dans les régions où sont localisés les organes jaunes. Cette substance est donc très probablement le pigment jaune responsable de leur vive coloration.

La substance 3 est, elle aussi, particulièrement abondante dans ces organes, de même que l'acide urique.

Une comparaison entre des extraits d'animaux laissés à l'obscurité et d'autres placés à la lumière ambiante (1000 lux environ) n'a pas montré de différence notable.

\section{Discussion}

Les seuls travaux sur les pigments et substances fluorescentes des Crustacés n’ont porté que sur les Décapodes (R. G. Busnel et A. Drilhon 1948 ; M. Viscontini, H. Schmidt et E. Hadorn 1955). Aucun travail de ce genre n'a été effectué sur les pigments fluorescents des Isopodes et, a fortiori, sur ceux des Isopodes cavernicoles. La présente étude montre l'existence d'un certain nombre de ces substances. La substance 3 est vraisemblablement de l'isoxanthoptérine, composé extrêmement répandu chez la plupart des Arthropodes. Le pigment jaune (substance 6) n'a pu être identifié avec certitude. Des séparations à l'échelle préparative seront effectuées ultérieurement pour déterminer sa structure. Des travaux récents ont d'ailleurs montré la variété des pigments jaunes des Arthropodes (M. Viscontini 1963; G. H. Schmidt et M. Viscontini 1964; H. Descimon 1965 ; M. Goto et al. 1966). La présence éventuelle de tétrahydroptérines est également assez vraisemblable.

Dans le domaine de la faune cavernicole, R. Bernasconi (1964) a obtenu d'intéressants résultats concernant les Coléoptères troglobies, chez lesquels il a pu mettre en évidence la présence de leucoptérine et de xanthoptérine.

Le rôle physiologique de ces pigments reste à élucider; des recherches récents ont montré la grande importance comme coenzymes d'oxydation des substances possédant le noyau ptéridine et en particulier des pigments jaunes (M. Viscontini et G. H. Schmidt 1965). La biologie très particulière de Caecosphaeroma burgundum est peut-être en relation avec l'accumulation frappante d'une telle substance chez cet animal.

\section{RÉSUMÉ}

L'analyse chromatographique des organes jaunes du Crustacé Isopode des eaux souterraines Caecosphaeroma burgundum Dollfus a permis de mettre en évidence, par observation des chromatogrammes en lumière ultra-violette, un certain nombre de substances absorbantes et de substances fluorescentes. Parmi ces dernières, seule l'isoxanthoptérine a été identifiée. 
Le pigment jaune, qui possède vraisemblablement le noyau ptéridine, n’a pu être identifié à un composé connu et fera l'objet de travaux ultérieurs.

\section{SUMMARY}

Chromatographic analysis of the yellow organs of the fresh-water Isopod Crustacean Caecosphaeroma burgundum Dollfus revealed, through observation of the chromatograms in ultraviolet light, the occurence of both absorbant and fluorescent substances. Among the latter, only isoxanthopterin has been identified. The yellow pigment, which probably has a pteridine nucleus, could not be identified as a known compound and will be the object of later investigations.

\section{B I B LI O GRAP H I E}

Bernasconi, R. (1964) - Recherches biochimiques sur les pigments des Insectes cavernicoles. Ann. de Spéléol., 19, 3: 553-572.

Busnel, R. G., et Drilhon, A. (1948) - Sur les pigments flaviniques et ptériniques des Crustacés. Bull. Soc. Zool. Fr., 73: 141-185.

DA u, J. (1954) - Zur Biologie einer Isopodenart unterirdischer Gewässer: Caecosphaeroma burgundum Dollfus. Ann. Univ. Sarav., 3: 104-160.

Descimon, H. (1965) - Identification de la sépiaptérine dans les ailes des Pieridae (Lepid. Rhopalocera). Bull. Soc. Chim. Biol., 47, $\mathrm{n}^{0}$ 6: 1095-1100.

Goto, M., Konishi, M., Sugiura, K., et Tsusue, M. (1966) - The structure of a yellow pigment from the mutant lemon of Bombyx mori. Bull. Chem. Soc. Jap., 39, no 5 .

Husson, R., et Daum, J. (1953) - Sur la Biologie de Caecosphaeroma burgundum. C.R. Ac. Sc., $236: 2345-2347$.

- - (1957) - Répartition des organes jaunes chez le troglobie Caecosphaeroma burgundum Doll. Notes biospéol., 12: 53-57.

Husson, R., et Henry, J. P. (1963) - Etude chez trois espèces du genre Asellus des concrétions des organes de Zenker. Bull. Soc. Zool. Fr., $88: 274-277$.

Husson, R., et Schorr, H. (1957) - Mise en évidence d'acide urique dans les organes jaunes du Crustacé troglobie Caecosphaeroma burgundum Dollfus. C.R. Ac. Sc., 244: 513-515.

Schindler, J. (1950) - Reservestoff- und Exkretspeicherung bei Bodentieren unter besonderer Berücksichtigung der Harnsäureverbindungen. Österr. Zool. Zeitschr. 2: 517-567.

Schmid t, G. H., et Viscontini, M. (1963) - Fluoreszierende Stoffe aus roten Waldameisen der Gattung Formica. Isolierung einer RiboflavinFormicapterin-Verbindung. Helvet. Chim. Acta, 47, fasc. 7.

Schorr, H. (1957) - Untersuchungen über Purine und Pigmente in den ,Gelben Organen" des Höhlenisopoden Caecosphaeroma burgundum Doll. Ann. Univer. Sarav.-Naturwiss., V: 311-328.

Viscontini, M. (1963) - Ptérines et génétique chez Drosophila melanogaster. Il Farmaco, no 1 .

Viscontini, M., et Sсниid t, G. H. (1965) - Über die physiologische Bedeutung der Pterine. Zeitschr. für Naturforsch., 20 b: 327-331.

Viscontini, M., Schmidt, H., et Hadorn, E. (1955) - Isolierung fluoreszierender Stoffe aus Astacus fluviatilis. Exper., XI : 390-392.

Ziegler, I. (1965) - Pterine als Wirkstoffe und Pigmente. Ergeb. Physiol., biol. Chem. und exper. Pharmak., 56. 



\title{
Algal Growth Experiments in the Baradla Cave at Aggtelek (Biospeleologica hungarica XXI)
}

\author{
By Erzsébet Kol ${ }^{1}$ )
}

\section{Introduction}

One of the most interesting problems facing speleobotanist today is the question of what energy source is used by the actively growing green algae which are found within caves throughout the world, since the eternally dark environment of the cave precludes the possibility of photosynthesis. Many algal species are known to be able, if necessary, to switch from their usual autotrophic assimilatory system to a heterotrophic nutrition if suitable organic materials are available (Chodat and Kol, 1934). In the present paper we are primarily concerned with those which apparently retain not only an autotrophic mode of life, but also their original green coloration.

\section{Materials and Methods}

In order to investigate this problem, several samples from axenic cultures of different algal strains present in the Kol collection of the Natural History Museum, Section of Botany, Budapest, were grown for varying periods of time in both light and dark, including cave environments. The cultures were inoculated into tubes on agar $+1 / 3$ Detmer-medium. For each experiment, three parallel cultures from each strain were included for each varying environmental condition. The laboratory investigations were carried out in the Natural History Museum, Section of Botany.

A total of 108 algal strains were used in these experiments. Cyanophyta was represented with 53 separate strains, Chlorophyta with 35, and Chrysophyta with 20. A list of the individual strains is found below. In the following work the strains will be denoted by their respective accession numbers in the Algotheca.

1) Botanical Division, Natural History Museum, Vajdahunyadvár, Budapest, Hungary. 


\title{
List of Algae Used in Experiments
}

\author{
CYANOPHYTA
}

230. Amorphonostoc paludosum (Kg.) Elenk.

23. Amorphonostoc punctiforme (Kg.) Elenk.

214. Amorphonostoc punctiforme (Kg.) Elenk.

215. Amorphonostoc punctiforme (Kg.) Elenk.

177. Chlorogloea microcystoides Geitler

176. Hammatoidea normanni W. et G. S. West

81. Lyngbya lagerheimii (Möb.) Gom.

53. Nostoc sp.

216. Nostoc sp.

218. Nostoc sp.

231.a. Oscillatoria acutissima Kuff.

234.a. Oscillatoria nigra Vaucher

122. Phormidium autumnale (Ag.) Gom.

122.a. Phormidium autumnale (Ag.) Gom.

223. Phormidium autumnale (Ag.) Gom.

225. Phormidium autumnale (Ag.) Gom.

225.x. Phormidium autumnale (Ag.) Gom.

233. Phormidium autumnale (Ag.) Gom.

29. Phormidium foveolarum (Mont.) Gom.

29.a. Phormidium foveolarum (Mont.) Gom.

138.a. Phormidium foveolarum (Mont.) Gom.

168. Phormidium foveolarum (Mont.) Gom.

172. Phormidium foveolarum (Mont.) Gom.

172.a. Phormidium foveolarum (Mont.) Gom.

217. Phormidium foveolarum (Mont.) Gom.

217.x. Phormidium foveolarum (Mont.) Gom.

217.xx. Phormidium foveolarum (Mont.) Gom.

144. Phormidium laminosum (Ag.) Gom.

144.a. Phormidium laminosum (Ag.) Gom.

144.b. Phormidium laminosum (Ag.) Gom.

206. Phormidium laminosum (Ag.) Gom.

209. Phormidium laminosum (Ag.) Gom.

209.a. Phormidium laminosum (Ag.) Gom.

209.b. Phormidium laminosum (Ag.) Gom.

209.c. Phormidium laminosum (Ag.) Gom.

209.d. Phormidium laminosum (Ag.) Gom.

209.e. Phormidium laminosum (Ag.) Gom.

211. Phormidium laminosum (Ag.) Gom.

211.a. Phormidium laminosum (Ag.) Gom.

309.a. Phormidium laminosum (Ag.) Gom.

309.b. Phormidium laminosum (Ag.) Gom.

11. Phormidium molle (Kg.) Gom.

227. Phormidium molle (Kg.) Gom.

212. Phormidium molle (Kg.) Gom.

234. Phormidium molle (Kg.) Gom.

226. Phormidium uncinatum (Ag.) Gom.

136. Plectonema sp.

254. Plectonema tenue Thur. 
62. Stratonostoc commune (Vaucher) Elenk.

47. Stratonostoc linckia (Roth) Elenk.

87.a. Stratonostoc linckia (Roth) Elenk.

207. Stratonostoc linckia (Roth) Elenk.

208. Stratonostoc linckia (Roth) Elenk.

\section{CHLOROPHYTA}

174. Ankistrodesmus falcatus (Corda) Ralfs

28. Chlamydomonas intermedia Chodat

149. Chlamydomonas intermedia Chodat

82. Chlorella miniata (Naeg.) Oltm.

101. Chlorella pyrenoidosa Chick

132. Chlorella pyrenoidosa Chick

143. Chlorella pyrenoidosa Chick

204. Chlorella pyrenoidosa Chick

63. Chlorella vulgaris Beyer.

66. Chlorella oulgaris Beyer.

91. Chlorella oulgaris Beyer.

106. Chlorella oulgaris Beyer.

124. Chlorella vulgaris Beyer.

135. Chlorella vulgaris Beyer.

138. Chlorella vulgaris Beyer.

138.b. Chlorella vulgaris Beyer.

146. Chlorella pulgaris Beyer.

151. Chlorella vulgaris Beyer.

159. Chlorella vulgaris Beyer.

159.a. Chlorella oulgaris Beyer.

162. Chlorella vulgaris Beyer.

166. Chlorella vulgaris Beyer.

219. Chlorella vulgaris Beyer.

233.a. Chlorella vulgaris Beyer.

68. Chlorella sp.

81.a. Chlorella sp.

205. Chlorella sp.

222. Chlorococcum humicolum (Naeg.) Rabenh.

154. Chlorococcum infusionum (Schrank) Menegh.

240. Chlorococcum sp.

5. Cystococcus humicola Naeg. em. Treb.

280. Dictyococcus cinnabarina (Kol et F. Chodat) Vischer

10. Hormidium flaccidum A. Br. sens. ampl.

65. Scenedesmus obliquus (Turpin) Kg.

230.a. Stichococcus bacillaris Naeg. sens. ampl.

\section{CHRYSOPHYTA}

\section{Xanthophyceae}

309. Botrydiopsis arhiza Borzi

37. Botrydiopsis minor (Schmidle) Chodat

216.a. Chlorocloster minimus Pascher

227.x. Ellipsoidion oocystoides Pascher 
227.xx. Ellipsoidion oocystoides Pascher

228. Ellipsoidion oocystoides Pascher

43. Ellipsoidion regulare Pascher

213. Ellipsoidion $\mathrm{sp}$.

213.a. Ellipsoidion $\mathrm{sp}$.

201. Monodus dactylococcoides Pascher

49. Monodus subterranae Boye-Petersen

50. Monodus subterranae Boye-Petersen

221. Monodus subterranae Boye-Petersen

232. Monodus subterranae Boye-Petersen

229. Pleurochloridella botrydiopsis Pascher

181. Pleurochloris commutata Pascher

87. Raphidiella fascicularis Pascher

\section{Bacillariophyceae}

224. Nitzschia palea (Kg.) W. Smith

231. Nitzschia palea (Kg.) W. Smith

Five different experimental series were performed on the algal strains.

1. Orientation experiments to determine which of the strains were best suited for our purposes. Ninetyfive algal strains were kept in darkness in the laboratory for 268 days (Table I.).

2. Parallel experiments with 27 algal strains, in the cave and in darkness in the laboratory, for 204 days, followed by 245 days in light for the cave cultures (Table II).

3. Parallel experiments with 103 algal strains, in the cave and in the laboratory darkness for 365 days (Table III).

4. Experiments in the cave environment for 175 days with 26 algal strains, which had previously been cultured under light conditions in the laboratory for 139 days (Table IV).

5. Parallel experiments with 27 algal strains in the cave, in a cellar and in darkness in the laboratory for 420 days and followed by exposure to light in the laboratory for 158 days (Table V).

The results of the experiments are summarized in Tables I-V, in which the degree of development of the cultures is denoted in two ways: 1. The surface magnitude of the algal thallus is measured in mm. ${ }^{2}$ or $\mathrm{cm}^{2} ; 2$. The overall growth in the culture is denoted as from 1 to 5 . (Details are found in Table I).

\section{Results}

\section{Orientation Experiments}

Ninetyfive strains were used, 44 Cyanophyta, 33 Chlorophyta and 18 Chrysophyta. Cultures for experiments in darkness were placed in 
boxes especially prepared for this purpose, the inside of which was lined with black paper. The cultures themselves were wrapped with a double-layered black cloth before placement into the boxes, the covers of which had an overlapping rim of several centimeters. This arrangement already retrains light penetration, but for even further security, the boxes were then wrapped with heavy duty black paper. Control cultures were placed in the same laboratory, under the same temperature conditions, under light. Thus, both of the series had the same environmental conditions with the exception of light. The purpose of this orientation was to separate and select those algal strains which can live in darkness and would thus prove to be the most suited for the purpose of the subsequent experiments. The cultures were kept in the boxes for a period of 268 days (1/22/60-10/18/60) after which they were removed, observed, and for another 150 days (10/18/60-6/ $25 / 61$ ) were kept in light in the laboratory.

It can be seen from Table I that most of the algal strains survived this long period of darkness, retained their green color, and many of them even showed satisfactory growth. However, some of the strains perished completely, in the dark, while in some cases, although the strains survived, their color changed from green to brownish or yellowish-green. In those strains which retained their green color some apparently actively grew, and in some cases only the original inoculum survived, as indicated by a lack of thallus development.

As much variation occurred in the reactions of the algae to the 150 days of light environment as to the 268 days of darkness. As can be seen from Table I, some of the algae developed with great intensity in the light, a few strains which had barely survived in the darkness underwent a vivid growth during this 150 days, a good number of the strains which had just survived the rigors of darkness did not improve in the light and some even perished. A few particularly interesting strains which had showed some development during the first part of this experiment quit growing in the light as through the light itself were actually a restraining factor. (\# 146, 149, 217.)

From Table I it is clear that light requirement for growth, or the ability to survive in lack of it, is not so much a characteristic of a species as it is of a single algal strain. We can see that in the same species (note Chlorella sulgaris, Phormidium foveolarum, Phormidium laminosum and Nostoc) some strains have shown quite satisfactory growth in darkness while others completely perished.

During the entire time of this experiment, out of the total 95 strains, 14 showed significant growth and 12 perished. 
2. Parallel Growth Experiments in the Cave and in the Laboratory in Darkness and in Light

Twentyseven selected strains of algae were kept in darkness both in the cave and in the laboratory for a period of 204 days $(4 / 1 / 60-10 /$ $22 / 60)$. After their removal from the dark environments, they were examined and placed in the light for a period of 245 days $(10 / 22 / 60-6$ / 25/61).

The results of these experiments are summarized in Table II, from which it becomes clear that some algal strains thrived well in the cave and showed excellent development. Others, however, barely stayed alive. Certain strains developed in the darkness of the cave better than in the dark in the laboratory, while others showed better development in the dark in the laboratory than in the cave. The strains in the former group apparently are able to tolerate the lack of light much better in the cooler cave environment whereas those in the latter group thrived better in the dark under the laboratory conditions at the higher temperature (room) which this provided for them.

In both experimental series the twentyseven strains were kept in total darkness for a period of 204 days and even under these conditions only four perished completely while ten showed excellent development.

The results of culturing the algae for an additional 245 days after their removal from the cave or after the removal of the wrapper in the laboratory are also compiled in Table II. Purposes of these studies were two-fold: 1 . to establish whether or not the strains which were weakened in the cave or in the darkness of the laboratory will be able to regenerate when placed in light; 2 . whether or not the strains which possibly changed to heterotrophism due to the long lightless condition will be able to revert to autotrophism. These experimental series at the same time served as a check to demonstrate that the strains kept in the cave or in the laboratory darkness were still alive. Some strains which showed only a small development or remained barely alive in the cave when placed to the light showed an excellent development. In general those strains which developed well in the cave retained their developmental intensity when exposed to light. Two strains, number 50 and 122 , in spite of the fact that they developed quite well in the cave lost this developmental intenstity in the light culturing. Two other strains, number 43 and 49 which, however, were barely viable when recovered from the cave, perished after light exposure. Some other factors which are not mentioned here may also played a role in this case. 
3. Parallel Experiments in Darkness in Cave and Laboratory

In these experiments parallel cultures of 103 algal strains were prepared for growth determinations in the cave and in the darkness of the laboratory for an entire year (12/19/60-12/20/61). The results are found in Table III.

Among the 103 cultures kept in the cave, ten showed significant growth and ten perished. In the laboratory six strains showed significant growth, none of these were the same as those developing well in the cave, and these six showed a smaller thallus than the very well developed thalli of the cave growers. In the darkness of the laboratory twelve strains died, again none of the same strains which perished in the cave. Strain \# 87 showed excellent development in the cave, but perished in the laboratory. We can generalize that a greater percentage of the cave cultures thrived, they established larger thallil, and a smaller percentage died, compared to the laboratory cultures.

Some general color differences can be seen between the two environments. Although the cultures all, in both biotypes, kept a green color, the fine shading had a general trend to dark green and brownish-green in the cave, with the exception of the strains of Phormidium which become a yellowish-green (see Table III). The laboratory cultures tended much more to true green and light green. Nitzschia palea (strains 224, 231) kept their brownish color in both environments.

The major differences in environmental parameters that the cultures had to contend with were the greater humidity of the cave, its lesser temperature, and the possible radiating energy that can be found in a cave.

\section{Experiments in Cave, with Cultures Previously Grown in Light}

Twentysix algal strains were used. Inoculated on February 15, 1961, these strains were grown in light for five months, and then were placed in the cave environment for 175 days (on July 20th, 1961). The purpose was to determine the reaction of the cultures, after having attained a good growth, in the laboratory to the cave environment. In previous experiments, the cultures were placed into the dark environment, either laboratory or cave, within a few days after inoculation, while in this instance they were placed into the cave after growing them during the best vegetation period in the light, i.e. spring and summer while still during the vegetation period. The results of these experiments are summarized in Table IV. 
Again, even among these few strains, the results are quite varying. A total of 14 out of the 26 strains acclimatized easily and retained their intensity of development. Five stopped development, probably due to some hindering circumstance of the cave, although the original thalli, in their original sizes, remained alive. One culture died and several became ill.

The general health pattern and developmental trends of the cultures is indicated not only by the size of the thallus but also by coloration changes. In every instance, such a change signifies a change in the health pattern of the culture. In poor health it seems that the green color fades, and often the coloration changes to brownish or yellowish. Those particular species which usually form large amounts of carotene, tend to produce even more in the cave environment and their color turned often to a stronger yellow, or reddish-yellow, as can be seen in Table IV, especially strains $65,280$.

From this Table it becomes evident that it is immaterial for these microorganisms, from the viewpoint of their ability to grow and develop in the cave, whether or not they have lived under light and have already developed a thallus of some size or whether they are placed in darkness immediately after inoculation with only a few cells in the medium. Their adaptation seems to be identical in either case, although there are a few strains which seem better able to endure cave conditions if placed there as very young cultures, and have not been grown in light first.

\section{Parallel Experiments in Cave, Laboratory and Cellar in Darkness, Followed by Light Culturing}

For 420 days (4/25/62-6/30/63) twentyseven algal strains were kept in darkness under the conditions described below, after which they were removed from the darkness, examined and placed in light for 158 days (6/30/63-11/26/63). In each instance at least three parallel cultures were used.

A. Cultures in formly sealed metal boxes in the cave.

B. Cultures placed in the cave without wrapping.

C. Cultures placed in a dark, damp cellar, after having been wrapped in several folds of black paper and textile.

D. Cultures placed in a dry cellar, wrapped as in C.

E. Cultures kept in dark metal boxes, in the laboratory at room temperature (thus at a higher temperature than A through D).

F. Cultures placed under light, in the laboratory. 
Some algal strains showed good development even when sealed within metal boxes in the cave, and some exhibited even better development under such conditions than when they were freely placed in the cave. However, other strains barely survived in the box. Many of the algae also showed good development when freely placed, while some grew equally well in both biotopes $(28,138,280)$.

The available moisture was identical for both algal groups due to the fact that those which were freely placed in the cave could directly utilize the moist air of their surrounding, while the others, placed in boxes, had at their disposal the moisture of the medium which was shielded from evaporation by the lid. Therefore, the cultures in the boxes had available to them the required quantity of moisture.

After removal from darkness these cultures were kept for 158 days under light, during which the phenomenon already known from Experiment 2 repeated itself, namely that those strains which in darkness could barely survive, when placed under light showed good development (See Table V); while those which exhibited good growth already when in the dark developed with even greater intensity under light.

Let us now see, how these same algal strains behaved in the darkness of the cellars under different moisture conditions. It should be noted here that the cultures which were placed in the cellars were not sealed in boxes, therefore, the moisture content of the cellars could reach these cultures directly. (Series C and D.)

Surprisingly only five algal strains showed better development in the damp cellar while eight strains thrived better in the dry one. Some apparently could not adapt well to either place, but merely survived, and strains nos. 149 and 162 died in the cellars.

In general, among the cultures of algae in the cave, as compared with those in the cellars, more strains were seen growing with greater intensity, even when sealed in a metal box. Strain no. 28 , showed very good development in series A and B, while in the damp cellar (C) it could merely survive. Although this strain did develop in the dry cellar (D) it was not to the same extent as when in the cave. Still a few strains showed better development in the cellar than in the cave.

We may conclude from the above experiments that in the cave there is some energy source available to the algae which is not present in the cellar or laboratory. This energy source has to be of the type which can penetrate a metal box, since some algal species showed better development in the boxes. Therefore, this energy can only be some kind of an emissive energy. Whether it is a readioactive radiation or some other type which is not known at the present must be ascertained by future experiments. 
Series $\mathrm{E}$ was kept in the laboratory in dark boxes at a higher temperature, i.e., room temperature, than the temperature of the cave or cellars. More of the algal strains showed better development in the cave, and even in the cellars, than those which were kept in the laboratory darkness at higher temperatures. The most resistant strain was no. 28, because under all six circumstances this strain showed the greatest development. Those strains which could hardly survive when kept in the dark in the laboratory became more-or-less regenerated when placed under light.

Series A-E of Experiment 5 were kept in darkness for 420 days, and thereafter under light for 158 days.

Series $\mathrm{F}$ was kept under light at room temperature in the laboratory for 578 days. Even under this latter condition, the intensity of development of the different algal strains varied; eight strains showing high development, small development displayed by six, and three $(28,151$ and 216) barely surviving.

It can be seen from the above that there seem to exist both photophilic and also sciophilic, that is dark demanding algal strains.

\section{Discussion}

\section{A. General Considerations}

It was already mentioned that there must be some kind of radiation in the cave which serves as an energy source for these plants. However, as it can also be seen from the above experiments, the simple existence of such energy is inadequate, since it is also necessary that the organisms, in this case the algae, should have the capacity of absorbing and utilizing such radiation as their source of energy. It can be said that the existence of indigenous life in caves is based on this fact, and serves also as a species selective factor. The adaptability of the individual living organism may also play an important role; those algal strains which can easily switch from an autotrophic to a heterotrophic existence can more-or-less utilize the energy source provided by the cave, and are able to survive and develop there. The algal strains which are unable to utilize the energy source available in the cave, but are hardy and able in general to bear unfavorable conditions, such as dessication, lack of light, etc. can survive, but not develop. Also important is the individual character of the organism, in this case the algal plant, how soon it is able to acclimatize, that is whether it is able to change its nutritional system under the force of the changed environmental conditions. 
The time period provided for these experiments in order to study and judge the behavior of algal strains under different conditions was undoubtedly sufficiently long and in some cases perhaps was even too long. The experiments were set up to include at least one vegetation period, i.e., spring and summer.

The cultures kept in the cave in many cases show deviations from the usual: (1) in color, the green color of the strains tends towards a yellowish, quite often brownish color, whereas the Cyanophyta become vivid bluish-green; (2) usually the pyrenoids of the cells do not develop, little or no starch is found in the cells; (3) while vigorous cell division occurs, the developing cells usually are very small; (4) in the filamentous algae the filaments are often disintegrating; in the Cyanophyta the mucous sheath of the filaments are well developed; (5) in the yellow colored strains carotene formation is higher than usual.

At the present time it is not known which species of the different algal groups can bear darkness better, this ability is, however, probably an individual characteristic. The plants of the caves belong mainly to the groups of edaphic and terrestrial algal species.

\section{B. Energy Sources Available to the Cultures During the Experiments}

Chodat and Kol (1934) carried out different experiments with the algal strains in R. Chodat's Algotheca at the Botanical Institute of the University of Geneva, Switzerland. The strains were kept in darkness and under light, in air and in vacuum, in inorganic medium, both with and without sugars. Attention is called only to the results of those experiments which seem to be relevant to the present studies and which are mainly concerned with the autotrophic and heterotrophic nutrition of the different algae under varying environmental conditions.

According to this paper (loc. cit.p. 5 Tab. I) some algal species could not only live in a vacuum and on inorganic medium in the laboratory but also develop and undergo cell division if kept in light. Under aerobic condition and in darkness (loc. cit. p. 10) there was cell division occurring to some degree even in the sugarless, inorganic medium, while under the same conditions but with a medium contaminated with sugar the rate of cell division of certain species dropped to from one-half to one-quarter of that shown under light. In the latter case, in the lack of light, the lower rate of cell division can be attributed to a change to heterotrophic nutrition. One can also see from this Table (loc. cit. p. 10. Tab. III) that cell division is significantly reduced in 
vacuum that is in unaerobic conditions, and darkness, that cell division in certain species kept in medium containing sugar is slight, and it disappears completely on the inorganic medium.

In the experiments referred to above the algae were provided with different energy sources as shown below:

$\mathrm{A}=$ energy utilized by photosynthetic assimilation, with the aid of chlorophyll, through autotrophic nutrition.

$H=$ energy sources provided and located in the medium itself.

$\mathrm{J}=$ energy liberated by anaerobic fermentation of different materials within the cells themselves in the vacuum.

$\mathrm{R}=$ energy developed by the algae themselves in the presence of oxygen and respirable materials.

Therefore, the cultures which were kept under light were provided with energy sources $\mathrm{A}+\mathrm{H}$, for those in darkness and inorganic, sugar free medium, the energy source was $\mathrm{R}$, and for cultures in sugar containing, therefore actually organic, medium and in darkness the energy sources $\mathrm{R}<\mathrm{H}$ were available. Therefore, accordingly (loc. cit. p. 13 Tab. IV) the carbon uptake can occur in both autotrophic and heterotrophic manner. In the presence of light green algae assimilate in autotrophic manner. On inorganic medium and in the absence of light, the functioning of the algal cells is reduced mainly to respiration, however, if in the medium organic material, like sugar, is available, a change to heterotrophic nutrition may take place.

In the case of algae in the caves and also those cultured in the cave, the medium contained purely inorganic salts and agar-agar. Therefore, obviously in this case the energy source needed from the medium for a heterotrophic nutrition was not available to the algal cells.

The experiments carried out in the cave in darkness show that: (1) The organic materials probably present in the cave could not have served as an energy source for a heterotrophic nutrition for the algal cultures. (2) Neither did, as was supposed by some that the energy liberated through chemosynthesis by different bacteria living in the cave, serves as an energy source, since the cultures were kept sterile, sealed with cotton plugs, which were intact when removed from the cave, therefore, no bacterial product could have penetrated to the algal cells.

In view of this, one must suppose that the algal cells have the capacity to intercept an as yet unknown radiation or radiating energy probably existing in the cave and to utilize it further for their life functioning. In my opinion, this capacity is a strictly individual characteristic of the different algae, as also proven by the experiments described herein. 
C. Different Influencing Factors during the Experiments

During the experiments, in the varying environmental conditions, different factors influenced the nutrition of the different algal strains:

1. Medium: $1.5 \%$ agar-agar $+1 / 3$ Detmer solution $=\mathrm{T}$.

2. Moisture content of the medium $=-\mathrm{V}$; degree of humidity of the air $=+\mathrm{V}$.

3. Temperature in the laboratory $=+\mathrm{H}$; the lower temperature of the cave $=-\mathrm{H}$.

4. Light $=\mathrm{F}$.

5. Aerobic conditions $=+\mathrm{L}$; aerobic conditions in tin boxes $=-\mathrm{L}$.

Among these factors, only the medium is constant in every case, all the other factors vary according to the different experimental conditions. Experiment 1: $+\mathrm{T},+\mathrm{V},+\mathrm{H},+\mathrm{L}$ and $-\mathrm{F}$.

Experiment 2:

a) $+\mathrm{T},+\mathrm{V},+\mathrm{L}$ and $-\mathrm{F},-\mathrm{H}$.

b) $+\mathrm{T},+\mathrm{V},+\mathrm{L},+\mathrm{H}$ and $-\mathrm{F}$.

c) $+\mathrm{T},+\mathrm{V},+\mathrm{L},+\mathrm{H},+\mathrm{F}$.

Experiment 3:

a) $+\mathrm{T},+\mathrm{V},+\mathrm{L}$ and $-\mathrm{F},-\mathrm{H}$.

b) $+\mathrm{T},+\mathrm{V},+\mathrm{L},+\mathrm{H}$ and $-\mathrm{F}$.

Experiment $4:+\mathrm{T},+\mathrm{V},+\mathrm{L}$ and $-\mathrm{F},-\mathrm{H}$.

Experiment 5:

A. $\quad+\mathrm{T}$ and $-\mathrm{V},-\mathrm{L},-\mathrm{F},-\mathrm{H}$ (minimum).

B. $+\mathrm{T},+\mathrm{L},+\mathrm{V}$ and $-\mathrm{F},-\mathrm{H}$.

C. $+\mathrm{T},+\mathrm{L},+\mathrm{V}$ and $-\mathrm{F},-\mathrm{H}$.

D. $+\mathrm{T},+\mathrm{L}$ and $-\mathrm{F},-\mathrm{H},-\mathrm{V}$.

E. $+\mathrm{T},+\mathrm{L},+\mathrm{V},+\mathrm{H}$ and $-\mathrm{F}$.

$\mathrm{F}$. $+\mathrm{T},+\mathrm{V},+\mathrm{L},+\mathrm{H},+\mathrm{F}$ (maximum).

The minimal life conditions, from point of view of energy sources, is available to the algae during Experiment 5, group A, since only the medium remains unchanged. There is no light in the cave, the humidity of the air cannot penetrate into the box, the air itself is limited somewhat by the box, and the algae are kept at the lower temperature of the cave.

The algal strains of Experiment 5, group F, are living in preferred, maximal conditions, as, by the way, did the other strains which were kept under light. However, strains of group $\mathrm{F}$ were living under the most favorable conditions as compared with the others, since they were placed in light immediately after inoculation, while the others were kept first in darkness and only thereafter in light. 
According to the present day concepts, one can speak of autotrophic nutrition only for cultures kept under light. Those cultures freely placed in the cave in darkness may have accidentally received some small amount of illumination and retained their autotrophism. However, no light was available for the cultures which were kept in complete darkness in the laboratory, cellar and in the cave, nor to those kept in tin boxes in the cave. In view of the fact that no organic material was present in the medium, it being constituted of only the inorganic salts of Detmer solution and the agar-agar, the plants could utilize only the energy source available in this inorganic medium and/or those provided by the cave.

Certain algal strains have specific chlorophylls differing from those of flowering plants, which may be a contributing factor to the fact that some algae are able, even in total darkness to produce chlorophylls and continue their development.

It is a well known fact that if organic material, such as carbohydrates, are available in the medium, some algal species are capable of utilizing them. In these cases, in the lack of light the algae can easily change to a heterotrophic nutrition. During these cave experiments however, we dealt solely with an inorganic medium, though some algal strains do react to a decrease in the humidity of air, this is not the critical factor here, nor is it, as it can be seen from the previous experimental series, the low temperature, nor the occasional deficiency of air, but the critical factor is the light, that is lack of light, or radiation of some type substituting for light. Wheter this radiation is or is not radioactive, will be proven by further experiments.

It is probable that more algal strains will become located in those places of the cave where illumination sometimes reaches the plant since in those places even such strains can survive and develop which are unable to bear total and permanent darkness.

Fehér's (1954) experiment, in which he kept algal cultures for 1-2 years, in complete darkness, in 1-2 meters in the earth is a further proof that some algal strains can easily endure a prolonged lack of light. His cultures survived, retained their green color, and even multiplied.

The hypothesis that the algae in the cave use as food organic material partially decomposed by bacteria or lower fungi is not applicable in our case because in the experiments presented here no such nutrients could have reached the algal cultures.

Although even a few decades ago it seemed very unlikely that green plants could inhabit the darkness of the caves, today we know from many experiments (Palik 1960a, Claus 1955, Suba 1957), that several 
algal species live in caves, and that the spores of even more can be found there. I shall not deal in this paper with the question of how these spores got into the caves.

It is quite probable that the algal species found in various caves vary according to the different light conditions found in them. Some algal strains can utilize even the most insignificant amount of light, while others are able to tolerate its complete absence. Many species representing the edaphon can be found in the caves which points out that other factors besides light may influence the populating of caves. Thus, the rock structure, the chemical composition of water, the humidity and temperature of the air, etc., all have a selective influence. The microorganisms found in ice caves are completely different from those which occur at the higher temperature of the dripstone caves. Those algal species which can be found in a cave only as spores, even if it is possible to culture them artificially when removed from the cave, cannot be enumerated as being part of the cave's microvegetation. Only those algal species which lead a vegetative life in the cave and which also multiply there belong to its flora. In my opinion one can enumerate as the organisms of a certain biotope only those which spend a significant portion of their vegetative and reproductive life cycle in this biotope.

It can also be seen from this paper, that in general algal strains belonging to the Cyanophyta, and to the edaphic and terrestrial Chlorophyta and Chrysophyta are those which showed the best development in darkness (Nos. 29, 47, 50). Among the Chlorophyta Chlamydomonas and Chlorella species with several strains tolerated the best the lack of light. Among the Chrysophyta, Monodus subterranea (Nos. 88, 50) and the Ellipsoidion species, among the Cyanophyta the species of Phormidium adopted best to darkness. According to Table V, among the species kept in darkness in the boxes in the cave No. 81 Lyngbya lagerheimii; No. 50. Monodus subterranea; Nos. 29, 29a. Phormidium foveolarum; No. 28. Chlamydomonas and No. 66. Chlorella species showed the highest development.

Whether there are exclusively cave dwelling algal species one does not know at present. Research in cave biology has to go a long way before it will have a real knowledge about the microorganisms living in the caves and will have ascertained their environmental conditions.

\section{ACKNOWLEDGEMENT}

I would like to express my sincere appreciation to Dr. Endre Dudich, Professor of Zoology and Director of the Cavebiological Laboratory at Aggtelek of the L. Eötvös University of Budapest for having made these experiments possible by delivering and placing the cultures within the cave. 


\section{SUMMARY}

The author kept 108 algal strains (Cyanophyta 53, Chlorophyta 35, Chrysophyta 20), of axenic cultures from the Kol-Algotheca in the Botanical Division of the Hungarian National Sciences Museum in the Baradla Cave, at Aggtelek (Hungary) in darkness for 204-420 days under different environmental conditions.

The experiments have proven that several algal strains can tolerate well the complete absence of light. Furthermore, that some algal strains show intensive development even under such conditions. These axenic cultures kept in the cave in metal boxes on inorganic medium have shown that the energy source used by these green colored algae is not some byproduct of chemotrophic bacteria, nor is it available organic material, but that it must be some kind of radiation which is able to penetrate even the metal boxes.

The ability to adapt to the conditions existing in a cave is not a general characteristic of algal species, but is the capability of individual algal strains within that species. Most probably the algae living in the caves are aerophytes, terrestrial forms, and also some belonging to the edaphon.

The cells were found to be smaller in the algae kept in the cave, there was almost no starch deposition in the cells, the pyrenoids were barely discernible, but the development of carotenes was more intense.

Whether there are specific cave dwelling algal strains must be determined by future algological research conducted in caves. The composition of the algal floras of the caves may be equally dependent upon the chemical and physical characteristics of the biotope, as is the case in every other biotope.

\section{ZUSAMMENFASSUNG}

108 Algenstämme (53 Cyanophyta, 35 Chlorophyta und 20 Chrysophyta), die aus axenen Kulturen der Kol-Algensammlung der Botanischen Abteilung des ungarischen Nationalmuseums der Wissenschaften beimpft wurden, wurden in der Baradlahöhle bei Aggtelek (Ungarn) während einer Zeitdauer von 204-420 Tagen unter verschiedenen Standortbedingungen kultiviert.

Die Versuche haben gezeigt, daß eine Anzahl von Algenstämmen vollständige Dunkelheit (Fehlen von Licht) sehr gut vertragen können. Darüber hinaus zeigen einige dieser Stämme unter den genannten Bedingungen eine intensive Entwicklung. Diese axenen Kulturen, die in der Höhle in Metallgefäßen auf anorganischem Medium gehalten wurden, haben gezeigt, daß die Energiequelle, die von diesen grüngefärbten Algen genutzt wird, kein Nebenprodukt chemotropher Bakterien ist, noch daß es sich dabei um verwertbares organisches Material handelt; es muß vielmehr irgendeine Strahlungsenergie sein, die in der Lage ist, selbst Metallbehälter zu durchdringen.

Die Fähigkeit, sich den in der Höhle herrschenden Bedingungen anzupassen, ist kein allgemeines Charakteristikum der Algenarten, sondern beruht auf speziellen Eigenschaften individueller Algenstämme innerhalb einer bestimmten Art. Höchstwahrscheinlich sind die in den Höhlen lebenden Algen Aerophyten, terrestrische Formen, oder sie gehören zum Edaphon.

Bei Algen, die in den Höhlen gehalten wurden, waren die Zellen kleiner, enthielten kaum Stärke in den Zellen, und die Pyrenoide waren kaum sichtbar. Demgegenüber war die Entwicklung von Karotinen sehr viel intensiver.

$\mathrm{Ob}$ es spezifische höhlenbewohnende Algenrassen gibt, muß durch weitere algologische Untersuchungen in den Höhlen entschieden werden. Die Zu- 
sammensetzung der Algenflora in den Höhlen dürfte in gleicher Weise von den chemischen und physikalischen Eigenschaften des Biotops abhängen, wie dies auch bei allen anderen Biotopen der Fall ist.

\section{REFERENCES}

Caumartin, V. (1957) - La microflora des cavernes. Not. Biospeleol. 12: $59-64$.

- (1959) - Quelques aspectes nouveaux de la microflore des cavernes. Ann. Spéléol. 14: 147-157.

Chodat, F., and Kol, E. (1934) - Quelques algues nouvelles des sols et de la neige du Parc National Suisse Engadine. Bull. Soc. Bot. Genève 25: 1-14.

Claus, G. (1955) - Algae and their Mode of Life in the Baradla Cave at Aggtelek. Acta Bot. Acad. Sci. Hung. 2: 1-26.

- (1959) - Concerning the Algal Flora of the Peace Cave at Aggtelek in Hungary. IX. Intern. Bot. Congr. Proc. 2A: 75.

- (1960) - Re-evaluation of the Genus Gomontiella. Rev. Algol. Nouv. Ser. 5: 103-111.

- (1962a) - Data on the Ecology of the Algae of Peace Cave in Hungary. Nova Hedwigia 4: 55-79.

- (1962b) - Beiträge zur Kenntnis der Algenflora der Abaligeter Höhle. Hydrobiologia 19: 192-222.

- (1964) - Algae and their Mode of Life in the Baradla Cave at Aggtelek II. Intern. J. Speleol. 1: 13-17.

Dudich, E. (1932a) - A barlangok biologiai osztályozása (Biological Classification of Caves) Barlangvilág 2:1-8.

- (1932b) - Biologie der Aggteleker Tropfsteinhöhle Baradla in Ungarn. $1-246$.

- (1955) - A barlang mint gyógytényezö (The Cave as a Factor in Curing) Födlr. Közl. 85: 353-359.

- (1958) - Klassifikation der Höhlen auf biologischen Grundlagen. Mitt. Höhlen-Karstforsch. 3: 35-43.

- (1959) - Barlangbiologia és problémái (Cave Biology and its Problems). Magy. Tud. Akad. Biol. Csop. Közl. 3: 323-357.

- (1960) - Das höhlenbiologische Laboratorium der Eötvös Loránd-Universität. Ann. Univ. Sci. Budapest. E. Eötvös nom. Sec. Biol. 3: 131-135.

FeHÉr, D. (1954) - Talajbiologia (Soil Biology). 1-1264.

GeBнARDT, A. (1934) - Az abaligeti barlang élövilága (The Biota of the Cave of Abaliget). 1-196.

JAKUTs, L. (1959) - A Béke barlang gyógyhatásának elsö eredményei (The First Results of the Curing Effects of the Peace Cave). Term. Tud. Közl. 90: 20-22.

Kol, E. (1964) - The Microvegetation of a Small Ice Cave in Hungary. Intern. J. Speleol. 1: 19-24.

Palik, P. (1960a) Study of the Algal Flora of Caves. Hidr. Közl. 5: 417-422. - (1960b) - A New Blue-green Alga from the Cave Baradla Near Aggtelek. Ann. Univ. Sci. Budapest, R. Eötvös nom. Sect. Biol. 3: 275-285. 
PALIK, P. - (1961) - Beiträge zur Fortpflanzung der Gomontiella subtubulosa Teodoresco und ein neueres Vorkommen der Species. Nova Hedwigia 3: 81-84.

- (1964a) - Eine neue Aulakochloris-Art aus der Tropfsteinhöhle von Aggtelek. Intern. J. Speleol. 1: 25-28.

- (1964b) - Über die Algenwelt der Höhlen in Ungarn. Intern. J. Speleol. 1: $35-43$.

Prát, S. (1925) - Das Aeroplankton neu geöffneter Höhlen. Zentralbl. Bakterbiol., II. Abt. 64: 39-42.

Prát, S., and Sesták, Z. (1959) - Autotroph-heterotroph Relationships in Natural Waters. Biol. Plant. 1: 81-92.

Radais, N. (1900) - Sur la culture pure d'une algue verte, formation de Chlorophylle à l'obscurité. C. R. Acad. Sci. Paris 130: 12.

Suba, E. (1957) - Die Algen der Pálvölgyer Höhle in Ungarn. Verh. Zool.Bot. Ges. Wien 97: 87-110. 
TABLE I.

DEVELOPMENT OF ALGAL STRAINS IN LABORATORY DARKNESS FOLLOWED BY CULTURING IN LIGHT

Algal strains

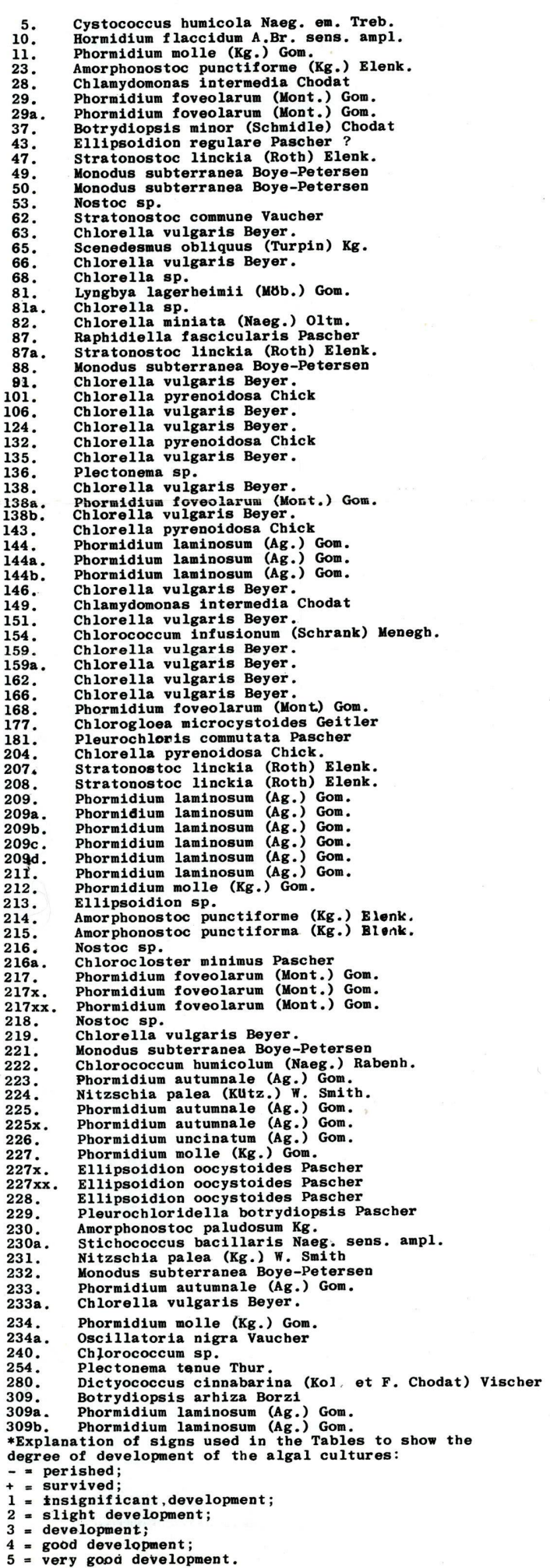

Darkness, 268 days
January 22, 1960 - October 18, 1960

Measurement of

Color of
a lgal thalli
Light, 150 days
Oc tober 18, 1960 - June 25, 1961

Development
algae

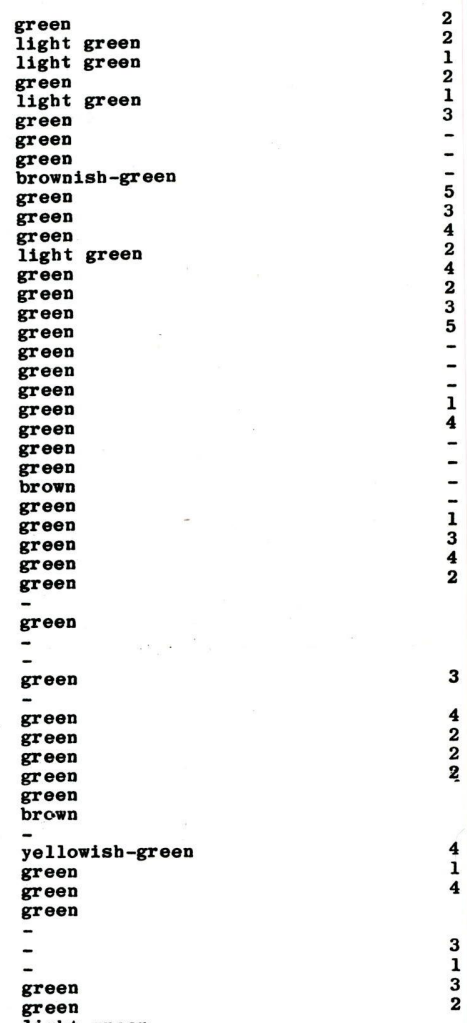

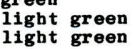

green

green

green

green 3

green

green

$\underset{\text { green }}{\text { green }}$

green

green

green

green
green

light green

light green

light green

green
green

green

green
green

green

green
green

green

green

green

ish-green

green
green

green
green

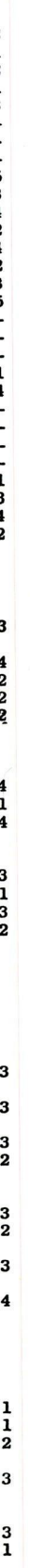




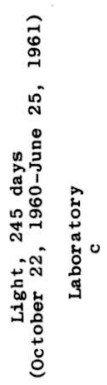
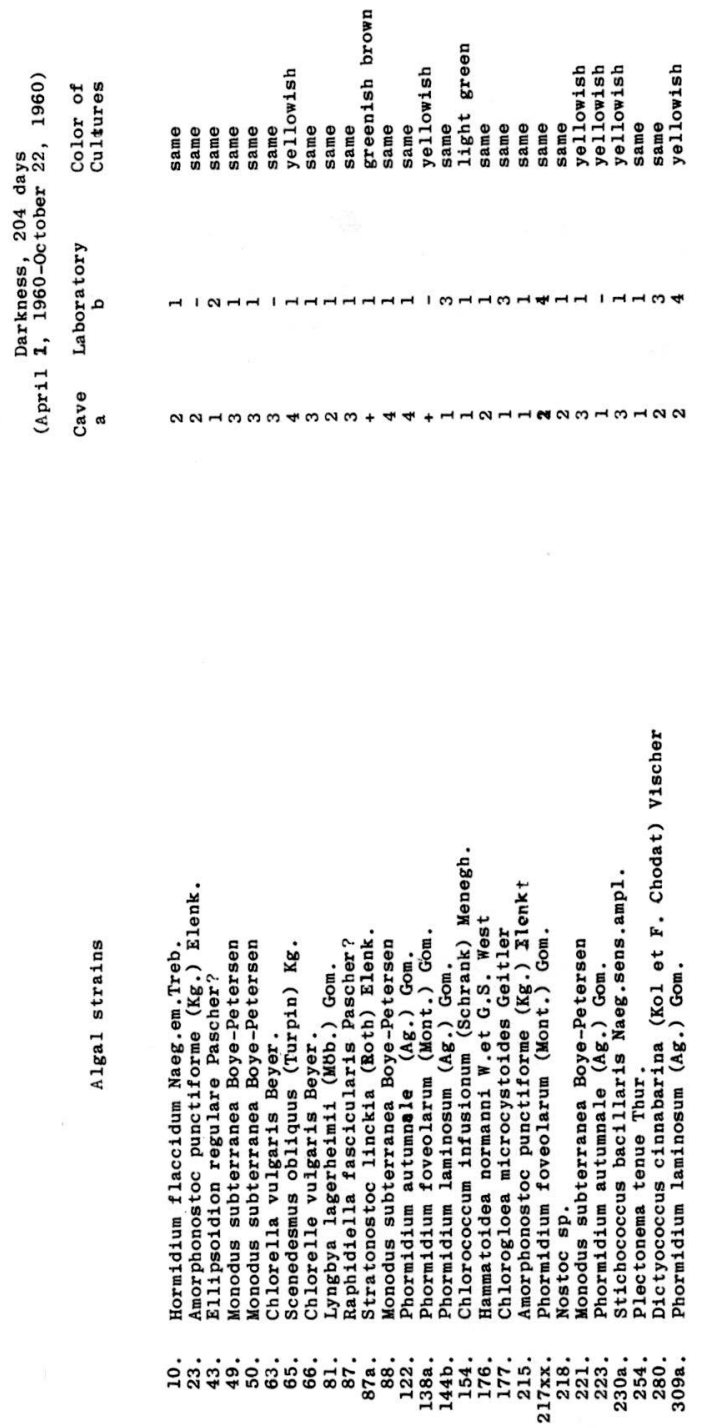


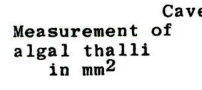

Color
5. Cystococcus humicola Naeg.em.Treb.

10. Hormidium flaccidum $A$. Br. sens. ampl.

11. Phormidium molle (Kg.) Gom. $\mathrm{Kg}$.) Elenk.

28. Chlamydomonas intermedia Chodat

29. Phormldium foveolarum (Mont.) Gom.

29a. Phormidium foveolarum (Mont.) Gom.

43. Ellipsoidion regulare Pascher?

47. Stratonostoc linckia (Roth) Elenk.

49. Monodus subterranea Boye-Petersen

53. Nostoc $\mathrm{sp}$

62. Stratonos toc commune (Vaucher) Elenk.

63. Chlorella vulgaris Beyer.

81. Chlorella vulgaris Beyer.) Gom.

81a. Chlorella sp.

82. Chlorella miniata (Naeg.) oltm.

87. Raphidiella fascicularis Pascher?

87. Stratonostoc linckia (Roth) Elenk.

91. Chlorella vulgaris Beyer

101. Chlorella pyrenoidosa Chick

106. Chlorella vulgaris Beyer.

122. Phormidium autumnale (Ag.) Gom.

124. Chlorella vulgaris Beyer.

132. Chlorella pyrenoidosa Chic

136. Plectonema sp.

138. Chlorella vulgaris Berer.

138a. Phormidium foveolarum (Mont.) Gom.

138b. Chlorella vulgaris Beyer

143. Chlorella pyrenoidosa Chick

144. Phormidium laminosum (Ag.) Gom.

144a. Phormidium laminosum (Ag.) Gom.

146. Chlorella vulgaris Beyer.

149. Chlamydomonas intermedia.

154. Chlorococcum infusionum (Schrank) Menegh

159. Chlorella vulgaris Beyer.

162. Chlorella vulgaris Beyer.

Chlorella vulgaris Beyer.

168. Phormidium foveolarum (Mont.) Gom.

172. Phormidium foveolarum (Mont.) Gom.

174. Ankistrodesmus falcatus (Corda) Ralfs

176. Hamma toidea normanni W. et G.S. West

181. Plouroch

201. Plour us dactylococcoida

01. Chlorella pyrenoidosa Chick

05. Chlorella sp.

206. Phormidium laminosum (Ag.) Gom.

207. Stratonostoc linckia (Roth) Elenk.

208. Stratonostoc linckia (Roth) Elenk.

209a. Phormidium laminosum (Ag.) Gom.

209b. Phormidium laminsum (Ag.) Gom.

209c. Phormidium laminosum (Ag.) Gom.

209d. Phormidium laminosum (Ag.) Gom.

209e. Phormidium laminosum (Ag.) Gom.

211. Phormidium laminosum (Ag.) Gom.

211a. Phormidium laminosum (Ag.) Gom.

213. Ellipsoidion sp.

13a. Ellipsoidion

214. Amorphonos toc punctiforme (Kg.) Elent.

215. Amor phonos

16a. Chlorocloster minimus Pascher

217. Phormidium foveolarum (Mont.) Gom.

217xx. Phormidium foveolarum (Mont.) Gom.

218. Nostorium.

219. Chlorella vulgaris Beyer.

221. Monodus subterranea Boye-Petersen

222. Chlorococcum bumicolum (Naeg.) Rabenh.

223. Phormidium autumnale (Ag.) Gom.

224. Nitzschia palea (Kg.) W. Smith

225. Phormidium autumnale (Ag.) Gom.

226. Phormidium uncinatum (Ag.) Gom.

227. Phormidium molle (Kg.) Go

227x. Ellipsoidion oocystoides Pascher

7xx. Ellipsoidion oocystoides pascher

Pleurochloridella botrydiopsis Pasche

230. Amorphonos toc paludosum (Kg.) Elenk.

231. Nitzschia palea (Kg.) W. Smith

232. Monodus subterranea Boye-Peterse

233. Phormidium autumnale (Ag.) Gom.

233a. Chlorella vulgaris Beyer.

280. Dictyococcus cinnabarina (Kol et F. Chodat) Vischer

309. Botrydiopsis arhiza Borzi

309a. Phormidium laminosum (Ag.) Gom.

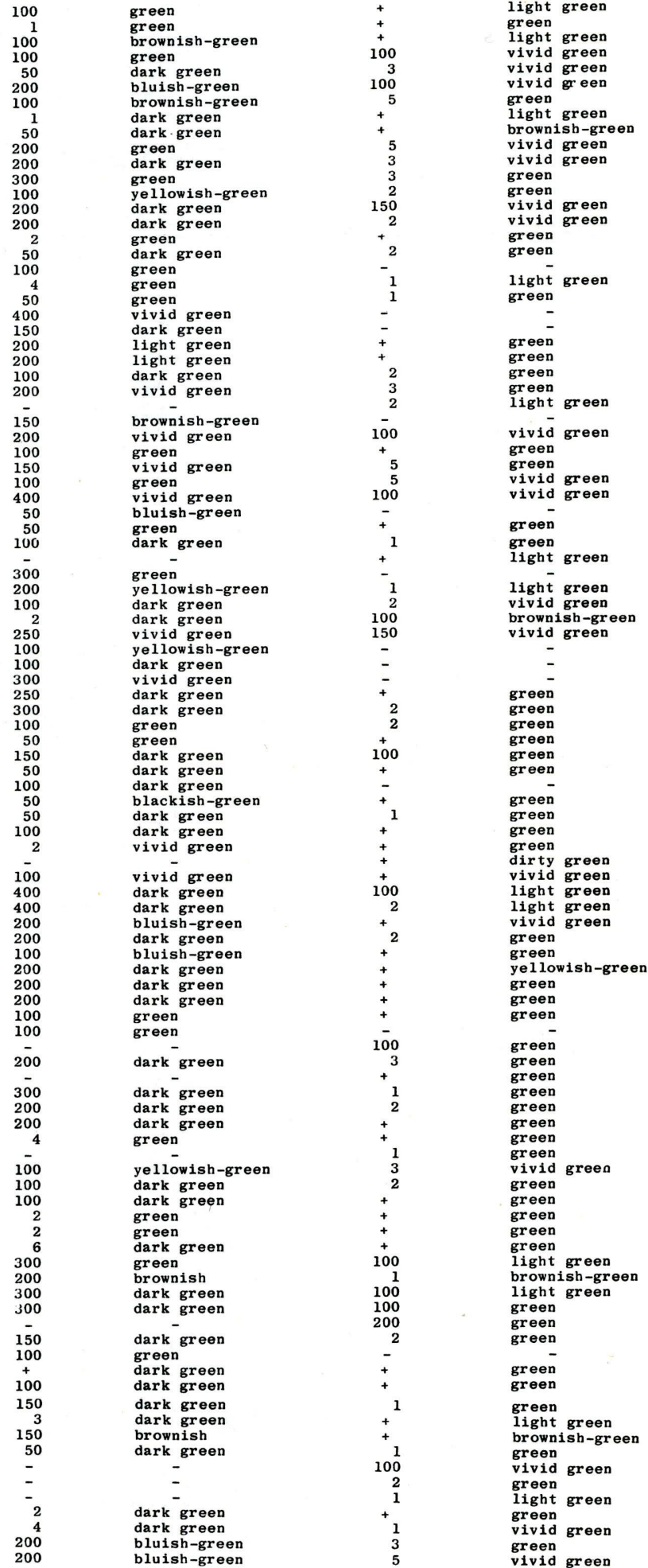




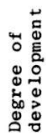

¿ั0

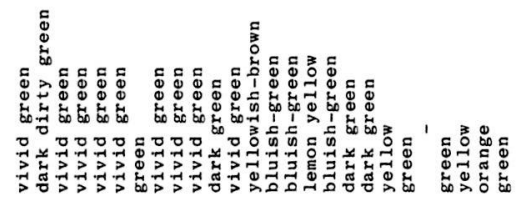

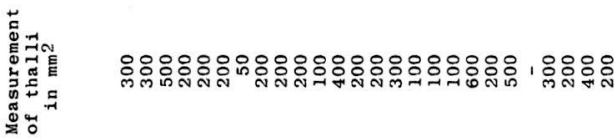

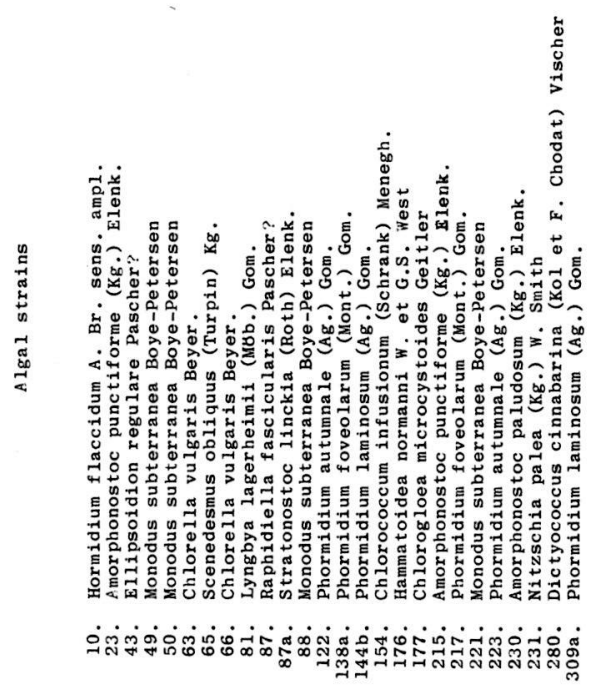


TABLE V

PARALLEL EXPERIMENTS IN CAVE, LABORATORY, CELLAR IN DARKNESS AND LIGHT In Darkness, 420 days (April 25, 1962-June 20, 1963)

In Light, 158 days (June 20, 1963-November 26, 1963)

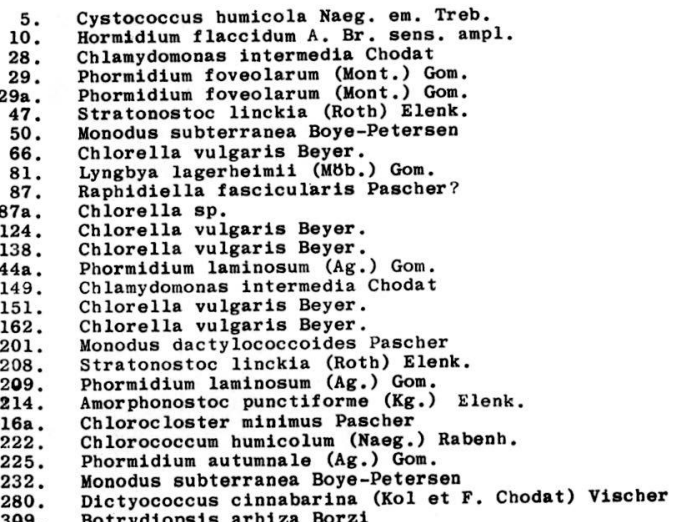

$\begin{array}{cr}+ & 50 \\ 100 & 50 \\ 300 & 100 \\ 300 & 100 \\ 300 & 100 \\ 300 & 200 \\ 300 & 100 \\ 300 & 100 \\ 400 & 300 \\ + & 50 \\ + & 50 \\ + & 50 \\ 200 & 100 \\ + & 20 \\ + & 25 \\ + & 50 \\ + & 25 \\ + & 50 \\ + & 20 \\ + & 50 \\ + & 50 \\ + & 50 \\ 150 & 50 \\ - & - \\ 200 & 50 \\ + & 50\end{array}$


Development of cultures,

\section{In darkness, in the caxe,} Ireely 420 days

$\begin{array}{cr}+ & 50 \\ 300 & 50 \\ 400 & 300 \\ - & - \\ 400 & 250 \\ + & + \\ 200 & 200 \\ + & 25 \\ 100 & 200 \\ + & 50 \\ 200 & - \\ 300 & 300 \\ + & 250 \\ + & - \\ 200 & 50 \\ + & 50 \\ 200 & 50 \\ 200 & 50 \\ + & 50 \\ + & - \\ - & - \\ + & - \\ - & 50 \\ 200 & - \\ 200 & 100 \\ & 50\end{array}$

measurement of thall in $\mathrm{mm}^{2}$

C In darkness In darknes In laboratory indry $\begin{array}{ll}\text { cellar } & \text { cellar } \\ 420 \text { days } & 420 \text { days }\end{array}$

\section{In} darkness 420 days

$\begin{array}{cc}\begin{array}{c}\text { In } \\ \text { In } \\ \text { l1ght }\end{array} & \begin{array}{c}\text { In laborat } \\ \text { In } \\ \text { light }\end{array} \\ 158 \text { days } & 578 \text { days }\end{array}$

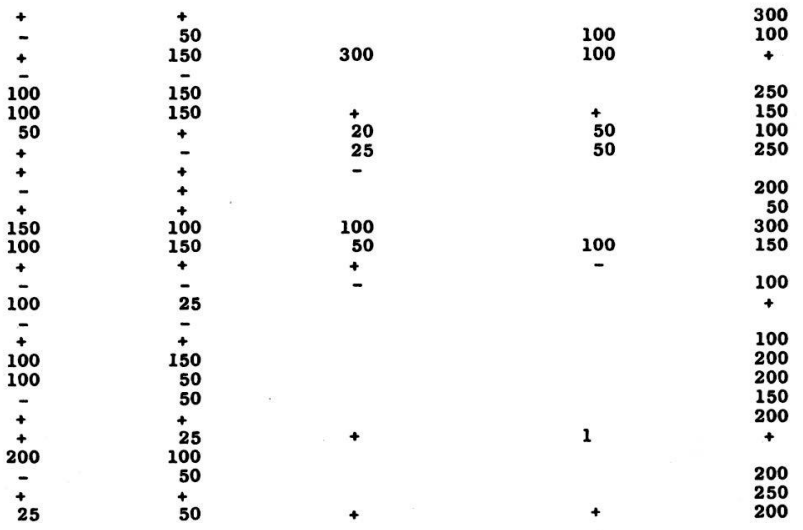





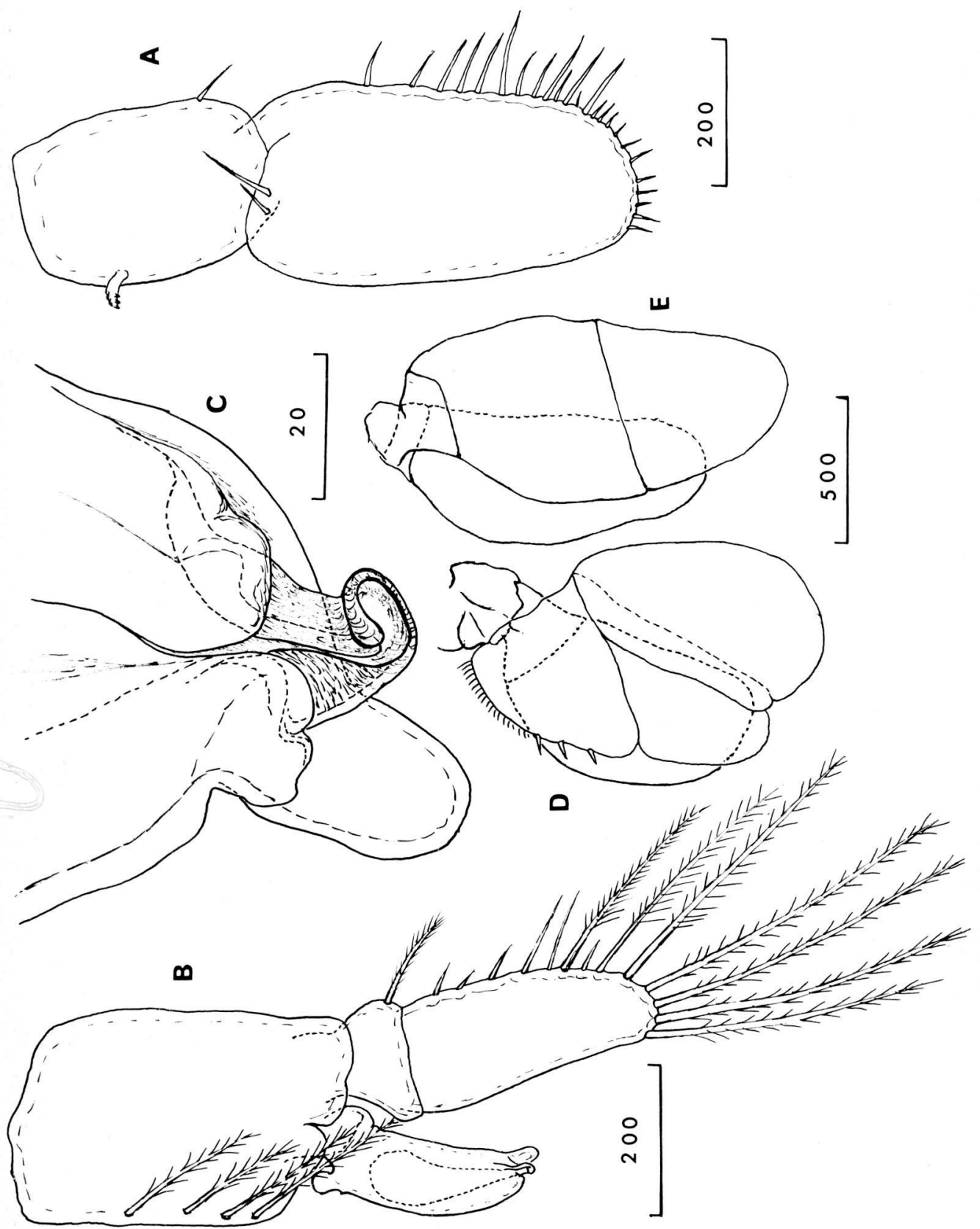




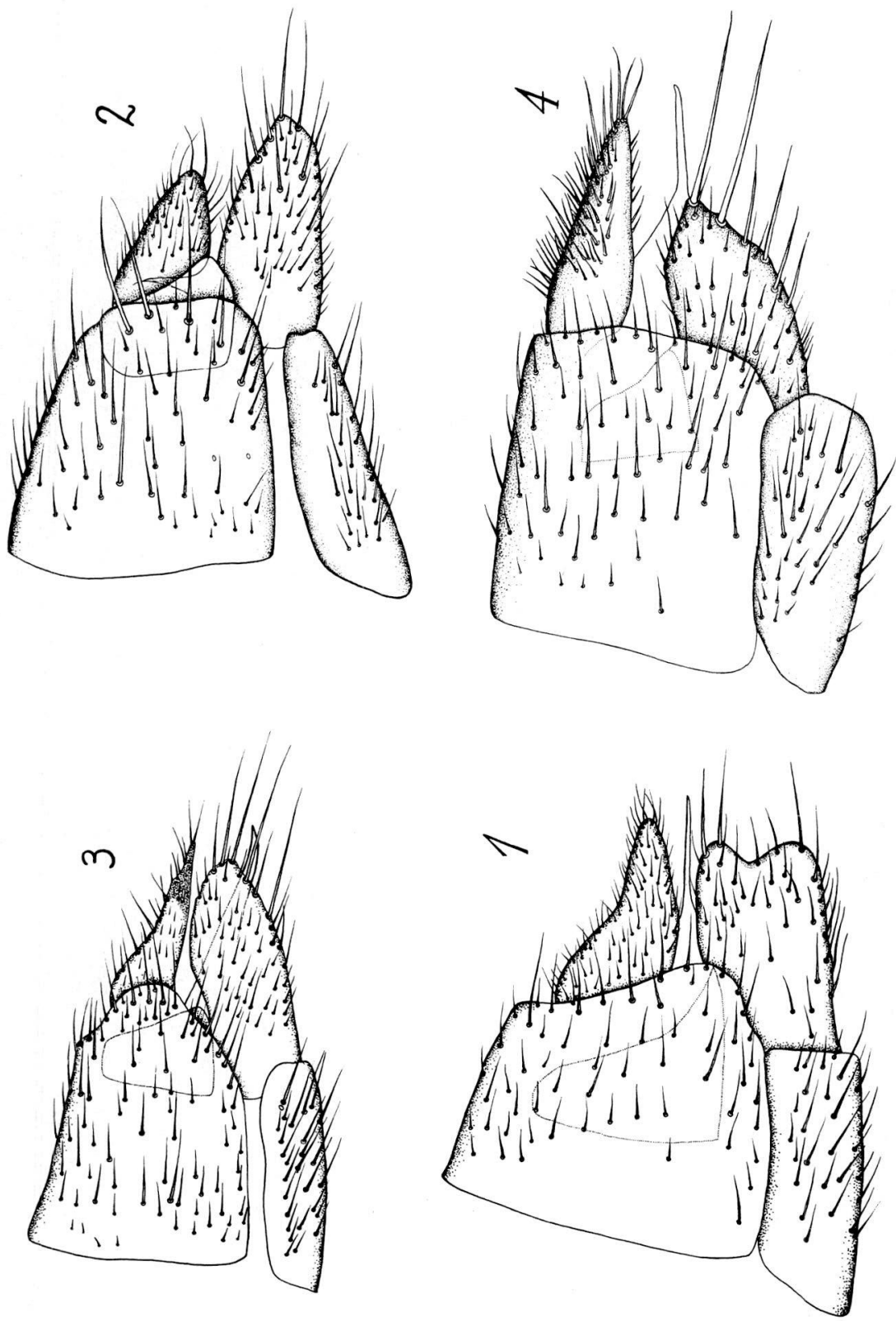

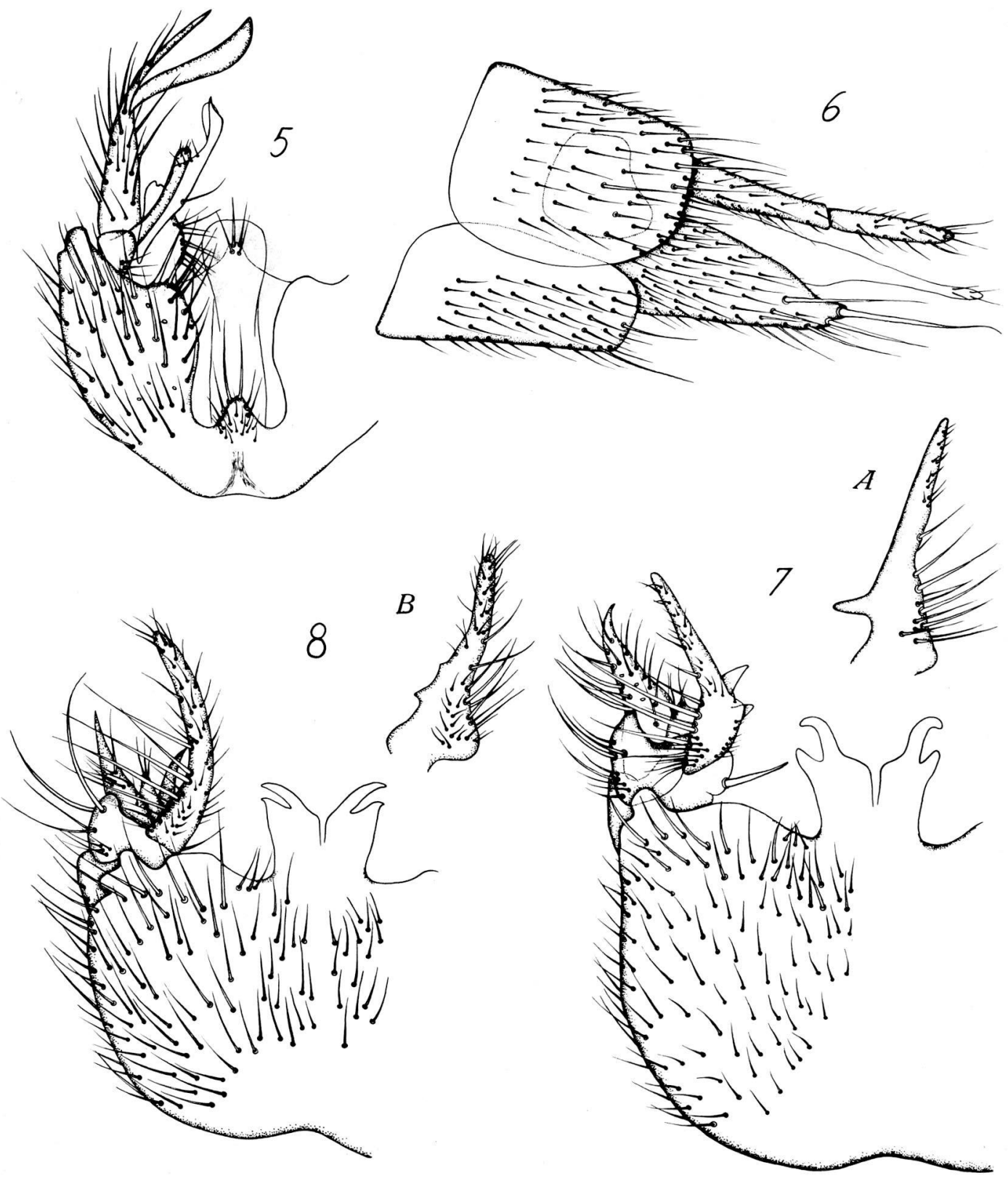


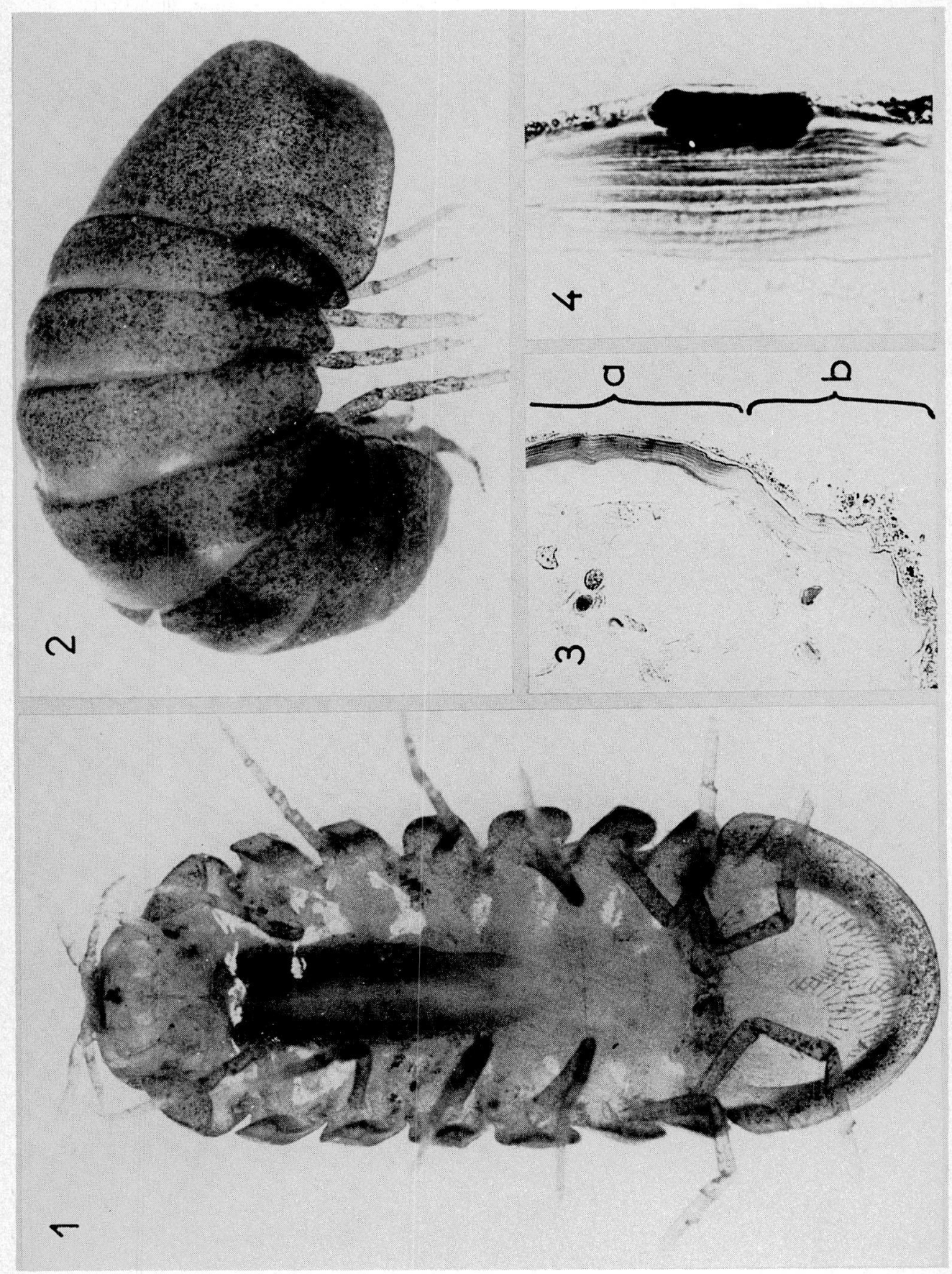





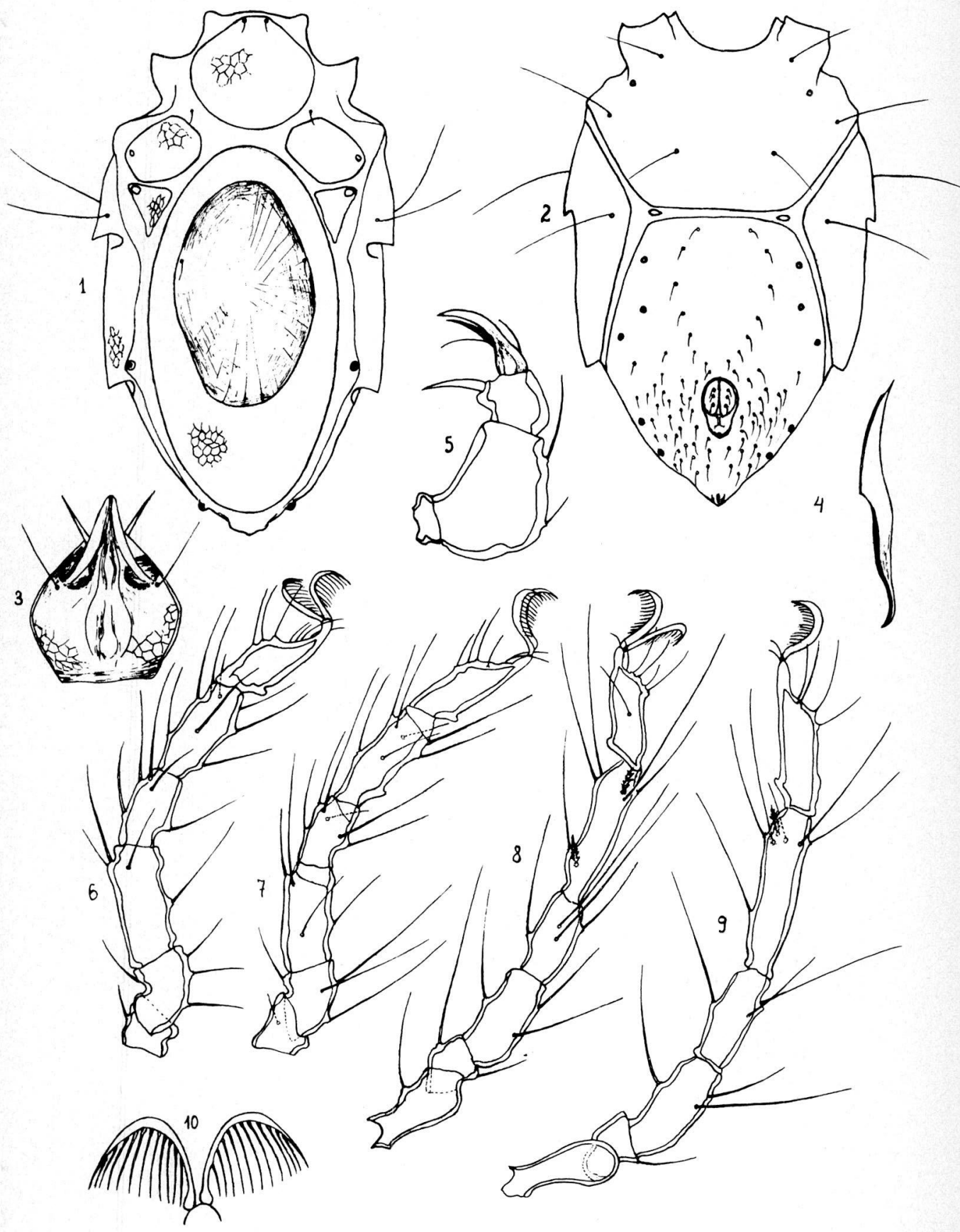




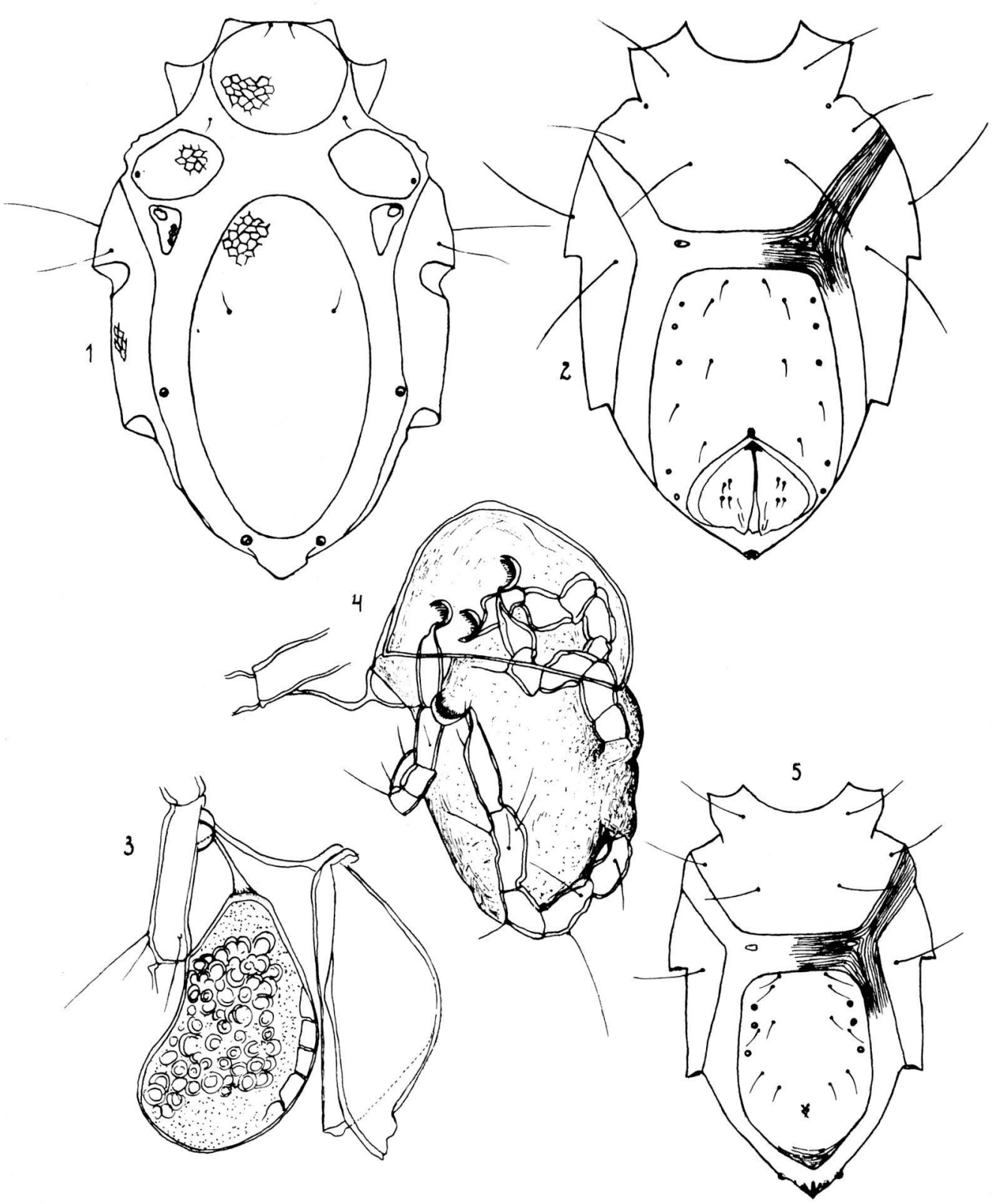




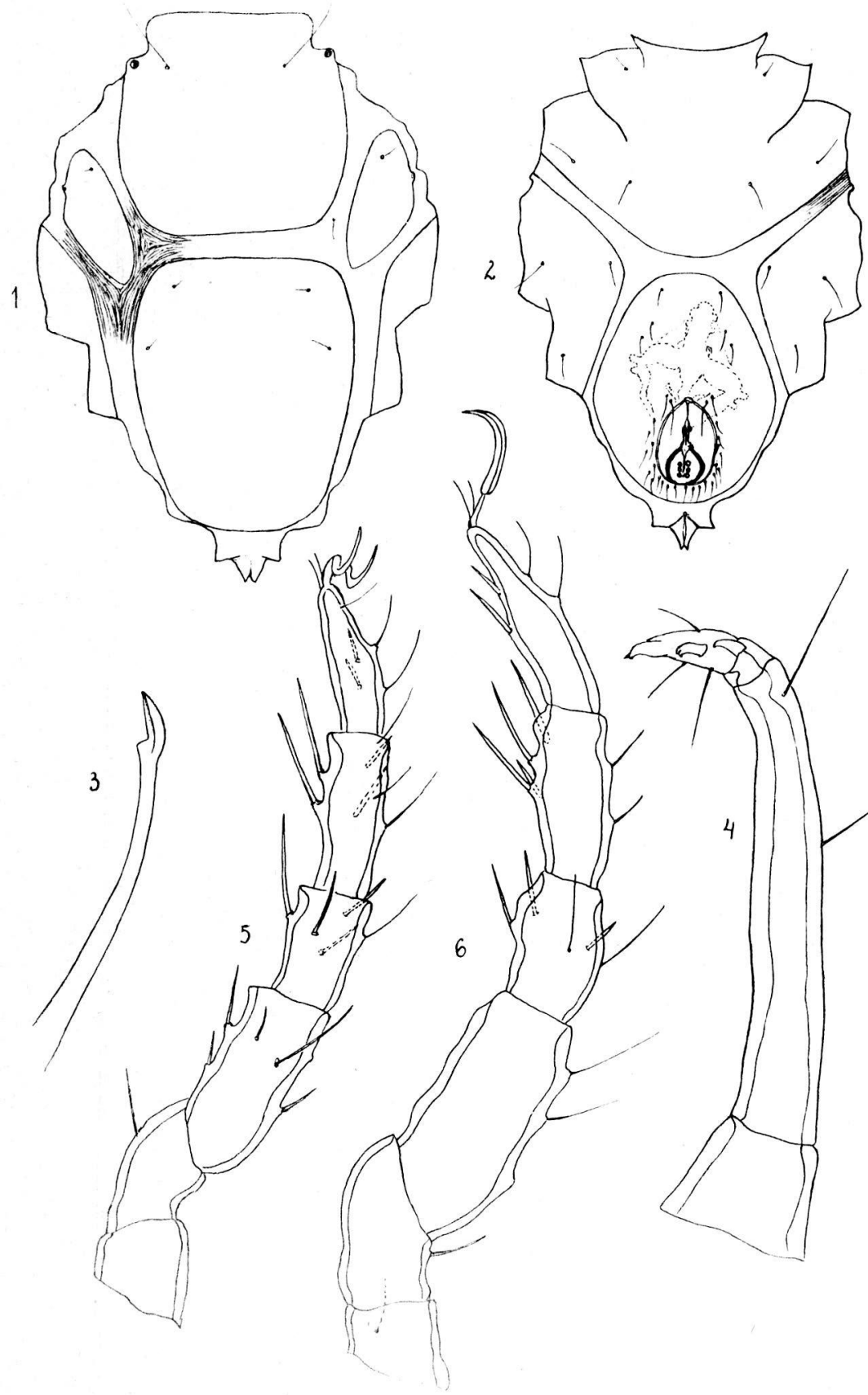




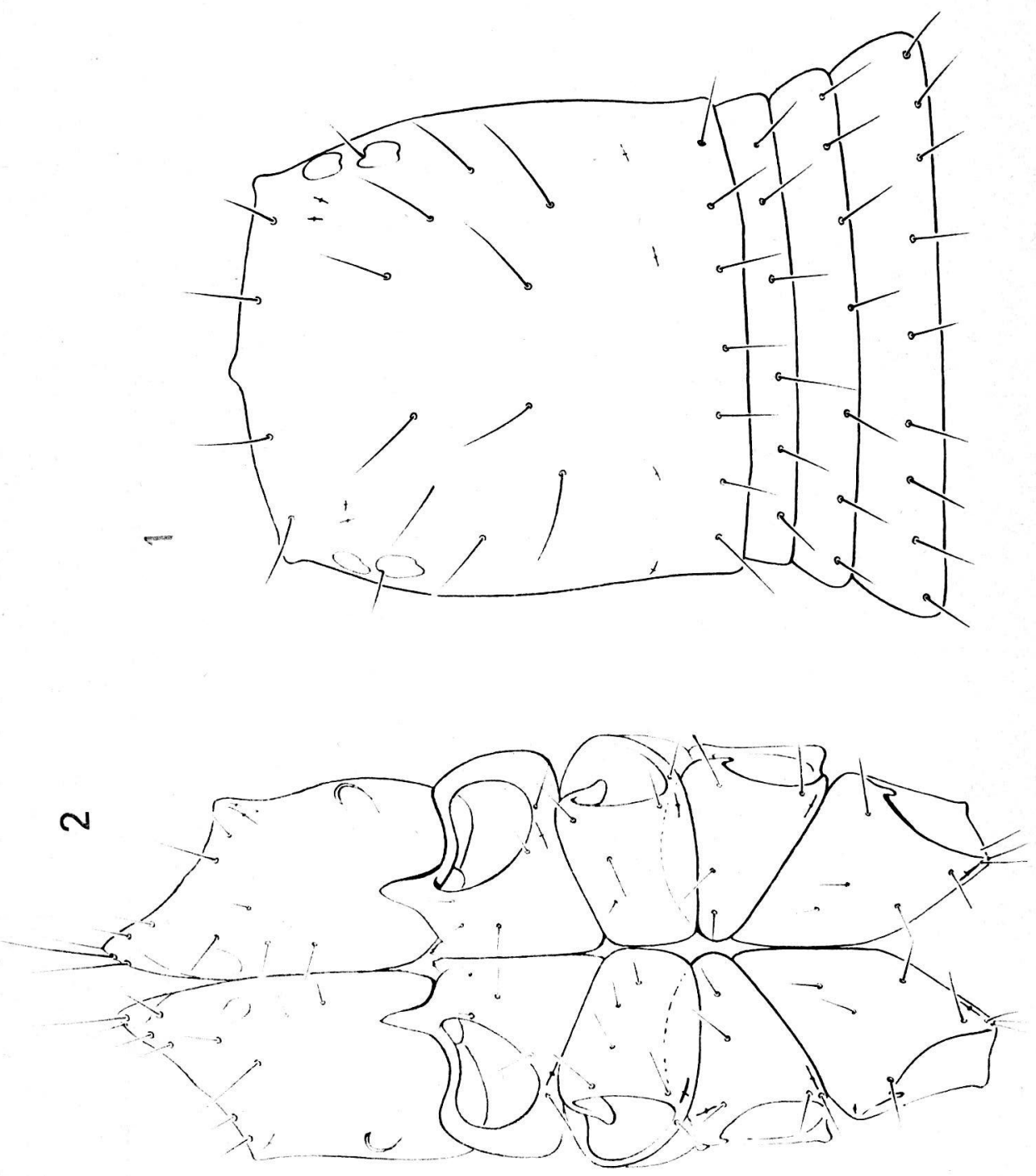


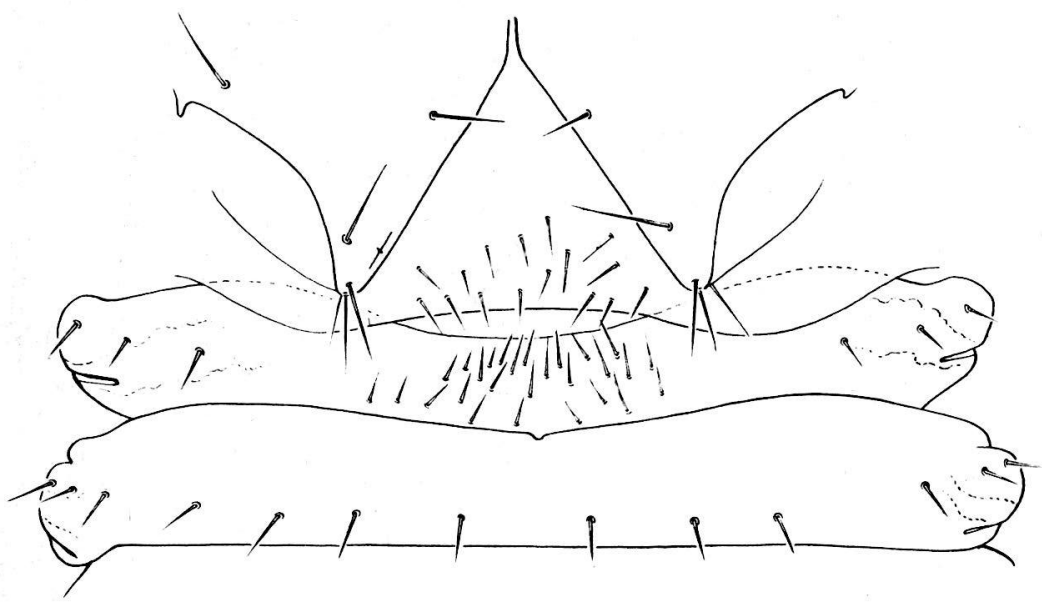

3

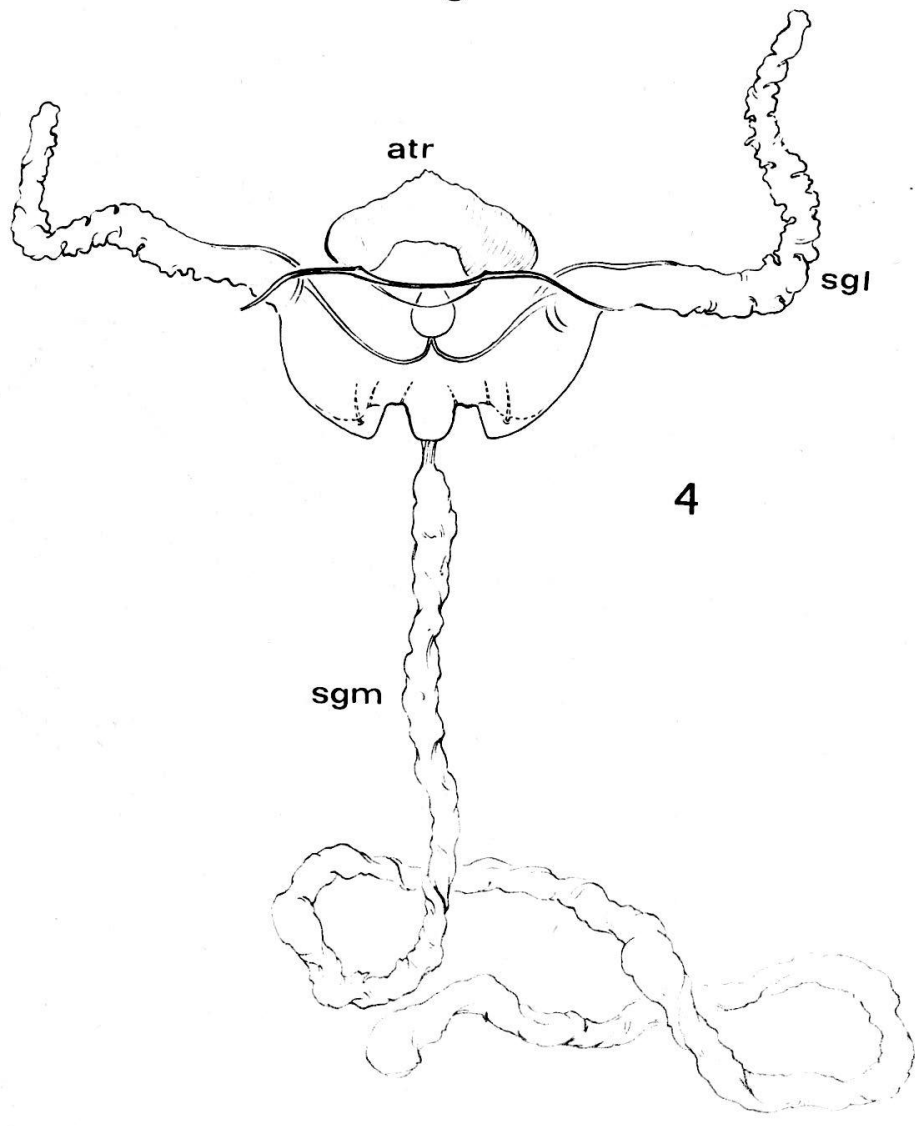




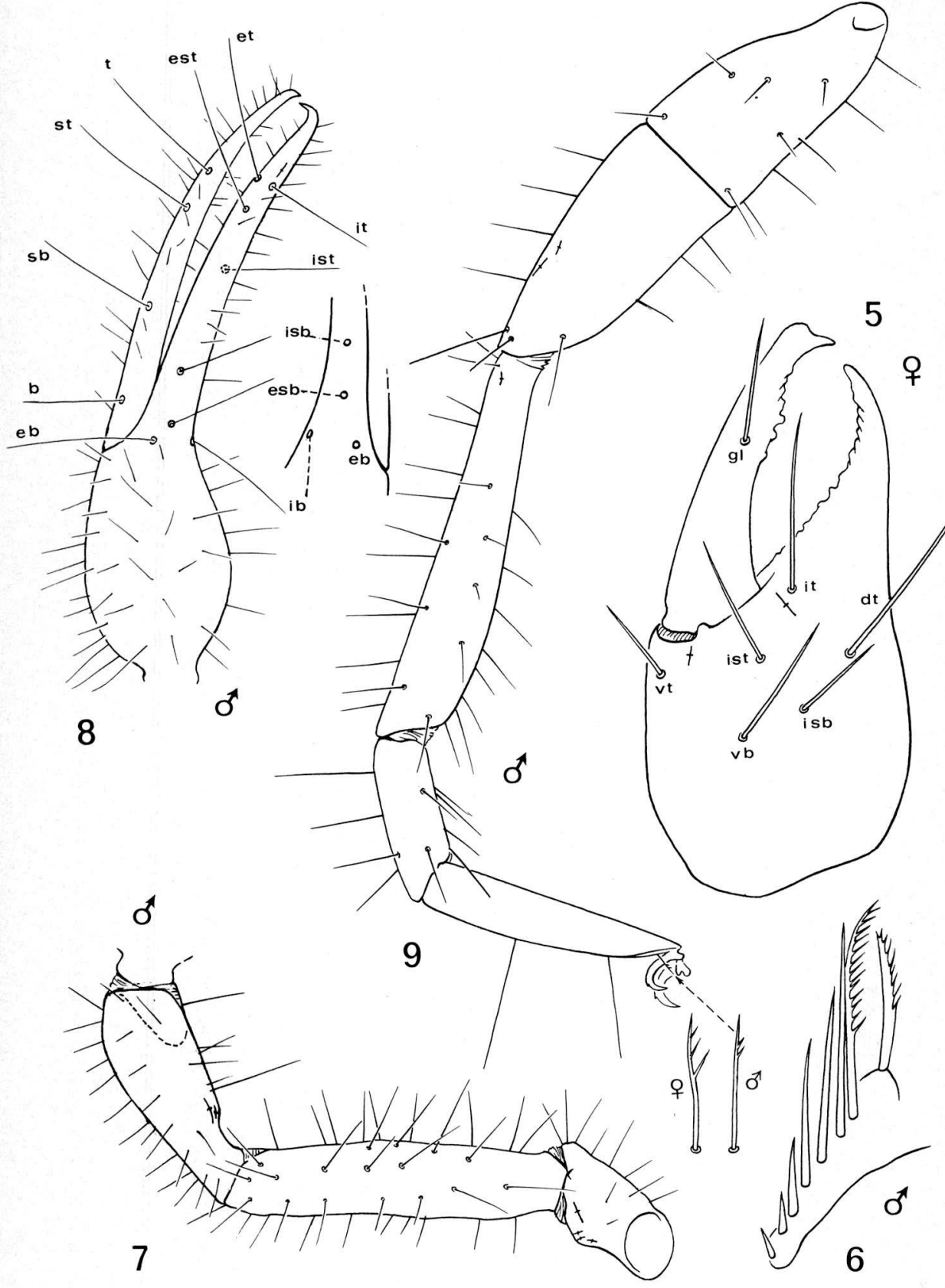


SPELEOLOGY II

(Vachon, 4)

PLATE 71

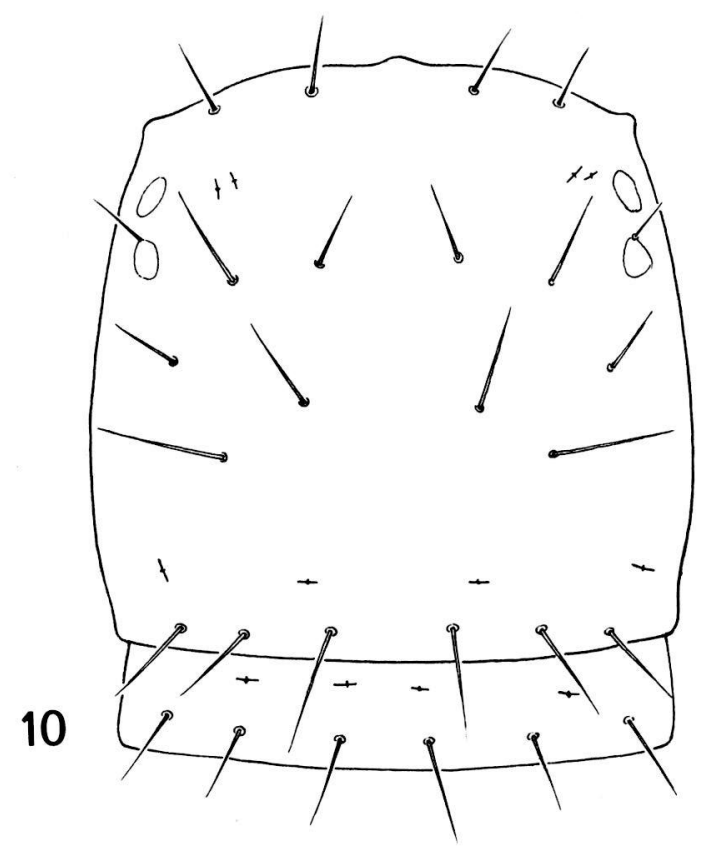

11

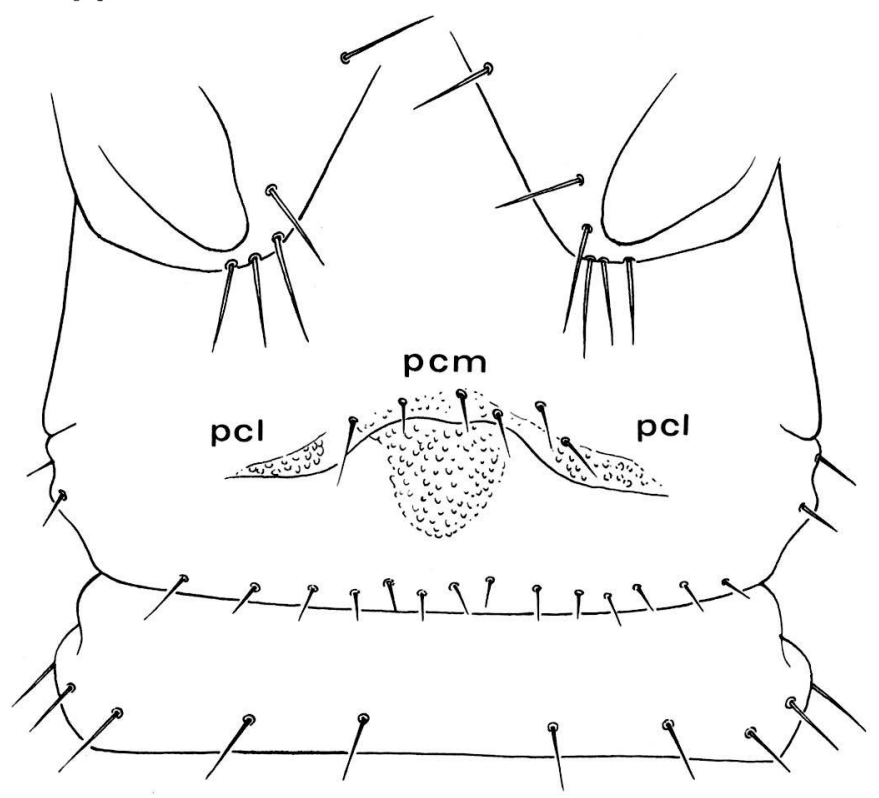



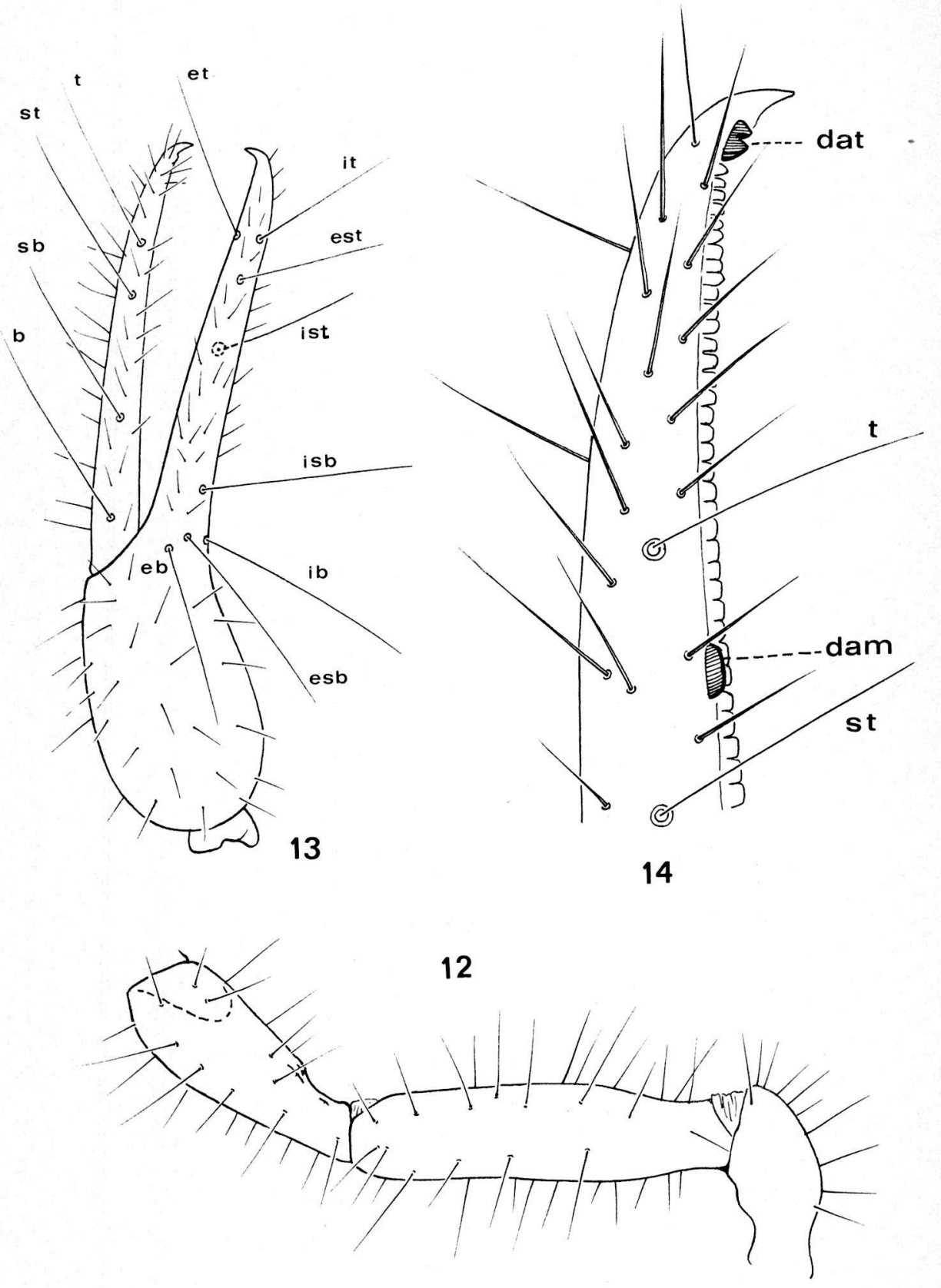



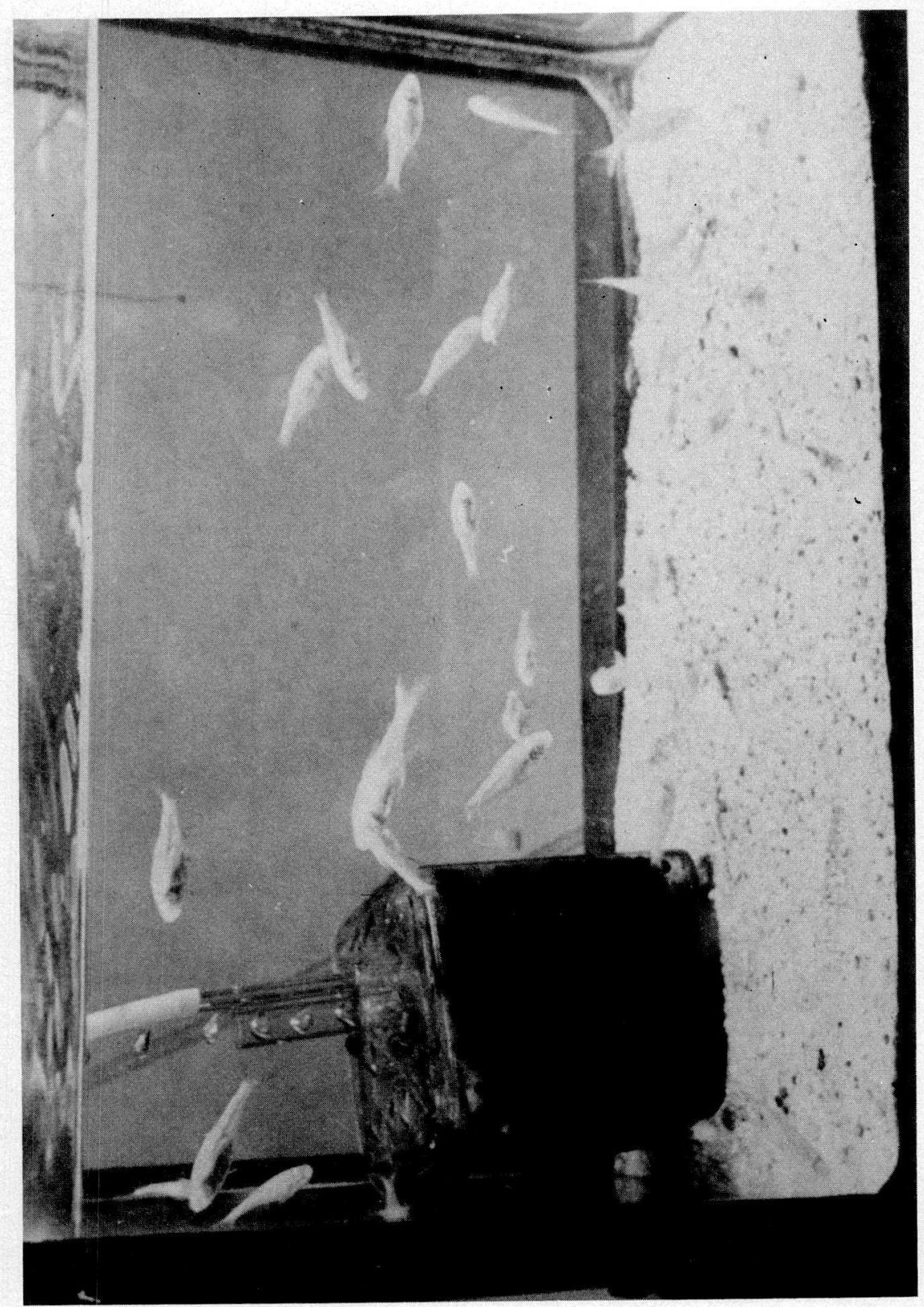




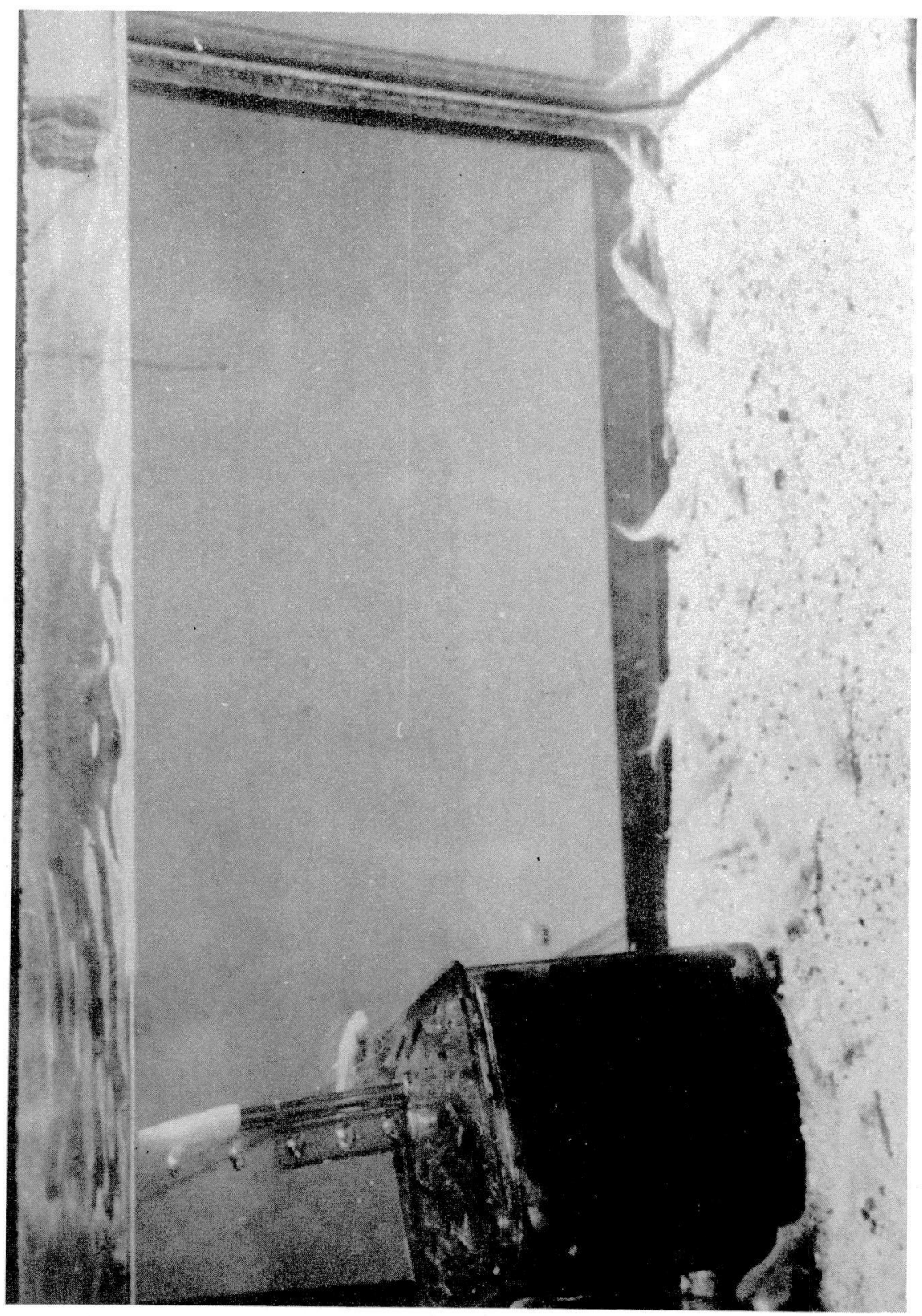




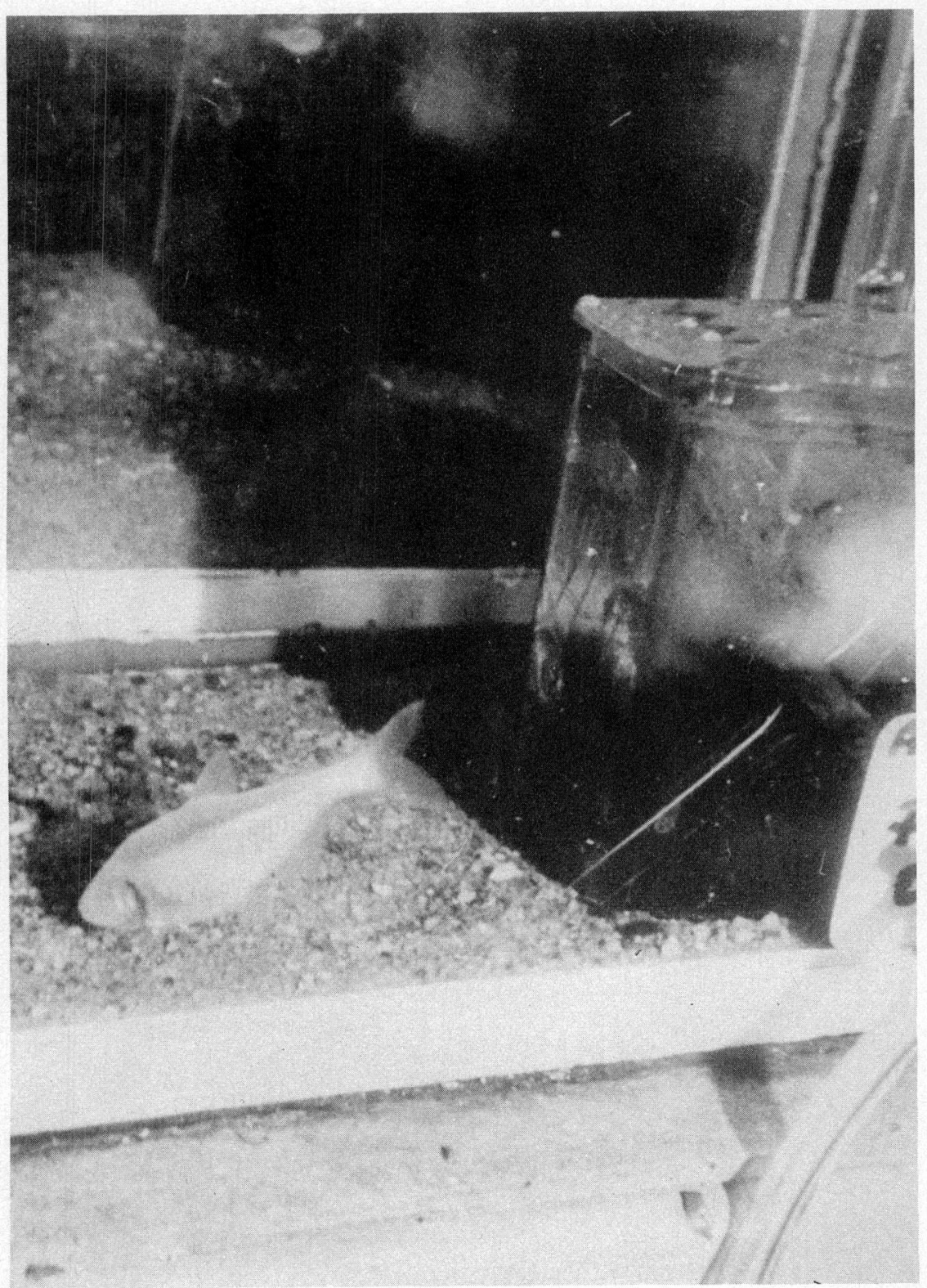




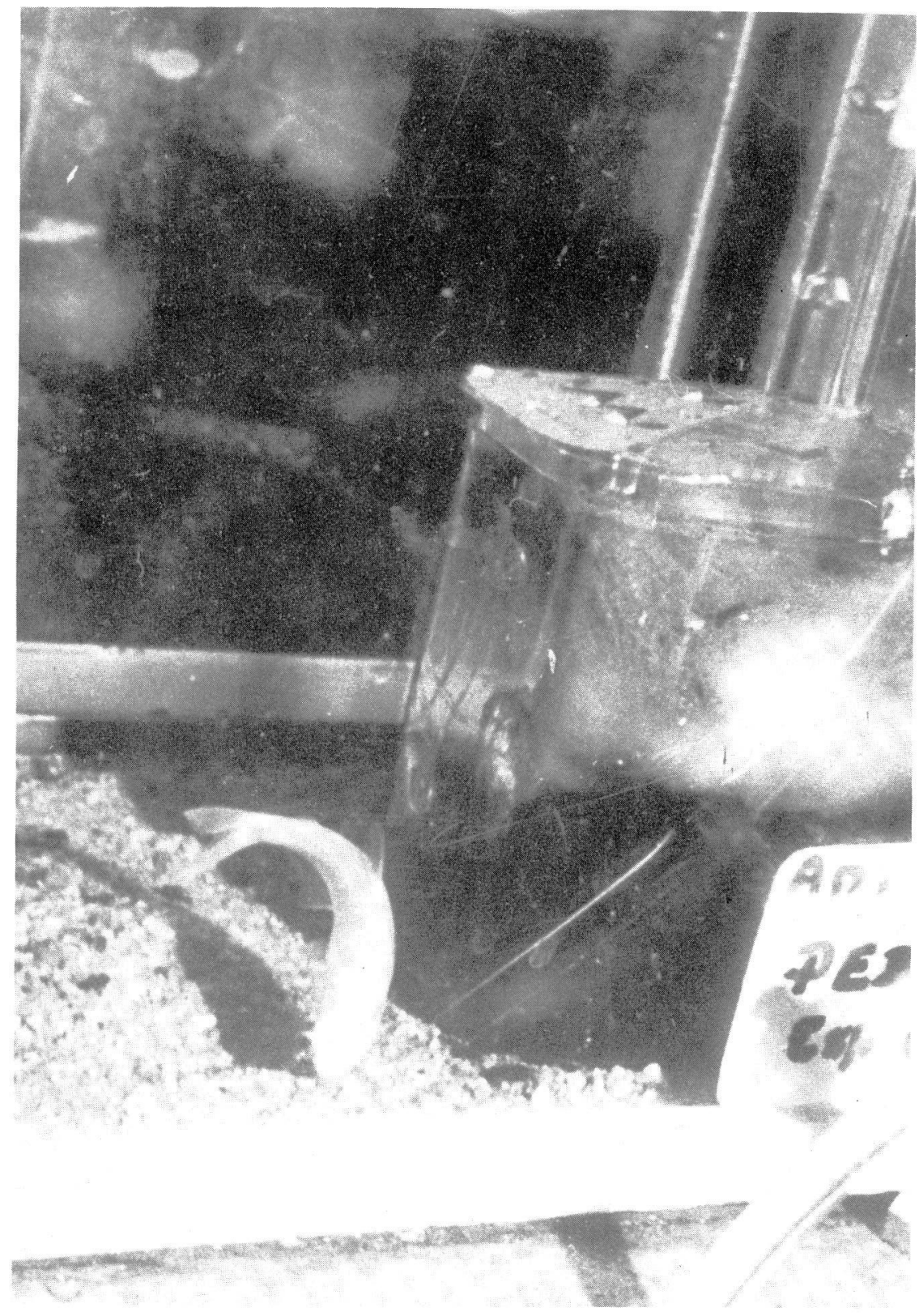




\title{
Voles, Mice, Lemmings : \\ Studies in Population Dynamics
}

by CharLES ELtoN

Oxford 1942 (Photomechanischer Nachdruck 1965). Royaloctavo. 500 pages frontispiece and folding table. Cloth bound. DM 84,- (\$21,-)

Dieses Standardwerk der populationsdynamischen Säugetierforschung, in dem der Verfasser in sechzehnjähriger Arbeit eigene und fremde Erfahrungen zusammengetragen hat, ist im Krieg erschienen und dadurch kaum über die Grenzen Englands hinausgedrungen. Da es immer noch die Grundlage für diese ganze Forschungsrichtung ist, wird es hier in einem photomechanischen Neudruck vorgelegt.

\section{The families and Genera of Living Rodents}

by J. R. ELLERMAN N

2 volumes. London 1940-41 (Photomechanischer Nachdruck Frühjahr 1966). Royal-octavo. Cloth bound.

je Band DM 120,- $(\$ 30,-)$

Die Rodentia, die artenreichste Säugetierordnung, haben in Ellermann's Studie die bisher noch nicht übertroffene systematische Bearbeitung gefunden, auf die jeder mit Nagetieren arbeitende Zoologe in irgendeinem Augenblick angewiesen ist. Beim Nachdruck wird besonders auf die einwandfreie Wiedergabe der zahlreichen Schädelzeichnungen Wert gelegt.

\section{Catalogue of the Chiroptera in the collection of the British Museum}

\author{
by George Edward Dobson
}

London 1878 (Photomechanischer Nachdruck Frühjahr 1966 Octavo. XLII \& 568 pages, 30 plates. Cloth bound.

DM 100,- (\$25,-)

Dовмом faßte alle rund 400 zu seiner Zeit bekannten Fledermausarten in diesem Katalog zusammen. Wenn auch im Laufe von 90 Jahren manche seiner Ansichten und Methoden fortschreitender Erkenntnis zum Opfer gefallen sind, so ist seine Zusammenfassung doch noch immer eines der Standardwerke der Fledermausforschung. 


\title{
The Families and Genera of Bats
}

\author{
by G. S. Miller \\ 14 plates. Cloth bound. \\ Subskriptionspreis DM 80,- $(\$ 20,-)$ \\ Nach Erscheinen DM 100,- $(\$ 25,-)$
}

Washington (Bull. U. S. Nat. Mus. 57) 1907 (Photomechanischer Nachdruck Sommer 1966). Royal-octavo. XVIII \& 282 pages

'Der Miller gehört auf den Arbeitstisch eines jeden Fledermausforschers und bedarf keiner speziellen Empfehlung.

\section{Index Generum Mammalium:}

\section{A List of the Genera and Families of Mammals}

\author{
by T. S. PALM E R
}

Washington (N. Am. Fauna 23) 1904 (Photomechanischer Nachdruck Sommer 1966). Octavo. 984 pages. Cloth bound.

Subskriptionspreis DM 160,- (\$40,-)

Nach Erscheinen DM 200,- (\$50,-)

Palmers Zusammenstellung, die weit über den Rahmen der `North American Faunar hinausgeht, fehlt fast immer, wenn diese Serie einmal zum Verkauf angeboten wird. Das Werk gehört, wie der vorher genannte Titel, zum täglichen Handwerkszeug des Mammologen und bedarf keiner speziellen Empfehlung.

Catalogus Mammalium tam viventium quam fossilium . . . nova editio (prima completa) et quinquennale supplementum

Auctore E. L. Trouessart

3 Bände. Berlin 1897-1905 (Photomechanischer Nachdruck Frühjahr 1967) Lexikon-Oktav. Ganzleinen

Subskriptionspreis je Band DM 160,- (\$40,-)

Nach Erscheinen je Band DM 200,- (\$50,-)

VERLAG VON J. CRAMER • 3301 LEHRE · GERMANY 